NBS

\title{
PUBLICATIONS
}

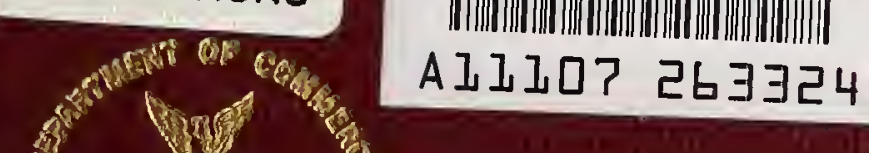

NBS FHECAML PUELICATION 388

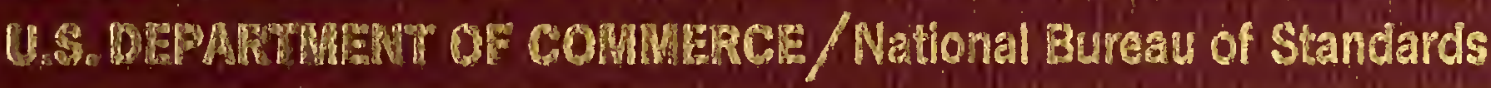

\section{The Public Need and the Role of the Inventor}





Proceedings of a Conference held in Monterey, California June 11-14, 1973

Edited by

Florence Essers and Jacob Rabinow

Office of Invention and Innovation Institute for Applied Technology National Bureau of Standards Washington, D.C. 20234

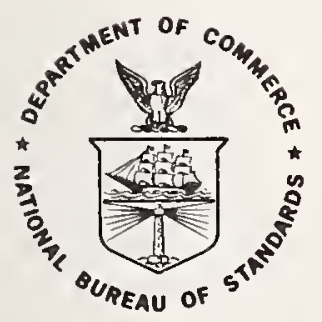

U.S. DEPARTMENT OF COMMERCE, Frederick B. Dent, Secretary NATIONAL BUREAU OF STANDARDS, Richard W. Roberts, Director 
Library of Congress Catalog Number: 73-600324.

\section{National Bureau of Standards Special Publication 388}

Nat. Bur. Stand. (U.S.), Spec. Publ. 388, 215 pages (May 1974)

CODEN: XNBSAV 


\begin{abstract}
This book presents the proceedings of the Conference on the Public Need and the Role of the Inven. tor, held at Monterey, Calif., on June 11-14, 1973. The conference, based on a recommendation of the National Inventors Council, was sponsored by the Office of Invention and Innovation, Institute for Applied Technology, under a grant from the Experimental Technology Incentives Program, NBS. The purpose of the conference was to study the climate for invention and how to make it one in which America's inventors can flourish for the common good. Eighteen invited papers were presented. In addition, the proceedings includes statements from the chairmen of the three sessions: Charles S. Draper, Jacob Rabinow, and Myron Coler. The proceedings are divided into three sessions with an edited version of the floor discussions following the papers. Following the presentation of papers, the participants of the conference separated into six workshop panels. Their recommendations are presented at the end of this volume.
\end{abstract}

Key words: Antitrust doctrine; employed inventors; entrepreneurship; innovation; invention; needs of society; new enterprises; Patent Office; patent system; technological policy making; technology. 


\section{Foreword}

The Conference on the Public Need and the Role of the Inventor was based on a recommendation by the National Inventors Council to the Secretary of Commerce, and was made possible by a grant from the Experimental Technology Incentives Program of the National Bureau of Standards.

The ETIP program was initiated in fiscal year 1973 as part of the President's program to stimulate technological innovation for the solution of national problems. The objective of the program is to learn how the Federal Government can provide policies and incentives which will encourage greater technological innovation in the private sector.

The recommendation of the National Inventors Council also arose from the Council's concern about the technological problems facing our Nation: increasing international competition, dwindling productivity, massive environmental problems, and the necessity for improving the quality of life for its citizens.

The Council felt that the challenge is to revitalize our capacity for beneficial technological innovation, strengthening our industries at home and bolstering our trade position abroad.

Yet, the Council recognized that there is considerable difference of opinion about the value of the patent system and about the processes of invention and innovation. Nor do we know enough about the barriers that impede the conception and nurture of new ideas and their development into new products and processes. We need to know more about what the climate for invention is and how to make it one in which America's inventors can flourish for the common good.

The Conference was organized to bring together experts in the fields of invention and innovation to present their views on these problems, with the hope of educating those not familiar with the issues involved, of stimulating further interest and discussion, and of recommending action in those instances where action is called for, and studies to be made in those areas where further information is most urgently needed.

The National Bureau of Standards is pleased to present the Proceedings of the Conference on the Public Need and the Role of the Inventor. Publication of this text expresses our appreciation to the participants and to all those who contributed to make this a successful conference.

JaCob Rabinow, Chief

Office of Invention and Innovation

F. Karl Willenbrock, Director

Institute for Applied Technology 


\section{Preface}

The purpose of this conference was to examine the economic and social effects of invention and innovation, and the ways in which they are influenced by selected legal and institutional structures.

The conference also addressed itself to the inventor's contribution to the invention and innovation process, comparing the roles played by independent and employed inventors. The foreseeable trends in policies and practices affecting the inventor were also examined.

The conference was attended by representatives from Government, industry, universities, research institutes, trade associations, and the patent bar.

Following the presentation of the papers, the conferees participated in six panels on the following subjects:

- The Role of the Patent System

- The Role of Industry

- The Role of Government

- The Role of the Educational System

- The Role of the Independent Inventor

- The International Aspect

The recommendations of the panel workshops follow the papers in this volume.

One of the main topics of concern to the conference was the recent deterioration of the regard held for the patent system. The Panel on the Role of the Patent System made recommendations with a view toward strengthening the patent system and Patent Office procedures, and toward preventing the erosion of the validity of patents in the courts.

The conferees were also concerned with the lack of uniformity in Government patent policy, and the problem of Government retention of patents. The Panels on Government, Industry and Education each recommended that the Government adopt a uniform patent policy, and that it should not retain patent rights to inventions resulting from Government-supported work, but only retain a license to practice for Government use, thus releasing inventions for further development and public use.

The role of the employed inventor was discussed in several papers, the systems of employee compensation in other countries being presented by Dr. Neumeyer. While recognizing that many companies in the United States have an enlightened policy toward encouraging and rewarding inventors they employ, the Panel on Industry recommended that national guidelines should be established that could be adapted to individual circumstances in those companies that do not have such a policy. A minority report was submitted by Robert Kuntz of the American Society of Professional Engineers.

The Panel on the Role of the Independent Inventor recommended that more information be developed on what knowledge and services are needed by inexperienced inventors, and that Government procurement practices encourage inventions by independent inventors. They also counseled against changing present patent practices which are favorable to the independent inventor. 
The role of the university in training innovators was examined by the Panel on Education, and several recommendations were made:

- that Government-financed fellowship programs be set up to encourage creative engineering

- that more innovation centers be created at or near universities

- that funds be set up for research and development activities in areas of critical national needs

- that industry internship experience be encouraged

- that some provision be made for continuing education for engineers

The international aspects of patents and incentives for inventors were discussed by the sixth panel. The panel felt that every effort should be made to develop a world patent system, with the exception that the "first-to-invent" system should be retained in the United States. It was further recommended that the United States participate in international conventions related to inventors or patents, and that continuing studies be made on matters pertaining to patents and innovation, both in the United States and the rest of the world.

Other studies, too, were recommended by the panels on matters on which they felt there is insufficient data:

- A study of changing attitudes of the courts over recent decades with respect to patents

- Organization of seminars with Federal Judges with respect to the patent system

- A study of Patent Office fee structure

- A study on the economic benefits of the patent system

-A study by the Patent Office as to what is involved in "quality review"

-A study on the patent-antitrust relationship

- A study on whether the independent inventor should get tax incentives, and financial, technical and administrative help

- A study to illuminate concentrated areas of technological research and development by competitive countries in the world market

- A collection and dissemination of information on the importance of inventors and the patent system to the national well-being.

The editors of this book would like to thank the members of the program committee: Drs. C. E. Anagnostopoulos, M. Coler, C. S. Draper, N. Kapany and J. Stedman; and Mrs. D. Blackmon, Miss C. Crosby, R. B. Johnson and Mrs. S. R. Torrence of the arrangements and finance committee. Additional thanks go to the session chairmen: C. S. Draper, of the Charles Stark Draper Laboratory, Inc., and M: Coler of New York University. Special thanks are due to Mrs. Sandra Wean and Mrs. Muriel Nichols for typing the manuscript and to Ms. Rebecca Morehouse and Ms. Miriam Oland for production of these proceedings using modern electronic typesetting techniques.

JaCOB RABINOW

Florence Essers 
Foreword IV

Preface

\section{SESSION I \\ Chairman: C. S. Draper}

Opening Remarks

C. S. Draper.

Inventions, Innovations, and Incentives

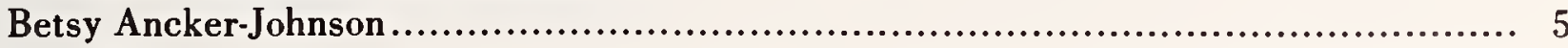

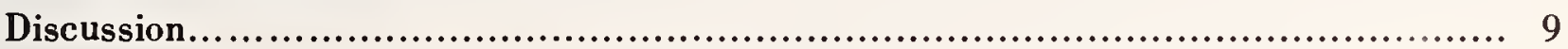

An Economist Looks at the Patent System

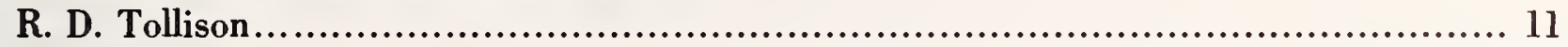

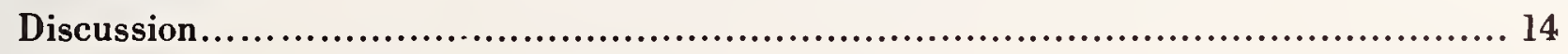

Trends in Technological Policy Making

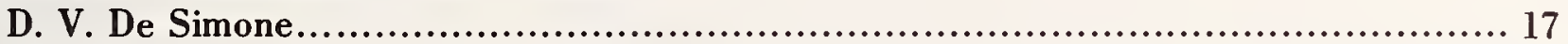

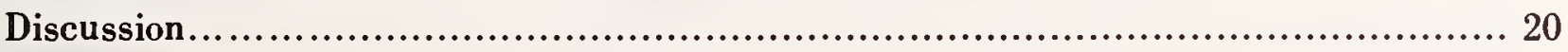

New Enterprise Generation

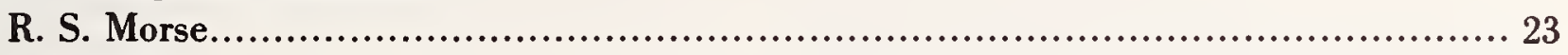

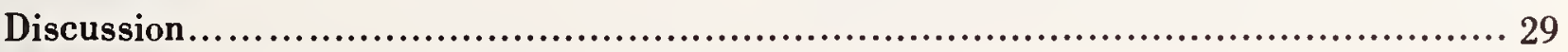

Inventor-Entrepreneurship and National Priorities

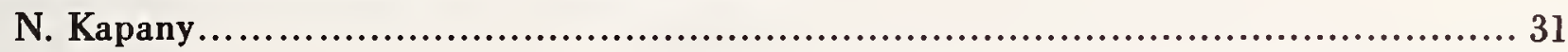

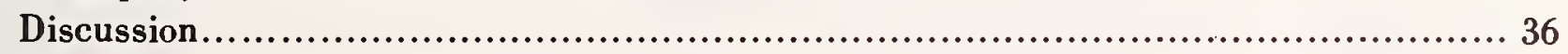

Invention and Innovation in the University

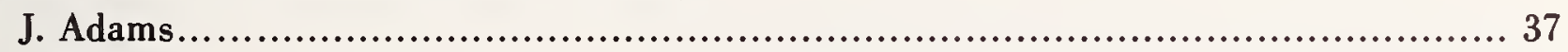

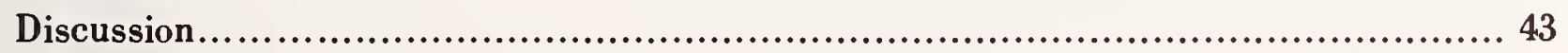

The Invention of the Transistor-An Example of "Creative-Failure Methodology"

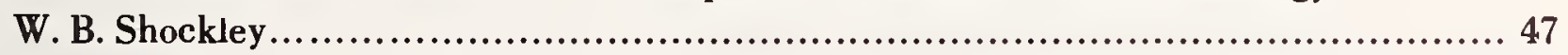

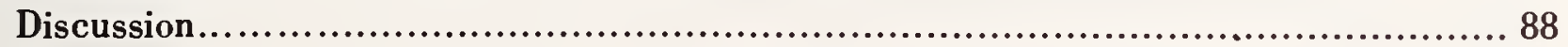

SESSION II

Chairman: J. Kabinow

Opening Remarks

J. Rabinow

Antitrust Doctrine vs. the Individual Inventor: Friend or Foe?

J. Stedman

Discussion.....

The Inventor in a Changing World of Patents

A. R. Whale 
The Role of the Patent Office in the Process of Invention and Innovation

E. J. Brenner

Discussion

U.S. Patent System: Fraud on the Inventor and the Public (and What Can Be Done About It)

I. Kayton

Discussion

NBS and the Inventive Process

R. W. Roberts

SESSION III

Chairman: M. Coler

Opening Remarks

M. Coler.

The Inventive Process - Where Does It Need Stimulation?

W. B. McLean ...

Discussion

The Employed Inventor and the Corporation

C. E. Anagnostopoulos

Discussion

The Institutions and Environment for Inventors in IBM

D. De Witt

Discussion

The Role of the Inventor in an Industrial Laboratory

J. Rajchman....

Discussion

Systems to Stimulate Employee-Inventions in Europe

F. Neumeyer.

A European Perspective of the Inventor Ecology

H. Romanus

Discussion.

\section{SESSION IV \\ WORKSHOP PANELS ON RECOMMENDATIONS AND QUESTIONS FOR FURTHER STUDY}

The Role of the Patent System

J. Stedman, Chairman. 
The Role of Industry

C. E. Anagnostopoulos, Chairman.

The Role of Government

W. B. McLean, Chairman.

The Role of the Educational System

W. Bollay, Chairman.

The Role of the Independent Inventor

S. Ruben and B. Walker, Chairmen

The International Aspect

J. Rabinow, Chairman

Participants

Appendix A. The Inventor-His Motivations and Society

S. Ruben.

Appendix B. Excerpts from F. Neumeyer, The Employed Inventor in the United States,

MIT Press, Cambridge, Mass., 1971. 



\title{
Opening Remarks
}

\author{
C. S. Draper*
}

Civilization is the crowning achievement that humanity has built up slowly and painfully during long ages of effort. There is no retreat for mankind from this way of life, a way that depends upon artificial modifications in the environment. The essential changes from natural states have always been forced by individuals, groups and organizations from basic motivations to realize situations with reduced unpleasantness in living and improved compatibility with the desires and needs of human beings. The complex of activities and resources devoted to providing means for accomplishing desired results by altering natural situations is called Technology. It is generally true that accepted benefits often have their price in effects on the environment that are incidental, undesired and damaging. When troublesome results become too difficult, Remedial Technology is required to keep environmental conditions within tolerable limits. Thus, the benefits from automobiles for purposes of transportation are accompanied by undesired air pollution that may be held to acceptable levels by applying "smog-control" technology to engines or by difficult-for-the-publicto-accept severe restrictions on the use of automobiles.

History tells that many civilizations have come into existence primarily on the basis of new technology, and have advanced beyond the levels current in competing countries. Situations of this kind have sometimes developed great nations and powerful empires that exercised strong influences on the progress of mankind. In several instances recorded by history, high achievement and recognition were followed by disaster because the beneficial technology used for generating great strength was not accompanied by effective remedial technology. Thus, urban technology made great cities possible, but remedial technology was not advanced to levels that provided capabilities for preventing sickness and starvation, for sanitation, for good transportation, for reliable food supplies and for effective

\footnotetext{
*Chairman of National Inventors Council
}

defense against the armies of rival powers. Another basic problem of political entities, such as the Roman Empire, was communication and transportation over great distances. Rome's empire disintegrated because the remedial technologies of rapid communication and fast transportation were lacking and civilization suffered a severe setback that lasted for several centuries.

Material and spiritual desires and needs of mankind are not absolute but continually change as travel and developments of technology modify local environments. Bathrooms with clean water and good sanitary equipment are today regarded as necessities, while even three or four generations ago much less convenient facilities were generally regarded as adequate. Today, almost all homes have electric light and power, telephones, radio, television, and one or more automobiles - things that within a few decades have passed from desired conveniences or luxuries for a relatively few people of affluence to generally recognized needs for everybody. Artificial alterations of natural circumstances by the use of technology are fundamental to all civilizations. The extent of these modifications varies with the level of sophistication in the societies involved and the climatic conditions under which they exist. Technological devices are much more apparent in, for example, London, than on the island of Tahiti. Progress in new developments, as desires develop strength to become needs, and as requirements for remedial technology build up when more benefits from artificial changes are accepted, comes faster for civilizations with high levels of technology than for societies existing closer to the state of nature. Progress for the United States of America as it achieved world leadership has always depended upon spiritual strength, rational thinking, creativity and the ability to develop, innovate and generally apply technology to the desires and needs of society.

Motivations for the complex of activities that combine to form the functional chains of technology come from ideas that have transformed from desires 
to needs by interactions among the individuals who make up society. Needs include the essentials for generally comfortable survival, for reasonably pleasant levels of spiritual and recreational wellbeing and for stimulating events and projects under consideration or in progress able to command interest and favorable reactions from large enough numbers of citizens to provide significant political power in support. The inherent nature of these needs is determined by the course taken by mankind as civilization developed on the basis of capabilities provided by technology. Maintenance of benefits and progress toward ever-more-agreeable living for everybody depends on the continued practice of existing benefits and advances in means to realize remedial measures for reducing undesired effects to tolerable levels. This background of circumstances makes it certain that technology will remain a primary concern and activity of mankind as long as needs are determined by the ways of civilization.

Technology, already developed and in operational use, may be kept in service by persons trained in routine maintenance of operating systems, but progress requires knowledge of real-world circumstances, imagination of desirable results and understanding of all the phases of technology as. sociated with transforming novel ideas into benefits for significant numbers of human beings. The overall process of realizing benefits from new concepts is called Innovation. Many activities are involved, including: engineering, testing, production design, promotion, manufacture, selling, distribution, service, etc. All of these phases can be carried out by people with routine education and training using material produced by manufacturing operations on the basis of information presented in routine patterns. It is also true that compensation for the services rendered is adequately provided by the conventional forms for transferring value, such as wages, salaries, stocks, bonds, dividends, options, etc. This means that all components of the innovation process, except the all-important sine qua non initial phase of creative imagination, are provided for by the ordinary workings of the business, industrial and financial communities.

Innovation cannot meet the desires and needs of society unless inputs defining problems of today and tomorrow that are important to society are clearly understood. The essential input from creativity occurs when inventors conceive and demonstrate feasibility of novel, practical means for providing benefits to society. Unless this beginning phase is present to start new developments, progress will cease. Ideas essential for the germination of pioneering technology come from one source-creative individuals with the special talents that make them capable of becoming inventors.

Invention and its various inter-relationships to the environment are different in various ways from all the other component activities that make up technology. Four of these ways are mentioned here for the purposes of discussion: (1) Without the availability of fundamentally new concepts, imagined and revealed by an inventor or group of inventors in forms adapted for starting new activities, significant advances in technology will not occur. (2) Benefits for all the persons of society can be realized only when inventors reveal the essential information from which novel developments of pioneering technology can be derived. If information of this kind exists but is completely withheld by the inventors, the situation is as if no new idea had appeared. (3) Information existing but held secret by inventors except for their own limited operations cannot serve as the basis for general benefits to society. In general, restrictions on ideas and pertinent data will not lead to the broad benefits for society that would be possible with complete cooperation from inventors. (4) Once the novel information associated with an invention or inventions is revealed, it is similar to water poured from a bucket on desert sands. Unrevealed information is like water in a bucket; it is under control. Once information is generally revealed, it is beyond control just as water poured on sand cannot be returned to the bucket.

Because advancing technology is essential for the maintenance and progress of civilization, a fundamental need of society is invention, the necessary element for the genesis of all pioneering technology. It follows that the inventor plays an indispensable role in the survival and advancement of human society. Because of this fact, society has a primary obligation to protect inventors and encourage their creative contributions to technology.

There is no way that the ordinary operations of the marketplace naturally and directly reward inventors for the values their ideas and results have created. Once the pertinent information on an invention is made available to everybody, the inventor has no directly effective hold on his contribution and cannot expect ordinary business operations to provide him with income. To avoid this unfair situation and to en- 
courage creativity, it is important to make special arrangements for compensating inventors in return for their revolutions of ideas with significant potential for benefiting society. Rewards to meet this special objective are based not only on the notion of fairness to inventors but also on the establishment of a compensation system strong enough to attract effective attention from creative individuals toward the problems of improving technological benefits to society.

The desirability of including special protection and rewards for inventors based on the unique and essential nature of their contributions to society and the fact that when significant information is revealed the natural "marketplace" value of the information disappears, caused many nations of earth to establish patent systems. In particular, as one of the fundamental principles of its national policy and law, the new United States of America established a system to protect inventors and encourage invention that has been a major factor in its long climb toward leadership among nations of earth.

The current state of affairs associated with inventors and the patent system is the primary subject for discussion by this conference. I am sure that enlightenment on existing situations and prospects for the future will develop as papers from our distimguished members are presented. My best wishes go with all of you. 



\title{
Inventions, Innovations, and Incentives
}

\author{
Betsy Ancker-Johnson \\ Assistant Secretary of Commerce for Science and Technology
}

\begin{abstract}
The Government has a responsibility to transfer the results of its research and development activities to wider use in the private sector. Last year, in the President's Science and Technology Message, and this year, in his budget, a strategic approach to technology was adopted as a national policy. The strategy includes increased funding, new emphasis on critical problems of special, national concern, and an effort to provide incentives to inventors, entrepreneurs, and research managers. The Department of Commerce is taking steps to promote actively the licensing of Government-owned patents, and the Experimental Technology Incentives Program in the National Bureau of Standards is asking such questions as "What cost-effective Federal actions can be taken to facilitate the commercialization of the technical inventions of the individual and small R. \& D. firms?"
\end{abstract}

Key words: Government patent policy; government R. \& D.; technology enhancement efforts; technological innovation; technology transfer programs.

The national resources devoted to science and technology are steadily increasing. Federal obligations for scientific research and development, including facilities, will go from $\$ 17.3$ billion in 1972 to $\$ 18.3$ billion in 1974 . At the same time, industry's expenditures for R. \& D. also are rising, from $\$ 11.4$ billion in 1972 to an expected $\$ 13$ billion in 1974 . Thus, the combined Federal and private investment for $\mathbf{R}$. \& D. in 1974 should exceed $\$ 31$ billion, the highest ever. Of this total, 69 percent will be spent by industry, about 14 percent by universities, the same by Government itself, and about 3 percent by nonprofit institutes.

This great R. \& D. effort has many public benefits. It creates wealth and builds a healthy economy. It provides a strong national defense. It gives us new and useful products and processes and creates jobs. It provides the means for environmental improvement and consumer protection. And, of course, R. \& D. supports education, medical care, the rebuilding of our cities, transportation, housing, and many other great social needs.

But the public is not receiving benefits, in many of these social areas, commensurate with the R. \& D. effort-or, I believe, with the potential inherent in such an effort. In fact, other nations, recognizing similar potential, have established advanced governmental programs whereby they attempt to increase the use of technology for public purposes. These frequently are called technology enhancement efforts. Late last year my office undertook a study of the technology enhancement programs of five foreign countries. The conclusion of the study was that the governments of the five countries visited (Canada, France, the Federal Republic of Germany, Japan, and the United Kingdom) strongly support invention, innovation, and the commercialization of research findings that they consider to have two criteria. First, they must be in the public interest. Second, they must appear to have good industrial potential for both domestic and foreign markets. The impetus for the study included such problems as the declining U.S. balance of trade, which in 1971 became unfavorable for the first time since 1893. In 1972 this negative balance was $\$ 6.3$ billion. (In April 1973, happily, U.S. trade was in surplus by about $\$ 200$ million.) Even in technology-intensive products, one of the mainstays of our foreign trade, the U.S. has been experiencing a steady decrease in its share of the world market. Many leaders in Government and business believe that not enough of this country's technology is being translated into civilian 
products and processes - perhaps because of the existence of institutional, legal, business, governmental, or other deterrents to investment in new technologies.

The first of two questions I'd like to pose today for your consideration is, "Shouldn't the Amcrican public be receiving more of the potential wealth from its tax expenditures of $\$ 17$ billion this year for R. \& D.?"

Concern over our national policies impinging upon this question reaches the highest level of government. President Nixon emphasized his personal concern when he said, in his Science and Technology Message last year, "Federal research and development activities generate a great deal of new technology which could be applied in ways which go well beyond the immediate mission of the supporting agency. In such cases, I believe the Government has a responsibility to transfer the results of its research and development activities to wider use in the private sector."

\section{Translating R. \& D. Results into Wider Use}

Technological innovation, although closely related to invention, is much more complex. The recent Battelle Memorial Institute report "Science, Technology, and Innovation" defines innovation as "a complex series of activities, beginning' at 'first conception,' when the original idea is conceived; proceeding through a succession of interwoven steps of research, development, engineering, design, market analysis, management decision making..." culminating in, as the report calls it, " 'first realization,' when an industrially successful 'product,' which may actually be a thing, a technique, or a process, is accepted in the marketplace." Most commonly, this process of innovation is a long one. In 10 innovations Battelle studied, the average duration was 19.2 years, ranging from 6 years for the video tape recorder to 25 years for hybrid corn, and 32 years for the heart pacemaker.

There have been many attempts, with limited success, to hasten this process of innovation. Some have been passive, on the theory that Government patents, to take one element, if made freely available, would be used. This theory is based on the assumption that there must be "acres of diamonds" in Government technology - an application of the old Horatio Alger-era expression signifying that wealth lies at everyone's doorstep, waiting to be discovered.
One passive attempt to unlock "free" technology came during, and immediately following, World War II. Patents of enemy aliens were made freely available to U.S. industry. Although many of the patents were of high commercial quality, almost no licenses were requested, and the patents generally fell into disuse.

To cite another case, the employees of the $\mathrm{Na}$ tional Bureau of Standards have received more than 400 patents, Government-owned, of course. On about 250 which are active, there have been granted only 34 non-exclusive licenses. (There was the exception of Abner Brenner's patents for a revolutionary chemical process for plating nickel on a metal surface without electricity, for which about 200 licenses were issued. Such breakthroughs are exceptional.)

The truth is that we know of very few products or processes from Government-sponsored technology that have reached civilian markets. In one study, mostly of Department of Defense inventions, only approximately 12 percent of the available inventions were commercialized.

A simple statistical comparison between the number of Government-owned patents, on the one hand, and privately owned patents, on the other, shows an imbalance favoring the private sector. Last year there were approximately 3,200 patents issued on Government inventions. (This breaks down to about 1,200 issued to the Government on employees' inventions; 200 assigned to the inventors, for inventions resulting from R. \& D. financed by the Government; 1,000 issued to the Government on contractors' R. \& D.; and 800 issued to contractors on Government-sponsored R. \& D.). Essentially the same rate of Government-sponsored patented technology has prevailed for several years. While Government's R. \& D. expenditures are 50 percent higher than industry's, its proportion of patents issued is ridiculous - less than 5 percent of the more than 70,000 domestic patents per year. Another way of looking at it is that there are almost 1 million "live" U.S. patents, of which the Government owns only about 22,000 .

In contrast to the passive programs, there have been, through the years, various "active" programs to take technology developed by or for the Government and transfer it into wider use in the private sector. The Department of Agriculture, for more than a century, has won renown for its extensive program to transfer agricultural technology from the experi- 
ment station to the farmer. The State Technical Services Act of 1965 was an attempt, through a program in the Department of Commerce, to apply the same pattern to the industrial sector and to assure increased utilization of technology, especially in small businesses. After 4 years' experience with the program, the Congress declined to fund it further, and it expired.

Often cited as examples of specialized technology transfer programs are those of the Department of Defense, the Atomic Energy Commission and the National Aeronautics and Space Administration. Yet they have had their limitations. A congressional staff study for the Senate concluded in 1967, "The transfer of technology from Federal military-space programs to commercial application is intrinsically inefficient compared to directed research and development sponsored for specific purposes by industry. Only the massiveness of the recent Government investment makes the promise of private sector gains possible.... The surest way to increase technological change is to provide incentives and remove disincentives for all of American industry to make privately funded scientific and engineering efforts."

Many students of the civilian technology transfer problem have emphasized the role of incentives. In the report "Technological Innovation: Its Environment and Management," published in 1967 by the panel of the Commerce Technical Advisory Board headed by Dr. Robert Charpie, a key conclusion was that, as a nation, "We should seek to provide incentives that will increase the Nation's total innovative potential and should aim our efforts at companies where the extra incentives are genuinely needed, or will provide the maximum innovative response per dollar spent." Another key conclusion was that "a unique cost-benefit opportunity exists in the provision of incentives aimed at encouraging independent inventors, inventor-entrepreneurs, and small technologically based businesses. The cost of special incentives to them is likely to be low. The benefits are likely to be high."

Not until last year, in the President's Science and Technology Message, and this year, in his budget, was a national strategic approach to technology-embracing incentives - adopted as national policy. The President's strategy is aimed at insuring that our overall R. \& D. efforts are focused on top priority needs, that our considerable scientific and technical capabilities are effectively utilized, and that the public receives a proper return on the public dollars invested in Federal research and development.

This strategy includes the increased funding which I spoke of earlier. It includes new emphasis on critical problems of special, national concern such as energy. The thrust of this R. \& D. budget, as with last year's, is to encourage partnership with private industry, examples being coal gasification and the breeder reactor. And the strategy embraces incentives to inventors, entrepreneurs, and research managers.

The Office of Management and Budget, in its special analysis of the Federal R. \& D. programs, stated, "Beyond the prime incentive of the favorable general economic climate, the Federal Government recognizes that additional actions may be desirable to encourage non-Federal investment in R. \& D. and its application." Consequently, the 1974 budget provides funds for enlargement of two programs inaugurated in 1973. One is in the National Science Foundation and is designed to improve our understanding of the effects of further investment in R. \& D. on economic growth and productivity. Another is the Experimental Technology Incentives Program in the National Bureau of Standards which is being funded this year by an initial allocation of $\$ 7$ million. In ETIP, we are asking such questions as - and this is the second crucial question I should like to pose today - "What cost-effective Federal actions can be taken to facilitate the commercialization of the technical inventions of the individual and small R. \& D. firms?"

\section{A Rational Program for Technology Transfer}

I would like to suggest that one practical step toward answering that question would be to imple. ment the President's program including those aspects designed to provide the necessary incentives and mechanisms to transfer Government-owned technology to the private sector. In an effort to speed the commercialization of Government-sponsored inventions by private industry, the President last year directed the Secretary of Commerce to develop "plans to promote actively the licensing of Government-owned patents."

Several steps have been taken, in response, by 
this Department. For one thing, our National Technical Information Service (NTIS), in cooperation with other Government agencies, has launched a patent promotion program aimed at carrying out the President's directive. NTIS regularly publishes in the Federal Register a number and title listing of Government patents and patent applications available for licensing. NTIS has published a special issue of its Weekly Government Abstracts devoted to Government Technology for Licensing, and plans to issue this on a regular basis.

Another step is that Battelle Memorial Laboratories of Columbus, Ohio evaluated 350 Governmentowned patents and selected 40 which are believed to have good commercial potential. Battelle has developed experimental communications packages. With these tools we are exploring opportunities for technology transfer to Government agencies and to the private sector.

A third step is that the General Services Administration has issued new regulations permitting the exclusive licensing of Government-owned inventions for limited periods. These regulations, however, are being challenged in the courts as unconstitutional.

Fourth, I have appointed, in my office, a Government Patent Task Force to examine all aspects of Government patent policy. One premise on which I established it was that, if the Government encouraged its own employees to invent and to apply for patent protection for their inventions, the public interest would be served.

While this study will not be completed for several months, some impressions already are emerging.

For example, I believe that we should adopt a national policy and establish a system under which the Government inventor is permitted to share equitably in the monetary rewards from his invention.

As it is now, inventions by Government inventors-made in line of duty-belong to the Government; and the Government, generally speaking, obtains entire title and then prosecutes the application.

Thus, the Government inventor is distinguished from the corporate inventor, who, in theory, can expect generous monetary rewards, and whose employer is probably vitally interested in commercializing the invention.

It is probably fair to say that a Federally-employed inventor rarely discloses with commercial gains in mind, and normally has no monetary incentive; as a result, the commercial aspects of his invention may well be lost.

The challenge to my task force - and ultimately to me and policymakers in the Executive Branch and the Congress - will be to consider changing Government patent policy relating to Government employee inventions, to change it rationally by bringing its provisions on employee rewards into line with general corporate policy respecting corporations' employees, to provide proper incentives for the Government inventor. In whatever changes are recommended, we shall assure that they reflect the overall public interest.

I should remind you that the Government has direct and automatic financial partnership in any profit made on an invention, because of the tax structure of the United States. Any profit made by an individual or a corporation is taxed heavily. In the case of corporations the tax is roughly 50 percent on profits over $\$ 25,000$, not even including taxes on salaries, on the distribution of dividends, sales tax, etc., which are part and parcel of our economic life.

The question is not whether the Government "gives away" anything to a particular group; the question is, what does the country get for the money? If we facilitated the exploitation of Government-owned patents, the public would gain new technology, new and useful products and services, new jobs and means for environmental improvement and consumer protection-to name a few advantages. Such gains would be consistent with the constitutional purpose of the patent system, namely to promote the general welfare.

I have asked two questions: First, "Shouldn't the American public be receiving more of the potential wealth from its tax expenditures of $\$ 17$ billion this year for research and development?" Second, "What cost-effective Federal actions can be taken to facilitate the commercialization of the technical inventions of the individual and small R. \& D. firms?" To the first question, I have answered, Emphatically yes! To the second, I have suggested that, if the Government encouraged its own employees to invent and to apply for patent protection for their inventions, the public interest would be served. 


\section{Discussion}

Question: Does Boeing have an inventor's incentive program?

B. Ancker-Johnson: Yes, I believe the patent policy that Boeing has is a relatively small fee that is paid upon making the disclosure, something like $\$ 50$ or so, another $\$ 50$ when the application is filed, and another $\$ 50$ or $\$ 100$ when the patent is issued. But something like 20 percent of the profits from any patent is paid to the inventor, and that can indeed be a very considerable income.

Question: In our system, as in Boeing, there's a trivial immediate reward to the inventor. This is, however, used as one of the measures of his technical success, and presumably he's rewarded salarywise. However, whether the patent is well written from the standpoint of being useful to the company is a matter on which the patent attorney will be very definitely measured, and he won't work there very long if he writes patents that aren't any good. It would seem to me that that is the proper focus, and I would like to ask, is there really any evidence about whether companies that follow one practice or the other with respect to direct rewarding of inventors have been more successful in acquiring and commercializing inventions?

B. Ancker-Johnson: There are two points you brought up. You mention the patent attorney that's not going to be around very long if he doesn't write an application that has good claims. One of the things that is not done well, in my opinion, currently in the government; is the writing of the disclosures because they are not generally thought of as being disclosures that will be used by the public for com. mercial gain. That can change very easily if the attitude changes.

With reference to your second question, the fact is that some industries do reward their inventors by means of royalty payments, and some don't. I do not know of any data that shows whether or not one system does seem to work better in stimulating invention, compared to another. That would be an interesting study to undertake, if the data can be obtained. But whether or not there should be a uniform situation in the private sector, I personally feel that government should set the style here, of trying to reward its inventors by one means or another, in order to stimulate the use of this tremendous amount of potential invention.

N. Parrish: At the University of California I'm in the continuing education group, putting on a number of programs including telling the individual how he can obtain a patent, and courses in brainstorming that enable him to expand his thinking so that he can better write the patent. Does your office offer support for this type of program?

B. Ancker-Johnson: Oh, yes. We have within the Patent Office a considerable amount of literature that is specially prepared for the private inventor. One thing that I'm really proud about in the Patent Office is that the examiners have a very high regard for the individual inventor and do everything they can to help him.

A. Ezra: We are one of your friendly competitors, from the Experimental R. \& D. Incentives Program. I would like to make one comment about the licensing of Government patents. I think I happen to be one of the few people in the United States who managed to negotiate an exclusive Government license in my previous job before I came to the $\mathrm{Na}$ tional Science Foundation. And let me tell you one of the most glaring difficulties there in making commercial use out of even an exclusive Government license. I discovered that the Government will not enforce its patent against infringers, whereas a private company will enforce against an infringer, against even a non-exclusive license. In other words, it is up to the licensee of a Government patent, even an exclusive licensee, to prosecute infringers, which is a very large expense, and that I found was a great handicap in trying to get commercial use of it.

B. Ancker-Johnson: What we're trying to do is to avoid that by the license being issued to someone, who then can take the litigation and defend the patent. So it would no longer be the responsibility of the original source, but those that got the patent would be the ones to defend it.

A. Ezra: I have one other comment on that: as long as they insist that the Government own the patent rights, if it turns out that some fortunate licensee of a Government patent is making millions of dollars, 
then the Government has the right to march in and say: "Give a license to Joe Blow down the road, who is a competitor, because he is also a taxpayer," and I've found quite a bit of resistance to that.

W. B. Shockley: My own feeling is that I don't believe in specific monetary rewards for patents, and I don't think I'd like to work in a large laboratory where this was done, because when you have a con- ference and you know if you got the disclosure out, that would clearly show that you had the conception, then you get in on the ground floor and the other people at the conference don't. I've seen people act that way. I think it would be unpleasant. I would much prefer, myself, that the management use good judgment. The fellow who gets his name on the disclosure may not necessarily have been the man who did the most creative job. 


\title{
An Economist Looks at the Patent System
}

\author{
Robert D. Tollison \\ Council of Economic Advisers, Old Executive Office Building, Washington, D.C.
20506
}

\begin{abstract}
This talk sketches the way an economist might view the tradeoffs involved in the social institution of a patent system. If the output that a patent is designed to protect can be loosely labeled as "information," then there will always be a tension between the need for patents to stimulate the production of new information and placing a short-run monopoly price on a good that, once produced, is inherently non-rival in consumption. A patent system is probably a socially efficient way to make this tradeoff, although the fact that societies impose different standards and procedures in the patent process suggests that study and discussion of patent reform may be worthwhile.
\end{abstract}

Key words: Economic tradeoffs; monopolies; new information; patent reform; patent system.

Thank you, Dr. Draper. I guess the best way to characterize how I feel at the moment is that there is reputed to be an epitaph on W. C. Fields' tombstone which says: "On the whole, I'd rather be in Philadelphia." That's exactly the way I feel, because I don't think that between Dan De Simone and Jack Rabinow, they could have found a more totally unqualified economist to look at the patent system. I would admit to being an economist, but I have little or nothing to do with the issues of patent policy in my responsibilities in the Government, and in my doings in professional economics I've never written about the patent system, and I've read very little about the patent system, except in the last few weeks. But anyway, Jack said, "Why don't you come on, and tell us about how an economist would look at the patent system." So, I warn you, these disclaimers are warning that you may have to jump on me for inaccuracies, data, or outlook, or whatever you might think to be wrong in the question and answer period that follows.

I would like to do two things, just to set a basis for discussion. I would like to talk about some of the trade-offs, philosophic, if you will, involved in the way economists would look at what inventors do, which is produce knowledge, produce information, and how this might happen in a price system, or the way we allocate and produce goods. And then I'd like to talk a little about what the trade-offs I talk about in a very general way have to do with the patent reform.

To talk about the way an economist would look at the patent system, I'd like to reason by process of an analogy. I recognize that this is a dangerous but potentially useful way to reason, and I'll leave it to you to decide whether the analogy is worth anything when I'm done. I think this might be more useful than sort of looking at the specific technical and legal and economic details of what's going on with respect to patents, and whether government takes away their employed inventors' rights, and other more specific issues.

I would like to take you back to a Garden of Eden sort of world, where there's an oasis which has a spring, and the people who live there, and the camels, all can come and drink, and there's no scarcity. It's essentially timeless: the water flows, it's super-abundant, there's an infinite supply of water, and there's absolutely no scarcity in this place. If you confronted an economist with that set of circumstances, and asked him should you place a positive price on that water, he would probably respond to the effect: "What function would a price perform; you don't have to ration the water, because there's plenty of water around, there's no long queue to get the water, there's no crowding of camels and people 
at the water-holes. So price can't perform a rationing function since there's no scarcity, you don't have to have people exploring to find new springs. Price just has no rationale in this setting; if anybody gets a net benefit from consuming the water, he should be allowed to do so at zero price. There would be no entry fee. And everybody's good-natured, so nobody builds a fence around the spring." So might run the response of a typical economist.

You have to be careful in making the analogy, but I think a reasonable case might be made that the existing stock of knowledge that society has at any point in time might be like that spring. Take the example of a theorem. When a theorem is developed by a mathematician and it's printed up and distributed around, if I consume that theorem, I don't reduce the amount of that theorem that you can consume; I don't change the total quantity of knowledge by your letting me have access to the knowledge. Using a little more technical terminology, the theorem and the spring are what an economist would call a "purely public good." Given the assumptions I've built up, there's literally no cost to allowing someone else to know that theorem. Now, notice I haven't said to use that theorem to make a profit; I've said only to know it.

Under that sort of timeless, no-scarcity assumption, if you scratched an economist and asked him what he thought of that, he might say, "Well, price has no function to perform, social welfare would be higher if you didn't charge a price for access to these things."

How might you go from that sort of situation to see a patent system emerge? I guess, to carry on the analogy, a number of things could happen. The guy who found the spring might be a reasonably wise fellow and say, "These people would be willing to pay a price to get this water. I don't know how much of a price they'd be willing to pay, but we could do some experimentation, and after all, it doesn't cost me much to build a fence around this thing and keep the people out." It could arise for that reason alone, just sort of self-interest maximizing behavior by an individual who found the spring. Or the King might take the spring, or the strongest guy might get his henchmen out and put up the fence and rope off access to the spring. Or the spring might become crowded, or the camels drinking at the water might cause a sanitary problem (here, of course, "clean water" becomes scarce). So there might be motiva- tion for somebody to look at this situation and say, "Well, I can sell that: I can take economic power over the spring, and somehow make an income."

I suspect that patents, or the expropriation of knowledge, arose in a very natural fashion like this, and ultimately got written into laws. But the question that you would pose at that point is, "What does a positive price and building a fence around the spring get you from a social point of view?" That's a question, I think, that an economist might pose. Well, it does a couple of things. If it were getting crowded, or if the entrepreneur had some incentive to control access to the spring or to the source of knowledge, then a price would do one thing for him: it would ration who got it. The entrepreneur would raise price and restrict access and control who got to use the spring or the source of information.

But it would also do another thing. If you again scratched an economist he would say, "This guy would behave like a profit-maximizing monopolist since it's the only spring around (for the time being)." So what does economic theory tell you that a profit-maximizing monopolist would do? He would restrict output, he would raise price, and there would be a flow of income set up from consumers to the monopolist, and there would be a little left over loss to society which nobody captures, called "lost consumer surplus."

Price rations who gets the water, but the formation of "ownership" of a single spring also generates some monopoly inefficiency. If we slightly expand the setting to make water scarce, placing a positive price on the water, even a monopoly price, will give somebody an incentive to go out and look for new springs. Pricing the water sets up a flow of income to someone which other people can observe, and if they wish, follow the example of the guy who expropriated the spring, go look for new knowledge, go look for new springs.

The trade-off that I would try to pose to you in the way a pricing system might work in a market society to produce and allocate knowledge or information and invention, is that on the one hand, there may be a case for not pricing the information that is generated. After all, that is recognized in most patent systems, because they expire at some point, and the knowledge becomes freely available. But there's also the other function of price to get people to go look for more knowledge.

So that would be a sort of rough and ready sketch 
of what you trade off: you trade off a certain type of pricing, the public grant of a monopoly right, which presumably from an antitrust point of view, people would be in general opposed to, against setting up a process of getting knowledge produced. And I think it's fair to say that the patent system is probably a fairly efficient social system for making that tradeoff, between future production and putting a price on the existing stock of knowledge. After all, patent systems are a quite general sort of thing that we see in societies and their constitutions.

Although you see patent systems in general, you see different societies who make these trade-offs differently. They do patent business differently. The Patent Office is run differently. They grant different types of patents. And I think the presumption of that, to me, is simply that the U.S. patent system may not be optimal. You may not be fine-tuning this trade-off between monopoly against wider dissemination of the information as well as you could. You may not be getting that trade-off exactly right, and there may be some form of gain from trade to worrying about how we do our patent system.

As far as I understand, and I have no profound understanding of the existing issues of patent reform, but you could run down a list of things that people have proposed. Take the objective of reforming the process of granting patents. Most every time I've heard it expressed, it is to insure that only valid patents are issued. I don't wish to get into any sort of numbers game with respect to the number of cases litigated, etc., because I simply don't know that data. But the objective of reform seems to be to insure that only valid patents are issued. Now, speaking as an economist, I think that's an objective that we could all agree on. From a social point of view, you don't want to grant or write monopolies into the law that don't have to be written into the law.

What are some of the things that are talked about to get at that objective? You could rank them from the situation where there's very little disagreement that there's room for improvement to where the heat starts getting generated, and that's probably what I ought to do. One of the first things that comes to mind is that you might allocate some more dollars to the budget and managerially reform the Patent Office. Again, I'm treading on thin ice, because I don't know how the Patent Office works; I just presume when they talk about inefficiencies in the Patent Office, that it's true, that it's an inefficient operation, and that, for instance, any one of you, if running the Patent Office were some monopoly like the Post Office, could bid for it, take over and charge a fee for examinations and make a profit. It's inefficient in that sense, that you could enter that business and do it better than the guys who are currently doing it.

I would find it hard to disagree with an argument, for instance, that the Patent Office ought to have a better information system, that it might be worth some budgetary dollars, some cost of other things foregone in the public budget, to spend dollars to make the Patent Office more manageable, either to increase examiners or increase the efficiency of examiners so that they can spend more time per patent and do a thorough job of deciding whether it meets the criteria in the law of a valid invention. I would think that none of us would have a hard time disagreeing with that, except one might argue that it's going to cost budgetary dollars, and where are they going to come from? I would accept that, and I really don't have any idea how many budgetary dollars it might cost.

Some of the other things that have been proposed in patent reform have to do with procedures in getting the patent. One of the things that has been proposed is to have a patentability brief written. Now, I don't know whether that differs from current procedure or not, but I take it that the Patent Bar has been opposed to a lot of these reforms on the very simple premise that they raise costs of being a patent lawyer. Literally, if you have to expend more effort to represent the client, the process is more complex, if there's a great deal more time on your feet defending the applicant, etc., those kinds of proposals would raise costs to the Patent Bar. Whether they would raise system costs or not, in the sense of sort of netting out the cost of the examiner's time vs. the information supplied by the applicant, I don't know. I really don't know how one would formulate a position on that kind of thing without a great deal more information than I have about how it's currently done.

Another procedure that's been proposed is to have an oath of invention. I guess my reaction to that is that it would raise a penalty to fraud; you would get into trouble, in effect, if you took this oath and it was later found out that you withheld information that was relevant to determining whether your invention met the criteria of patentability. An oath is not too costly a thing, to me, for an individual to take who is 
making a patent application, but it does raise a penalty to fraud. It does help you meet this objective of only issuing valid patents.

There are a whole set of other procedural things that have been proposed which have to do with, for instance, having some sort of public counsel-making the hearings for a patent open, or reasonably open-that is, opening up the process between the patent lawyer, his client, and the examiner. Apparently, the Justice Department would like to have their own counsel in the Patent Office who could sort of choose which cases he wanted to challenge on validity grounds. And there have even been proposals, I think, to allow competitors to come in and complain in the patent proceedings. With virtually no knowledge of the way existing procedures go, I think that I would have some problems with protecting the rights of secrecy of the applicant, and I don't know that I would want Antitrust to have a judicial agent there to challenge selectively. I don't know whether one could find a more amenable ombudsman role where information from outside can be conveyed into the process for the examiner to hear, but not in such a way that the inventor's rights of secrecy are violated in a serious way. I think that a trade-off could be made, but since I'm not a lawyer, I'm not sure 100 percent of what's involved there, or what sort of process one could set up to open up the examination of a patent to a more general audience than the three people who apparently currently do it.

There is one other area tied to patent reform, and that's the Scott Amendments. Is it fair to say that everyone knows what the Scott Amendments are? What they amount to are a series of amendments which would be placed on a patent reform bill. It makes legal, by definition, a whole bunch of pricing practices for holders of patents - that is, licensing practices of all sorts are sort of written into the law as legal. I would say a couple of things about this. First, this issue is related to the patent system, obviously, because it affects the income of the inventor.
It affects how he can use his patents and how he can generate income from them. But it seems to me that Antitrust apparently has the position on this, that many of the devices proposed to be made legal by definition in those amendments can have quite pernicious social consequences - market segmentation, pooling of patents, etc. Many of the famous price-fixing agreements which we have in American industrial history were built around patents or a patent base. The Antitrust position is that if these practices are necessary, if various forms of price discrimination and restrictive licensing agreements are necessary to bring the invention into existence, then they're willing to tolerate them. If they're not, they're going to be very skeptical of them. To me, as an economist, that's a reasonably sensible position to be in.

To pose a trade-off differently, if you want to grant inventors the right to be more perfect monopolists, literally to extract more income from their monopoly, then I think I would say you might want to consider trading that off against the length of the patent, lower the life of the patent, and allow inventors to capture more income immediately.

It seems to me that the only rationale we would have for tampering with the law on the ability of a monopolist to price like this is that somehow the income flow that we set up under patents is not sufficient to induce the supply of innovation and invention that we want.

I think if the Scott Amendments are attached to a patent reform bill, you are just asking for trouble, because I think the Scott Amendments won't stand on their own merits as a part of that legislation. I, for one, would rather see some of the objectives of reform of the patent system met, as such, than to tie the Scott Amendments to them and just complicate the issues, so to speak, by getting the problems of income flow to the inventor confused with meeting the objective of only issuing valid patents under criteria that we agree upon.

\section{Discussion}

I. Kayton: Why do you call patents a monopoly?

R. D. Tollison: What is a monopoly under the law? It's a single seller of something; is that correct?
I. Kayton: No, it's control of the source of supply over a relevant market. There are practically no patents that control a relevant market. 
R. D. Tollison: Would you like to elaborate on that, rather than assert it?

I. Kayton: Yes, I would. A very valuable form of patent property is in the form of the patent on the Accutron watch. That's very valuable, and it's property, very significant property. It is not a monopoly because this does not control a relevant market. How many people here have an Accutron watch on? How many people here have a wrist watch on? I've now demonstrated what $I$ intended to show. The patent on the Accutron watch is valuable, it's property, it is not a monopoly. And monopoly is a pejorative term.

R. F. Tollison: Why? It's a technical term.

J. Rabinow: I agree with Dr. Kayton that the word monopoly has a bad connotation, and this is the only objection we have to it; otherwise, from the economic point of view it makes no difference, of course. From the Congressional point of view it does; Congress does not like the word monopoly.

R. D. Tollison: Why do we write the word monopoly into the law? We do have an antitrust law that uses the term.

J. Rabinow: Yes. I would suggest that you read the speech by Judge Rifkind who said that it's time to divorce the antitrust laws from the constitutional rights of patents, because he says it's curious that the basic law is the patent law, and the later law was antitrust.

You talked about the efficiency of the Patent Office. If you talk about the quality of patents, you are quite right; if you talk about efficiency, you are not right. They're quite efficient, but they don't spend very much time, and for the time they spend on a patent they do quite well. Unfortunately, the average patent's total work takes about 15 to 20 hours - if you compare that with the search that goes into a court case, where hundreds and thousands of hours go, it's obvious that the Patent Office simply cannot make the search, and it's not surprising that new art is discovered. I think that Dr. Brenner, who will talk about the Patent Office, will bring these things up. I noticed that Dr. Ancker-Johnson was quite upset when you say they aren't efficient. They're efficient; they just don't do a good enough job, which is not the same thing, of course.

R. D. Tollison: O.K., I didn't mean inefficient in any pejorative sense; I just meant that it's possible that more budgetary dollars could go into the Patent Office.

J. Rabinow: That's certainly so, but unfortunately Congress doesn't want to see it that way.

B. Ancker-Johnson: I've just come from the Senate budget hearings, and in that hearing I asked the Senators if we could shell out enough money to give the Patent Office 94 more positions for just that purpose, and make the examination better, and I just about got shot full of holes. "You're always coming up here asking for more money," and "Why are you always asking for more money when the workload is approximately the same?"

Now, just a couple of days before that I was over visiting the Patent Office again, and I had a long talk with some of the examiners. You know what their beef is: "We want to do a better job on the search. Everybody is always telling us that we have so many that we have to turn out in such and such a time, and that's not professional. We want to do the job better." Now, somewhere in here we've got to have a balance. We could spend lots more money in the Patent Office and make each search much better, and that would make all the examiners happy, because they're all professional, good people-almost all of them-every outfit has some duds. But generally they're very good. On the other hand, you can't exactly expect the taxpayer to pay and pay and pay. So we've got to find some sort of balance, and that's what I think we have to recognize. 



\title{
Trends in Technological Policy Making
}

\author{
Daniel V. De Simone \\ Federal Council for Science \& Technology, National Science Foundation, \\ Washington, D.C. 20550
}

\begin{abstract}
Federal programs and policies contribute to technological advances in numerous ways. Many Federal incentives for technological innovation have been proposed over the years, but none has been put into effect. We need to develop a better basis for choosing courses of action.

Three Federal programs recently begun are aimed at this deficiency: the systematic assessment of the state of industrial technology by the Department of Commerce, a study on the barriers to technological innovation by NSF, and the experimental incentives programs being conducted by NSF and NBS. These are small-scale pilot projects, but the experiments and studies will help us understand more about the factors influencing technological advance. As a result, decision makers will be better equipped to determine what should be the nature and extent of Federal encouragement of private investment in technological innovation.
\end{abstract}

Key words: Experimental incentives programs; Federal incentives; technological policy making; technology assessment program.

Thank you, Jack.

After this morning's session, one would get the impression that this was the annual meeting of the American Bar Association. Last night when I came in, I noticed the big billboard for this conference and it said "National Inventors COUNSEL."

Jack mentioned that I used to be associated with the National Inventors Council, and I am very proud of that. Several years ago, the Council decided that it would be a nice thing to have a meeting out here in Monterey, California, and I was asked to arrange for it. So, I went to see the boss and I put the proposition to him, and the upshot of that discussion was that our next meeting was held in Washington. I couldn't deliver.

By way of contrast, several years later, Jack, too, decided that it would be a good idea to have a meeting of the National Inventors Council in Monterey, and so he went to see the boss. Jack is a very loquacious guy. It would have taken you or me 20 minutes to argue the case, but he did it in about 5 seconds flat, whereupon the boss signed the travel orders and apologized to Jack for having kept him waiting. That's how we finally made it out here. There's a saying back in the Capital City that Billy the Kid may have been the fastest gun in the West, but Jack Rabinow is the fastest tongue in Washington. If he were the Speaker of the House, the rest of the Congress would be out of business.

Anyway, I'm delighted to be here. Last year began as an auspicious one for Science and Technology. In unprecedented ways, the Federal Government extolled the virtues of invention and innovation. It had all the earmarks of a marriage, if not of the heart then at least of convenience. Seldom have science and technology been given such billing, first in the State of the Union Message, and then in the Pre. sident's Special Message to the Congress on Science and Technology.

In his State of the Union Message in January of 1972, the President announced that he would soon unveil "a new program of Federal partnership in technological research and development with Federal incentives to increase private research." Two months later, on March 16, 1972, he sent the Congress his Special Message on Science and Technology, in which he outlined an incentives program and other initiatives aimed at improving the 
climate for innovation. So 1972 , we would have to say, was an extraordinary year of declarations, one of those peak years of interest in technological innovation.

Now, to say that there have been peak years of interest in technological innovation implies that there have also been valleys (years in which the interest in technology faded). It is unfortunate, but nonetheless true, that just as fashions come and go, so does the interest in the technological health of the country. There have been, broadly, four cycles of concern about technological innovation since the second World War. The peaks of these cycles - that is, the years of greatest concern for technology-occurred in the late 1940 's, the late 1950 's, the early to middle 1960 's and the past 2 years. These peaks of concern, not surprisingly, coincided with times when we were also concerned about the health of our economy, both domestically and in the context of international trade. National security and prestige also contributed to these peaks of interest.

The low points between the peaks seem to occur whenever things look rosy and bullish. When the economy is booming, and a sense of security prevails, the concern for future technological advance ebbs, and eventually gets lost in the noise level of euphoria. There is a natural tendency to attribute good times to things that are being done now; in good times, rarely do people perceive their happy state to be the result of policies that were pursued diligently and wisely years before. Even less do they perceive that if things are to go well in the future, then thoughtful actions must be taken now. Which leads us to a law of science policy that has to do with cause and effect. The longer the interval between policy and payoff, the greater the burden of carrying the policy through.

Now, as you'll hear from our next speaker, research and development are very risky investments. The private return on such investments is often highly uncertain; the reward, if any, lies elusively in the mists of the future. It takes intense dedication and resolve to take an idea, big or small, whether in government or in private industry, and to build this idea into something of consequence that solves a national problem, or creates a new market, or launches a new business or company. There has to be patience, and devotion, and commitment over a long period of time. In government, as in industry, such qualities are rare.
Now, let's look at this problem from a national standpoint and in an historical context as well. From its beginning, America has been blessed with a marvelous breed of inventors, innovators and entrepreneurs with vast natural resources at their disposal-almost, you might say, the spring in the Garden of Eden, that Dr. Tollison referred to, and the acres of diamonds that Betsy. Ancker-Johnson referred to. With these vast natural resources at their disposal, and in a free and relatively competitive environment that nurtured creative achievement, these technological frontiersmen made this country the envy of the world. Other nations clamored for our high technology products and services and our productivity rose to meet demands at home and abroad.

Now, as we approach the bicentennial, we see a different picture:

-In many fields of world commerce, our technological edge is shrinking, and in some cases we have been overtaken by others.

-For the first time since 1893, our balance of trade in 1971 showed a deficit, and in 1972 this deficit grew to almost $\$ 6-1 / 2$ billion, the largest trade deficit ever.

- There is increasing concern that the rate of increase in our productivity may be inadequate compared to the rates in other advanced industrial countries.

- Rising aspirations with respect to environmental quality, pose new challenges in the production of goods and services.

- One of the results of 2 centuries of social change is a maze of intricate regulatory requirements and restrictions, some valid and some that are perhaps questionable, that may be inhibiting innovation and discouraging entrepreneurial initiative.

- The level of risk and economies of scale required for some technological developments are so great that individual firms are sometimes unable to tackle them alone; and to cite just one more factor,

- Many people have become hostile to technology or, as illustrated by the space program, have become jaded, and now take technological achievements for granted.

I don't have to tell this audience that these are not times for complacency or hostility toward technology, for the trends I have outlined are persuasive evidence that we can no longer take for granted the continued rise and preeminence of American 
technology. And that is why a salutary and conducive climate for innovation is so important to the future of this country.

Federal programs and policies contribute to technological advance in at least six different ways. First, the Federal Government is directly responsible for sponsoring or performing research and development in such fields as national security, space exploration, and health research. That's a clearly defined role. Second, the Federal Government also has a responsibility to stimulate the transfer into the private economy of the technologies developed at public expense. The hope is that additional net benefits may be derived from the investments in such fields as defense and space.

Now, the third role is not so obvious. As the largest single purchaser of most products - for example, computers, aircraft and buildings - the Federal Government can require and encourage improvements in these items by conditioning its purchases on the satisfaction of specified performance standards, which, in effect, advance the state of the art.

The fourth role, and one that is featured prominently in this conference, as you have already seen, is the Federal Government's responsibility for maintaining the patent system. The fifth role is the responsibility for supporting basic science.

The sixth role is indirect and often subtle, but nonetheless important. It comes as a result of Federal laws and policies which do not have as their purpose the encouragement or discouragement of technological innovation, but which nevertheless may have this side effect. This indirect role of the Federal Government is inherent in laws and policies that influence the rate and direction of research and development, competition in the economy, the allocation of productive resources and countless other economic and personal decisions that range from determinations of whether or not to invest in a new enterprise, to personal decisions such as the desirability of pursuing an education in science or engineering. Examples of this sixth category are regulatory laws that specify permissible activities in such fields as patent licensing, product safety-incidentally, we have a Commissioner of the new Product Safety Commission with us today, Dr. Larry Kushner-transportation, and energy production and distribution. All of these laws have been enacted for other than technological reasons; nevertheless, many of their side effects contribute to what we call the climate for technological innovation.

Earlier, I mentioned the peaks of national concern that have occurred since World War II. During these peaks, many incentives for technological innovation have been proposed. Most of these proposals have centered on large scale, across-the-board tax credits that would have given preferential treatment to corporate expenditures for research and development, and which would have cost billions of dollars in tax revenues which, of course, other taxpayers would have had to make up. Other proposals have called for amendment of the antitrust laws so that private enterprises could engage in a much wider range of joint research and development activities.

None of these proposals has ever been adopted and put into practice. And the reason is that the proponents were unable to carry the burden of proving that their proposals would, after restructuring the tax laws and the rules of competition, result in a net benefit to society as a whole. Perhaps this burden of proof is impossible. But the problem has always been that the factual basis for even attempting to carry this burden of proof was never at hand. And as soon as each cycle of concern for the health of American technology subsided, so did the quest for evidence to support incentives for technological innovation. Therein lies the problem: we need to develop a better basis for choosing courses of action. Dr. Tollison mentioned this morning that there are a number of ways in which one can finely tune the patent system. But where is the factual basis for deciding which one is likely to be the most successful? We just can't afford the fire-drill approach which has generally characterized technological policy making in the past. Whenever these peaks of concern have occurred, we have gone into the fire drill mode and in the intervening years of apparent good times, economically and internationally, the fire engines have been put away.

There are three Federal programs that were announced and begun last year, which are aimed at this deficiency in the shaping of public policy. One of these programs is a systematic assessment of the state of industrial technology, which the President has directed the Department of Commerce to undertake. Another, is a comprehensive program of study on the barriers to technological innovation in our society, which the President has assigned to the 
National Science Foundation. And the third consists of two so-called experimental incentives programs, of which I'm sure most of you are aware. One of these, called the Experimental R. \& D. Incentives Program, is being conducted at the National Science Foundation. The other, referred to this morning, called the Experimental Technology Incentives Program, is under way at the National Bureau of Standards. These programs will be covered in detail later in the conference. At this point in the proceedings, I need only point out that the assessments and studies, per se, are aimed at the knotty questions concerning barriers, alleged and perceived, to technological innovation in the economy.

Through the experiments, on the other hand, NSF and NBS will seek to learn by doing rather than studying. These experiments will be analogous to the small-scale pilot projects that are undertaken in industry to determine whether a full-blown program is likely to pay off. They will involve partnership arrangements between the Federal Government, on the one hand, and industrial groups, universities, state and local governments, on the other. Now, the experimental incentives program, conducted partly at NBS and partly at NSF, is a modest undertaking, as it should be. It is characterized by a sense of humility which ought to come as a relief to the taxpayers of this country. For the purpose of these experiments is to learn, through small scale trials, what is worth doing and what is not, rather than to launch into a major program of one sort or another, which has a tremendous price tag attached to it, without any indication of whether it is relevant to the problem or will be successful in solving whatever it is setting out to do.

In combination with the studies and assessments, the experiments will help us to understand more about the factors influencing technological advance.
From the experience and insights that will have been gained, the decision makers will be better equipped to determine what should be the nature and extent of Federal encouragement of private investment in technological innovation. By decision makers, here I mean, of course, the people in the Office of Management and Budget. That's where, ultimately, the question of funding gets decided. No one should expect that this program will make a discernible, short-term impact on our economy, as some have suggested. It's not intended to do this. We will, in effect, be learning to crawl before we try to walk, which is a perfectly honorable procedure. And we will learn just as much from failures as from successes. That is what pilot projects, of course, are for. I believe that there will be dividends along the way and I'm thinking particularly of the potential that this experimental incentives program has for dramatizing the importance of invention, innovation and entrepreneurship to the well being of our nation.

Several years ago, I had the privilege of working on a study of the problems of technological innovation with a distinguished panel of experts and scholars, which included Dr. Richard Morse, our next speaker, and Professor John Stedman, from whom we will hear tomorrow. In 1967 we published a report on "Technological Innovation: Its Environment and Management," which concluded, "The major effort should be placed on getting more managers, executives and other key individuals, both in and out of government, to learn, feel, understand and appreciate how technological innovation is spawned, nurtured, financed, and managed into new technological businesses that grow, provide jobs, and satisfy people." We said that 6 years ago, and to sum up, I believe that the need for such understanding and appreciation is even greater today than it was then.

\section{Discussion}

Question: The Department of Commerce has a program called DISC. Do you think that we could have something that would parallel this from the standpoint of the inventor, perhaps that the government would allow him a certain tax credit for having come up with a creative idea that would benefit the country?
D. De Simone: The DISC program, as you probably all know, is a program that is designed to improve our export picture, and it does provide certain deferments of profits earned in the export of American products and services. There is one recommendation in the President's Message on 
Science and Technology which, in effect, would implement the very first recommendation of the Charpie Panel Report that was referred to. That is to provide for inventors a loss carry forward period of 10 years rather than the current 5 -year period. This would help a great deal, we thought, when we undertook the Charpie Panel Study. We still believe that it would help a great deal. Your suggestion would give to inventors an analogous preferential treatment to the DISC Program, but you put it in terms, as I recall, of an inventor having achieved a successful commercial product or the introduction and use of an invention of any kind, and at that point being given the deferral of preference of the DISC Program. It seems to me that if the invention is successfully introduced into commerce, that this is really not the kind of concern that we had on the Charpie Panel; we're concerned about the inventor who has to go through this long period of developing a product, of getting it successfully introduced, and being able as a consequence to cover the expenditures he has incurred over a longer period of time than is now permitted under the Internal Revenue Code. My instinct says that it would be better to concentrate on that situation than on special tax preferences for one who has successfully introduced his invention into commercial use, because he will get his reward, by definition under your question.
R. L. Fullman: I wonder if you could amplify why you believe there is a special ignorance about the consequences of Federal policies relative to technology as compared with other fields? I grant all of this uncertainty but I don't see why it's different with respect to technology. I would tend to hang the adjective timid, rather than humble, on these experimental incentive programs, which I really question even provide enough funds for adequate experiments to get information.

D. De Simone: That's why I said that nobody should expect them to make a discernible impact on the economy. The Experimental Technology Incentives Program, which is now going into its second year, is funded at a level of $\$ 7$ million. The Experimental R. \& D. Incentives Program at NSF, I believe, has been allocated to date $-\$ 2$ million. It's really a small amount; and on the other hand, I don't think that's too bad, because I think anybody who's faced with trying to do something with the concept of experimental incentives has to realize it's a very difficult proposition to develop experiments which are relevant to what are perceived beforehand to be important technological policy problems, and after their completion can be generalized and applied to the entire economy. 



\title{
New Enterprise Generation
}

\author{
Richard S. Morse
}

\section{MIT Development Foundation, Inc., 50 Memorial Drive, Cambridge, Mass. 02139}

\begin{abstract}
The national environment for innovation is examined: in government, industry, the university, and the public.

The administration is concerned for the environment of science and technology, but centralized leadership and responsibility for long-range analysis and planning are absent. New rules and policies, or new legislation by Congress are needed.

Industry has been trying new methods in the management of R. \& D., both in establishing centers for entrepreneurship within the company, and providing venture capital to acquire new technology outside the company. The key to success in these enterprises is the entrepreneur who can judge the market and bring a new product into public use.

Universities should study the mechanisms that industry is using; there is need for research in these areas, and a need for a coupling of effort between the university and the industrial community. The university can also play an important role in teaching entrepreneurship.

The President should delegate authority either in the Executive Office or in the Department of Commerce to review the problems of invention, innovation, and entrepreneurship for the generation of new enterprises. New approaches should be tried to cxpedite the public use of technology and a closer relationship among government, industry, and the university.
\end{abstract}

Key words: Entrepreneurship; environment for innovation; government policy for innovation; industry R. \& D.; new enterprises; university R. \& D.

In the early days of the Commerce Technical Advisory Board, or C.T.A.B., which was organized by Dr. Hollomon, then Assistant Secretary of Commerce-Science and Technology, a number of studies were conducted with respect to important national problems in which science and technology were relevant. One of the better reports generated by C.T.A.B., "Technological Innovation: Its Environment and Management," dealt with most of the topics with which we are concerned today and has been widely read since its publication in January 1967. The success of the early Commerce Technical Advisory Board was not just the fact that it comprised an interested and concerned group of people with diverse backgrounds such as we have at this meeting, but after we wrote a report a serious attempt was at least made to implement the recommendations. Such an attitude is very important in Washington. There is hardly a subject of national concern that has not been studied by one or more committees and reports published. I hope something will happen as a result of this meeting, but special techniques are necessary to initiate action in government.

Many of our discussions relate particularly to problems of the inventor and $I$ in no way wish to deprecate his role in society. It is perhaps, however, more appropriate to discuss the "innovation process." This process often involves the inventor in one of its early phases, but when you come right down to it there aren't very many individual, successful, lone inventors in the United States. The total "innovation process" should be better understood and placed in perspective relative to our national environment. If this meeting is going to have any future impact, we should think in terms of specific recommended changes in the environment within which the innovation process operates in America. Such changes may take the form of new rules, policies or regulations to be adopted by exist- 
ing Departments or Agencies or new legislation by Congress.

The role of the entrepreneur is becoming recognized as an essential ingredient of our changing technological society. The term "entrepreneur" means a "ball carrier," i.e., a motivated individual who takes an idea whether it be in the form of a product, process or technique and assumes complete responsibility for its effective and rapid introduction into public use. He usually does this within an industrial organization or in concert with venture capital and some form of new enterprise activity outside the firm. Venture capital is also now established as an organized business operation. Quite often neither the inventor nor the entrepreneur subsequently demonstrates the ability to run "the company" or "the business" as it becomes a large viable enterprise. In Boston, for example, there is a successful, technically based company which was founded by a typical inventor/entrepreneur. This founder has now resigned as President and his title is "Inventor-at-Large." He just wants to get back and invent; he probably still will be pretty good at it and the company is undoubtedly better off to employ his talents in non-management areas.

There is a very definite lack of understanding with respect to the total innovation process within the Government, our less innovative industries and universities. The mechanism by which the innovation process operates, particularly in terms of new enterprise generation, is relatively unknown in many parts of the country. The availability of venture capital varies greatly between different sections of the country and financial and legal expertise tends to be concentrated in relatively few sections of the United States. The role of science, alone, as a stimu lus for the creation of employment has been grossly misrepresented. There is certainly no evidence to support the thesis that greater support of R. \& D. necessarily means either a higher standard of living at the national level, improved profits for an industrial company or a higher employment level. New technology is brought to the marketplace by a "people transfer process," not by reports or merely more money for science per se. The "Entrepreneur" operating in the proper environment is primarily responsible for making things happen in the technology transfer area.
Government leadership in the area of innovation or new enterprises has been almost totally absent. The C.T.A.B. report on "Technological Innovation: Its Environment and Management" was published in 1967 and yet little definitive government action has been taken to implement its recommendations.

The Technical Services Act failed to recognize the real mechanisms by which new technology is introduced into the marketplace and, hence, failed to produce any significant, useful results. No one individual in Washington apparently has the appropriate authority and responsibility for promulgating action to render the innovation process more effective. Certainly, the record of the Small Business Administration is unimpressive and almost all of the major SBIC's involved in financing of new technical ventures, except those associated with banks, have now been abandoned.

The National Science Foundation has only recently been concerned with any phases of the innovation process and, historically, has had a history of supporting more basic science in our universities. Recent NSF and NBS programs are moving in the direction of developing a better understanding as to how science and technology may be brought into public use. Success in this area will require people in these agencies with a broad background in the management of technology, new innovative mechanisms for its commercialization as well as new contracting procedures. Neither the National Academy of Sciences nor the National Academy of Engineering has addressed itself to the general problem of creating a national environment necessary for technical innovation and more effective application of science. Maybe our new Assistant Secretary of Commerce-Science and Technology can assume greater responsibility in this area. There is no better mission for the Commerce Department than to recognize the tremendous importance of technology as an essential ingredient in the competitive position of the United States in world trade, a solution to many domestic problems and the creation of a higher level of employment.

This country will never compete in the world markets on the basis of cheap labor and our most successful exports have generally been based on the application of combined management and technical skills. We used to talk about the Japanese as being copiers, but no competent industrialist says that 
today. Until recently, innovation in Japan was relatively unknown, individualism was suppressed, and a worker tended to go with Mitsubishi or some other large corporation and was pretty well indentured for life. Honda, Sony, Nippon Steel and Toyo Kogyo, the maker of the new Mazda car, and major Japanese shipbuilders represent new, technically based enterprises with an impressive record of innovative management operating with aggressive and effective government support. In this country, the Federal Government tends to be a watchdog over big business. In Japan, the government operates in partnership with industry in an attempt to enhance productivity and industry's ability to compete in the world markets. The Germans had the Wankel engine a long time ago, but we now see Japan assuming a position of technical leadership in this and other areas where Germany and America were once the principal competitors. The United States has no monopoly on new technology and the flow of science and of technical ideas is now very rapid throughout the world.

It might be interesting to review some aspects of the current national environment. First, the Government, industry, and the public have become disillusioned with respect to science and technology. Regardless of the reasons, this is, in fact, apparent. Certainly the idea that our massive Apollo Space Program would suddenly create jobs and solve problems associated with our declining quality of life has been greatly oversold. The NASA Technological Utilization Program has certainly not been successful. The technological achievement of Apollo was certainly outstanding, but large numbers of highly qualified people were taken out of the economy and few of them can ever get back into the current competitive business environment. Neither NASA, nor Congress, really understood the mechanisms by which so-called "space technology" might have been employed for the benefit of the public and the useful, practical applications of this tremendous technical and management achievement were greatly exaggerated and misrepresented.

Industry is becoming more concerned with the costs of R. \& D. and our more innovative industries are making radical organizational changes in their research organizations. In general, they are decentralizing research and development work in order to get better coupling with the marketplace. In the cur- rent, highly competitive world-wide business climate few industries can now afford the luxury of the older "central lab" established on the theory that products will "come out of basic research." Notable exceptions, such as Bell Labs, etc., are fortunately still operating.

A few years ago a survey of the Fortune 500 determined that about 60 percent of these large, industrial companies were going into the "venture capital" business or at least thinking about it. The reasons are interesting. Non-innovative, large companies cannot hire first-class entrepreneurs. The incentive for this new business activity was not the idea of just making money via the investment route. Our larger organizations had decided to go outside the firm via the venture capital route as a means of attracting the entrepreneur and developing windows on new technology that was not otherwise easily available. Innovative companies in this country now recognize that the development of new technical products or entry into a new market area is highly dependent on the efforts of a very few talented entrepreneurmanagers with a specific mission. They want the "ball carrier," who is technically innovative, market oriented, to develop a product and go do something with it. Unfortunately, many of our major companies don't even know the word "innovation," and there are wide variations in management attitudes and approaches to commercial development within American industry. Change in the management of R. \& D. is taking place in more innovative companies on a very large scale at the present time.

Many companies are doing their product development by establishing centers of entrepreneurship within the firm. Many of these same companies are also engaged in so-called, "external entrepreneurship." The concept of "external entrepreneurship" involves the use of venture capital to permit the acquisition, by a variety of mechanisms, of an interest in the small, technical enterprise. One of our major oil companies, for example, has funded inventors and small companies in new technological fields both here and abroad with provision for a minority position in the new enterprise. A major chemical company insists on a majority position, or 100 percent control. A wide spectrum of experiments are now going on in industry, perhaps on a scale larger than most people realize. This is good. The key to success is the entrepreneur and, particularly, his 
ability to judge the market at the right time-and later manage a business. Science, technology and money are usually of secondary importance to the other essential ingredients to successfully launching a new product.

Less innovative industrial sectors of the country should review the mechanisms employed by more successful companies in their efforts to enhance the effectiveness of R. \& D. and product development activities through the use of new organizational mechanisms. The experiments that some of these innovative companies are doing are very interesting, although it may be too early to determine their degree of success. These new concepts should be carefully monitored, research on the process undertaken and reported. R. \& D. is not only very expensive, but there is always a great shortage of really first-class, innovative managers, scientists and engineers, and entrepreneurs.

Student attitudes have changed. Students in today's world aren't anti-business, but they're antinon-innovative business. They don't care if it's a big company or a small company; they are perfectly willing to work with Texas Instruments or $3 \mathrm{M}$ because they view those companies as being innovative where an entrepreneur-employee can participate in the action. Surveys of students, knowledgeable people, and major company executives reveal consistent attitudes when asked to name the 10 most innovative and most non-innovative U.S. companies. The non-innovative companies are generally unsuccessful in attracting any of the talented graduates of our better universities. Companies have an image and this is important in attracting those employees that will determine their future and customers in a competitive business.

In the venture capital area, there are more sources and amounts of venture capital available today than at any time in the past. On the other hand, there is less and less interest in funding so-called "startups," the inventor or the zero phase company, if you want to call it that. The reason is very simple: the venture capitalists are doing very well with enterprises that are already "in business." They are making very good deals and getting a large part of the equity.

Recent trends in our tax structure and SEC regulations should be of concern to anyone interested in the generation of new business enterprises and the respective roles of venture capital and the en- trepreneur. We now have a narrower gap between the tax on capital gains and personal income. This means that there is less incentive for the wealthy individual investor to back a new technical venture and, historically, the small, new enterprise and the "inventor" tends to be funded by friends and individual sources of risk money. We have also had a radical change in rules governing stock options, all of which act to the detriment of founders and key employees of a new business. It appears that the changes in such regulations, while made in an ap. parent effort to forestall inappropriate benefits for executives of large companies have, in fact, primarily harmed the small company. The new company can never compete with the large organization in terms of salary, pensions, benefits or assurance of employment. Stock options were the one incentive to permit a new company to attract those few key in. dividuals who clearly determine success or failure of the firm. The so-called qualified stock option plan is now essentially worthless for a small company.with unlisted stock, and other compensation mechanisms are required. All of these changes were made on the theory of people in Washington that somebody was getting away with something, without having the knowledge of the impact of such action on a small venture. If a small company wants to hire a real firstclass manager from GE or Du Pont, it can't offer security. It can't offer salary. It can offer a very exciting life and feeling of accomplishment. Unfortunately, it is getting very difficult to now offer the prospect of capital gains under present IRS and SEC rulings.

The R. \& D. organization of the Federal Government is also undergoing change. We have now in. itiated a general attitude of relevance with respect to R. \& D. and this is perhaps long overdue. President Nixon has decentralized the position of Science Advisor, a concept perhaps not as disastrous as the academic community believes. Historically, the President's Science Advisor and PSAC have frequently become far too heavily involved in "project" analysis and the details of technical programs rather than a concern for policy and the environment of science and technology. These changes should be viewed not with alarm, but constructively. If we can attract the proper qualified people, the new system will work.

The newly proposed Office of Technology Assess- 
ment will be established within and by Congress. If Congress proceeds to operate in the R. \& D. area rather than do long-range analysis and planning as an aid to its funding and legislative responsibility, such action should be viewed with concern. If the NSF and other Executive Departments and Agencies can maintain a high level of scientific, technical and management competence, the Executive and Legislative branches of government now have an opportunity to jointly enhance the usefulness of science and technology. Perhaps NSF and the newly proposed Office of Technology Assessment will also recognize the need for introducing specific changes in the national environment for entrepreneurship.

Our universities have a great opportunity to study these new mechanisms that industry is using for expediting the product development cycle within the firm and the support of new enterprises outside the firm. There is an urgent need for more information and research work in the field and many good thesis opportunities. We should also have a closer coupling between the university and the industrial community such as now takes place in some limited areas. Studies at the Sloan School at MIT a few years ago identified some 250 companies that had been generated out of MIT and its associated laboratories, such as the Draper and Lincoln Laboratory. The total MIT complex is now currently operating a total budget of about $\$ 250$ million a year and unlike the attitude of most academic institutions, MIT has encouraged its faculty and staff to be concerned with the public application of research activities and recognize that MIT has a responsibility to the local community as well as the nation as a whole. The country's first and largest publicly owned venture capital corporation had a net worth of about $\$ 500$ million at the time of its recent merger with another industrial corporation. A very large number of the new enterprises in which this organization had invested were a direct result of people and/or technology associated with the MIT community and over 90 percent of this net worth of $\$ 500$ million com prised ownership in such MIT related ventures.

In an effort to expedite the so-called technology transfer process, generate new, technically-based enterprises, employment, and, hopefully, bring benefits to both the community and MIT, the MIT Development Foundation, Inc. was established as a Massachusetts Charitable Corporation on April 3,
1972. This organization represents a form of experiment that, hopefully, will provide a new mechanism for expediting the public use of some of the research activities conducted by MIT and perhaps other institutions in the Boston area, alumni, or independent inventors. The Foundation operates as a separate corporation with a majority of the directors appointed by the MIT Corporation. The Foundation was organized for the benefit of MIT, although it may collaborate with other universities or institutions. Initial financing of this "Experiment in New Enterprises" has been by MIT and a series of sponsors, currently including: Air Products \& Chemicals, Inc., Cabot Corp., Dow Chemical Co., Dresser Industries, Inc., Eastman Technology, Inc., Exxon Corp., The First National Bank of Boston, John Hancock Mutual Life Insurance Co., Johnson \& Johnson, Macmillan, Inc., Monsanto Company, Martin Marietta Corp., G.A. Saxton \& Co., Inc., Alfred P. Sloan Foundation, Texas Instruments, Inc.

Most of these organizations are interested in supplying venture capital for new ventures and, perhaps more important, assisting in the critical market appraisal process faced by the Foundation in its analy. sis of new technologies to determine their potential usefulness. The industrial sponsors of the Foundation certainly view this operation as an experiment, but they are interested in developing windows on new technologies and most of them have an organized division or department whose sole responsibility is to lend some form of financial support as well as marketing and management assistance to new, technical ventures outside the firm.

An important function of the Foundation involves support of a continuing research program to develop a better understanding of the technology transfer process, the role of the entrepreneur, venture capital, improved coupling mechanisms between industry and the university, and teaching in the field of "New Enterprises," their organization, financing and management.

The MIT Development Foundation has now analyzed over 75 projects and identified four potential new ventures which may be worthy of funding as new business enterprises. In each case, it is in. tended that the Foundation will keep an equity position for the benefit of MIT. A potential manager/entrepreneur is first identified by the Foundation and then a new company is organized with him assuming responsibility for its business plan and subsequent 
successful implementation. This is an example of a new organization which should permit the operation of an effective coupling mechanism between the industrial and academic sectors of society. No doubt other approaches should be tried in an effort to expedite the public use of technology and closer relations between government, industry and our universities.

Problems associated with innovation, invention and entrepreneurship for the generation of new enterprises have been inadequately understood by either the Executive or Legislative Branches of the Federal Government. Because of our changing internal environment as well as our deteriorating competitive position vis a vis new, emerging, industrial countries, the President should delegate appropriate authority and responsibility either within the Executive Office or to an appropriate Department, such as Commerce, to review this general problem and make appropriate recommendations with suggested mechanisms for their implementation, either by Executive action or initiation of necessary legislation.

In the 1967 report, "Technological Innovation: Its Environment and Management," for example, it was suggested that a change in IRS regulations be in. itiated to permit a longer loss-carry-forward period for small companies in order to overcome disadvantages which accrue to a small operation vis a vis those of a large corporation. Because of the recent changes in the structure of our personal income taxes, we now have a diminishing discrepancy between taxes and capital gains and income with the potential threat of minimizing incentives for venture capitalists to invest in ventures. Special incentives may be required whereby, for example, special tax credits are permitted to encourage investment in new companies, particularly those with a high technological base. For some time so-called " 1244 stock" has made it possible for investors to make deductions in cases of business failures, but this mechanism has never been widely employed, nor been effective as a means for stimulating venture capital from the private sector. Neither Congress, nor our operating departments, have clearly understood the appropriate role of the patent system as a mechanism for encouraging the commercial applications of Government-sponsored R. \& D. We still do not have any uniformity of contract patent poli- cies governing the use of inventions by government contractors, nor have all branches of the Government clearly recognized the need for exclusive licensing to encourage necessary development work with private funding to expedite certain product development activities. Some of our most competent industrial talent has always remained unavailable to government programs in peace time because of our patent policy and contractual difficulties in doing "business" with the Government.

Rules and regulations of both the SEC and the IRS have radically changed the incentives of qualified stock options which, historically, have represented an essential ingredient in the ability of the new enterprise to attract and hold key technical management personnel so essential for its success. Within our own Government laboratories, there are, no doubt, many potential useful ideas, products and processes, but no effective mechanism has been em. ployed for their commercial exploitation by industry.

While entrepreneurship is probably an inherent characteristic of an individual, it appears that the teaching process can enhance a latent interest in qualified individuals. A few of our graduate schools such as the Sloan School at MIT have been teaching courses in R. \& D. Management and New Enterprises for over a decade. More of such activities should be undertaken by the academic community, particularly in close collaboration with industry. Our universities should also conduct experiments in an effort to find new methods for the more effective public utilization of this country's great technical resources, including the science and technology generated within the university and by the Govern. ment.

The concept of "relevance" has now been clearly enunciated by the Administration as a fundamental guide to be employed in the development of R. \& D. policy and program. We also, however, need greater support from the Federal Government by our regulatory agencies in the Executive and Legislative Branches. Hopefully, as a result of this meeting, the President will delegate responsibility to an appropriate Department head within the Executive Branch to review this situation and make recommendations for action in the near future. 


\section{Discussion}

J. Rabinow: I predict that a market analysis is completely useless when the invention is really new. In really new innovations there's no way of knowing; that is, nobody could predict what radar would have done, what the computer business would have done; maybe the transistor was an exception, we'll hear from Shockley and he'll tell us; maybe that was a case where they could see the future clearer. My contention is that you cannot predict logically, that invention comes, sometimes, completely illogically. Do you want to comment on this?

R. Morse: Well, I would agree with you, Jack; perhaps I didn't put my comments in the right perspective. I meant to say that the normal industrial method of operating to meet their market needs or their growth problems, are associated first with identifying the market.

M. Harris: Recent studies show (many of you know the Sussex Study of Chris Freeman and other groups, and they're very large studies) that a lot of very important developments did not fail because of technological failures, they failed because the people either did not understand or did not know the marketplace. I don't want us to write off the man who has the great single invention, but I also want to warn all of us who are interested in taking one of these inventions that unless we do understand the marketplace, we haven't got a chance.

J. Rabinow: I agree with you also. That's absolutely correct that many inventions fail because of, not technology, but because the market wasn't ready. That doesn't mean that it could have been predicted; it simply means that the market cannot absorb all of the inventions that people can put on the market, and I think that's inherent in the system. I think this is the dice we play. The only thing is that the inventor should know what the odds are, and unfortunately, he doesn't. 



\title{
Inventor-Entrepreneurship and National Priorities
}

\author{
Narinder S. Kapany \\ Department of Physics, Stanford University, Stanford, Calif. 94305
}

\begin{abstract}
Because he is capable in science, invention, management and business, the inventor-entrepreneur has a high potential for solving some of the urgent problems of mankind today.

The attributes of the inventor and of the entrepreneur are briefly examined: the inventor-entrepreneur combines these talents in a bold, imaginative way.

Although some national problems are of such a nature that they must be solved by massive, largescale interdisciplinary effort, there are still many high-priority areas that can be attacked by the inventor-entrepreneur.

The optimum climate for nurturing his efforts must include:

- A strong technological and industrial base

- A free-enterprise economic system

-A healthy reception by the financial community and a sympathetic public attitude

- A cooperative, benevolent government attitude.

The inventor-entrepreneur is a pioneer - a champion of innovation-and as such, he deserves attention, support, and a chance to share the responsibility for solving the problems of society today.
\end{abstract}

Key words: Business management; inventor-entrepreneur; national priorities; national problems; technological innovation.

The changing nature of our society, our domestic and international responsibilities, increasing demand for better life, and greater opportunity for a larger number of members of the society are factors creating some very urgent problems for mankind today. These are problems of a magnitude hitherto unprecedented. The solution to these problems will require humane and constructive efforts on the part of a large number of people, something similar to the mobilization of scientific research during war time. We, however, need full-time interdisciplinary teams combining professional men of different specialities: natural scientists, social scientists, doctors, engineers, teachers, lawyers and many other inventive minds. The key to success in achieving our national goals and priorities is a much greater interdisciplinary, interfacial interaction. Today we need the development of science for overcoming some very urgent problems and to provide the basis for real growth and survival. It is in this context that inventor-entrepreneurship acquires a very significant role, inasmuch as it combines the capabilities in science, invention, management and business. In these four functions we can sum up the " 20 links of the productisation chain" that were talked about this morning. However rare this talent may be, its potential role in the world of tomorrow must not be overlooked, and means for fostering and assisting such people should be actively pursued.

\section{The Inventor}

We are dealing with three different items here: viz. inventor, entrepreneurship and national priorities. What is an invention? The dictionary says: "invention is the act or process of inventing; skill in generating or contriving; mental fabrication or concoction; the process of devising or producing by independent investigation and experimentation, something not previously known or existing." An inventor, therefore, is "one who invents, especially one who has originated some method, process or device, or who devotes his time to inventing."

An inventor maintains, consciously or subconsciously, an inventory of useful bits of technical in- 
formation. On one hand are his technical solutions, and on the other are the worthwhile problems for which he would like to find solutions. He continuously updates these two inventories, and once again, consciously or subconsciously, rearranges them whenever he encounters a new bit of technical information, a new solution, or a new problem. It is essentially a process of reshuffling all the bits of information from a large number of mental pigeon holes, throwing them together and rearranging them, much in the way a jigsaw puzzle is solved.

The act of inventing can be subconscious. I don't know how many inventors here have invented in sleep, but I have. I recall one fine morning, I got up and remembered that while I was at least half asleep I had thought of a method for measuring the refractive index of liquids photometrically. The idea is simple: you shine light into a glass rod, and when you imbed it into the liquid to be tested, the critical angle for total internal reflection changes and therefore the amount of light transmitted through the rod changes. A photodetector placed at the other end of the rod thus measures the refractive index of the surrounding liquid. The irony of this mechanism of the inventive process is that maybe a lot of us invent during sleep and don't remember it the next morning!

As we all know, there are many other factors that can nurture the inventive process. These are various forms of incentives, training, accidents, etc., etc. You recall Newton's accidental discovery of the law of gravity from the observation of a falling apple.

An inventor is generally thought of as a person interested in what he is doing, primarily from a technical standpoint. But whether we admit it or not, most inventors spend a lot of time selling. Whether it is an independent inventor, an inventor working in a large corporation, or an inventor working for the Govern. ment, he must sell his invention to a potential manu facturer, a marketeer, to his boss, or his colleagues. However, inventors have had to adapt to many drastic changes of environment in recent years. There have been significant changes in the company and client attitudes, in team inventing process, in large resource requirements for solutions to a number of problems. In addition there remains the age old problem of the attitude of "not-inventedhere" on the part of potential clients.

\section{The Entrepreneur}

So much about an inventor, what's an entrepreneur? Again, relying on the dictionary, the meaning of the word entrepreneur is: "One who undertakes to start and conduct an enterprise or business, assuming full control and risk." An entrepreneur is not necessarily an inventor; he is most inspired to couple an idea or an invention, his own or someone else's, to the marketplace. And this coupling process has within it many intricate and critical links which need to be fully recognized and respected. He understands intuitively, by training or by experience, the process of finance, marketing, production and management. Of course, one can take each one of these areas and divide them further into large numbers of subcategories. An entrepreneur is an inspirer and organizer of men and women; he faces with vision and determination the ficklemindedness of the venture capitalist. (The previous speaker correctly stated that in this country there is more venture capital available today than ever before, but as far as new high technology startup situations are concerned, it is just about as constipated as it can get.) The entrepreneur also faces with vision and determination the hazards of the marketplace, the conservatism of the bankers, the unreliability of his vendors, the uncertainty of technical development programs and the absolute certainty of rising costs due to inflation. He also knows how to evaluate realistically the "investments to return ratio," and a good. entrepreneur knows when to stop the development of a certain product or process. In other words, he doesn't get married to an idea; if the development costs go out of hand, he knows when to stop it. Most of all, he recognizes the complete array of talents that are required to make an enterprise successful. He understands his own personal strengths and weaknesses, selects appropriate and competent people to complement him, inspires them, trains them, organizes them, and then delegates to them. With all this, and an awful lot of luck, he may succeed.

\section{The Inventor-Entrepreneur}

A person who combines the talents of an inventor and an entrepreneur is rare, but he is invariably very bold and imaginative. An entrepreneur is invariably triggered to initiate a new enterprise by one or more 
of the following factors. He may be dedicated to his idea or invention and committed to couple it to an identified need in the marketplace. He may be imbedded in a large company and terribly frustrated by the slow moving and unimaginative hierarchy. I will present an example. An engineer became annoyed with his management in a large company and started a small basement operation smack dab opposite the headquarters of the large corporation. In a period of a few years he expanded his operation into about a $\$ 5$ million a year business. By that time his temper had cooled down so he sold his company to another corporation for $\$ 5$ million. He installed a ticker tape at his home and gradually lost most of his money in the stock market.

Of course, in motivating an entrepreneur, money and power are important factors, although these may not be the dominant factors. Many inventor-entrepreneurs possess that unique psychological and personality makeup needed for success. In the growth of a corporation accidents can have a positive effect, but there is no substitute for a viable plan and hard work.

A basement operation can mushroom into a big business. Hewlett-Packard started off as a garage operation a number of years ago. They received an initial order from Walt Disney and with a great deal of technical ingenuity, business agility and some luck, built it up into one of the most successful scientific corporations in the United States.

This breed of man, an inventor-entrepreneur, is rare but they have mushroomed in recent decades, primarily in the United States. Take the example of Land. He started work, not on cameras but on a plastic polarizer film. He worked on it for some time, didn't really find any application for it and got into cameras, and we all know what he has done with that.

Varian Brothers started work on the Klystron at Stanford, built it and related developments into a large and successful corporation. Arnold Beckman started with spectroscopic instruments and built Beckman into a successful instrument company.

Another interesting and more recent example is of Dr. Alex Zaffaroni. He developed the basic technique of paper chromatography and was involved in the development of Synalar and the birth control pill. A few years ago he decided to leave the presidency of a large drug firm, and started a new operation called Alza Corporation, dedicated to new and revolutionary methods of drug delivery. Zaffaroni's basic theme is that a large portion of human anatomy is bombarded with drugs, generally through the gastrointestinal tract, while the drug is needed only by a certain small portion of the body-hence the need for a localized drug delivery system using unusual scientific phenomena. He did not have a specific fully developed product, but because of a high degree of credibility amongst the financial circles he managed to raise nearly $\$ 30$ million. I believe, after nearly 3 years, his company is on the threshold of introducing some very exciting products: viz, an Ocusert insert which is placed under the eyelid to deliver continuously medication for glaucoma patients. Other similar drug delivery methods for birth control, etc., also seem to be well on their way.

The climate for nurturing an inventor-entrepreneur requires a number of elements: 1 . There must be a strong technological and industrial base, preferably nationwide; 2 . It obviously has to be imbedded in an economic system of free enterprise; 3 . There must be a healthy reception by the financial community and, of course, sympathetic public attitudes; 4 . There has to be a cooperative and benevolent Government attitude.

It's quite interesting how these elements have evolved naturally in this country, although recently we're probably losing some of the edge. When we go abroad and compare the situation we invariably conclude that there is still a great deal more potential for an inventor-entrepreneur in the United States. Let me give you an example. In Europe I was involved in a joint venture as a member of the Board of Directors of a Belgian company. We acquired nearly one-third of that 50-year-old company's stock in return for our technology. While we were negotiating with our partners, who happen to be one of the largest holding companies in Europe, I delayed our agreement for at least 3 weeks because I have always believed that the management of the company must get incentives through stock options. Six months after the agreement was signed I was authorized to offer stock options to the top management; viz, the general manager, the director of research, the director of marketing and so on. To my great surprise every one of them refused to take any stock options because they felt that it might be considered unethical to 
acquire a portion of the company in which they worked, and also feared incurring the displeasure of the majority shareholders. This gives an indication of the kinds of problems with incentives and motivation that exist in other parts of the world.

Looking at the other side of the picture, the inventor-entrepreneur is exposed to a number of hazards. Because he's generally preeminent as an inventor and perhaps has even acquired fame for his invention, he's suspect as a manager or a businessman. The situation is even worse if he also happens to have a $\mathrm{Ph}$. $\mathrm{D}$. At times his name and/or his invention will be touted by the vested interests to a point of being oversold. This overselling frequently subjects him to the pressures of the speculative investors and the stock market. He generally has a high visibility and that makes him a hero at times and a bum at others. By and large there is no middle course. And when the times go really rough, the bankers very hurriedly relegate him to the back dungeons of the laboratory. $\mathrm{He}$ is often frustrated, frequently maligned and sometimes prostituted. In spite of all these hazards he invariably flourishes, grows and continues to invent and engage in entrepreneurship!

\section{National Priorities}

How does all this play a role in national priorities? When one dwells upon national problems and priorities, one thinks of problems of very large magnitude that require governmental action or action by very large corporations. This is true only in part. National priorities fall into two categories: those that have been recognized, and others that have not been recognized by the powers that be. Among the recognized priorities there are also two sub-categories: viz, those that are being acted upon and others that are not being acted upon. The latter generally fall prey to the lip service of the politician, and we have a lot of those, too! The unrecognized priorities are the ones that constitute the largest potential damage spots for the society. Therefore, there is a great need to deploy a concerted effort in the area of technological forecasting and to find mechanisms and procedures whereby some national problems can be taken out of the political arena, in order that concerted effort on them can go on regardless of who is in or out of power. This may well appear to be a search for Utopia, but it is something that must be worked out.

There is such a thing as shift of national priorities, and it's a logical phenomenon; environments and problems change and therefore national priorities must change. But they must change on a planned basis and they must change in such a manner that a significant fraction of precious national resources are not sacrificed. Generally the most vulnerable resource is trained professional manpower. We saw an example of that only a few years ago when hundreds of thousands of scientists and engineers were thrown out of jobs. We realize how expensive it is for the Nation to train a scientist or an engineer. A shift in economy which renders jobless very well-trained professional people, who are entirely capable of solving other relevant problems of the society, is a criminal national waste. Such a fiasco can be avoided by adequate definition of new priorities and shifting the resource on a well-planned time scale. This is not intended to defend every scientist and engineer who lost his job in the last few years, because it is also true that science and engineering have developed a horrendous hierarchy, and there are many people who are sitting in the ivory tower and don't really belong there. Whereas there had to be a cure for this ailment, we must cure the disease and not kill the patient!

I would like to try and illustrate to you that an inventor-entrepreneur can find niches in areas of national interest and priorities. Some of these illustrations may be familiar to you. We talk about an energy crisis. Why did it come upon us so suddenly? We should have been able to predict it many years ago and prepare ourselves for it. An average inventor-entrepreneur can be overwhelmed by the fact that multimillion dollars a year are being spent by the Government on laser fusion activity. This is an activity where deuterium pellets will be subjected to high energy laser radiation from all directions, the electrons are heated to a point where you get fusion action. This may provide controlled and a clean source of energy. However, there remain a large number of other very sophisticated problems which are looking for imaginative and ingenious solutions. There is no reason for an inventor-entrepreneur to be discouraged, since there lies a very potent role for him in these areas. For example, when we look at the fact that there's a lot of photon energy falling on the surface of the earth, even on a cloudy day, it becomes clear that solar energy, when economically 
harnessed, will indeed be a very useful source. How ever, three problems need to be solved. Firstly, we need a very high efficiency absorbing layer, an effectively black layer with very low IR emission; secondly, we need windows with high light transmission for the solar energy and high reflectance for the infrared generated by absorption of the sun's energy. Thirdly, we need an efficient energy conversion/storage mechanism. Now, you may not need the resources of a very large company for the demonstration of the feasibility of some clever solutions to these problems. Although it is possible that most new inventions related to solar energy utilization will not find their way to the market place when looked upon from marketing, manufacturing or business standpoint, there is also no question that enough solar energy is available on most areas of the globe to be able to produce economically feasible domestic solar water heaters, space heaters and air conditioning units. Along the same lines let us consider the amount of wastage of energy. The efficiency of a large percentage of our equipment and machinery is very low. Consider a simple optical problem: you're illuminating streets in every city of the country during the night and the filament of the lamp that is illuminating a portion of the street is sending out energy in all directions. The percentage of photons emitted by the light sources that reach the retina of human beings is extremely low. By some clever thinking and new developments it might be possible to control the directionality of light with respect to the observers and thus reduce the amount of energy consumed.

You can go through other national priorities of today, such as pollution. You've heard about auto exhaust detection devices, self-contained toilets, pollution surveillance and monitoring, sterilization, etc. All of these problems present a fertile ground for an inventor-entrepreneur.

In the area of crime there exist many opportunities for potential inventions. For example, the method of fingerprinting used today is primitive. Black ink is used on your fingers and the quality of the image is generally less than optimum. In the 1970's, surely there are easier and more efficient methods available.

The area of medical instrumentation is full of fantastical potential. I will give you a couple of examples. At this time, in order to stop bleeding in the stomach or in some other portion of the body we in- variably have to undergo surgery. However, it is within the state of the art today to insert some kind of an endoscopic device using Fiber Optics which goes in the stomach and not only permits visualization of remote regions but also conducts laser radiation or cryogenic probe in order to coagulate the bleeding region.

Recently there have been some very exciting developments for helping people who have been paralyzed by a stroke. The theory is rather interesting. It was believed that as a result of stroke a certain portion of the brain dies and therefore some motor actions, memory, speech or whatever, are impaired and generally other portions of the brain cannot take over the function. The recent theory is that for every muscular action there is a positive force as well as a braking force. According to this theory the "brakes are jammed" as a result of stroke. The treatment consists of going down to the appropriate portion of the brain and touching it with a cryogenic probe in order to "release the brakes." I have seen patients suffering from the effects of a stroke of 7 or 8 years ago and partially paralyzed on one side, undergoing hours of surgery, a couple of weeks of convalescense, and walking out of the hospital. There are a number of problems still remaining: the accurate determination of the spot where the treatment is to be performed; the need for navigating the probe accurately; and a requirement for surgical devices, whether they are lasers or cryogenic probes, that will allow the surgeon to manipulate accurately, preferably with the aid of some optical visualization scheme.

In the area of education, we are at the threshold of a revolution. Why should books be used only for reading? Why cannot there be talking books, and not only talking but translating books - a book in which you turn the page and place a little gadget on it to speak distinctly to you in English, or with the pressing of another button to translate the material into another language, such as French, German, Japanese, etc.? The technology to achieve this is here today and, for an inventive mind, there are numerous potential solutions to the problems.

Potential breakthroughs in areas of critical social need are unlimited and there are opportunities for a small inventor-entrepreneur in them. In the area in international trade, we have heard a great deal recently. J. J. Severan Schreiber, in his book "The 
American Challenge," nearly 10 years ago predicted that in the 1980's the United States industry in Europe will be the third largest economic force in the world. Although today we have some problems in the area of international trade, we have enough inventive brains in this country which, if focussed on the national priorities of other nations, perhaps developing nations, can solve many of their problems with our know-how and create excellent economic opportunities for us. I'm not trying to minimize the problems involved in technology transfer and doing business abroad. They exist, but if the profits are attractive enough they are worth solving. There's no reason why a number of the developing nations have to go through the development cycles that we went through 30 or 40 years ago and have already discovered some of the solutions to be obsolete or even undesirable. We can make available to them solutions that are cheaper, more modern and pertinent to their environments.
To sum up, I'm not saying that the inventor-entrepreneur is the panacea of the society, and that he's the answer to all problems. More importantly, I have not said that he's superior to the professional manager or the professional businessman. Nor am I saying that this is the most opportune time from an economic, venture capital, climate standpoint to encourage a large number of inventor-entrepreneurs to get into the act. However, I do contend that an inventor-entrepreneur is a pioneer with unusual imagination, and a burning desire to do his own thing. This is a rare and effective national resource. $\mathrm{He}$ is a champion of innovation, and at the same time, a champion of the system of free enterprise. $\mathrm{He}$ is the creator of the yet unborn industries and also an inspirer of inventors and technology. I'd like to submit that he deserves attention, support, and more importantly, his share of responsibility in the handling of the problems of society today. Thank you.

\section{Discussion}

I. Kayton: How do you protect this delicate flower, so that he can be nurtured?

N. Kapany: "Protect" is a bad word. I think a true inventor-entrepreneur really doesn't need protection, he needs encouragement from the financial end, from the marketing end, and so on. Government could help him a great deal; the Small Business Administration could play some role in these areas. As you know, there are such things as Government purchases from small business. But I happen to feel that a true inventor-entrepreneur is so dynamic, so strong headed, that all he needs is encouragement, and not a lot of protection.

J. Rabinow: The fact is that in other countries they do specific things: in the five countries that have been studied, that Dr. Ancker-Johnson spoke about, there are positive government programs-in Canada, Japan, England, Western Germany, and France-to help new companies. The government invests money, industry invests money, government guarantees loans and so on. The United States has never needed this because we've been always so successful, until a few years ago, that it was assumed there was enough market to take care of situations like this; and so for the first time in our history we worry about this entrepreneur. In the past, the Horatio Alger story was strong enough to carry itself. And apparently it did. But the other countries do do specific things; I can give you, if you like, some of the facts about it.

J. Stephens: I have a comment with respect to local rather than governmental encouragement of an inventor. I picked up an idea at the Woods Hole Conference which I have put to what I consider good use in the years that have intervened since then. A speaker at that meeting made what I thought was a very innovative point. And this was, that the ideas which an inventor may have produced, if ingenious, but which might not, just because they were ingenious, have a market, should still be commended. In other words, if a man has a good idea, good in terms of being a clean, ingeniòus solution to a problem, compliment him, pat him on the back. Don't say, "How can you make a dollar out of this particular idea?" And I think this is a very interesting point, and the speaker at that time, whose name I hesitate to mention because he's already getting so much publicity, said that if you want inventors really to work for you, compliment them and love them, even though they don't make a dollar for you. 


\title{
Invention and Innovation in the University
}

\author{
James Adams \\ Design Division, Mechanical Engineering Department, Stanford University, \\ Stanford, Calif. 94305
}

\begin{abstract}
Universities are not fulfilling their potential as a source of public need-oriented invention and innovation. Their potential is inhibited by three constraints: risk, time, and business.

There is an academic risk to the student in undertaking projects where the outcome must be uncertain. The risk to the faculty lies in the fact that the academic rating procedure treats entrepreneurial activities as unusual and academic publication as usual.

Time is another constraint: there is insufficient time in the academic year to develop a product and market it.

The business constraint is a lack of knowledge as to how ideas could be carried to reality with a just division of the compensation among the students, faculty, university, Government, and commercial business interests involved.

Government funding might help to solve the risk and time constraints by forming peer groups and allowing employment of long-term professional support.

People in the educational community would appreciate help on solving the business-Governmentuniversity relationship problems. Frameworks must be found and publicized in which universities can put their intellectual resources to work in a more applied way and gain reasonable financial and intellectual rewards.
\end{abstract}

Key words: Academic risk; business-Government-university relationship; faculty risk; time constraints; university entrepreneurial activities.

As an engineering professor, I'm quite used to talking about theoretically perfect things. It therefore causes me no pain to say that a university should be a theoretically perfect place for invention and innovation, especially invention and innovation which is responsible to public needs. After all, universities have been brooding about public need intensively for the past 8 or 10 years. Universities collect people who are intelligent, intellectually independent, and curious. They are one of the few institutions where thinking is acceptable as a full-time job. One might therefore easily think that universities should be an optimum environment for invention and innovation to flourish.

My message is that universities are not fulfilling their potential as a source of public need-oriented invention and innovation. They certainly are sources of invention. However, this invention usually results when one of two situations occurs. The first occurs when individuals with a strong drive to invent join the university. People with a drive to invent and suitable talent find the university a reasonable environment for invention. However, such people are not all that numerous in the university. The second situation occurs if high-technology programs are underway, which naturally result in inventions and innovations. A good present example is the research occurring in solid-state devices.

However, if one considers invention with a small "i" (not radar, the transistor, or the computer) and if one looks at the teaching and instructional end of education, there are some fairly serious inhibitions to invention and innovation in the university. There is little that occurs, for instance, in the low-technology, commercially oriented area. There is a scarcity of activity in what might be called middle-technology, focusing upon the application of technology which was new and exciting a few years ago. I think that this is unfortunate, because even if one ignores the direct contributions the universities could make 
to invention and innovation, one must look at the contributions they make in the form of people. Good or bad, a lot of bright people go to universities and in a serse universities are a filter and a conditioning system on the people that come out.

I am head of a group of nine faculty members at Stanford which is called the Design Division of the School of Engineering. This group is about 15 years old and was started by a man named John Arnold, who at the time was a somewhat controversial educator with a high interest in creativity among technical people. The group's activities center in mechanical engineering, although it does have a cross-departmental program with the art department and works closely with other engineering departments. The Design Division is somewhat unique in engineering education in that it has an overriding concern with open ended problems. It is problem-rather than tool-oriented in that the main emphasis is to give people an idea of how to use various tools to solve problems, rather than to improve the tools themselves. It is concerned with emotional and intellectual aspects of design (aesthetics) as well as the physical, and is concerned with public need.

Another factor that makes our group somewhat unique is that we place a large emphasis on projects done by the students and faculty as a teaching technique. We have found, along with many others, that it is not too effective to tell students stories about the accomplishments of others if one is trying to teach design, since such stories are usually doomed to the status of advice, which is usually tolerated, sometimes rejected, and hardly ever given the importance of experience. We therefore try to collapse the time needed for experiences and lead the students through them.

Our projects range from short (a week or two) individual projects leading to designs on paper or in mock-up form, to long (a year or more) projects leading to prototype hardware. They range in orientation from mechanical to purely visual, and from "big picture" to extremely detailed. In a given year, our students are involved in perhaps a thousand projects, most of them minor and not leading to anything marketable. However, in many cases, ingenious and well-detailed prototypes of marketable items emerge. Figures 1 through 8 show a few examples of student projects. Figure 1 is purely an exercise in conceptualization and visualization. The problem was to design a device into which a golf ball could be dropped. The golf ball was to fall out of the device
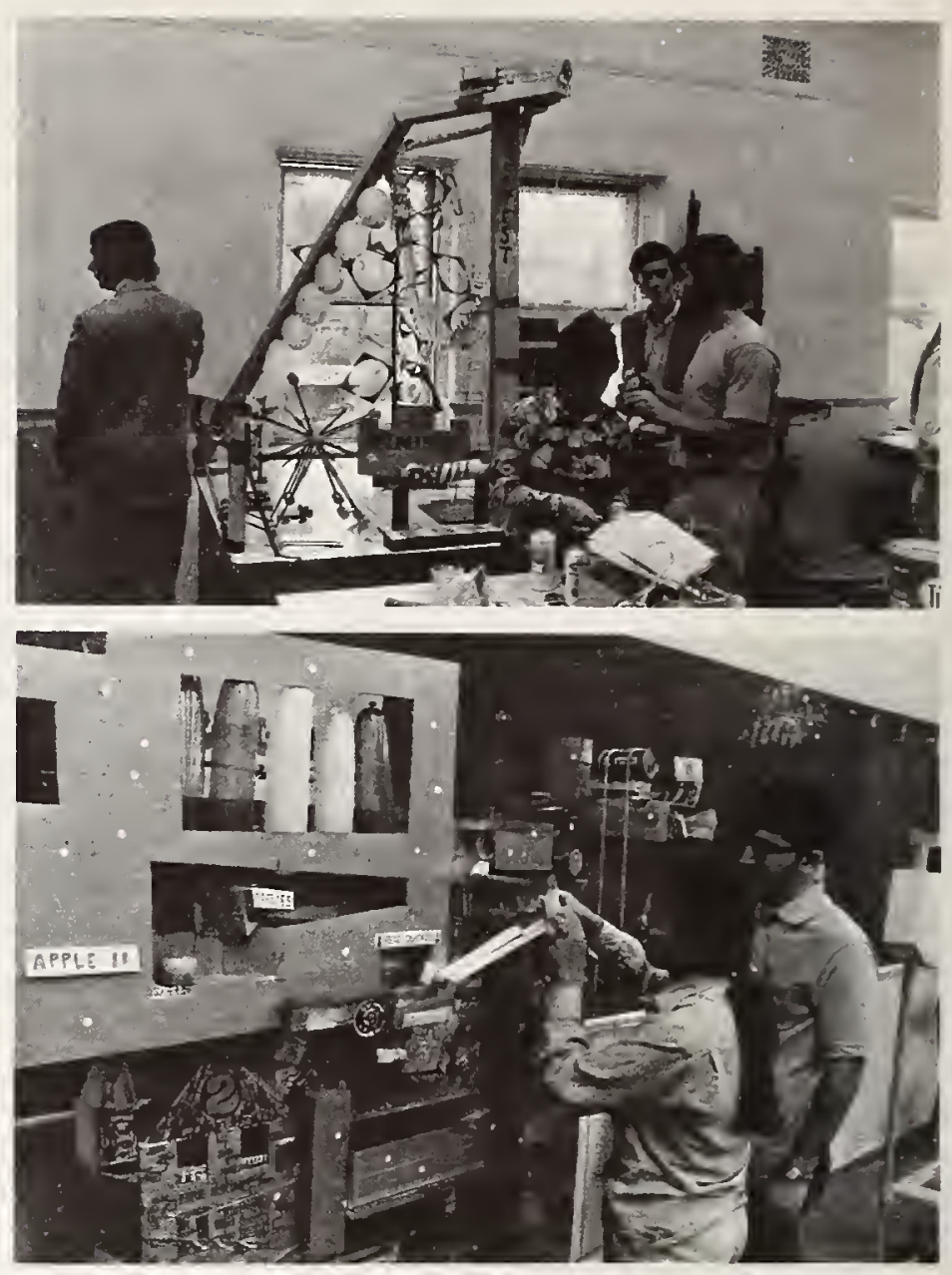

exactly one minute later and raise as much visual hell as possible on its way through. Figure 2 is a music synthesizer that is controlled by the movements of a dancer. This was a project that required a great deal of consideration of the emotional aspects of design.

Figure 3 is a device which allows analogue data, such as an EKG, to be superimposed upon an x-ray movie. Figure 4 is a prototype of a machine that punches holes through paper cleanly, cheaply, and in a programmed manner. Figure 5 is a prototype baby incubator which controls biological contamination by controlling air flow and utilizes radiant heating. It maximizes access to the infant, and thereby solves a serious problem. Figure 6 is a hand-held ultrasonic camera for medical scanning. Figure 7 is a prototype of a unidirectional vehicle and figure 8 is a percussive breathing device of cystic fibrosis patients. Other recent student projects include a lowcost silencing device for a commercial blower, a machine that would convert water-weeds to cattle food, a grinder to convert dried garbage to rawmaterial for wallboard, a flowmeter utilizing heat transfer, and all types of toys and games. 

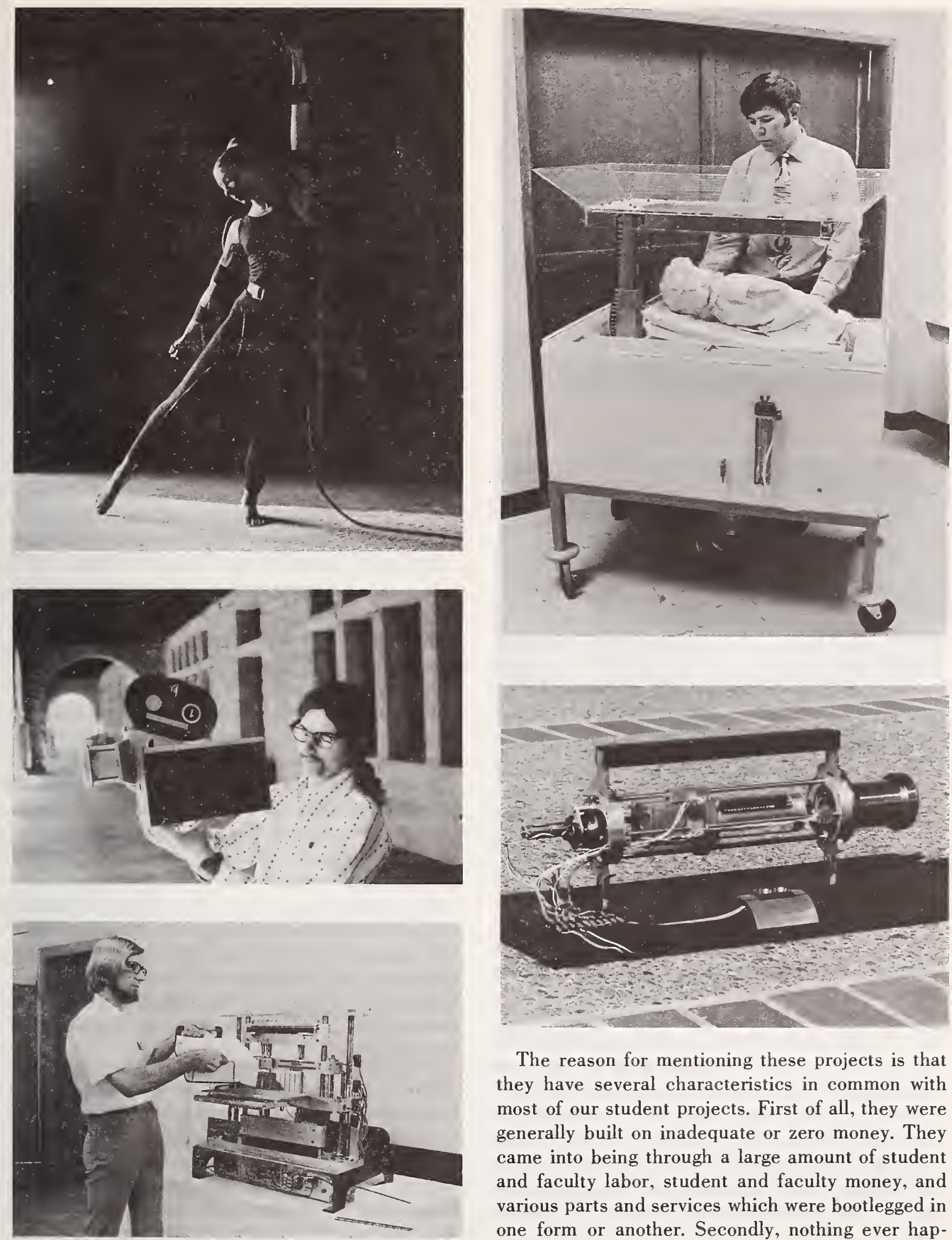

The reason for mentioning these projects is that they have several characteristics in common with most of our student projects. First of all, they were generally built on inadequate or zero money. They came into being through a large amount of student and faculty labor, student and faculty money, and various parts and services which were bootlegged in one form or another. Secondly, nothing ever hap- 

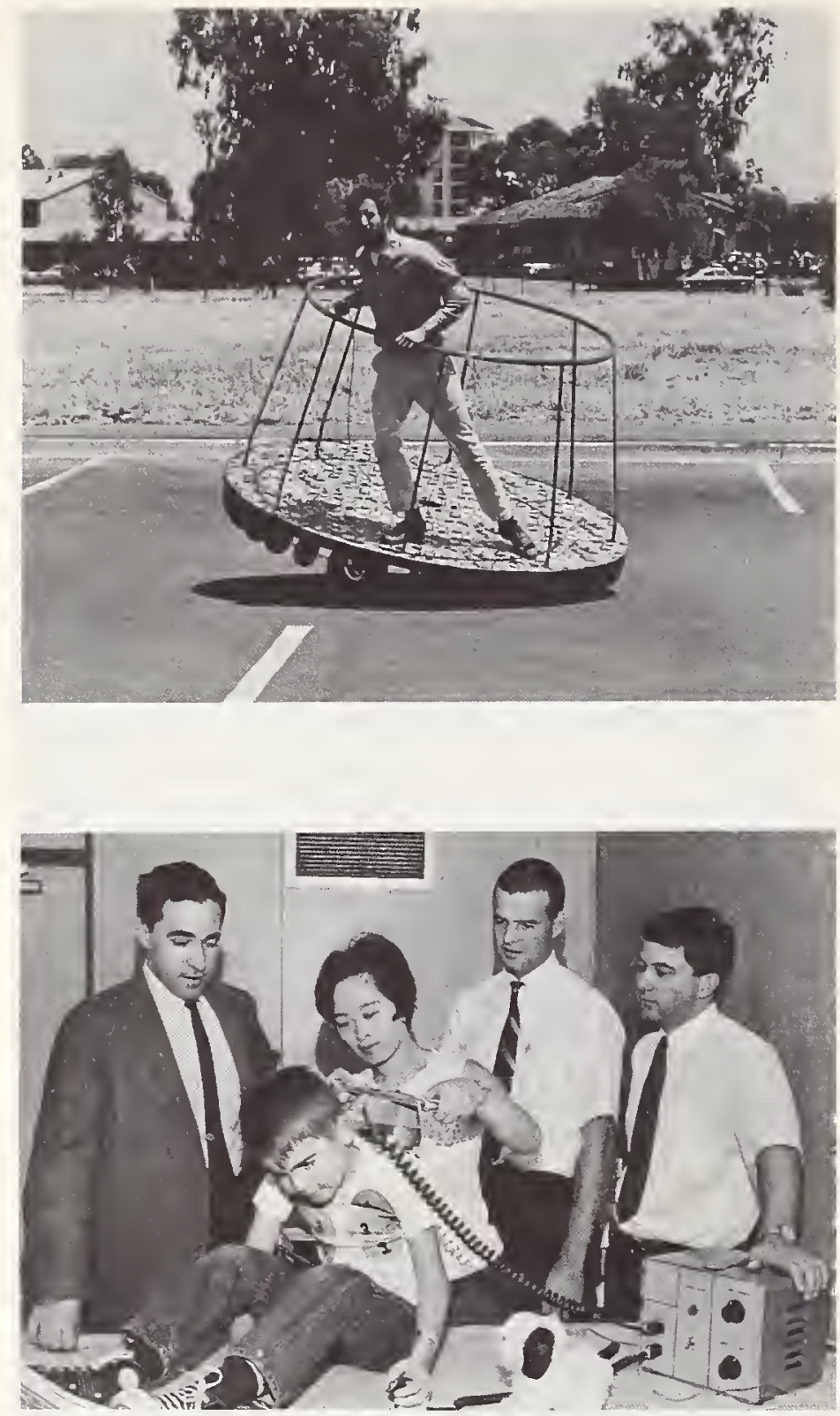

pened to take them past the stages shown in the photographs. That is significant to the message I am trying to make. These projects were done for educational reasons that we consider quite important. These educational aims were fulfilled. However, the projects, together with all of the thinking and effort that went into them, were essentially dropped at that point.

The activities of the Stanford Design Division were initially more educationally unusual than they now are. Many schools are now placing an increased emphasis on project work and we are fairly confident that we are riding on a pendulum swing that is returning middle and low technology to schools along with an increased emphasis on application. We therefore believe that the type of project work we are involved in is going to increase in universities.
The question to ask at this time is, "Well, if entrepreneurs go to college, if project work is on the rise and if it results in output which has something to do with societal needs, then why can't something be done in the universities to carry this work to the marketplace, rather than merely to the stage where students are awarded grades or degrees and photographs are taken?" I think that there are three reasons which inhibit entrepreneurial activities in universities which could transform thinking done in the course of research and instruction into marketable products. These three reasons are all curable, and I think they will be cured. However, some conscious efforts on the part of universities, governments, and the commercial sector are necessary to cure them.

The three reasons can be briefly labeled as risk, time, and business. I would like to discuss each in turn, beginning with risk, which is perhaps the most important one. Risk is an inhibiting factor to the student, the faculty, and the university administration, none of whom is used to entrepreneurial risk. Looking first of all at the student, those who come to the highly-rated universities are carefully filtered. They in general have high verbal and mathematical aptitude, excellent references, a good achievement record and above all, high grades. Generally, they are grade-oriented, since it is through getting good grades that they have been rewarded. This tendency may come to a peak in engineering schools, where one finds the students who have opted for subjects (physics, trig, maybe calculus) which are considered extremely challenging in most high schools. Such students are not used to taking academic risks. The ultimate example of this I can point to is embodied in a small but constant number of graduate students (not from Stanford, happily) who will not take design courses because we cannot give them a copy of the last exams (which we do not give) and tell them exactly how they can earn an " $A$ " in the course. They instead take analytical courses which follow familiar patterns and in which they have no trouble at all earning an "A".

There is academic risk in a design course (although not as much as many students think, since the "good" students usually continue to get the high grades) and the farther the project is taken, the higher the risk becomes. I have advised several $\mathrm{Ph}$. D. students on design-oriented dissertations, which diverged from the standard engineering $\mathrm{Ph}$. D. for- 
mula in that they were more oriented towards project work and less towards hard science. The baby incubator included in the photographs was the outcome of a Ph. D. dissertation. These students were somewhat less secure during their work than those working on a more conventional dissertation. It was more difficult for them (and for me) to see where they were, where they were going, what their "contribution to knowledge" would be, and what they were learning that would make them unique. In general their work took them at least as much, if not more, time, and was more difficult to publish. The incubator work was published in the Journal of Pediatrics, because it did not seem to fit well in engineering journals.

Although project work is extremely satisfying in that the results are real and represent (usually) the successful ordering of a complex problem, and although we believe it to be extremely valuable educationally, some risk is involved and the present system sometimes causes the risk to be seen as probably frustration, time wasted, lower grades, and less academic status. There is similar risk to faculty.

Stanford's "recommendation for appointment to the faculty" form, when completely filled out, runs to 20 or more pages in most cases. However, in all of this information, there are actually only two items of extreme importance. One is called "bibliographical information." The instruction for this section reads, "please attach a complete list, in bibliographical form, of scholarly publications grouped as books, monographs, significant book reviews, articles (indicate volumes and pages, the scholarly journal in which the review or article appears). If pertinent, list other writings such as abstracts, technical reports, speeches, etc. with an indication of why they are deemed significant. Attach a statement of not more than a page discussing the two to four most important items on the candidate's list of publications, stating in clear and nontechnical language why they are deemed significant. Please indicate the author of this statement."

There is nothing here about invention, innovation, or entrepreneurship. During the last year I was chairman of two search committees, one looking for a person who would have proven design competence in the area of electromechanical devices, the other an architect. Neither of the two people we hired was a prolific publisher. However the first man had a great deal of experience, some patents, and a large amount of accomplishment in design. The second had an excellent professional record and was wellknown in the field. It was a struggle to fit these men and their accomplishments into the "appointment form." This is merely symptomatic of a larger problem, which is that the academic rating procedure treats entrepreneurial activities as unusual and traditional academic publication as usual. It therefore requires an unusual effort to hire and keep faculty members who are active in invention and innovation unless they also are prominent in a traditional field.

The other portion of the appointment procedure that is important is a so-called search report, which documents the candidate's competence by opinions from persons outside the university who are judged to be in the candidate's peer group. This peer-group judgment is equally important in promotions and in general academic success. Such peer-group judgment can be somewhat risky in fields such as invention and innovation.

A friend of mine who is in our group at Stanford is a kinematician and I sometimes envy him his academic situation. Kinematics had an upsurge 20 years ago or so under the leadership of people such as Ferdinand Freudenstein and the development of the computer. The kinematicians now have a nice academic club going with a journal and a tight peer group. They deal in fairly abstract mathematics and produce work which is intellectually beautiful, although debatably applicable. They can, however, operate well within the university structure since they attest to each other's competence and publish easily. Such good words and publications are much rarer among faculty involved in project activity such as that discussed earlier.

I consider myself a teacher of design, not invention and innovation. However, a common problem exists concerning peer-group judgment. Although friends of mine in design would willingly attest to my overall competence, they would no doubt be much less willing to describe any specific designs I have done as being exceptional. This is not so much a function of my design capability as of the tendency of those involved in design (or invention) to be less charitable to the acts of others in similar activities than those involved in more disciplinary fields. This is partly because entrepreneurs are more oriented toward competing than cooperating. Such things hurt faculty involved in such activities. Visibility 
also becomes a problem if one is involved in a risky venture. Another faculty member in my group was for 2 years deeply involved in a project which was a cooperative venture with the Mission Coalition (a community self-help organization) in San Francisco. This was just when "Public Need" was becoming a catch phrase, when interdisciplinary work was being encouraged, and when the late 60's were in full flower. This faculty member put a great amount of energy into this work, eventually acquired NSF backing, and was by many measures a success. However, the work was mostly exploratory and did not produce traditional publications. He had a lot of valuable experience, learned a lot, and involved a lot of students in highly intellectual work. However, these 2 years came out of an initial 5-year appointment and put him in a great deal of trouble as far as demonstrating what he had done towards tenure. Although his activities were not in the area of invention and innovation, his personal problems are similar to those he would have had were he entrepreneurially oriented. In these days when universities are not expanding and jobs are hard to get, junior faculty do not gain much by taking risks. The academic rewards system discourages risk taking on the part of the faculty as well as on the part of the students when invention and innovation are concerned.

Besides risk, two more inhibitions to invention and innovation in universities are the time situation and business patterns. A student's lifetime in a university ranges between 4 and 8 or 9 years. In a typical course, a student expends approximately 100 hours. When courses or academic quarters are over, most students physically and emotionally leave what they are doing the instant the course concludes. In fact, mosi students are in the habit of working in short intense bursts with discontinuities between. The faculty reflect this time pattern to some extent, although they do have much longer things going on in conjunction with a few longer-term students ( $\mathrm{Ph}$. D. candidates). However, in general the time in a university is chopped up in a way which is not consistent with carrying things through the entire entrepreneurial process. You simply do not get something into the market place in 100 hours, or 10 weeks, or in any other of the commonly accepted academic time units. This lack of continuity for development and marketing is an important inhibiting effect on entrepreneurial activities in the university.
As far as business is concerned, I can be brief since Dr. Morse alludes to the problems involved in his paper. When he described the MIT Development Corporation as a charitable organization which would donate its profits to agencies including ones outside of MIT, I had several reactions. My first, of course, was to quickly write him a proposal. My next was a distinct feeling that the charitable nature of the institution sounds as though taxes are involved. My next reaction was one of envy, since I do not understand enough about the relationship between universities, Government, and business to put together an organization of this sort.

I do not think that I am the only person around universities who is vague about how to make money off invention and innovation and I include many people in the business side of university organizations. I think that a great amount of understanding is necessary here before universities can comfortably bridge the gap to marketing products, for instance. In many cases those of us in Design at Stanford have avoided business questions merely because they led to complexities that we did not want to consider during the heat of the academic year. Certainly it should be possible to clarify means by which ideas could be carried to reality with a just division of the spoils between the students, faculty, universities, governments, and commercial business interests involved. However, this knowledge is presently hard to come by.

I mentioned risk, time, and business as inhibiting factors in extracting more public-need-oriented invention and innovation from universities. Let me conclude by briefly mentioning things that need to happen before problems in these areas can be overcome. As far as risk is concerned, something has to happen so that there is intellectual, monetary, and prestige reward for those involved in academia and taking risk in an entrepreneurial, inventive, or innovative venture. A peer group must be established somehow that can give judgment on accomplishments in this area that is as influential as the judgments available in traditional academic fields.

A nice way to accomplish this and simultaneously do something about the time problem is at the Government level with funding, because funding seems to form peer groups and allows the employment of long-term professional support. It seems to me that astronautics became much more of a legitimate discipline when NASA and other agencies started pouring money into it. I think that this is un- 
derstandable, since money allows long-term research to be done and peer-groups assemble both to meter out the money and judge the work. At the present time, funding sources are not tuned to the type of work we do at Stanford, for instance. They are not compatible with developments where the outcome is unknown. If we want to put a student or a class to work on a 1-quarter or 1-year project and we do not know the outcome or about the problem a year ahead of time, it is extremely difficult to find government funding to back it. If we want to carry something to the point where it is a candidate for a commercial push we also run short on money sources. Money is available for backing a proven commercial candidate from conventional sources. However, there is an embarrassing time before this point is reached when it is difficult to find support in a university.

I think that schools will become more involved in entrepreneurship as a money source as well as an educational area and that a peer group will form in time. However, some type of institutionalized support and official recognition of this area must occur in order to support the people who must do the work. The technology and knowledge are available. The only think lacking is critical mass, which comes generally from an infusion of money.

As far as business is concerned, I think Dr. Morse's start at MIT is excellent not only for MIT but as a pattern for other people. I think that a lot of people in the educational community would appreciate help on solving the business-Governmentuniversity relationship problems and such knowledge will come either from the experiments of such people as Dr. Morse or from Government attempts such as the Technology Incentives Program. Frameworks must be found and publicized in which universities can put their intellectual resources to work in a more applied way and gain reasonable financial and intellectual rewards.

\section{Discussion}

A. Ezra: If you recall, this morning Dr. AnckerJohnson referred to that report which was put out by Battelle on a contract with NSF on 10 innovations. One of the prime observations in that report was that if you really want to bring about technological innovations, find if you can a technological entrepreneur. And these are getting scarcer than hen's teeth these days. That means several recommendations have been made along these lines. At the last Woods Hole meeting in 1965, there were about 40 recommendations, 18 of which were picked up by us and put into this experiment which we call innovation centers that we are initiating at the National Science Foundation. In fact, there is even one major recommendation in the Charpie report which forms the basis for these innovation centers. And the idea is to do just what Jim Adams is talking about. In universities we have a combined effort between the Business Administration School and the Engineering School. Instead of giving the kids a hypothetical class project, you give them something for real where they carry it all the way from the gleam in somebody's eye, not just stopping at the design, which you normally do, but actually building a prototype, seeing what manufacturers' costs are, preparing a business plan, preparing cash flow projections, capital for projection, etc., and actually selling it if you can to industry. The main object of this is of course educational, to see if we can produce more technological entrepreneurs. This thing is going to be run as a pretty rigorous experiment in the sense that there will be a control group consisting of students who wanted to take this course but weren't allowed to because we put them into the control group (if we can pull that off) and we have to see what percentage of students that took this course really became technological entrepreneurs. These people are needed not just in private industry, but in the Government also. I'm talking of people like the Hyman Rickovers and the Billy Mitchells and so forth. This is one of the things that the National Science Foundation is trying. The inherent policy here, that we have to prove is, will such an approach produce more technological entrepreneurs in the future, will these guys as a result of this particular program bring about more innovation, will new products come into the marketplace, will they generate new jobs, and so forth? The idea is that we have to come up with some kind of a quantitative analysis to show us what are the benefits provided for every buck that we spent and if, hopefully, the stuff turns out to be a success, then we could recommend it to the administration as a policy for the country; that is, set up a certain number of innovation centers at $\$ 1 \mathrm{mil}$ lion per year. 
S. Yerazunis: I've worked with Jim a long time and I have to agree with everything he's said. It's very crucial, the rewards system, the recognitions; the university makes it very difficult to do these things. Funding from the outside is very important. I'm going to visit with Jim to see how he's managed to keep his group going. At RPI we do have one unusual project that has survived for 5 years, has been very productive, because of NASA's support in the neighborhood of $\$ 100,000$ per year, addressing problems relating to unmanned missions to Mars. It's design, it's inventive, it's conceptual, it has the continuity Jim can't get in his projects. We run about 30 students or more per year, with about 6 faculty. They are very real problems; they go all the way from ideas to prototypes, proving, feasibility, and so forth. I would encourage this group in its workshop on education to think very seriously about coming out with some strong positions. I think that we can, in fact, in education create the attitude in many students, fit them for this kind of activity, but we do need support from the outside, until we can create an internal image that this activity is of intellectual quality, stature, and scholarship, but to be measured by different standards. At the university level we face very formidable obstacles.

\section{S. C. Gilfillan: I approve of Professor Adams' ideas} of project methods in invention, and the last speaker, likewise. The sciences have advanced inseparably from the education in the sciences. I think it must be the same in invention, and that chemists and engineers should be trained, some of them, to be inventors. Of course not all of them are suited for that. A professor of engineering said that many of his engineering pupils had the ambition to be a machine jockey; that is, to get good pay from superintending the operation of machinery. Perfectly useless to try to make such a man an inventor. But others have it in them, as could be determined by psychologic tests, their early lives and so forth, to be inventors and they might have definite courses in the art and development of a science of invention.

R. Morse: The tax problems are complicated. I spent 4 months with more lawyers than I want to name, before we set up this Foundation. We do have a tax exempt ruling which permits industry or others to make donations on a tax exempt basis to the Foundation. We're using that money for operations. We ourselves are not going to invest much money in these ventures; we can use our sponsors, such as Dow, Monsanto, and Texas Instruments.

I would want to put in a plug, in the sense that we are now at the Sloane School looking for a full professorship. RCA has given a million dollars to both the Sloane School and to the Harvard Business School, in the field of innovation. So industry is not completely unmindful of this problem, and I can't speak for the academic characters with whom I cavort periodically, but I think it's fair to say that the man for this job may not necessarily have to have all the usual trappings associated with publications. If you know anybody that wants the job, the chair is open. It's good pay.

I'd like to make another comment: that "entrepreneurship breeds entrepreneurship." In areas where entrepreneurship has worked, it tends to work even more so. At Stanford it has worked, as you know, and it has in Cambridge. On the other hand, it doesn't happen very much up at Harvard, at least not as much as at some of the other universities. But, historically Harvard has taken a position, rightly or wrongly, that they're against any Government work or classified information type of activity. All the presidents at MIT since I've been around there have always said that MIT should become involved with industry; they do have an obligation to make jobs in the area, and it's caught on. It's a thing to do. In the Charpie Report we had the information that nothing happens in Chicago or Philadelphia, vis-a-vis Stanford or Cambridge. And I think mainly because it had happened, the lawyers, the bankers, the total community knew how to do things, and it was a thing one did. You did it because you knew another fellow had done it. And I think this is terribly important.

\section{J. Rabinow: That's a definition of climate.}

L. L. D. Shaffer: I'm here representing what is called the Oregon Inventors Council. I enjoyed Mr. Adams' comments very much because it's primarily what we're doing up at the University of Oregon. He said that in terms of the rewards system, the student faces the low grade concept because of project work and this makes it hard to get jobs. From my experience up in the Pacific Northwest, we find that the students that get involved in projects are eagerly sought for by employers, because they've done something different. They've taken the time to get involved in something that's beyond the standard course work. 
You mentioned three things: risk, time, and money. The risk involved in terms of the peer group judgment: this is true. But there are a few lights shining perhaps in the darkness. The other day, for example, a faculty member that hasn't spoken to me in 5 years invited me for a cup of coffee, and maybe I'll get a drink next time. But there are these things coming about, sir, particularly when we find that people in the area-Oregon and Washington-are coming into the university to talk about particular projects, to say "thanks" or to talk about them and to express their concern. And as a result this is a countervailing power, you might say, that's starting to react in terms of this peer group judgment concept. In terms of time, this is a hard one, because quarter systems are quarter systems, and students come and go. But there is one way that we found that helps to resolve this, and that is the idea of continuity. Where one student leaves off, the next student takes over and this is understood and built into the program. So as a result we have projects that are not only just a few years old but some that are four and five, and I like to think they're getting better all the time. With respect to money, this is a hard one and we always look for funding because there are so many things to do.

The last comment I have to make, Mr. Adams, has to do with your new interest in getting involved in housing. If you plan to build these houses out of wood, we'll be glad to sell you the lumber, and at a very good profit.

J. Adams: That sounds interesting; I'd like to visit you if I could get to Eugene. One comment I wanted to make, because I probably stuck my tongue between my teeth and said the wrong thing. I think the thing that the students see is an apparent risk. We have the same experience, that companies, especially these days, seem to be very eager for people who show any sort of project interest or entrepreneurial interest, as opposed to straight engineering science. And in fact we get so happy with our students we usually give them very high grades in the courses so their overall grades are good anyway. However, this still doesn't keep a lot of students from being fairly worried when they look down the path from in front and don't see the conventional rewards system existing there.

R. J. Kuntz: Since there are quite a few individuals here from academia, I'd like to comment on your presentation related to something that's been of great concern to us. And that is what has happened to the Bachelor's Degree program, and the drift away from applied technology, or the technology content of the Bachelor's program. I think everyone realizes that an engineer is probably 20 times more likely to be an inventor than just about anyone else involved in the process. Did I hear a rumble somewhere?

J. Rabinow: That happens to be correct, even though there are physicists present who are also good engineers.

R. J. Kuntz: And I think it's interesting to note that if we examine the basic curriculum for a Bachelor's in engineering it is very difficult to find any guidance whatsoever in the area of invention or innovation, or anything at all about the patent system or the operation of patent law, or the process one has to go through, and last, but not least, what the individual is going to be asked to sign when he accepts employment as an engineer when he graduates. If we're concerned about it we ought to be providing some input to these new people entering the profession, since they are more likely to have an influence on the whole patent system, as to what it's all about and provide some guidance so that they can use their intellect to contribute to the system. If we don't, the system, I'm afraid, is in real trouble. Would you like to comment on what Stanford is doing in that area?

J. Adams: I think there is a change. I think Stanford is, in fact, putting more such things as patents back into the program. We start a new graduate program this year which devotes roughly a quarter to things having to do with entrepreneurials, protection of intellectual property and so on. There's a great variation in engineering schools, and being somewhat full of ego, I tend to think of Stanford as one of the so-called leading institutions. I think you can see a swing back towards application. There are a lot of schools which are still swinging away and I don't know what to say there. It's kind of horrifying.

J. Rabinow: Many schools where I have talked occasionally are teaching creativity and invention; it takes a long time to change courses, but it's being changed.

I. Fleischmann: I think this is about as good a time as any to get in a commercial for one of the programs at the Patent Office. I want to credit a former Commissioner of Patents under whose administration we 
got underway our Annual Briefing Conference: that's the former Commissioner Ed Brenner, who's in our midst, and our current commissioners have made it possible to continue the program. Your discussion this afternoon has concerned me basically because of the lack of information imparted by members of the faculty of our universities to the engineering students, and we have this information from the 100 plus new examiners we bring in from our colleges and universities each year. I want to refer to our Annual Briefing Conference; No. 7 will take place on February 15, 1974. We invite the members, the faculty, the deans of our engineering schools, to come to the Patent Office for a one-day program to get a feel and appreciation for the patent system in action. Your chairman this afternoon has participated in the program for the past 6 years, and we have found that those who attend reap a great deal of benefit from this program. So a cordial invitation is extended to attend our Annual Briefing Conference. And if special coverage is necessary at any time during the year at the Patent Office, we will be glad to assist in every way possible. 


\title{
The Invention of the Transistor - "An Example of Creative-Failure Methodology"*
}

\author{
William Shockley \\ Bell Laboratories, Murray Hill, N.J. 07974.
}

\begin{abstract}
Presents a general historical perspective on the invention of the transistor, from the standpoint of the patents issued and the men involved in the inventions.

Five applications for patents on transistor devices were filed prior to the first public announcement of the transistor on June 30,1948 . The development of the essential inventive ideas for these five patents is described.

Several attempts to make semiconductor amplifiers failed. These failures were used creatively by the team involved - an example of effective research, of which one of the principal elements is the "will to think." The day-to-day development of important ideas and the interaction between them are presented.

The story is continued through the invention and realization of the junction transistor.
\end{abstract}

Key words: Creative-failure methodology; invention of transistor; junction transistor; patents; semiconductor amplifiers; will-to-think.

\section{Introduction}

\subsection{Three Men and Five Patents}

The invention of the transistor can be described from many different viewpoints. I shall use several in this lecture. For the framework upon which to assemble and interrelate the many specific incidents that form the pattern of the story, I have chosen one of the fundamental features of inventions in presentday society - patents.

Five applications for patents on transistor devices were filed prior to the first public announcement of the transistor on June 30 , 1948. I shall describe how the essential inventive ideas for these five patents developed. In the story I shall use these five inventions as landmarks on the path to creativity. Thus from the point of view of specific technical contributions, the story of the invention of the transistor might be appropriately called a tale of five patents.

But in justice the story might also be told as a tale of many men. An attempt to partition appropriate credit to every individual whose contributions were significant to the final achievements is an impossible

*Copy right retained by Dr. Shockley and Bell Laboratories. task for at least two reasons: too many individuals were involved and satisfactory criteria for judging the relative merit of the contributions do not exist. Therefore I shall follow the decision of the Nobel committee that awarded the physics prize for 1956 jointly to John Bardeen, Walter Housner Brattain and me. Furthermore, we are the three who did contribute what has proved to be of most enduring value in the five patents.

The social consequences of the application of the transistor invention are, of course, what is really of most significance. However, they are not a part of the story of the invention. There is, however, another significant aspect that it is appropriate to discuss here-the aspect that is part of the title of this lecture - "Creative-Failure Methodology." The transistor was not invented until after several attempts to make semiconductor amplifiers had failed. How these failures were used creatively by the team involved and under the stimulating conditions for research at Bell Laboratories is an important feature of the history. Several phrases give meaningful insights about effective research. Most important, and most difficult to create, is "the will to think" - the theme that runs through "the magic month" when 
the point-contact transistor was invented and the following 5 weeks that led to the invention of minority carrier injection in the junction transistor.

The relationship of patents to motivation has a long history in the United States. The key concept was embodied in the U.S. Constitution in section 8 , Powers of Congress. The first power delegated to Congress concerns taxes. The relevant power is the eighth. It concerns patents and reads:

"The Congress shall have power to promote the progress of science and useful arts, by securing for limited times to authors and inventors the exclusive right to their respective writings and discoveries."

This "exclusive rights" paragraph has, indeed, contributed forcefully to our Nation's technological progress. I regard it as an outstanding example of the practical conservative wisdom of the framers of the Constitution. It draws into the service of the $\mathrm{Na}$ tion, in addition to those idealistic or compulsive inventors whose motivations are either altruistic or instinctive, also those profit-motivated inventors who would regard it as naively improvident to fail to realize gains from the fruits of their efforts. The patent law, by offering the competitive advantage of legal protection of exclusive rights, appeals even to selfish motivations and induces those who would otherwise be as secretive as possible about their discoveries to share their knowledge and contribute to the progress of others-even to the progress of potential competitors. To be granted the patent that ensures the exclusive rights, the inventor is required to make his discoveries available in understandable written form in the specification of his patent application. Furthermore, his teaching must stand the test of being adequate for one versed in the related practical art to be able to achieve the results claimed in the invention.

A closely related aspect of the patent law is frequently misunderstood by young workers in industrial research laboratories. Many young scientists resent being restrained by their organizations from telling the world about their accomplishments until after patents have been filed. They come to the erroneous conclusion that it is the patent system that prevents them from claiming scientific recognition for their work. Actually, the opposite is true. If it were not for the rights that their organizations acquire by obtaining patents, then the effective way for the organizations to receive returns from in- vestments in research would be to maintain secrecy. In other words the patent system permits, rather than prevents, publications.

A vital input to the preparation of this contribution came as a by-product of procedures at Bell Laboratories designed to optimize the advantages offered by the "exclusive rights" paragraph in the Powers of Congress. In determining which of two competing inventors should be granted the patent, priority of conception and diligence are weighted heavily. The date of conception of the invention is usually established by the record of when it was clearly disclosed to and understood by a coworker. Usually such endorsements by witnesses are made on the pages of laboratory notebooks. These records are of vital importance in establishing facts in patent litigation. Consequently, information on the issuance and status of such notebooks is carefully maintained in organizations like Bell Laboratories.

These carefully preserved records were essential in the research that $I$ undertook 25 years after the birth of the transistor that led me to identify the "magic month" and to reconstruct the sequence of events and their interactions during that period. This research is discussed in detail in sections 3 and 4 .

\subsection{Can Creativity Be Taught?}

One of my principal purposes in selecting the format for this presentation is to choose one that might encourage creativity on the part of the readers. A basic truth that the history of the invention of the transistor reveals is that the foundations of transistor electronics were created by making errors and following hunches that failed to give what was expected. Pure inspiration contributed less to progress than did perseverance and the willingness to try again after an experiment or an idea had failed to deliver the wanted result-evidence for the truth of the saying that "inspiration is ninety percent perspiration." "Creative-Failure Methodology" is a phrase designed to characterize the importance of making constructive responses to failures and errors. The emphasis on this aspect of transistor history in my presentation is intended to stimulate the creativity of receptive readers who may learn from our experience that failures need not be accepted simply as causes for low self-esteem but can instead be recognized as opportunities to learn so that these failures become stepping stones on the path to creativity. 
Can creativity be taught by experiences that illustrate how progress can be made by floundering around while looking for the hunch that will produce a breakthrough? My experience in some educational experiments makes me believe that creativity can be enhanced by teaching students to live more comfortably with their own limitations. This can be accomplished through experiences involving searching unsuccessfully for hidden key attributes in problem situations that they then do discover largely on their own and thus learn that persistence does pay off.

The teaching method uses a diagram called the creative search pattern. ${ }^{1}$ This is illustrated in figure 1. In general it is not intended to be a map to

\footnotetext{
'For details see "Mechanics" by William Shockley and Walter A. Gong. (Charles E. Merrill Books, Inc., Columbus, Ohio, 1966).
}

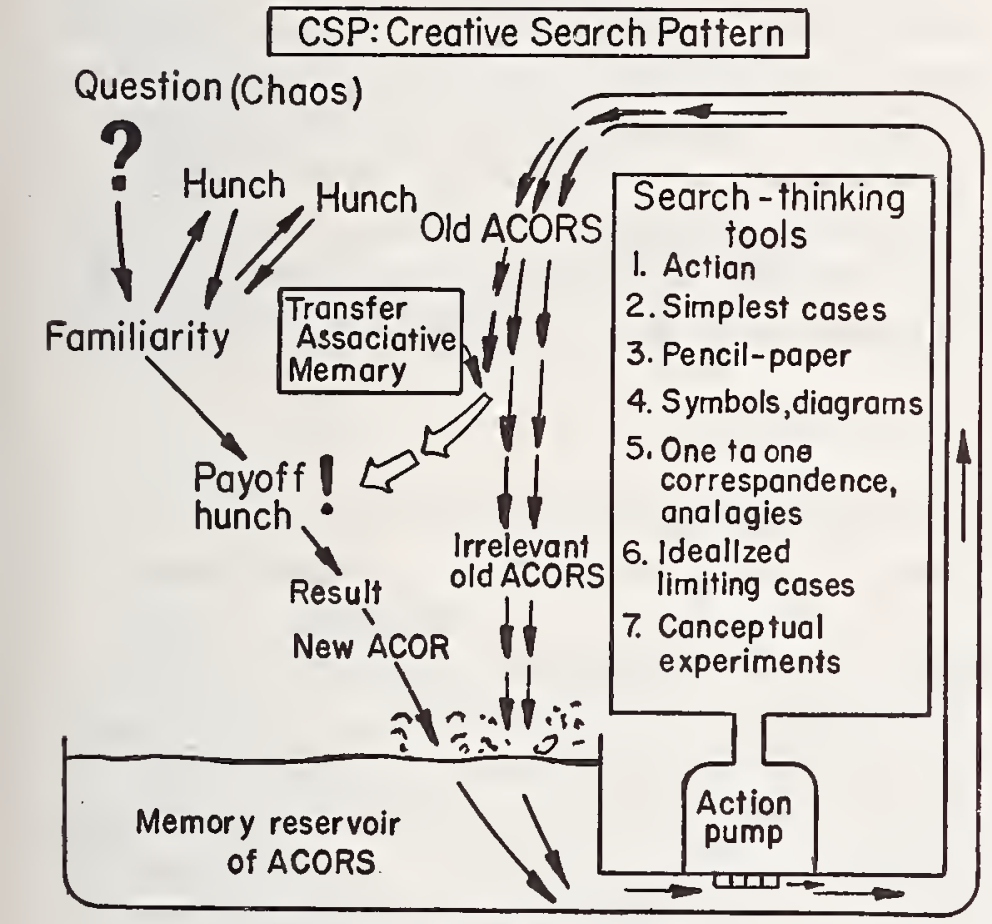

Scientific logical structure

\begin{tabular}{|c|c|}
\hline ACORS & QLF Oualified Law Form \\
\hline Key Attributes & $\begin{array}{l}\text { - What it is alwoys true } \\
\text { CE Qualified-eduction }\end{array}$ \\
\hline $\begin{array}{c}\text { Comparison } \\
\text { operations }\end{array}$ & When No matter what \\
\hline $\begin{array}{l}\text { Orderly } \\
\text { Relationship }\end{array}$ & When not: But not if \\
\hline
\end{tabular}

Flgure 1. The Creative Search Pattern (CSP), including seven search-thinking tools, and the scientific logical structure based on $A C O R, Q L F$ and $Q E$ that are four basic science-thinking tools.

The hunches that do not pay off are examples of creative-failure methodology. tell how to do research but instead to understand the natural blundering process of finding one's way when unfamiliar material is dealt with. Thus, it indicates that a number of poor hunches will occur that serve to increase one's familiarity with the subject matter involved. If one has stored in his memory a collection of patterns that are logically similar to the one that is finally found in the problem, then a payoff hunch is likely to occur in which the benefits of the previous experience are transferred to the new situation - a relationship established by associative memory.

This type of teaching has been tried experimentally in high school, undergraduate college situations and in my own experience with graduate students and in my own research. The result of an experiment involving 3 successive years of Stanford freshmen students is shown in figure 2. The data there was gathered 4 years after the first teaching experiment occurred. The students who entered by freshman seminar entitled "Mental Tools for Scientific Think-

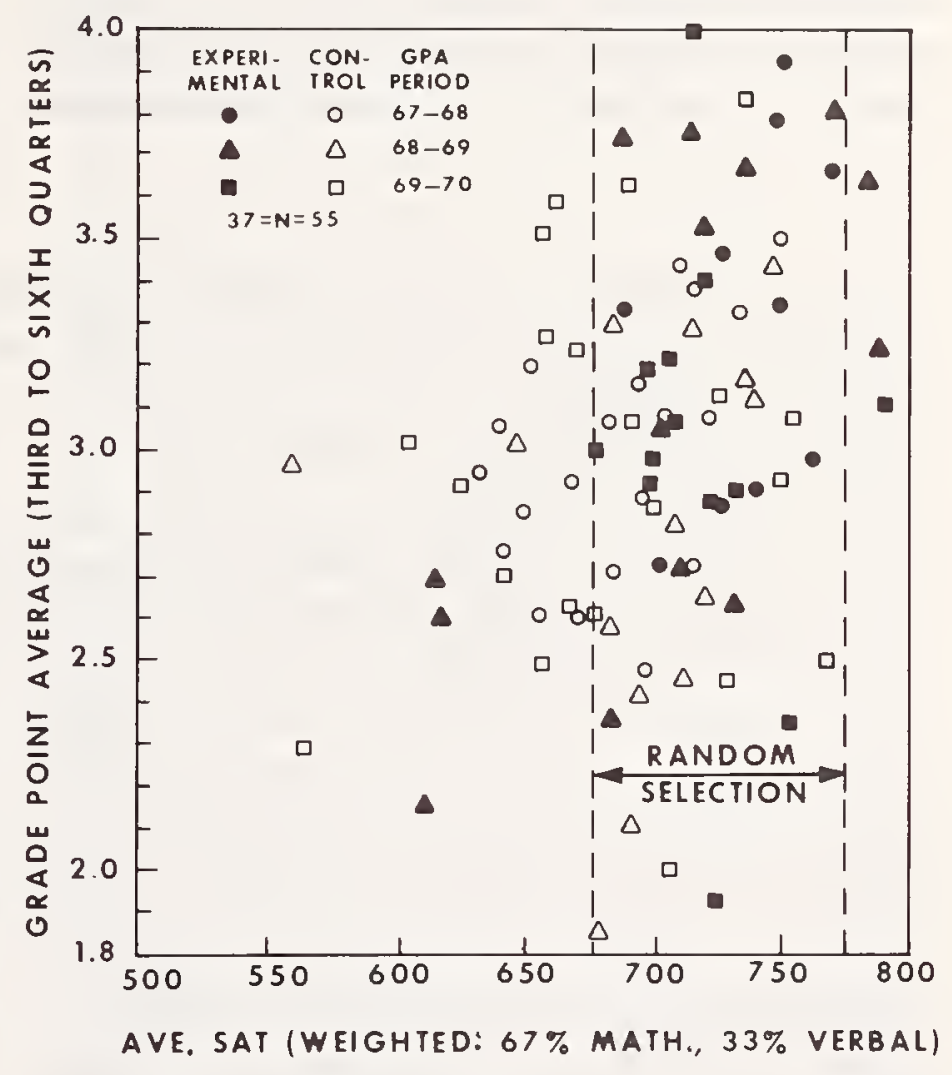

FIGURE 2. Results of a controlled experiment on randomly selected applicants for a Stanford University freshman seminar on mental tools for scientific thinking.

In the four quarters subsequent to the two in which the seminar was taken, the "experimental" students outperformed the controls at a significance level of better than $0 \cdot 05$ 
ing" took the seminar for the first two quarters of their freshman year. The seminar was over-subscribed and I selected the experimental students who took it by constructing matched groups of students, based on their scholastic aptitude tests for verbal and mathematical ability (with math rated twice as heavily as verbal). From these matched groups I selected by chance approximately half of the students in the range of scores shown on the figure. The follow-up study of the effectiveness of the seminar on the students' intellectual performance consisted of determining the cumulative grade point average for the following four quarters, comprising the final quarter of the freshman year and the three quarters of the sophomore year. Inspection of figure 2 shows that on the average, students who took the seminar obtained better grades for the following four quarters than those who did not although both groups were matched in terms of their potential when they entered Stanford and their interest in studying my seminar. The result is significant in the sense that if the points shown in the random selection region of figure 2 had been assigned randomly to the experimental and control group, then there is only about 1 chance in 20 that the ex- perimental group would have ended up as much ahead as they actually did.

Somewhat similar results were obtained with ninth grade students and with freshmen students at San Jose State College. It is on the basis of this background that I hope a description of the failures and confusions that went into the creating of the transistor will contribute towards the creativity of readers of this article.

\subsection{Format of This Presentation}

This presentation is organized by presenting in section 2 a general historical perspective on the invention of the transistor starting with some of the factors that motivated the workers as early as 1939 , 8 years before the invention of the transistor. This treatment hits the high points and does not delve deeply into the interactions that occurred among the three men and led to the five patents. For convenience in following this discussion, table 1 presents certain key information on the five patents. (The reader with sophistication may consider a table with at least two and perhaps four patents for transistors to be an inconsistency in an article hav-

Table 1. The Five Transistor Device Patents filed before the Public Announcement on 30 June 1947

\begin{tabular}{|c|c|c|c|c|c|c|c|}
\hline \multirow{2}{*}{ No. } & \multicolumn{2}{|c|}{ Patent dates } & \multirow{2}{*}{ Inventors ${ }^{\mathbf{c}}$} & \multirow{2}{*}{ Invention ${ }^{d}$} & \multirow{2}{*}{ Conception } & \multirow{2}{*}{$\begin{array}{c}\text { Reduction to } \\
\text { practice }\end{array}$} & \multirow{2}{*}{$\begin{array}{l}\text { Div. } \\
\text { C.I.P. }\end{array}$} \\
\hline & Filed & Issued $^{b}$ & & & & & \\
\hline $1 \ldots \ldots$. & $26 \mathrm{Feb} 48$ & 3 Oct 50 & WHB RBG & Electrolyte F.E.T..... & 20 Nov 47 & 21 Nov 47 & 0 \\
\hline $2 \ldots \ldots \ldots$ & $26 \mathrm{Feb} 48$ & 3 Oct 50 & $\mathrm{JB}$ & Inver. Layer IGFET ................ & 23 Nov 47 & $?$ & 0 \\
\hline $3 \ldots \ldots$ & $26 \mathrm{Feb} 48$ & 17 Jul 51 & RBG & Elect-Form Inver. Layer............ & Dec $47 ?$ & Dec $47 ?$ & 0 \\
\hline $4 \ldots \ldots$. & 17 Jun $48^{a}$ & 3 Oct 50 & JB WHB & Point-Contact Transistor............ & 15 Dec 47 & $23 \operatorname{Dec} 47$ & 3 \\
\hline $5 \ldots \ldots$. & 26 Jun 48 & 25 Sep 51 & WS & Junction Transistor ................. & $23 \mathrm{Jan} 48^{\mathrm{e}}$ & Apr $50^{e}$ & $3^{g}$ \\
\hline
\end{tabular}

a Originally filed $26 \mathrm{Feb} 48$; abandoned and refiled to include current gain at collector.

' Patent numbers: $2,524,034 ; 2,524,033 ; 2,560,792 ; 2,524,035$; $2,569,347$.

c John Bardeen, Walter Houser Brattain, Robert Bernard Gibney, William (Bradford) Shockley.

d Modern terminology is used: IGFET = insulated-gate, fieldeffect transistor. (1) is inversion-layer channel FET with electrolyte gate. (2) is IGFET with inversion layer channel. (3) is electro- lytic processing to form inversion layer. (4) and (5) are the basic point contact and junction transistor patents.

e The dates are late November 1947 for the $p-n$ junction with drop of electrolyte, see discussion of Claim 29 under 4 Dec 47 in the "Magic Month," subsection III A.

"Includes "divisions" and "continuations in part" of these patent applications.

${ }^{g}$ One C.I.P. on negative resistance from transit time, conceived on 24 Jan 48 , had in turn two additional C.I.P.'s. 
ing in its title the phrase "the invention of the transistor." Perhaps it was a compromise. Consider an alternative attempt to be more precise such as "the inventions of the point-contact and the junction transistor together with several precursors.")

Table 2 contains a listing of amplifying principles that had been conceived prior to the public announcement of the transistor. These are discussed in the following sections.

TABLE 2. Amplification concepts conceived before public announcement on 30 June 1948

Field Effect

Schottky-Barrier and Depletion '39

Insulated-Gate Thin Layer ('32?) '45

Inversion-Layer Electrolyte ' 47

Inversion-Layer Insulated Gate ' 47

Junction Field-Effect Transistor '47

Point-contact collector current gain '47-('48)

voltage gain from reverse bias $p-n$ junction ' 47

injection across $p-n$ junction ' 48

negative resistance from transit time-effects ' 48

New research was carried out in preparing this lecture. In September of 1972, about 2 months earlier than the 25th Anniversary of the invention of the transistor, I undertook research on just what had gone on at the time of the invention of the transistor. Probably no one had previously taken all of the laboratory notebooks of the three men principally involved and of their colleagues and endeavored to trace out the day by day development of important ideas and the interactions between them. The details of this history have been organized in section 3 entitled Creative-Failure Methodology and "The Will to Think," the section that follows the historical perspective.

Section 4 extends into 1951 so as to cover the conversion of the junction transistor from a patent application to the device that launched the solid-state era about 1951.

\section{Historical Perspective on the Invention of the Transistor}

\subsection{Pre-World War II}

One of the most important motivations in the entire transistor program at Bell Telephone Laboratories was imparted to me by Mervin J. Kelly shortly after he had been promoted to Director of Research from his position as Head of the Vacuum Tube Development Department. My personal contact with Kelly began in 1936, when he recruited me as a fresh Ph. D. from MIT to work with C. J. Davisson in the Physical Research Department. Kelly arranged for me to have an initial indoctrination experience with high frequency vacuum tubes. This included spending some months of 1937 in the Vacuum Tube Department. During that time Kelly gave me an eloquent pep talk-one that had a long-lasting influence on my own motivations. He pointed out that relays in telephone exchanges caused problems and were expensive to maintain. He felt that electronics should contribute to telephone exchanges in addition to making long distance transmission possible.

After I left the Vacuum Tube Department and returned to Physical Research, I kept Kelly's objec. tive in mind. The move put me in contact with Walter Brattain and his interest with copper oxide rectifiers and with the theories of their mechanisms of rectification then recently developed. On the 29 th of December 1939 I wrote a disclosure of what in principle was a sound concept of a semiconductor amplifier. The leisurely time scale of the ensuing events is interesting to compare with the accelerated developments that occurred 8 years later during the "magic month" discussed in the next section. Research on my notebook entries show that experiments based on the 1939 disclosure were carried out before 6 February 1940. However, my disclosure waited nearly 2 months, until 27 February 1940, before it was witnessed by J. A. Becker, Walter Brat. tain's supervisor. Two days later, on leap year day of 1940, Walter Brattain and I both signed a modification of the earlier disclosure. This disclosure, shown in figure 3 , shows a more or less standard copper oxide varistor unit with two lines of metal forming electrodes on the surface of the oxide. It would today be called a Schottky-barrier, field-effect transistor. 


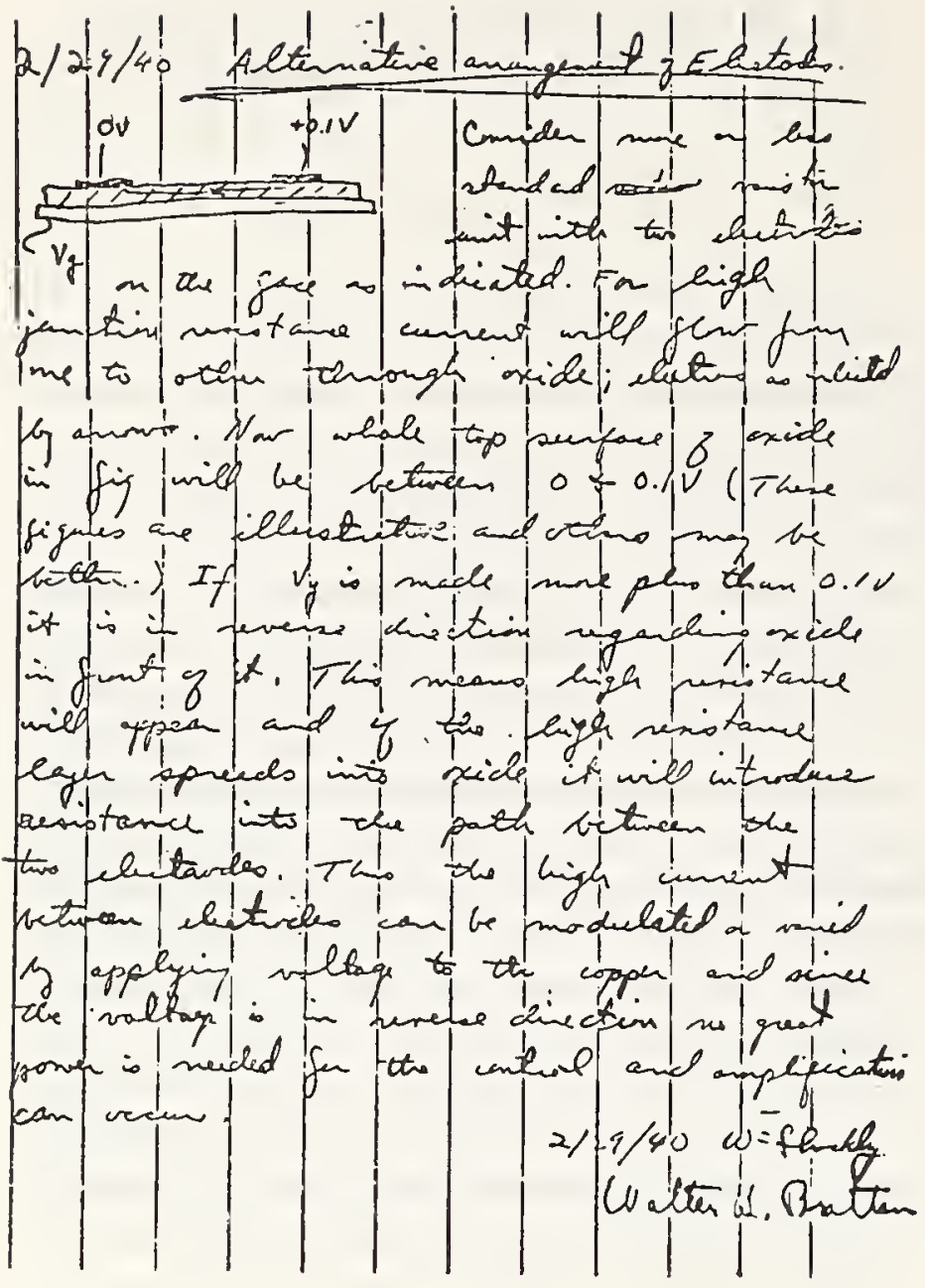

FIGURE 3. The disclosure of a theoretically-sound, Schottkybarrier, field-effect transistor, signed by W. Shockley and $W$. H. Brattain on 29 February 1940.

It was prophetic of developments that were to come 20 years later as parts of integrated circuits using field-effect transistors.

The early results that Brattain and I obtained in experiments related to these disclosures were not encouraging. Shortly after, we quite willingly responded to calls to apply ourselves to different areas of research and development related to America's entry into World War II. Eight years elapsed after the 1940 disclosure before significant field effects in copper oxide were achieved. These 1948 results were reported in one of the three letters to the editor in the Physical Review published simultaneously with the public announcement of the transistor by Bell Telephone Laboratories.

Perspective on the hiatus in research on semiconductor physics is clearly presented in laboratory notebook 18194, which Walter Brattain used both before and after his period of war related activities. His last prewar entry on page 39 is dated 7 November 1941-one month before Japan was to bomb Pearl Harbor. A gap of more than four and one half years elapsed before Brattain made his next entry on 23 A pril 1946. Page 40 starts with one sentence: "The war is over." The remainder of page 40 describes an experiment with a point contact on germanium: "All points rectify n-type." It was a prophetic combination of structure and semiconductor. Eighteen months later on 16 December 1947 on page 193 of the same notebook Brattain was to report that the addition of a second gold point contact on a piece of n-type germanium achieved power gain.

In 1945, during the last months of the war, Kelly once again took actions that indirectly contributed to the transistor program. He invited me to make a series of return visits from the Pentagon back to Bell Telephone Laboratories. I returned full time immediately after the explosion of the atomic bombs that ended the war with Japan.

Kelly's invitation to visit was preparation for my post war position at Bell Telephone Laboratories as Co-Supervisor of a solid-state physics research group. A visit to the Laboratories' Holmdel facility had reawakened my interest in semiconductor amplifiers. At Holmdel Kelly had arranged a demonstration of a radio set lacking vacuum tubes. In this radio the amplification was accomplished by pointcontact detectors. These semiconductor devices acted as negative resistances, a phenomenon probably due to heating effects that lowered their resistance as occurs for thermistors. These devices indicated that semiconductors held exciting potentials but they themselves had many shortcomings-so many that they were failures in pointing the way to make semiconductor amplifiers-but creativefailures in stimulating the will to think of better approaches.

During my visits in 1945, a series of ideas led me again to the concept of a field-effect amplifier. I do not now recall, or for that matter did the research that I did on my laboratory notebooks while preparing this paper suggest, that in 1945 I saw clearly how closely these field effect ideas were related to the copper-oxide concepts of 1939 and 1940. The sequence of ideas in 1945 had a different starting point than the Schottky barrier of 1939.

The basic field-effect concept of 1945 is shown in figure 4. Here a thin layer of n-type semiconductor is represented. This layer forms one plate of a paral- 


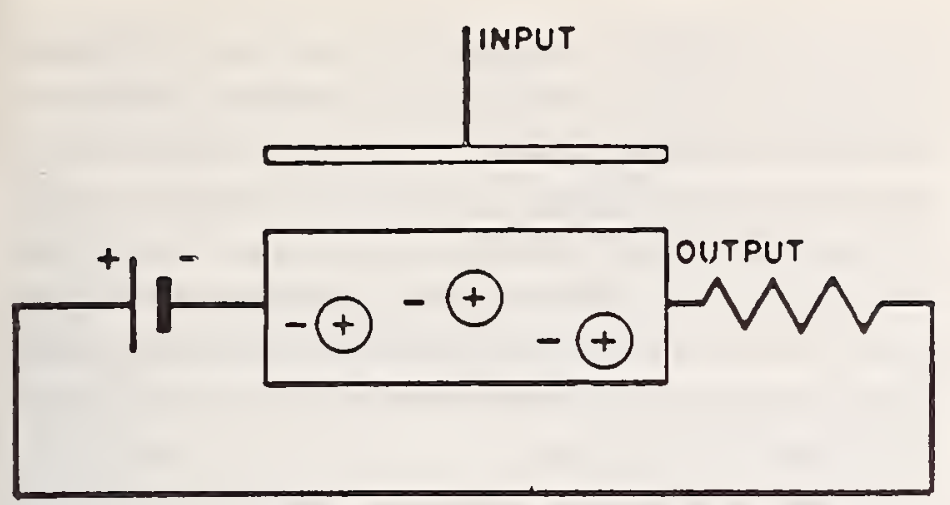

(a)

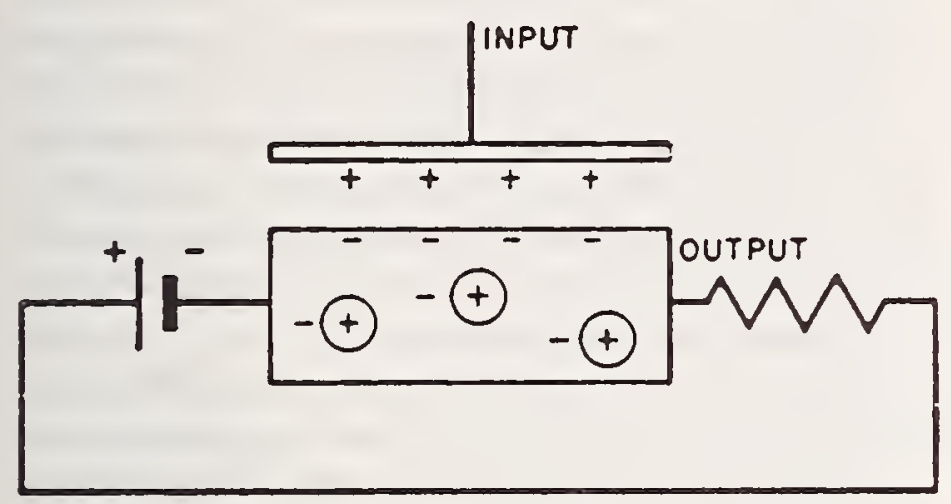

(b)

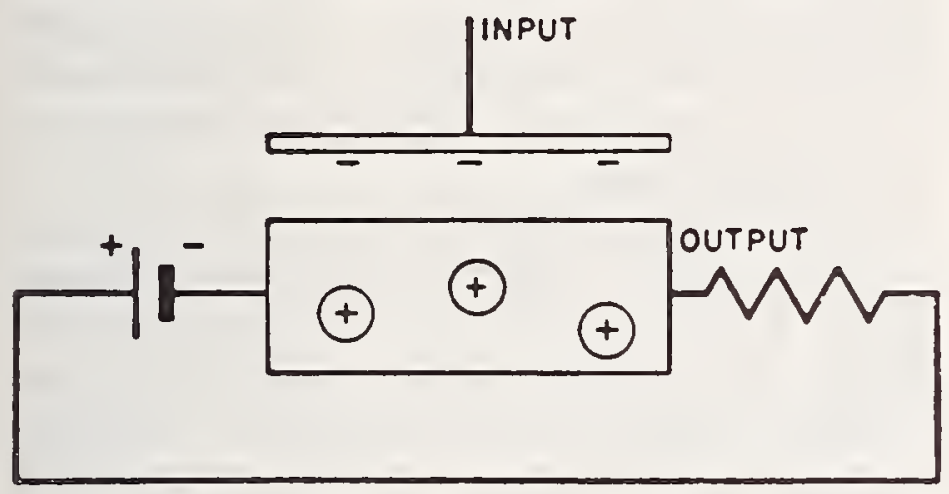

(c)

FIGURE 4. The theory of a field-effect transistor using a thin layer of semi-conductor: (a) The structure of the transistor with no control voltage applied. (b) The situation prevailing when a positive charge is placed on a control plate so as to increase the conductance of the semiconductor. (c) The situation when a negative charge is put on the capacitor plate so as to reduce the conductance of the semiconductor.

lel plate capacitor, the other plate being a sheet of metal. Charging the capacitor alters the number of electrons on the semiconductor. This modulates the conductance of the layer much as did the reverse bias on the copper plate in the concept of figure 3 .

A number of experiments on the field-effect struc. ture of figure 4 were undertaken. These had become possible in 1945 because of the great advances in semiconductor technology that had taken place in point-contact, or "cat's-whisker," radar detectors during World War II. The work at Holmdel had played a key role in this and so had also the metallurgical work at the Murray Hill Laboratory. Silicon and germanium, both elements of the fourth column of the periodic table, had become two of the technologically best-controlled semiconductors in existence. Methods of using impurities from the third and fifth columns of the periodic table to act as acceptors and donors had been developed. The designations p-type and n-type were in common use. Compensation of donors and acceptors had been used at Murray Hill to control or adjust resistivity and, indeed, had been patented by J. H. Scaff and H. C. Theuerer. A particularly important form of high purity, n-type germanium had been developed. In point-contact rectifiers it would stand high reverse voltages, also called "back" voltages, and was referred to as "high back-voltage germanium." This germanium was to play a vital role in the point-contact transistor of patent 4 in table 1.

Thin films of silicon that had been deposited, largely by the work of Gordon Teal, seemed ideally adapted to field-effect experiments. My calculations showed that very substantial modulation of the resistance should occur. None was observed. On 23 June 1945 , I wrote that the effects were at least 1,500 times smaller than what I predicted should have been observable.

I brought my calculations to the attention of John Bardeen. In October of 1945. he had joined the Laboratories as a member of the solid-state group. He was a theoretical physicist with a background in solid-state physics founded on research carried out while he was obtaining his $\mathrm{Ph}$. D. under Professor Eugene Wigner of Princeton University. When I did research for the 25th Anniversary of the transistor, I found an entry in Bardeen's laboratory notebook recording my request to him to check my calculations. On November 7, 1945, 2 weeks later, he verified my formula.

\subsection{Scientific Aspects of the Failure of the Field-Effect}

Attempts to observe the field-effect and use it for amplification failed during 1945 and early 1946. But this failure became a stepping stone on the path to creativity. On 19 March 1946 John Bardeen recorded 
in his notebook his explanation for the failure: the electrons drawn to the surface of the semiconductor, when it was negatively charged as represented in figure 3 , were not free to move as were the electrons in the interior. Instead, they were trapped in surface states, as represented in figure 5 , so that they were immobile. Thus, in effect, the surface states trapped the induced charge of electrons and thereby shielded the interior of the semiconductor from the influence of the positively charged control plate. The externally applied field was thus blocked at the surface and did not penetrate.
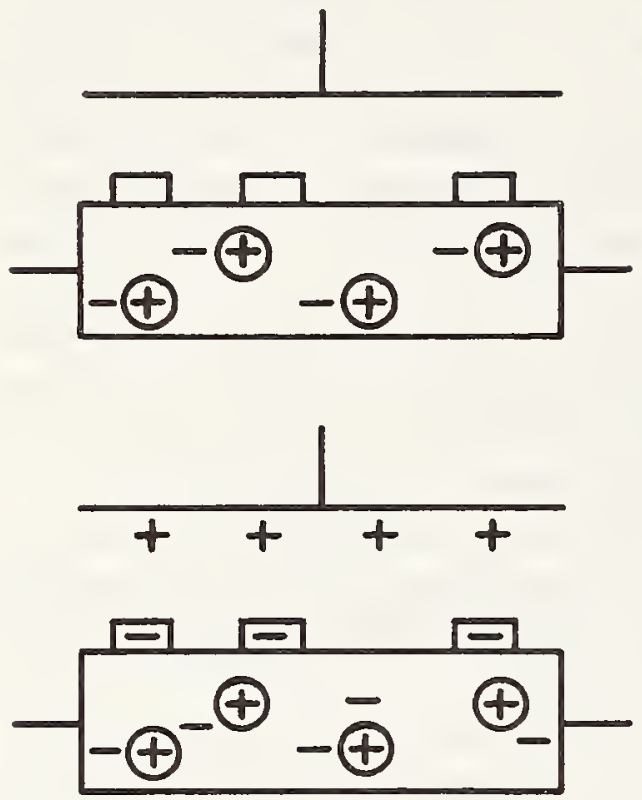

FigurE 5. Bardeen's explanation of the failure of the field effect structure through the presence of surface states.

(a) The structure with no applied voltage. (b) The capture in surface states of the electrons induced by the surface charge.

"Creative-Failure Methodology" is the phrase that I formulated some two decades later to describe what we intuitively put into action when frustrated by the failure of the field-effect experiments. Bardeen's concept of surface states as shielding the interior from external fields gave a practical significance to what had before been largely a theoretical concept. Both Igor Tamm in Russia (co-winner of the 1958 Nobel prize in physics for work on Cerenkov radiation) and I had done theoretical calculations showing that surface states should exist. However, no significant observable implications of these had been proposed. Indeed our surface states were of a highly mathematical nature and related to perfect crystalline surfaces. In contrast, Bardeen's concept of surface states was more empirical. His states were undefined in terms of their quantum mechanical origin and allowed for the possibility that defects on the surface might contribute to their existence-concepts in harmony with knowledge about the states due to donors and acceptors in the interior of the semiconductor.

Bardeen quickly recognized the value of his proposal. His surface states had broad implications and their use was not restricted solely to explaining the field-effect failure. His surface states also resolved a number of mysteries about semiconductor surfaces including their rectifying characteristics when contacted either by metal points or else by other semiconductors - a dramatic example of creative-failure methodology in action.

Our semiconductor research team abandoned efforts to make a field-effect transistor and instead emphasized research on new science related to Bardeen's surface states. The course of action that we intuitively put into action is what I have subsequently analyzed as an effective feature of creative-failure methodology valuable for research related to applications:

I have referred to this creative principle as respect for the scientific aspects of practical problems. Figure 6 represents how this principle works in general with the interpretation of its vital role in creating the transistor indicated by the phrases in parentheses: The attempt to make a semiconductor

CREATIVE PRINCIPLE: RESPECT FOR SCIENTIFIC ASPECTS OF PRACTICAL PROBLEMS

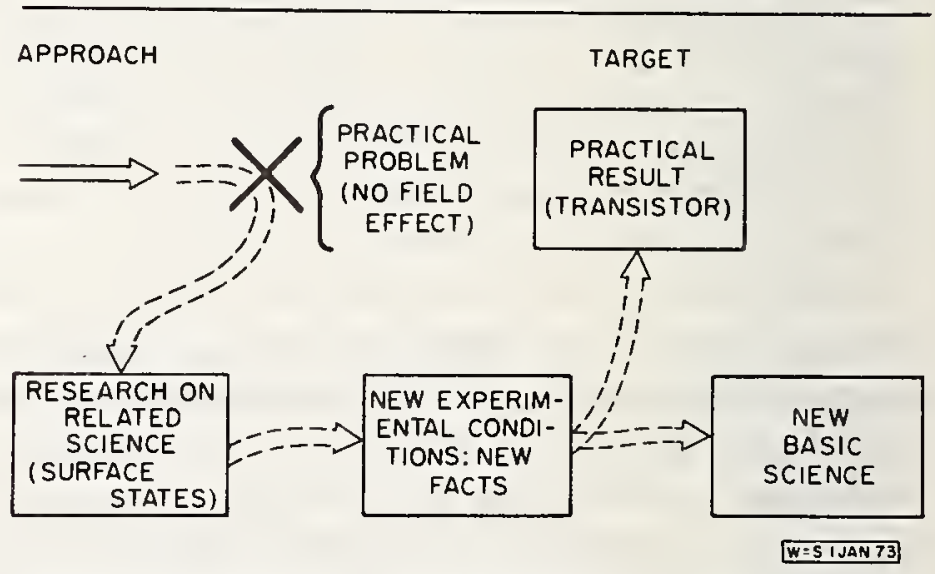

Figure 6. Respect for the scientific aspects of practical problems-a feature of the creative failure methodology which led to the invention of the transistor. 
amplifier was blocked by a practical problem. But how we responded to this failure to reach the practical result was creative. The failure stimulated Bardeen's creative suggestion of the surface states. Our research on the science related to the surface states led to new experimental conditions and to new observations. As discussed below under the "magic month" heading of section 3 , the new experimental conditions produced a particularly revealing observation that suggested that at long last the blocking effect of the surface states had been overcome. This new possibility motivated "the will to think" phenomenon that led to the phenomenal degree of creativity that followed immediately thereafter.

There may be today, 25 years after the invention of the transistor, an ironic aspect of the emphasis that I have given to "respect for the scientific aspects of practical problems" as an important creative principle in industrial research. By assigning so much emphasis to this feature of creative-failure methodology - a feature that I helped to establish - I may have become out-dated and be reflecting attitudes that are more appropriate to the experiences that I recall of the 1940 's than they are to industrial research today.

In 1946 when the semiconductor research group focussed emphasis on the basic science, I recall that leaders of some other groups of the Research Department suggested, emphatically, that we should put more stress on practical semiconductor problems - those related closely to the difficulties in the telephone plant. Our group was of one mind and we followed the wise course of working, not upon such practical but messy semiconductors as selenium, copper oxide and nickel oxide, but instead on the best understood semiconductors of all-silicon and germanium. For these semiconductors, not all of the theoretical concepts, developed largely during World War II, had been experimentally verified; accordingly, we elected to concentrate upon the resulting gaps in this branch of science, among them the recently proposed surface states. We felt that it was better to understand these two simplest, elemental semiconductors in depth rather than to attempt to add piecemeal contributions to a variety of other materials. Thus we assigned highest priority to the primarily scientific aspects. But in our selection of emphasis, we did choose those scientific aspects that were related to the problems that blocked our approach to the long-range, practical goal - the crea- tion of a semiconductor amplifier, later to be called the transistor.

My feeling of being out of date occurred after I had stressed the creative principle of "respect for scientific aspects of practical problems" at Bell Laboratories during a rehearsal in February 1973 of a lecture version of this presentation. During a subsequent luncheon conference, a young scientist told me that he was puzzled about my reasons for according such emphasis to the "respect for the scientific aspects of practical problems." The approach that I endorsed so vehemently seemed so natural to him that it scarcely called for any emphasis at all. I felt separated from his appraisal by a "generation gap": What in 1947 had been, in the eyes of at least some colleagues, a pioneering advance from the Edisonian methods of trial and error to achieve practical goals was now, 25 years later, to be taken for granted. And the transistor story had probably helped to bring this about. By giving such a strong sales pitch to what today did not need selling, I had made my words become an echo of the past.

\subsection{The Invention of the Point-Contact Transistor}

The research on silicon and germanium and their surface states led to a series of experiments. As described on figure 6 , these created new experimental conditions and led to the discovery of new scientific facts. A detailed description and interpretation of the sequence of events is the subject of section 3 . As will be described there, a period that I have called "the magic month" began with a breakthrough observation on 17 November 1947 and culminated with what I shall take as the starting point here-the reduction to practice of the pointcontact transistor-an achievement recorded, as discussed above, on page 193 of Brattain's notebook. The famous prototype structure of the point-contact transistor came into existence on 16 December 1947 - the date at which Walter Brattain used a wedge-shaped piece of plastic to press two narrowlyspaced, parallel-line, gold contacts against a block of high-back voltage germanium. This prototype is shown in figure 7 . The observation that it amplified and oscillated is recorded in that very famous notebook entry - the one written by Walter Brattain in 1947 on the day before Christmas. It appears in figure 8 . The date of 23 December cited in figure 8 


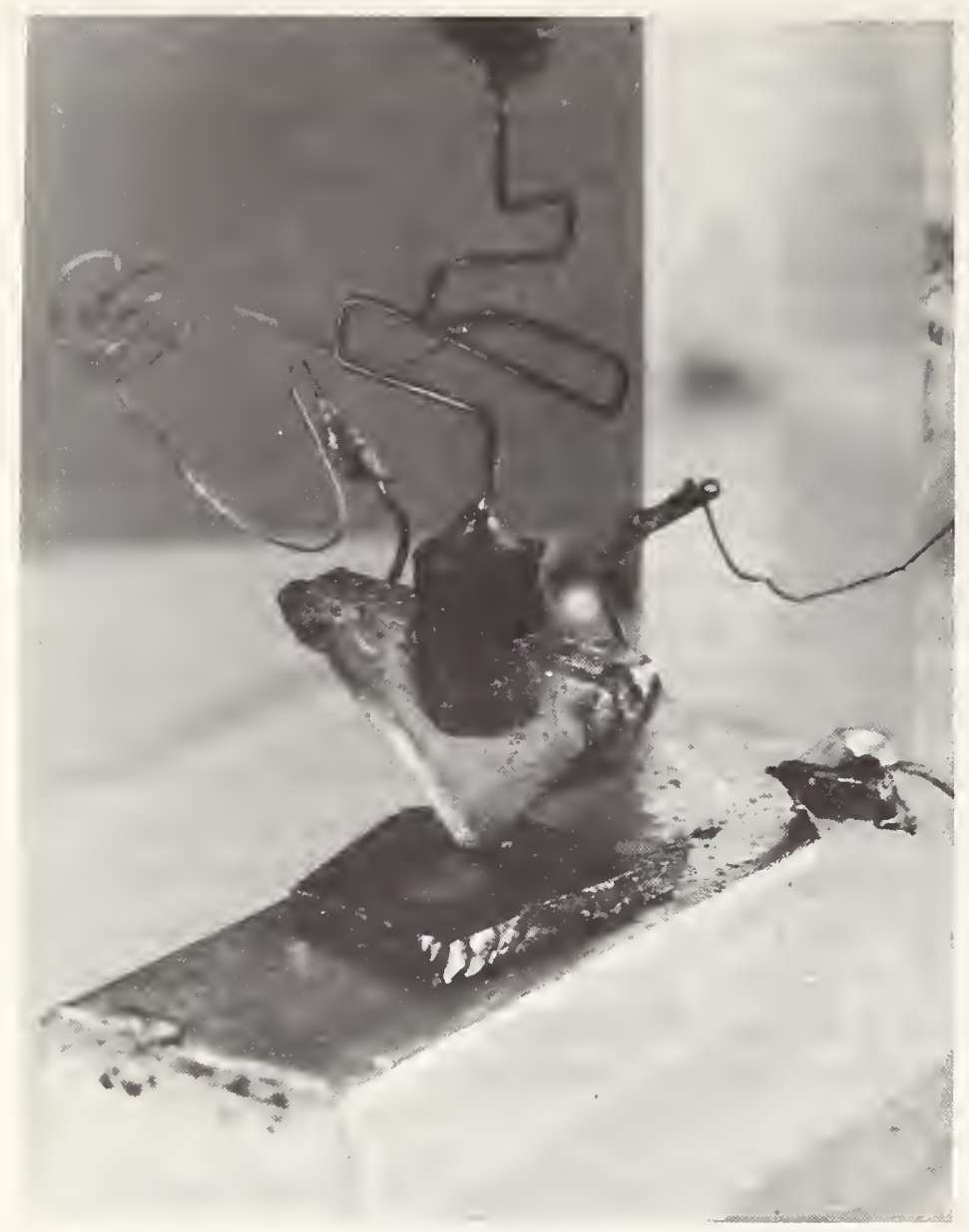

FiguRE 7. The original point-contact transistor structure comprising the plate of n-type germanium and two line-contacts of gold supported on a plastic wedge.

and shown as the date of "reduction to practice" in table 1 is the generally accepted date for the birth of the transistor. However, 15 and 16 December 1947 , are equally significant because, as discussed under those dates in section 3 , these are the dates of conception and of first successful amplification. Actually, amplification was obtained even earlier with semiconductor devices using electrolytes. But these earlier devices had such poor frequency response that they failed to hold promise of developing into useful amplifiers. But they were creative-failures and did directly stimulate the research that led to the point-contact transistor. One such device was covered by the Brattain-Gibney invention, patent 1 of table 1 . Another was incorporated in patent 5 , the junction transistor.

The point-contact transistor, patent 4 of table 1 was originally filed, not on $17 \mathrm{June} 1948$ as shown in table 1, but on February 26, 1948, simultaneously with patents 1,2 and 3 . The issued version of patent 4 states in itc first paragraph that it is a continuation- in-part of the earlier application that had actually been abandoned. The reason for abandoning and refiling (I was told by R. J. Guenther shortly before he retired as General Patent Attorney almost exactly on the date of the 25th Anniversary of the transistor) was that the original filing failed to mention current gain at the collector - an important feature in obtaining power gain and in simplifying the design of circuits. (Current gain is covered in the issued patent in col. 10, line 35 and col. 16, line 26.)

Patent 3, of table 1, involved treatments of semiconductor surfaces electrolytically-concepts important to the theory of the point-contact transistor. Both versions of patent 4 depended heavily upon the concept of an inversion layer on the semiconductor surface caused by syrface charges, related to Bardeen's surface states. The most appropriate surface conditions for these charges were produced by electrolytic treatments, specifically those treatments that were the subject of patent number 3 of table 1; indeed an example of the treatment specified in patent 3 is described in detail in a paragraph of the point contact transistor patent (col. 8 , lines 8 to 44 ).

The concept of surface inversion layers was an essential stepping stone along the path of development of transistor technology. It was also prophetic. As discussed further below, in actuality inversion layers were probably not important for the point-contact transistors in pilot production in 1948 nor for the junction transistors or junction field-effect transistors that came somewhat later. However, the surface-state concepts of inversion layers disclosed in patents 2 and 4 are probably now playing an essential role in MOS (metal-oxide-semiconductor) field-effect transistors in integrated circuits.

The importance attributed to the inversion layer in early 1948 may be appreciated by reading the claims of the point-contact transistor patent; for example, claim 1:

"1. A circuit element which comprises a block of semiconductive material at which the body is of one conductivity type and a thin surface layer is of the opposite conductivity type, and an emitter electrode making contact with said layer, a collector or electrode making contact with said layer disposed to collect current spreading from said emitter electrode, and a base electrode making contact with the body of the block." 
8 DATE $\operatorname{Aec} 24$ 1947 CASE No. $38139-7$

Whe altimed the fallaring A. C. values ax aro ifles

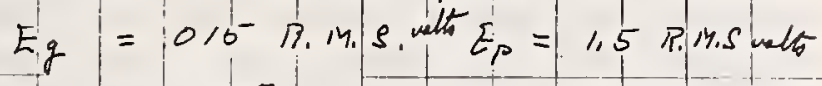

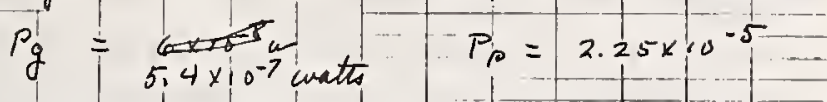

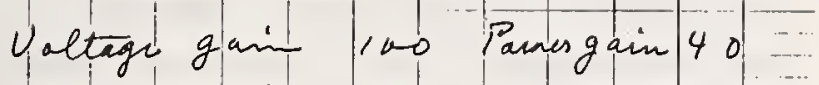
Carsent laxt $\frac{1}{2,5}$ Leis cuit cras then camietes

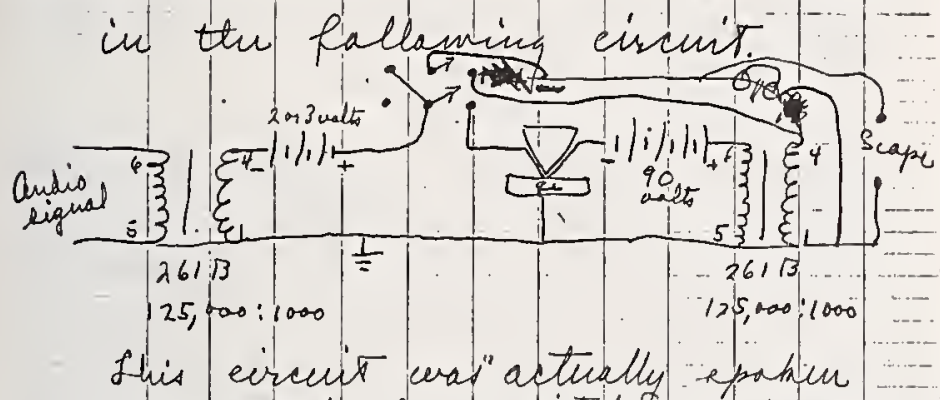
ous and hy kufiteling. the diviu in and ant a dintinet. gain in spedeh level cased h. liand and hen on the reape misutation with un siaticable change in quality. Th- -

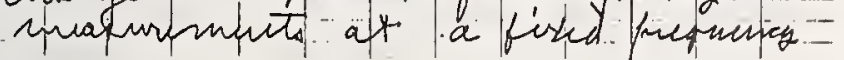

in if mas ditermined that thi I pamer gain cuas the opdis fafectsof 18 or guates. Variass puple:(icuiremud this text and litined -of whom rame cues the fallowing R. B. Gibury, H. R. maxe! J. Bardem gr. Prarran, w shackly, H. Fletelus R. Bown. Un. N. B. Kiave acrilted in setting up the circint and the demantration aceured an thi aftirioun of Des 231947

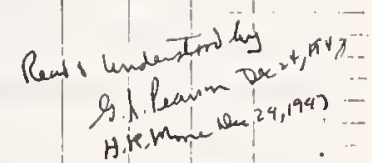

FIGURE 8. Notebook entry of 24 December 1947 describing the point-contact transistor demonstration of 23 December 1947 at Bell Telephone Laboratories.
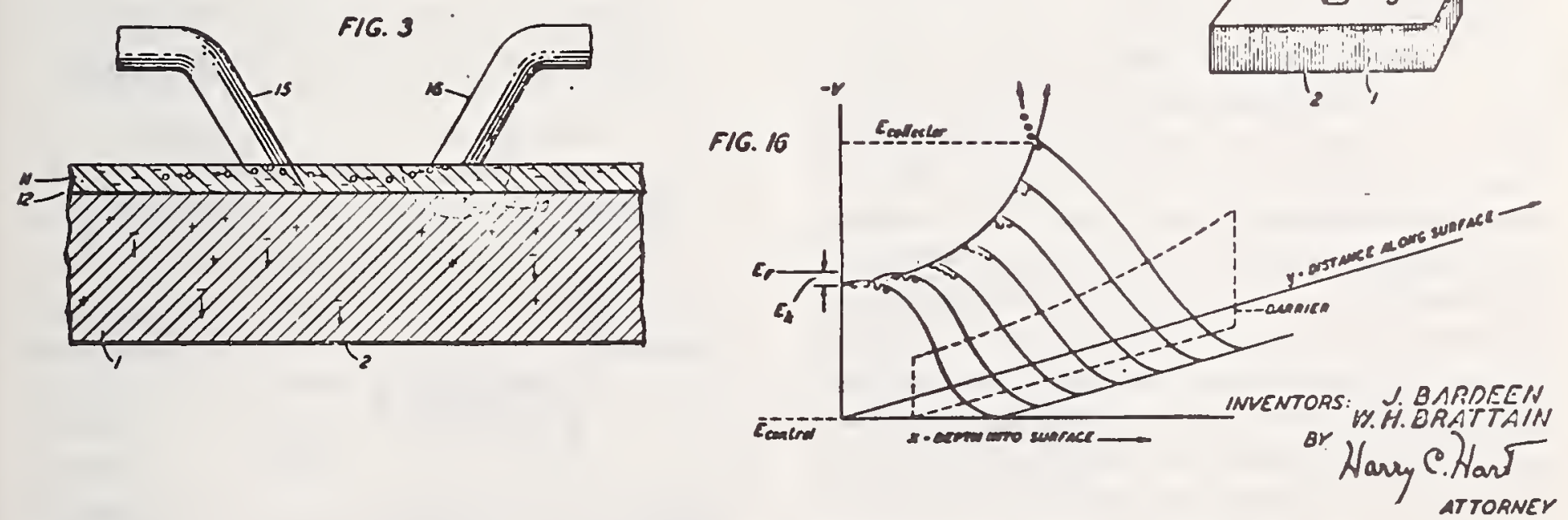

FIGURE 9. Patent figures for the point-contact transistor (patent 4 of table 1).

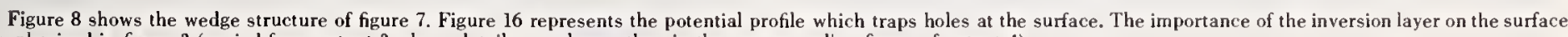
is emphasized in figure 3 (copied from patent 3 where details are clearer than in the corresponding figure of patent 4 ). 
These concepts are clearly illustrated in figure 9 . Figure 3 (taken from patent 3 is almost identical with a more congested figure of patent 4) shows the inversion layer and the emitter and collector electrodes. Figure 8 from patent 4 shows the drawing of the wedge structure discussed for figure 7 . Figure 16 from patent 4 shows a potential energy diagram for the p-type channel of the inversion layer, the holes being represented as small circles.

Means of forming the inversion layer were a central topic in patent 3 . Indeed, the final claim 9 of the issued patent read directly upon the inversion layer shown in figure 4.

"9. A block of high back voltage germanium material of which the main body is of $n$-conductivity type, having on a surface thereof a thin layer of the order of $10^{-5} \mathrm{~cm}$ in thickness whose characteristics are of the p-type, separated from the body of the block by a high resistance barrier."

Thus it is evident that patent 3 of table 2 contains a claim essential to important general concepts of the first four patents. (The significance of this feature was put in perspective by Bardeen in his Nobel lecture as quoted below, see 9-12 December 1947 in sec. 3.)

The prominence of Gibney's name on the five patents and in the notebooks raised questions in my mind as I did the research for this lecture. What had happened to Gibney? Why had he left? I wondered if lack of recognition in respect to his significant contributions might have provoked him to go away mad during the following 6 months or so. My speculation was unsound. I learned the truth by telephoning to him at Los Alamos. He had indeed left with a dislike for his situation in New Jersey - but not with his situation at Bell Telephone Laboratories. He was mad at the New Jersey weather. The New Jersey winters had contributed to strep throats, colds, and other health problems for all of his family including his children. The problems had been most severe for the preceding winter of 1946-1947. Furthermore, it turned out that both he and Mrs. Gibney, although they had not known this when they married, had years before fallen in love with New Mexico. When in the fall of 1947 Gibney saw an advertisement from the Los Alamos Laboratories seeking a man with his scientific background, he applied. Actually, during part of the magic month, he was at Los Alamos for interviews. Since the spring of 1948 he has been at
Los Alamos. For 20 years he was in charge of a group doing physical metallurgy and graphite research.

I had recruited Gibney into the group shortly after it was formed to add otherwise lacking expertise in physical chemistry. The great loss that we suffered when he left for Los Alamos, prior to the announcement of the transistor, was later balanced by the acquisition of Morgan Sparks. Sparks played, as I shall describe in section 4 , an essential role in bringing useful junction transistors into existence.

\section{Speculations and Anecdotes Related to the Public Announcement of the Transistor}

What was the scientific atmosphere at the time the transistor was announced? What was the press reaction? Would, in any event, the transistor have soon been invented somewhere else? What were some of the key scientific matters left undecided at the time of the announcement? I shall endeavor to put these questions in perspective by describing my own recollections of the events that occurred at approximately the same time-close to the first of July 1948 when news stories of the invention of the transistor first appeared. Some of the important scientific questions concern the role of the inversion layer on the surface and the phenomena associated with the emitter point.

Figure 10 is a chart that was used at the public presentation to describe the region of interaction that surrounds the emitter point. Power gain occurs when the collector point is placed in this region. This diagram suggests how the transistor might have

\section{INTERACTION BETWEEN TRANSISTOR ELECTRODES}

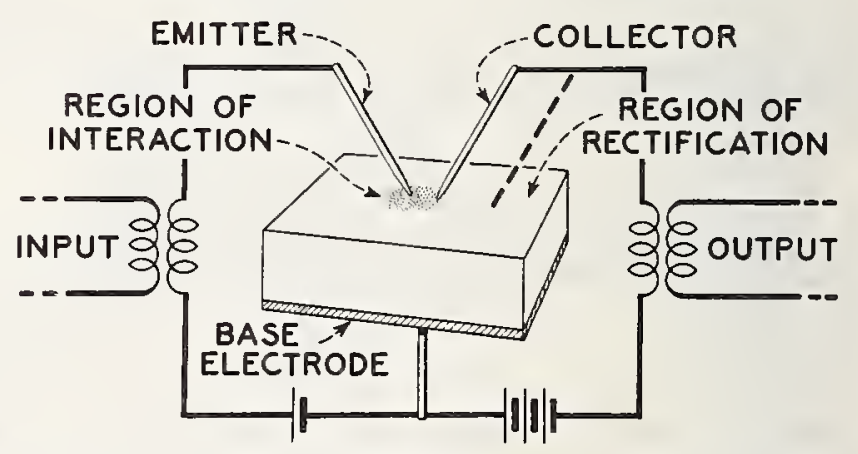

Figure 10. A chart used at the time of the public announcement of the transistor illustrating the concept of the region of interaction surrounding the emitter electrode. 
been discovered elsewhere by a study of the effect upon the voltage and conductance of a probe point when placed in the region of the interaction surrounding another current carrying point. Such research would have led to observing phenomena that, one would think, could easily have suggested the amplification mechanism of the point-contact transistor. That this did perhaps come very near to happening at Purdue University in mid-1948 is suggested by the following facts.

An important motivation to the Bell Laboratories group resulted from competition with the outstanding semiconductor group at Purdue University, directed by Professor Karl Lark-Horowitz. Interest in making semiconductor amplifiers must have existed at Purdue University. The idea that semiconductor amplifiers could probably be realized had already had a long history. (One example is discussed below in connection with table 2.) At a meeting of the American Physical Society in May of 1947 a doctoral candidate at Purdue, Ralph Bray, had undertaken research on what was equivalent to a forward biased emitter point, although not so recognized then. What Bray concluded, and reported in more detail in a paper read in 1948 two months before the announcement of the transistor, was an explanation of how the "spreading resistance" of a point contact depended upon the emitter current. He used large forward currents that produced electric fields of 100 volts per centimeter. Bray concluded that these high electric fields caused the resistivity of the germanium to decrease. ("Hot electron" experiments carried out at Bell Laboratories later showed that high electric fields actually tend to increase the resistance.) It is hard to guess how long it would have taken for Bray or his colleagues at Purdue to discover that the effect that they were analyzing was in actuality the injection of minority carriers into the germanium if transistor related research at Bell Laboratories had not already published the answer in January of 1949.

Before the announcement of the transistor, I had proposed injection as a key feature of the junction transistor, patent 5 of table 1. Experiments, described in more detail in the next section, had also indicated that injection might be an important mechanism for point-contact transistors. Several programs to resolve the question were undertaken of which the best known is the Haynes-Shockley experiment that measures "drift mobility" of injected minority carriers. The first definitive result to be published was submitted to the Physical Review on 1 December 1948 by E. J. Ryder and me and published in the 15 January 1948 issue. Figure 11 shows the essential features. A circular slice of highback voltage n-type germanium was cut into the shape of a piece of pie and two metal electrodes were applied, one at the point and the other on the crust, or rim. When we applied a flat-topped voltage pulse across these electrodes with the narrow point negative, we observed a flat-topped current pulse of just the magnitude expected from the specimen's low-voltage resistance. There was no change in resistance although our fields were more than 10 times larger than those Bray had used. However, when we reversed the voltage and made the narrow end positive, we did observe a decreasing resistance and a current pulse that increased with time. By assuming that holes were injected from the positive electrode we interpreted these observations as follows. When the positive electrode was the narrow end, then the high current density caused injection of holes into this restricted region and thereby produced a substantial reduction of the resistance of the specimen with a resultant increase of current. On the other hand, when the large end was positive, the efficiency of hole injection was less, because the current density was less, and the holes injected were injected into a region that contributed much less to the resistance of the specimen so that the increase in current was negligible throughout the duration of the voltage pulse.

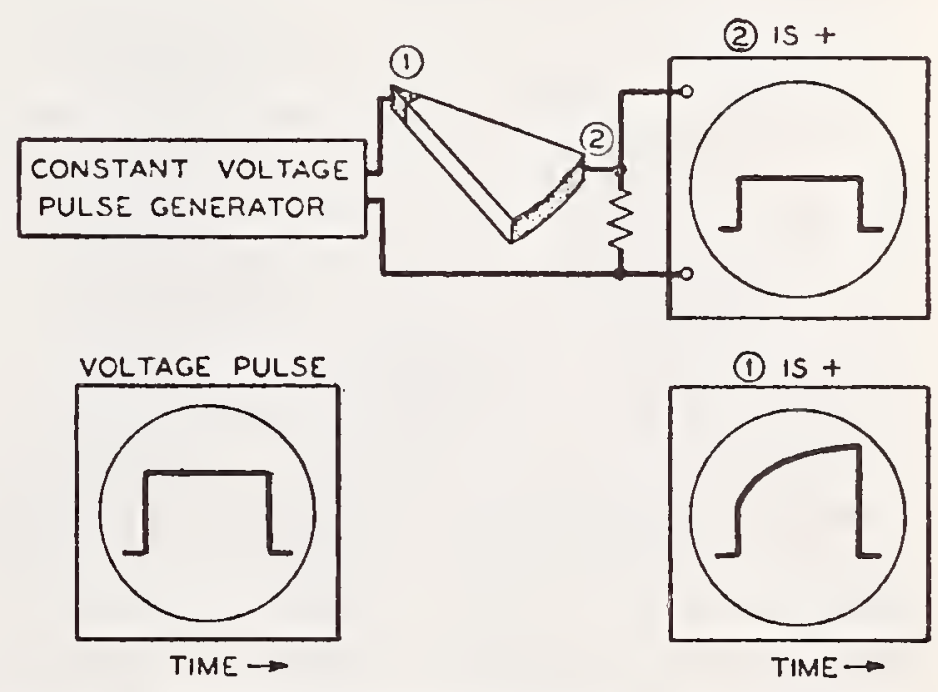

FIGURE 11. The Ryder-Shockley experiment demonstrating conductivity modulation by hole injection at a positively biased electrode. 
As I pointed out above, this experiment was closely related to the injection concept of the junction transistor. My historical research into photographic files unearthed the presentation of injection shown in figure 12. I speculate that the date of this figure was probably in 1949 or early 1950 - a conclusion based on the somewhat wistful expression on my face. During that period the theory of the junction transistor was well developed but the goal of producing one with desirable characteristics was frustratingly out of reach. I was photographed elucidating junction-transistor theory on a blackboard diagram. The proportionality at which I was pointing suggested that the unwanted current of carriers from the base layer to the emitter should vary inversely as the conductivity of the emitter layer.

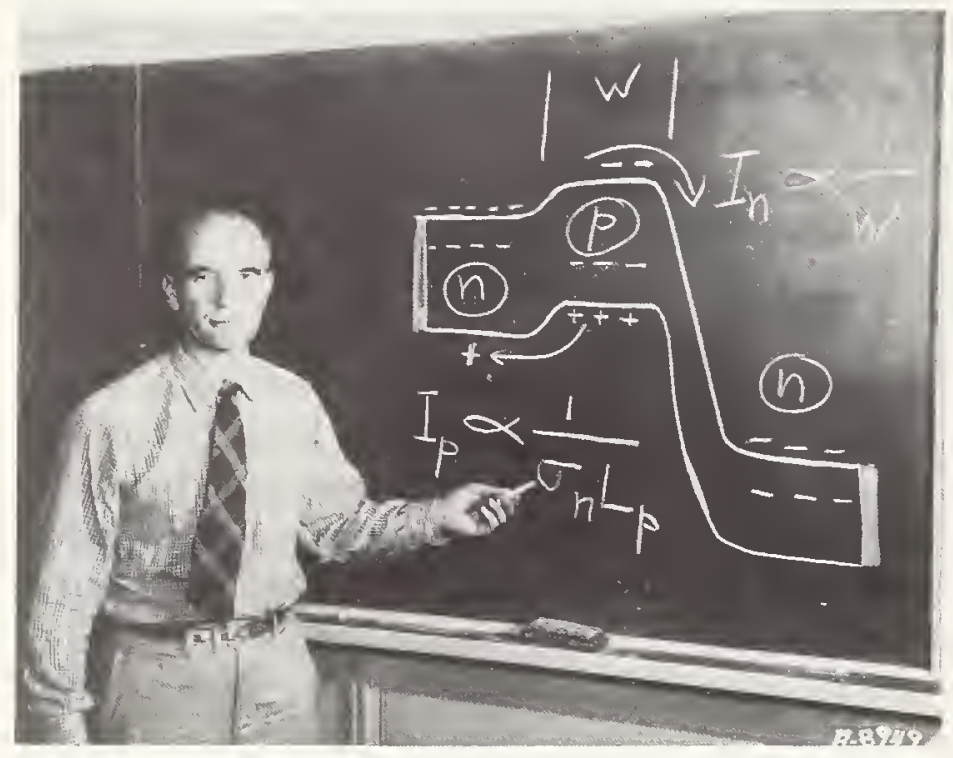

FIGURE 12. The author presenting the theory of the junction transistor probably in 1949 or early 1950.

The concept of injection across an emitter junction completed the invention of the junction transistor of patent 5 in table 1 and added one more item to the list of table 2. Amplification Concepts Conceived Before Public Announcement on 30 June 1948. The specification for the application for patent 5 also contained a discussion of negative resistance arising from transit time effects - a consequence of familiarity that I had acquired during the initial portion of the indoctrination period arranged by Dr. Kelly when I was assigned to work with Dr. F. B. Llewellyn. This transit time disclosure was later developed into a continuation in part of patent 5 that resulted finally, as shown in table 1 , in three additional issued patents.
In all cases, save one, the dates in table 2 of conception are established within narrow limits from records in laboratory notebooks. The insulated-gate, thin-layer, field-effect concept may have been a significant aspect of the Lilienfeld patents that issued in 1930, 1932, and 1933. Two dates are shown for collector current gain in the point contact transistor. Although gain may have been achieved in 1947, it was not clearly recognized in the 26 February 1948 filing of patent 4 . It was, however, clearly expressed in the continuation-in-part filed on 17 June 1948, less than 2 weeks before the public announcement of the transistor.

Do these observations cast any light on the question of when the transistor would have been invented had it not happened at Bell Telephone Laboratories? Sometimes a long time may elapse before a vigorous effort is mounted to overcome an obstacle that blocks progress. However, once "the will to think" is motivated, as discussed in section 3 , progress accelerates enormously. In the case of the amplifying principle of injection across a p-n emitter junction, such motivation would have occurred soon at Bell Laboratories if I had not invented injection on the $23 \mathrm{~d}$ of January 1948. This reasoning is presented in detail in the junction-transistor portion of section 3 .

An example of how the existence of established possibilities upon motivations accelerates accomplishments is illustrated by the success of thin film, field-effect experiments like those whose failure was used by Bardeen as a stepping stone to his theory of surface states. Shortly after Bardeen's theoretical proposal in 1946, very feeble field effects were observed by G. L. Pearson at the low temperatures of liquid nitrogen. But room temperature results remained negligible. However, once semiconductor amplification had been achieved, then after only a few months, substantial field effects were observed by Pearson at room temperature, using structures essentially of the form of figure 4. Pearson and I reported on them in one of the first three publications on transistor effects. These publications appeared in the Physical Review and the public announcement was scheduled to coincide with the date of their publication.

Further evidence that the invention of the transistor might have been inevitable and not much longer in coming is illustrated by the following personal anecdote about an experience at the Naval 
Research Laboratory. The incident occurred during the week at the end of June 1948 between a private transistor demonstration for members of the Department of Defense and the subsequent public presentation to the press. Ralph Bown, then the Director of Research, and I responded to an invitation to discuss at the Naval Research Laboratory in Washington their proposal that the public announcement of the transistor might be made jointly with them. One of their scientists had been carrying out experiments aimed at producing a semiconductor amplifier. This project was, they thought, far enough along so that these developments should also be recognized. After Bown and I had discussed with them the new scientific interpretations, based largely on the theory of inversion layers, and had stressed to them the fact that their program had not actually achieved power gain, they gracefully withdrew their suggestion. This story shows that other competent laboratories were actively in pursuit of the same goal.

The initial impact of the public announcement of the transistor was disappointing to those of us who were most intimately involved. Figure 13 is representative of the exhibits at the press con- ference. It shows two typical vacuum tubes compared with a packaged, point-contact transistor. The New York Times report of the press conference was discouraging to us. It occupied four paragraphs of the News and Radio column on the radio page of their July lst issue:

"A device called the transistor, which has several applications in radio where a vacuum tube ordinarily is employed, was demonstrated for the first time yesterday at Bell Telephone Laboratories, 463 West Street, where it was invented.

"The device was demonstrated in a radio receiver, which contained none of the conventional tubes. It also was shown in a telephone system and in a television unit controlled by a receiver on a lower floor. In each case the transistor was employed as an amplifier, although it is claimed that it also can be used as an oscillator in that it will create and send radio waves.

"In the shape of a small metal cylinder about half an inch long, the transistor contains no vacuum, grid, plate or glass envelope to keep the air away. Its action is instantaneous, there being no warm-up
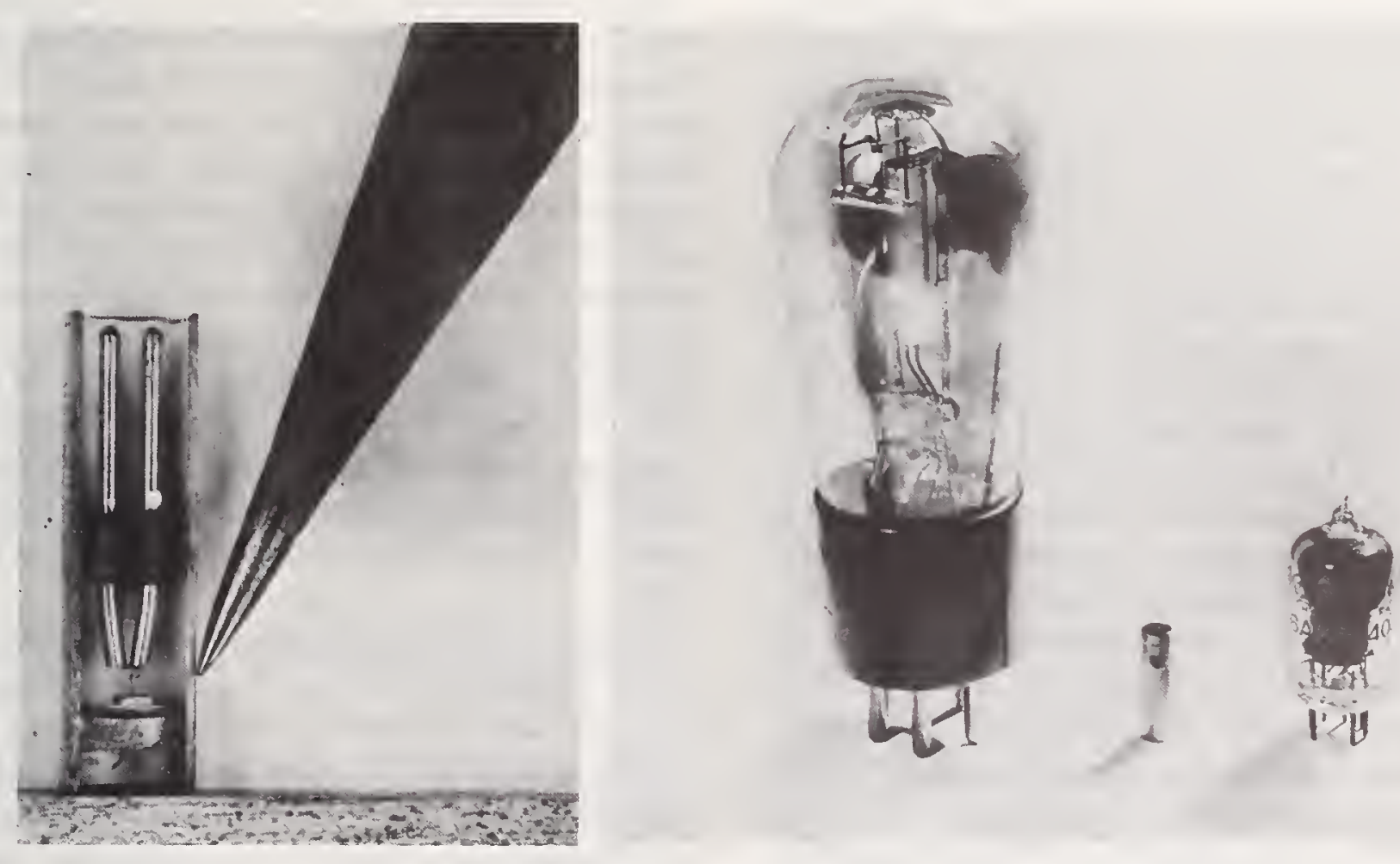

FiguRE 13. A typical exhibit at the first public announcement of the transistor comparing representative vacuum tubes with a packaged point-contact transistor.

(Comparison with the point of a pencil dramatized the smallness of the transistor in the cutaway picture. This photograph was furnished by W. G. Pfann whose group made the transistors used in the demonstration. Pfann later achieved fame by inventing zone refining and applying it to germanium - the process that achieved unprecedented chemical purity of crystals.) 
delay since no heat is developed as in a vacuum tube.

"The working parts of the device consist solely of two fine wires that run down to a pinh zad of solid semiconductive material soldered to a metal base. The substance on the metal base amplifies the current carried to it by one wire and the other wire carries away the amplified current."

The emphasis on "no warm-up delay" does accurately describe the atmosphere at the time. During the next 5 years lecturers who deinonstrated transistors found that the almost instantaneous emergence of sound from the loudspeaker after a transistor radio was first turned on usually brought a gasp from the audience who were used to waiting for warm-up times of about 1 minute before a vacuum-tube radio would go into action.

\section{The "Magic Month" and the Birth of the Point-Contact Transistor}

\section{1. "The Will to Think" and Creative- Failure Methodology}

"The will to think" is a phrase that properly describes the actions of the semiconductor research group at Bell Telephone Laboratories after a crucial new fact was observed on the 17th of November 1947. I first heard the phrase "the will to think" from Professor Enrico Fermi in 1940 when he was researching atomic energy. Several of us at Bell Telephone Laboratories were also exploring the possible military significance of nuclear fission in response to a request from the National Academy of Sciences. In the course of our research, James B. Fisk (who moved from President to Chairman of the Board of Bell Laboratories on almost exactly the date of the 25th Anniversary of the transistor) and I had invented the "lumped" moderator principle for producing chain reactions and had been calculating optimum dimensions for the periodic structures of nuclear reactors. Fermi's group was undertaking similar investigations at Columbia University. Neither group knew of the other's invention. During the conference when I first heard Fermi use "the will to think" phrase, neither he nor I mentioned the possibility of using "lumps" or uranium in a "pile."

Fermi was designing experiments to study the slowing down of neutrons in graphite. He had con- fidence that such experiments would be carried out because financial support by the U.S. Government had already been assured to the project. He said that this assurance gave him "the will to think." In these four words he distilled the essence of a very significant insight: A competent thinker will be reluctant to commit himself to the effort that tedious and exacting thinking demands - he will lack the will to think - unless he has conviction that, if by thinking he does create new and significant ideas, then these ideas will be used in worthwhile ways. This, Fermi told me, was why the assurance of financial support gave him the will to think of what would be the optimum design for his experiments.

Many years later Fermi gave me another valuable word. This time it was one related to transistors. I had discussed with him aspects of semiconductor theory related to minority carrier injection at emitter junctions. I defined quasi-Fermi levels and said that these concepts deserved a more compact label. He suggested "imref." I introduced this word into the scientific literature in the first paper on microwatt junction transistors, coauthored by M. Sparks and G. K. Teal. A footnote reported that the most appropriate authority had suggested imref. (If in doubt, spell imref backwards.)

How a significant contribution to "the will to think" had a major impact on the activities of the semiconductor research group is shown in the statistics of figure 14. The data are based on research that I undertook a few days after the transistor's 25th birthday. It shows on a month-bymonth basis the number of pages in laboratory notebooks used by Bardeen, Brattain and myself. The "magic month" of November 17 to December 17,1947 has been extended to 5 weeks so as to include the famous notebook entry of Brattain of Christmas Eve, 1947. For each of three men, a dashed line shows the number of pages used per month on the average for a preceding period of about 1 year.

The abrupt increase in activity shown in figure 14 started during the week of 17 to 24 November for Bardeen's and Brattain's notebooks. During that week Brattain used 15 pages and Bardeen used 10 pages compared respectively to 8 and 0 the week before. Compared to their long-term average weekly rates of filling pages, these l-week records were more than 4 times faster for Brattain and more than 10 times for Bardeen. Chance statistical fluctuations 
can be ruled out as the explanation for the high activity of the 17 to 24 November week simply by inspection of figure 14-the persistence of the high level for the magic month through the whole first quarter of 1948 is clear evidence that the 17 to 24 November week initiated a real jump upwards in activity. My own increased notebook activity started 3 weeks later on 8 December. In the following week, I used 5 pages - about 10 times my long-term weekly average - thus starting a pronounced upward trend that lasted many months.
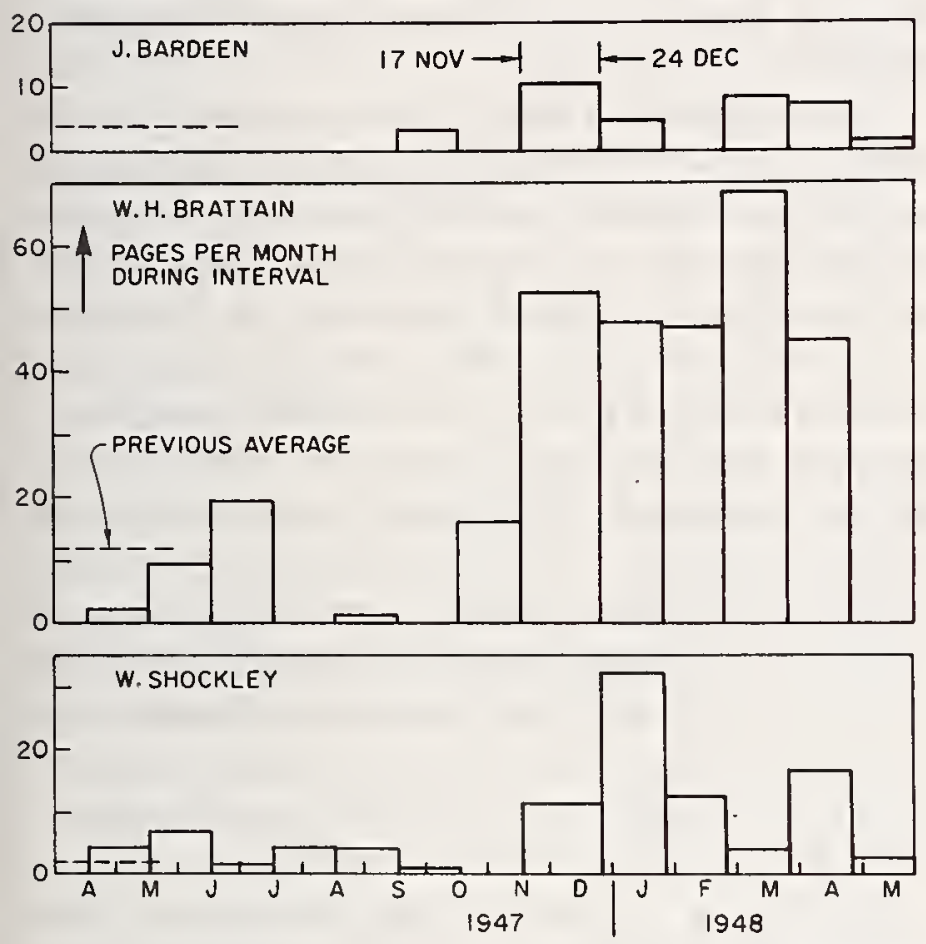

W=S I JAN 73

FIGURE 14. The influence of "the will to think," initiated on 17 November 1947, upon the rate at which notebook entries were made related to the patents of table $I$.

(Areas represent total pages and ordinates represent rates. For Brattain's notebook the period of 25 April to 25 May 1948 was not comparable to earlier dates because he shared additional new notebooks with technical assistants.)

What initiated this dramatic step-up of tempo? What stimulated the will to think of items worth entering as permanent records in our laboratory notebooks?

These questions are answered by understanding the "breakthrough observation" which occurred on Monday, November 17. This important event is recorded in the notebook entry of Walter Brattain shown in figure 23. This breakthrough observation led at once to a "breakthrough interpretation": the discovery of a way to overcome the blocking effect of the surface states that, so frustratingly, had caused our many failures to make a field-effect amplifier during the previous 2 years.

This breakthrough interpretation was based on the "new facts" resulting from "new experimental conditions" brought about by the "research on the related science (surface states)" in the language used to define the research principle of "respect for the scientific aspects of practical problems" - the chart of figure 6 . All the needed facts for the breakthrough interpretation are recorded in figure 15: p-type silicon in the circuit diagram and, in the text, the new fact that "a plus potential as shown increased the effect and the opposite potential reduced the effect to almost zero."

When it was made in November 1947, the breakthrough interpretation was a basic new insight about the science of semiconductor surfaces. Twenty-five years later, the interpretation is simple-perhaps obvious-to an electronic device engineer. Here is the background:

According to Bardeen's surface-states theory, the surface of the semiconductor might be so charged as to repel majority carriers. In the case of the p-type silicon specimen of figure 15 , a positive surface-state charge would repel holes. If photons of light fall on the semiconductor and generate hole-electron pairs, then the field just below the surface will separate them, electrons going to the surface and holes to the interior. This separation will cause surface potential to become more negative. Such effects had been observed and were being actively studied by Brattain - a key feature, in the phrasing of figure 6, of the research on the scientific aspects of the practical problem that surface states had prevented the achievement of amplification by using the field-effect.

Brattain used an intermittent flashing light that produced an AC voltage on the silicon surface. This voltage change was detected and measured by using the metal plate parallel to the silicon surface.

The observations reported in figure 15 initiated the burst of creativity evidenced by the statistical effects of figure 14. In the following text, to emphasize the tempo of "the magic month," I have prominently displayed the date including the day of the week at the beginning of many of the paragraphs. 


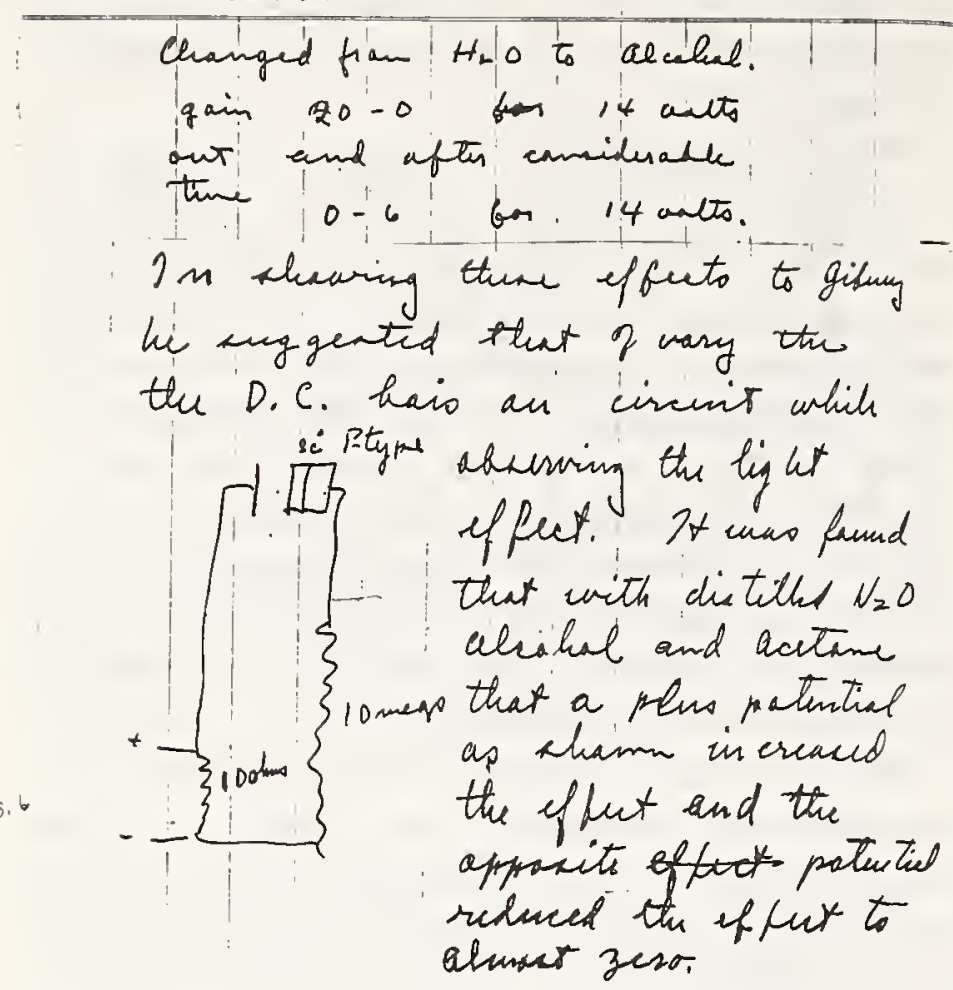

FIgURE 15. Brattain's notebook entry of 17 November 1947 that motivated the "will to think" that initiated the "magic month" culminating in the invention of the point-contact transistor on 16 December 1947.

(This figure shows the upper three-quarters of page 142 of Brattain's notebook 18194. In subsequent figures such headings are deleted and in some cases consecutive pages are joined continuously.)

\subsection{The Magic Month and the Birth of the Point-Contact Transistor}

Monday, 17 November 1947. On this date, as recorded by Brattain in figure 15, Gibney made the key suggestion that voltage be applied between the metal plate and the semiconductor while both were immersed in an electrolyte. By this means a strong electric field was generated perpendicular to the semiconductor surface. The effects observed by Brattain showed that, when the polarity of the applied field was such as to make the silicon surface more positive, there was an increase in the negative photovoltaic change produced on the surface by the light. This new phenomenon could best be explained by assuming that the internal field inside the semiconductor had been increased so as to repel the majority holes further from the surface, and, more important for the experiment, to draw photoelectrons more effectively to the surface and thus to enhance the separation of the hole-electron pairs.
This is the significance of Brattain's words "that a plus potential as shown increased the effect." Similar reasoning explains why "the opposite potential reduced the effect to almost zero."

At long last, Brattain and Gibney had overcome the blocking effect of the surface states - the practical problem that had caused our failure to succeed in making a field-effect transistor work.

The phrase "accident favors the prepared mind" - in this case minds prepared to try to make field-effect amplifiers-applies to what happened next. In the phrasing of figure 6 , the new experimental conditions and the resulting new facts motivated the will to think of ways to achieve a practical result. Within a week, the inventions of patents 1 and 2 of table 1 were conceived.

These inventions included at least one field-effect concept that was far ahead of its time. This was the inversion-layer, insulated-gate, field-effect transistor of Bardeen's patent 2 of table 1. The basic concept was clearly expressed by Bardeen, as discussed below, on 23 November 1947. However, more than 10 years had to elapse before the IGFET (insulatedgate-field-effect-transistor) became a useful device. Indeed, the useful IGFET technology was founded on earlier development of silicon junction transistor technology; for example, diffused source and drain regions, not contemplated in Bardeen's patent. These techniques needed even further refinements to produce the silicon dioxide insulating layers suitable for the MOSFET (metal-oxide-semiconductorfield-effect-transistor) of integrated circuits.

The role of the will to think provoked by the breakthrough observation of 17 November 1947 appears clearly in Bardeen's recognition of the role of the inversion layer. His concept of inversion layers had been well developed before. So had his interest in field-effect amplifiers. But the inventive combination was not conceived before the breakthrough observation. Then, only 4 days later, the inversionlayer, electrolyte combination was actually used in a device that controlled current. These observations about inversion layers and field-effect amplifiers are similar to those discussed in section 4 about injection in junction transistors. In each case all the concepts needed for the inventive combination were available to Bardeen or to me long before either he or I conceived of the new inventive combination.

The discussion presented in this section calls for a remark relevant to the influence of the "exclusive 

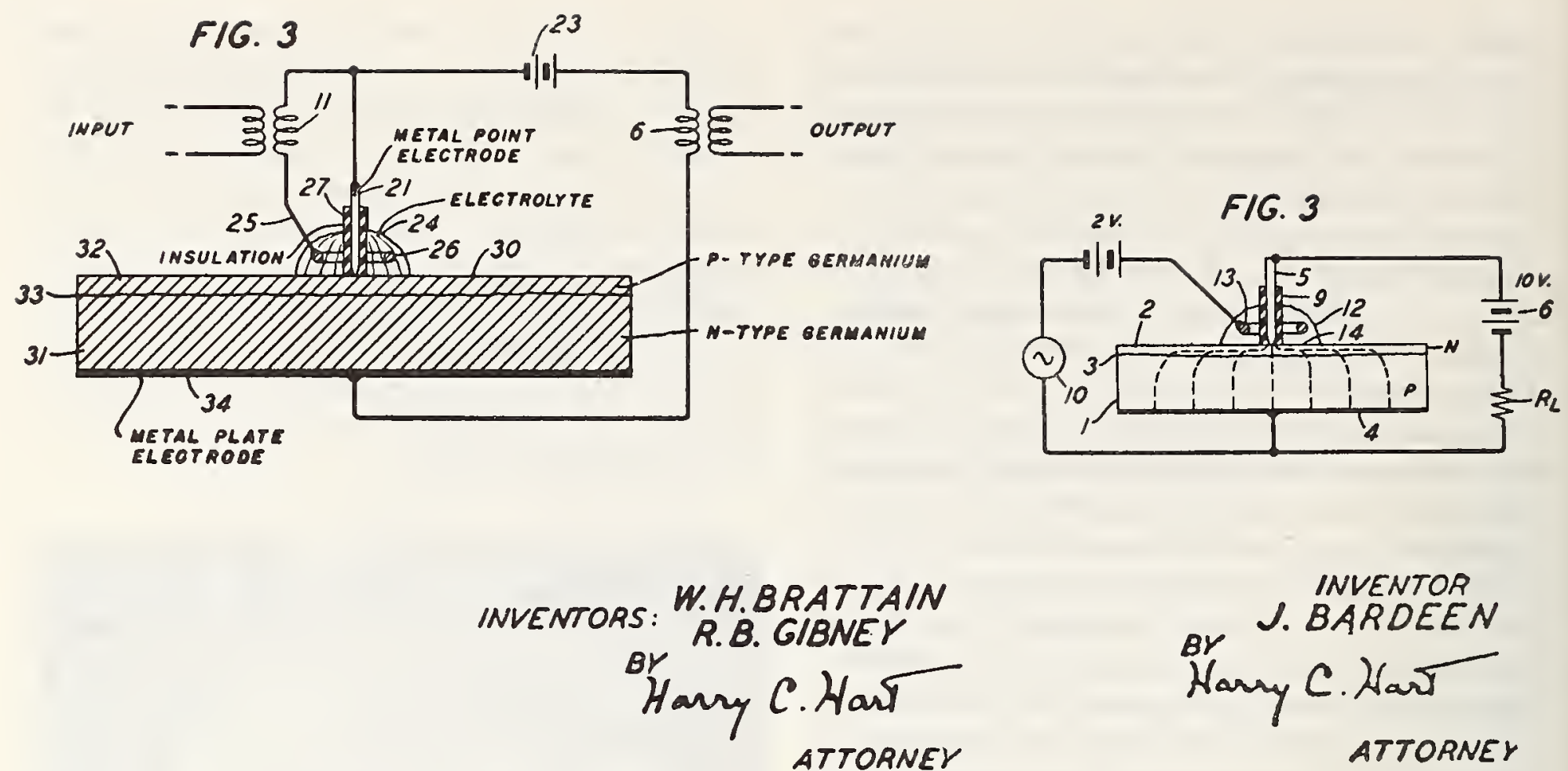

FigURE 18. Corresponding figures from the issued version of patents 1 and 2 showing the structure of the electrolytic semiconductor amplifier.

a block of p-type Si. It was suggested that this be tried because thin films so far developed did not exhibit normal rectifying characteristics."

The final paragraph of this notebook entry of Bardeen's emphasized the "will to think" relevance of the new experiments to the practical goal of an amplifier: "...these tests show definitely that it is possible to introduce an electrode or grid to control the flow of current in a semiconductor."

Sunday, 23 November 1947. The impact of the new facts stimulated Bardeen's will to think more incisively about amplifiers. Figure 19 shows his discussion of the mechanism of current flow from a point contact made to the inversion layer on the surface. Figure 20 shows how he conceived the invention of patent 2 in table 1 and figure 21 shows the same diagram as printed in the issued patent.

Monday, 24 November 1947. On this date Bardeen disclosed his invention for Walter Brattain's signature as a witness. Two days later, on the Wednesday before Thanksgiving, I also wrote "witnessed and understood" under this disclosure.

Bardeen's patent 2 of table 1 is, in the language developed 25 years later, a form of an insulated-gate, field-effect transistor with an inversion-layer chan- nel. The use of a second electrode contact to the inversion layer, like the second electrode shown in figure 3 proposed in 1940, does not appear to have been included in patent 2 . Instead the current that was controlled was considered to flow out through the inversion layer gradually leaking across the barrier into the underlying base. The basic concept of saturating drain currents, so important for field-effect transistors, was first to appear 4 years later in my field-effect paper.

Thursday, 4 December 1947. This is the date of the very informative discussion of three experiments entered in Bratiain's notebook shown in figure 22. The experiments designated I and II had both been successfully tried. One of these, experiment I, was the previously discussed concept of patent 1 . The third, marked III, anticipates the structure of the pointcontact transistor of patent 4 . The second experiment, designated II, was based on a suggestion that I had made of placing a drop of electrolyte across a p-n junction. This proposal was probably reduced to practice by G. L. Pearson within a few days of Thanksgiving, 27 November 1947.

$A$ digression on patent-writing art and the junction transistor. Experiment II, like experiment I, was a 
success as an amplifier at low frequencies - frequencies so low due to the limitations imposed by the response of the electrolyte that experiment II was a failure as a possible telephone amplifier. But Experiment II was a creative failure in several ways. One of these occurred, as discussed below, on 8 December. Another was its significant role in the preparation of the patent application for the junction transistor-indeed the electrolyte across p-n junction is figure 1 in patent 5 of table 1 . The dates that $I$ have given for conception and for reduction to practice for patent 5 are not in November 1947 as would be in keeping with Brattain's report that Pearson had been successful before 4 December 1947.

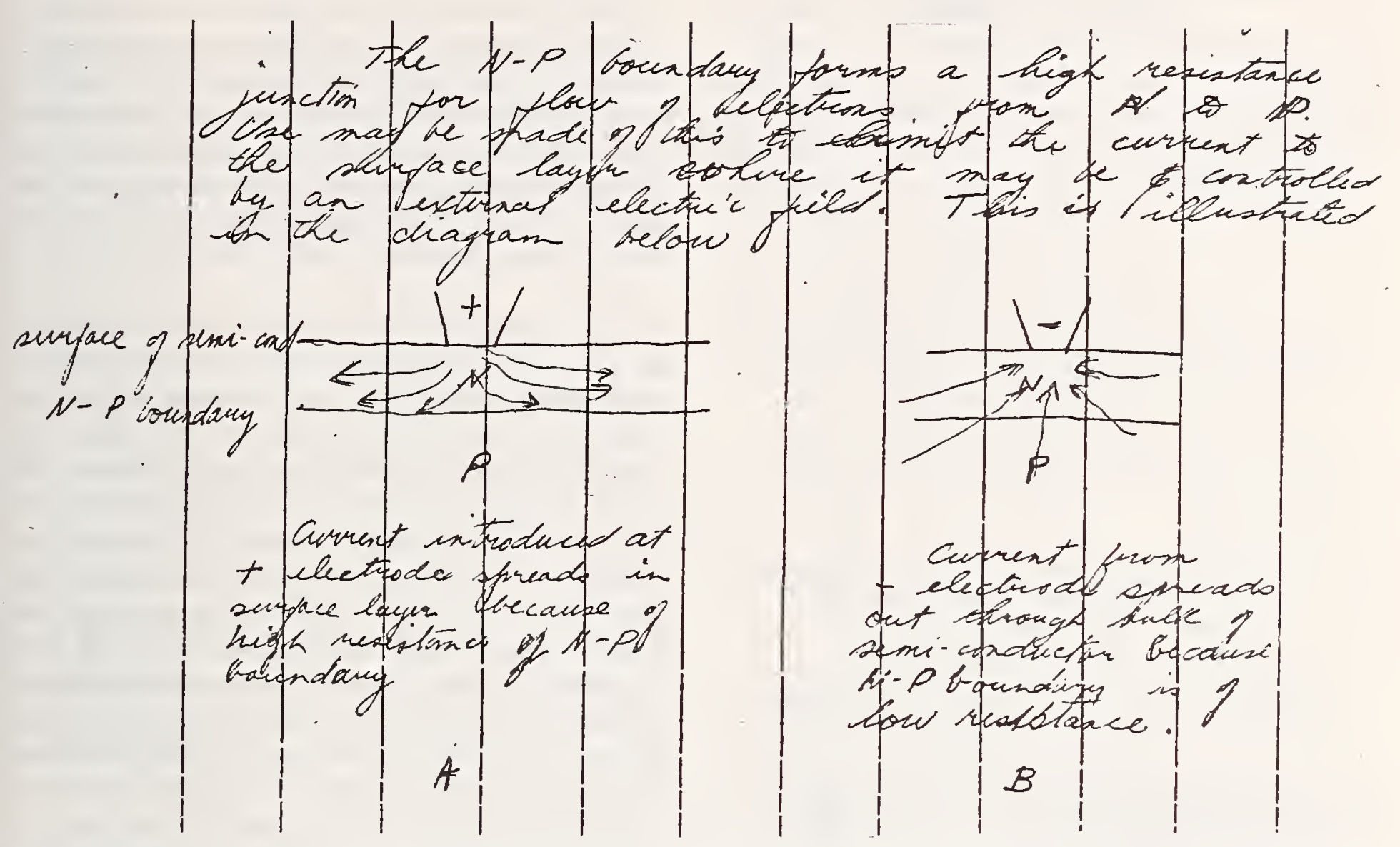

FIGURE 19. Bardeen's notebook entry of Sunday, 23 November 1947 on the theory of current flow from a point-contact through an inversion layer on a semiconductor circuit.

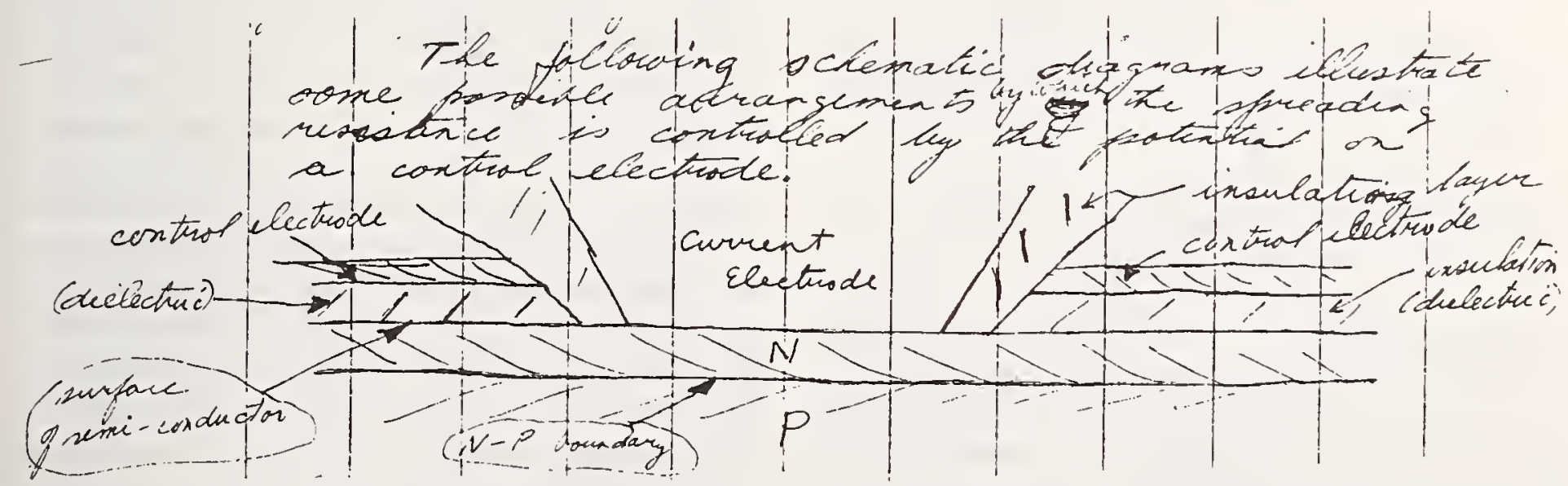

FIGURE 20. Bardeen's, conception of patent 2 in table I that anticipates an insulated-gate field-effect transistor with an inversion layer channel. 


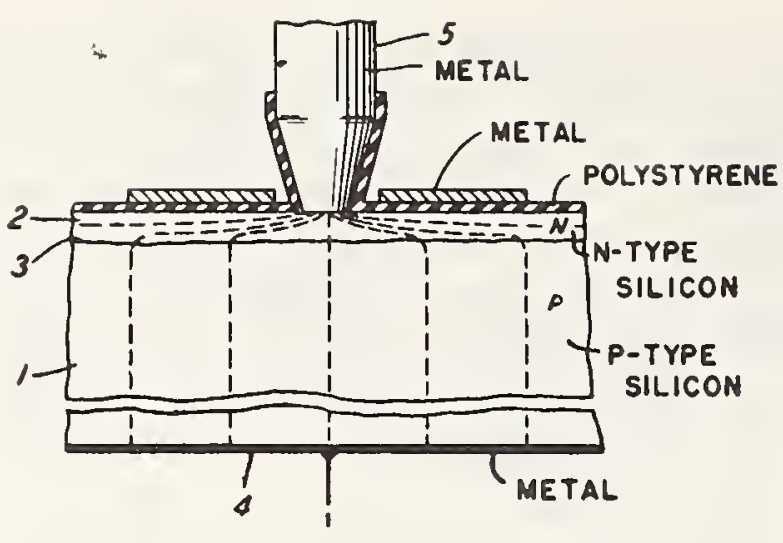

FIGURE 21. The version of Bardeen's conception of the insulatedgate inversion layer channel structure as it appears in the issued form of patent 2 of tab. $I$.

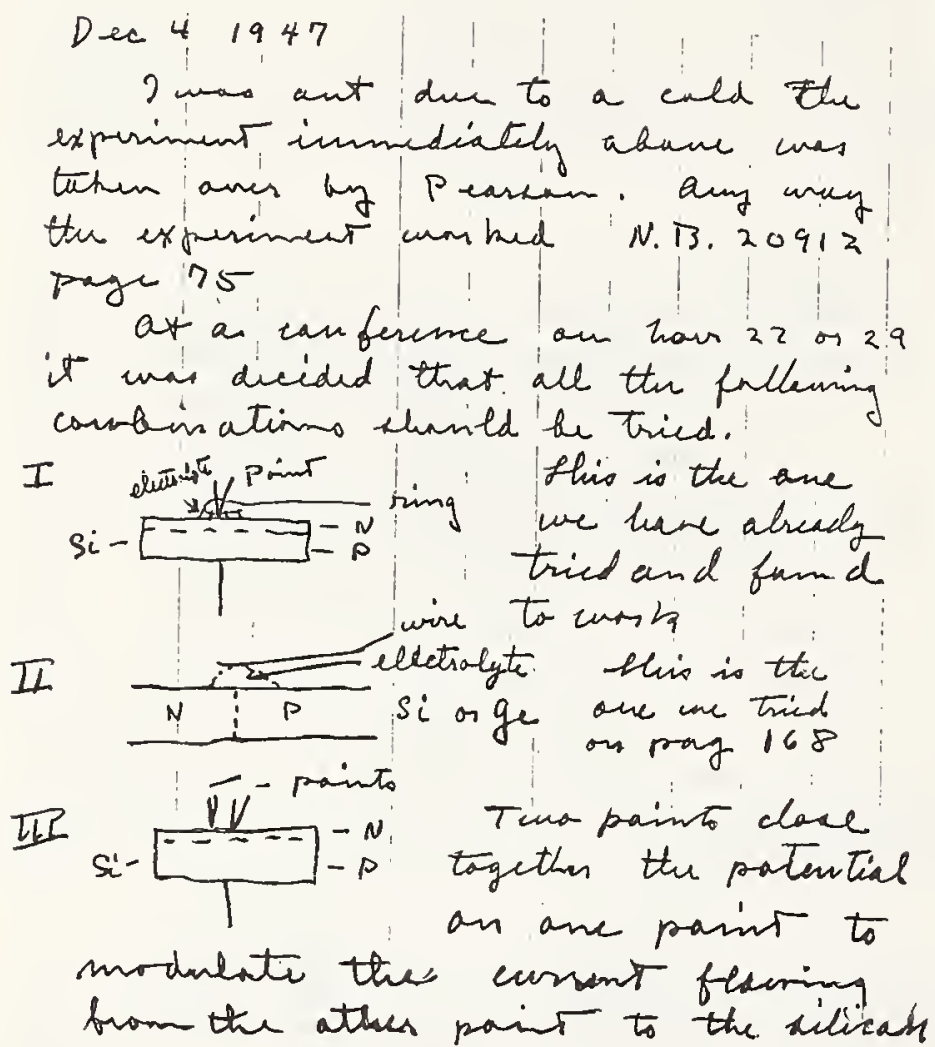

FIGURE 22. Three key experiments recorded in Brattain's note. book on 4 December 1947.

Patent 5 teaches in detail how to make "electrolyte on p-n junction" amplifiers. Furthermore, some of the allowed claims in patent 5 , the junction transistor patent, read directly on experiment II. The suggested electrotyte, glycol-borate, was then a readily available laboratory commodity, being used in standard electrolytic capacitors. (The customary glycol-borate extraction method required a hammer, a nail, and a vise.) Claim 29 of patent 5, which I shall analyze as an example of the art of patent writing, is a typical example of several similar claims in the junction transistor patent that read on the structure of the device employing glycol-borate across a p-n junction (a structure that the patent specification does indeed clearly teach how to construct):

"29. An electrical translating device comprising a body of semiconductive material having two zones of unlike conductivity type separated by a barrier, means of establishing current flow between said two zones, and means separate from said first means for controlling the impedance to such current flow introduced by said barrier." (Emphasis added here for purposes of exposition.)

I do not recall now that I was impressed then, when the patent was filed, by the ingenuity of this claim. It was only in the course of the research reported in this article that I really appreciated the quality of patent-writing art displayed by Rudi Guenther who was the attorney. Claim 29 reads directly on the structure of experiment II, figure 22 ; and yet, this claim is so constructed that it reads equally well upon a three-layer sandwich-type transistor such as the one in figure 12 that I am shown explaining on a blackboard. For the case of the electrolyte across the p-n junction, the "means separate from said first means" of Claim 29 obviously signifies effects produced by voltage applied to the electrode in the drop of electrolyte. But the identical phrase does indeed apply equally well to the case of the three-layer structure of the true junction transistor. For this the three-layer structure the "barrier" is the collector junction and the "means separate from said first means" signifies injection across the emitter junction followed by diffusion through the base layer. Guenther had structured the patent application, including Claim 29, so that the specification clearly taught how to practice the electrolyte embodiment on which Claim 29 read. But at the same time Guenther had kept Claim 29 broad enough to cover the concept of the true junction transistor, which, while described in detail in patent 5 , we did not then know how to make. As a matter of fact, however, those "skilled in the art" - or did they subsequently become skilled? - did successfully make them about 2 years later at approximately the same date that patent 5 was issued. 
In table 1, I have put a date of 23 January 1947 for the conception of the junction transistor and April 1950 for the reduction to practice. Both dates apply to a proper three-layer, junction-transistor structure. If the drop of electrolyte were accepted as a form of junction transistor, then both the "conception" and the "reduction to practice" dates would fall in November 1947. Actually, none of the electrolyte devices of table 1 turned out to have any practical value. In April 1949, another possible date for "reduction to practice," a germanium transistor was made with a geometry like the original point-contact transistor of figure 9, but with the gold contacts replaced by p-type stripes making p-n junction connections with the n-type base. (The method of fabrication is discussed with figs. 38 and 49.) Power gains as high as 16 were obtained. However, a good 3-layer structure was not achieved until about 1 year later. Thus the dates shown in table 1 for patent 5 are the realistic ones for a true junction transistor.

This discussion of the "electrolyte on p-n junction" devices described in Brattain's note of 8 December 1947 has carried the discussion far ahead. I shall now return to the "magic month."

Monday, 8 December 1947. On this date several significant stepping stones were laid on the path to the point-contact transistor. As shown in figure 23 from Walter Brattain's notebook, observation of significant voltage and power gains were reported over the signatures of Bardeen and Brattain. The amplify. ing device which they used consisted of the drop of electrolyte and point-contact structure of patent 1 .

$$
\begin{aligned}
& \text { this a waltage amplifaction of } 2 \\
& \text { and a paines angolifuetion ( } 3.3 \times 10^{-5} \text { wates } \\
& \text { out } 4 \times 10^{-7} \text { matto in) } 330 \\
& \text { evaltu 15. Brattain } \\
& \text { hate the ahrre ruing g.Bardein or experiment } \\
& \text { was started ai riesnex } 77 \text { a lumchem } \\
& \text { diacensiain cintt slinchlin and Pardeen } \\
& \text { and the final lengyoution by } \\
& \text { exphriment was pus formed an }
\end{aligned}
$$

F1GURE 23. The achievement of voltage gain on 8 December 1947 by Bardeen and Brattain using high back-voltage n-type germanium.
However, a key new feature was the material used-high back-voltage, n-type germanium-later a central feature in achieving the voltage gain of the point-contact transistor. As figure 23 shows, Brattain reported that the key suggestion was made by Bardeen while the three of us had a luncheon discussion. The circumstance of this discussion presents an important illustration of the mixture of cooperation and competition that characterized the interactions within the semiconductor group.

Monday, 8 December 1947. Background for the subject of discussion at the luncheon is given by the last of several of my own notebook entries for the same date-the date that initiated my own steppedup tempo of notebook pages per month. These entries commence with the disclosure in figure 24 of the junction, field-effect amplifying principle that thus authenticates the 1947 date on table 2. The topic connected with the lunch conference of 8 December appears somewhat lower on the same

DATE

CASE Na

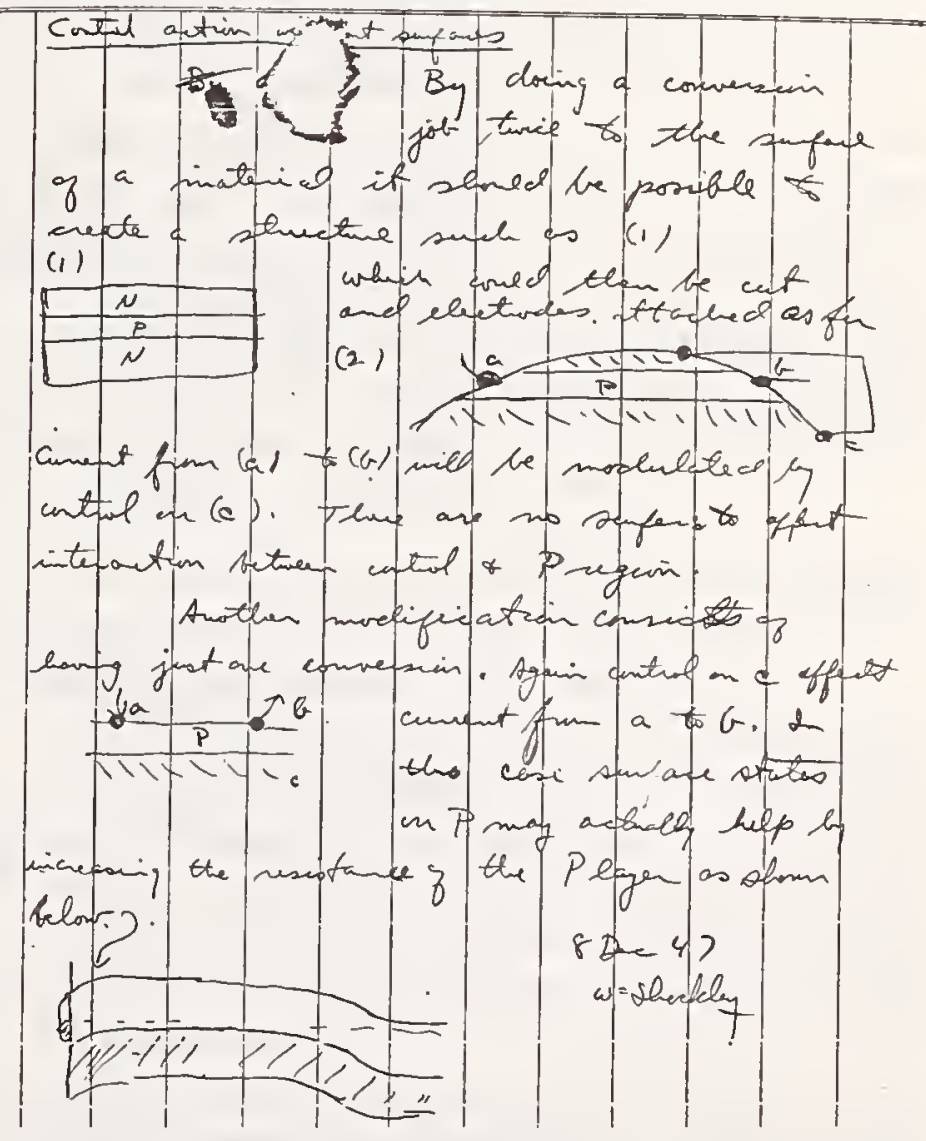

FIGURE 24. The disclosure of a junction, field-effect transistor structure by Shockley on 8 December 1947. 
page and is reproduced on figures 25 and 26 . What this disclosure proposes is that a wide $\mathbf{p}-\mathrm{n}$ junction operated at high reverse bias might be used to obtain voltage gain. Placing drops of electrolyte at localized intermediate points on the junction might control reverse current using relatively small voltages applied to the electrolyte and thus produce large voltage changes across the p-n junction.

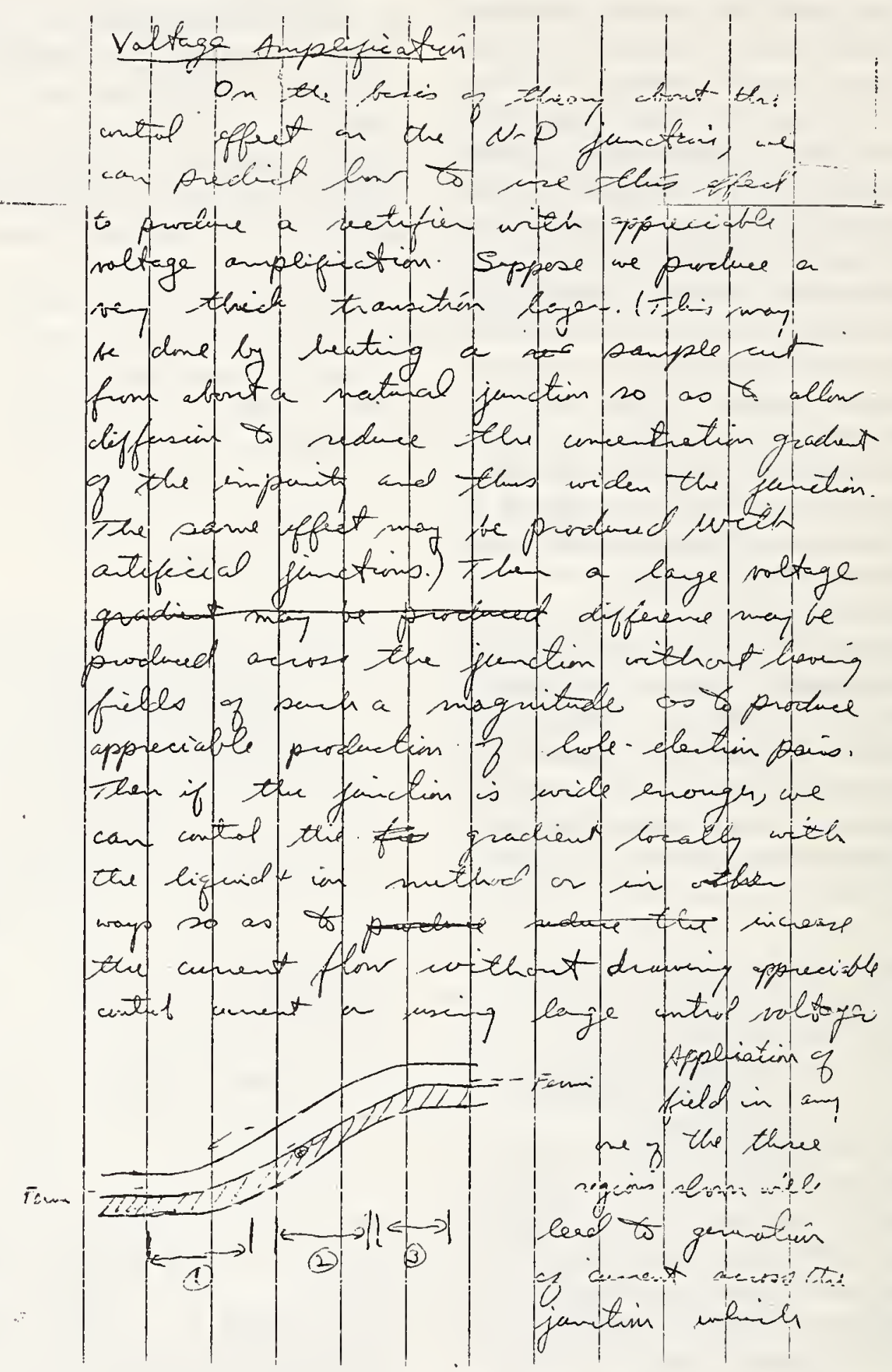

Figure 25. The proposal of using a wide $\mathrm{p}-\mathrm{n}$ junction with electrolyte to obtain voltage gain from Shockley's notebook on 8 December 1947. 


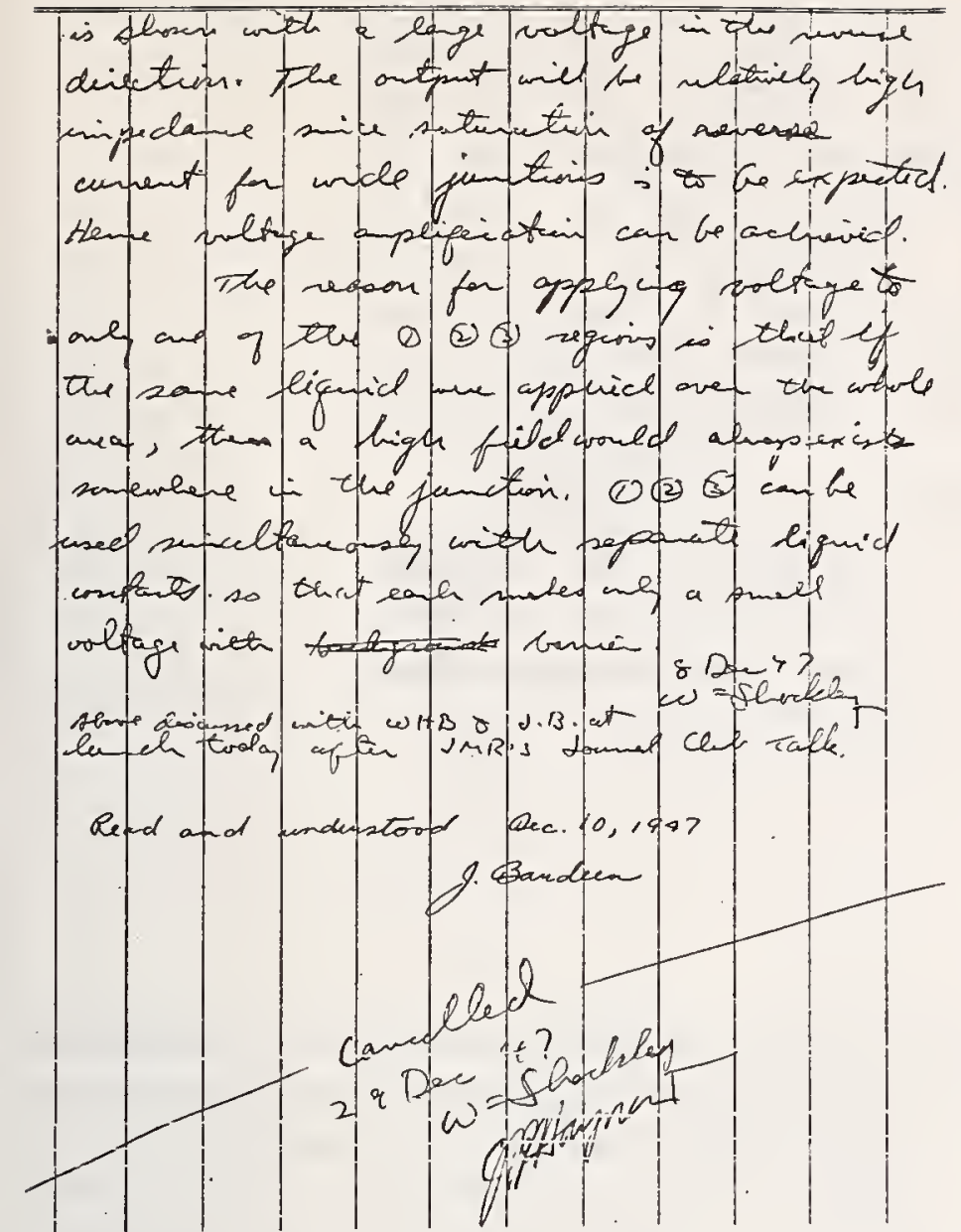

FIGURE 26. A continuation from figure 25 of the disclosure of 8 December 1947.

Typical examples of creative-failure methodology are illustrated by the circumstances related to the suggestion of figures 25 and 26 . The idea was unquestionably half-baked. Almost certainly the device employing "electrolyte on the p-n junction" operated in ways that we probably did not conceive of and would not have been effective in the arrangement that I discussed with Bardeen, as recorded in figure 26. The actual working mechanism of experiment II (described in Brattain's notebook on 4 December shown in figure 22) was probably the formation of surface-channels near the junction. These would then increase the reverse current. However, this half-baked, reverse-biased junction idea of 8 December did (as Brattain's reference to Bardeen's suggestion on fig. 23 indicates) serve as a stepping stone in Bardeen's thinking and led him to consider the advantages of using a rectifying contact at high reverse bias and thus to suggest trying high backvoltage germanium. The suggestion paid off. Later the same day, he and Brattain obtained voltage gains with the patent 1 or 2 form of device with which they were experimenting as Brattain reported in the 8 December 1947 entry of figure 23.

This voltage gain was an important step forward on the path to the point-contact transistor. They arrived there 8 days later.

Tuesday to Friday, 9 to 12 December 1947. During the remainder of the week, a series of experiments was tried. Exactly 9 years later in Stockholm - Nobel prizes are awarded on December tenth-John Bardeen discussed these experiments in the first of his two Nobel Lectures. In "Le Prix Nobel" he published the lecture as "Semiconductor Research Leading to the Point Contact Transistor" and wrote as follows:

"It was next decided to try a similar arrangement with a block of n-type germanium. Although we had no prior knowledge of a p-type inversion layer on the surface, the experiments showed definitely that a large part of the reverse current consisted of holes flowing in an inversion layer near the surface. A positive change in voltage on the probe [the ring in the electrolyte of figure 17 and 18] decreased the reverse current. Considerable voltage as well as current and power amplification was observed.

"Because of the long time constants of the electrolyte used, amplification was obtained only at very low frequencies. We next tried to replace the electrolyte by a metal control electrode insulated from the surface by either a thin oxide layer or by a rectifying contact. A surface was prepared by Gibney by anodizing the surface and then evaporating several gold spots on it. Although none made the desired high resistance contact to the block, we decided to see what effects would be obtained...."

The culmination of these efforts, as described in Brattain's notebook, was achieved in the first 2 days of the week starting on 15 December 1947.

Monday, 15 December 1947. On this day Brattain recorded experiments in which the electrolyte had been replaced by evaporated gold. The gold was divided into two areas, spots $A$ and $B$. Figure 27 shows the last nine lines of Brattain's notebook entries for 15 December 1947 appearing on the bottom of page 191 to the top of 192.

The polarity of the effects with a gold spot are consistent with hole injection: a plus voltage on spot $\mathrm{B}$ would inject holes into the n-type germanium that were then collected to increase the positive current 


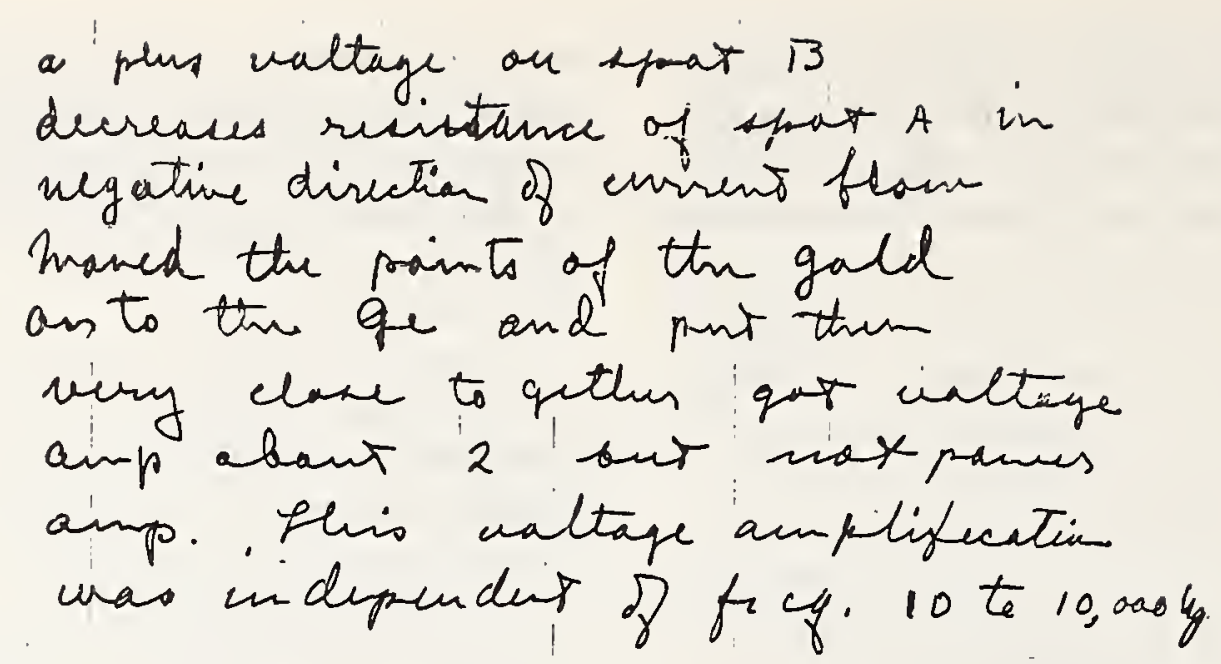

FiguRE 27. Brattain's notebook entry of 15 December 1947 describing an experiment involving a concept of the point-contact transistor.

flowing out of $\mathrm{A}$, the directions corresponding to a "negative direction of current flow."

But the crucial circumstance that occurred on 15 December was to move the two point contacts from the gold spots to the germanium - an advance in research technique specified by the two prepositions "off" and "on to." As one more example of the human fallibilities that characterized the creation of the transistor - a trivial example compared to some of my conjectures about making transistors by evaporation-note that on figure 27 the key feature of leaving the gold spots and working on the germanium-the act described by the preposition "off" - indeed, the first feature of the breakway that would create the point contact-transistor within 32 hours - was spelled "of": "of the gold and on to the germanium."

But no matter how it is spelled, the experiment worked. Brattain reported voltage gains with both points on the germanium. This experiment appears to be the first clear conception of the point-contact transistor and accounts for the date of 15 December 1947 for patent 4 in table 1.

Tuesday, 16 December 1947. As Brattain's notebook entries show, this was the date at which the point-contact transistor was reduced to practice in the form shown in figure 7. Figure 28 describes the structure constructed under Brattain's direction by his assistant, E. G. Dreher. In figure 29 Brattain reports both a voltage gain of 15 and a power gain of
1.3. On the next page (not shown here in a figure) he reports probably the first example of current gain for a point-contact transistor-a voltage gain of 4 associated with a greater power gain of 4.5 thus implying a current gain of more than $1.1-$ a feature that in due course led to the later filing date discussed in table 1.

Clearly, the transistor had been born. But had it been "invented?" This is a question of patent law.

Tuesday, 23 December 1947, was the date of the private demonstration for executives that is described in Brattain's famous notebook entry of Christmas Eve, 1947, figure 8. Although this date of 23 December 1947 has been publicly accepted in some instances as the date for the birth of the transistor, as discussed above, my research on laboratory notebooks documents that 16 December is the first date when a point-contact transistor did amplify. The period of 29 days from the breakthrough observation of 17 November to the point-contact amplification of 16 December thus includes so many creative contributions and starts and finishes with such significant events as to deserve the title "the magic month."

There is an element of obvious, and entertaining, naivete about accepting the day before Christmas Eve of 1947 as the date of the birth of the transistor. The demonstration of 23 December was attended by Harvey Fletcher, the Director of Physical Research, to whom I reported, and Ralph Bown, the Director of 


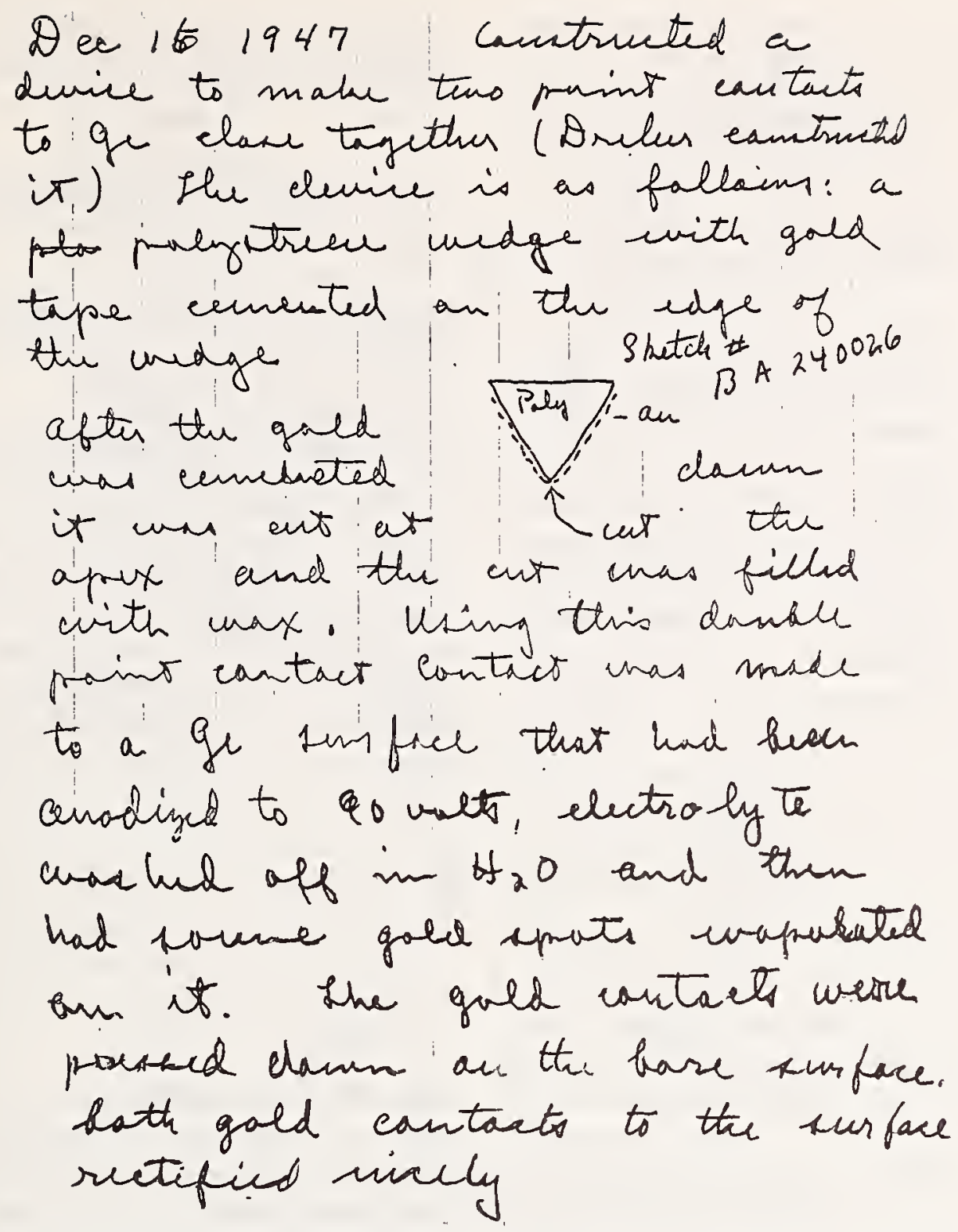

FiguRE 28. Brattain's notebook entry for 16 December 1947 describing the construction of the "wedge" arrangement for bringing two point-contacts close together in a point-contact transistor.

Research, to whom Harvey Fletcher reported. To believe that such a demonstration occurred on the first day that a transistor had worked - the schedules of these executives - the reliability of the demonstration equipment-a decision by the research scientists that they were sure-what better definition of naivete? But this is an example of creativefailure methodology in public relations. The 24 December 1947 notebook entry is dramatic; hearing speech amplified by the transistor was in the tradition of Alexander Graham Bell's famous "Mr. Watson, come here, I want you!" (Unfortunately, there is no record that these words were transmitted through a transistor during the 23 December 1947 demonstration.) Thus the failure to date correctly the birth of the transistor led to a warm Christmas Eve atmosphere for the first coming of age of a transistor that achieved the goal of aiding people, when separated, to communicate more easily than ever before with each other.

There is no record that Brattain's and Bardeen's experiments of 16-22 December were formally witnessed by others - an important factor of "reduction to practice." The 24 December notebook entry was witnessed by others who confirmed the recorded facts about the 23 December demonstration. Thus the date of 23 December does appear on the records of the Patent Department as the date of "reduction 


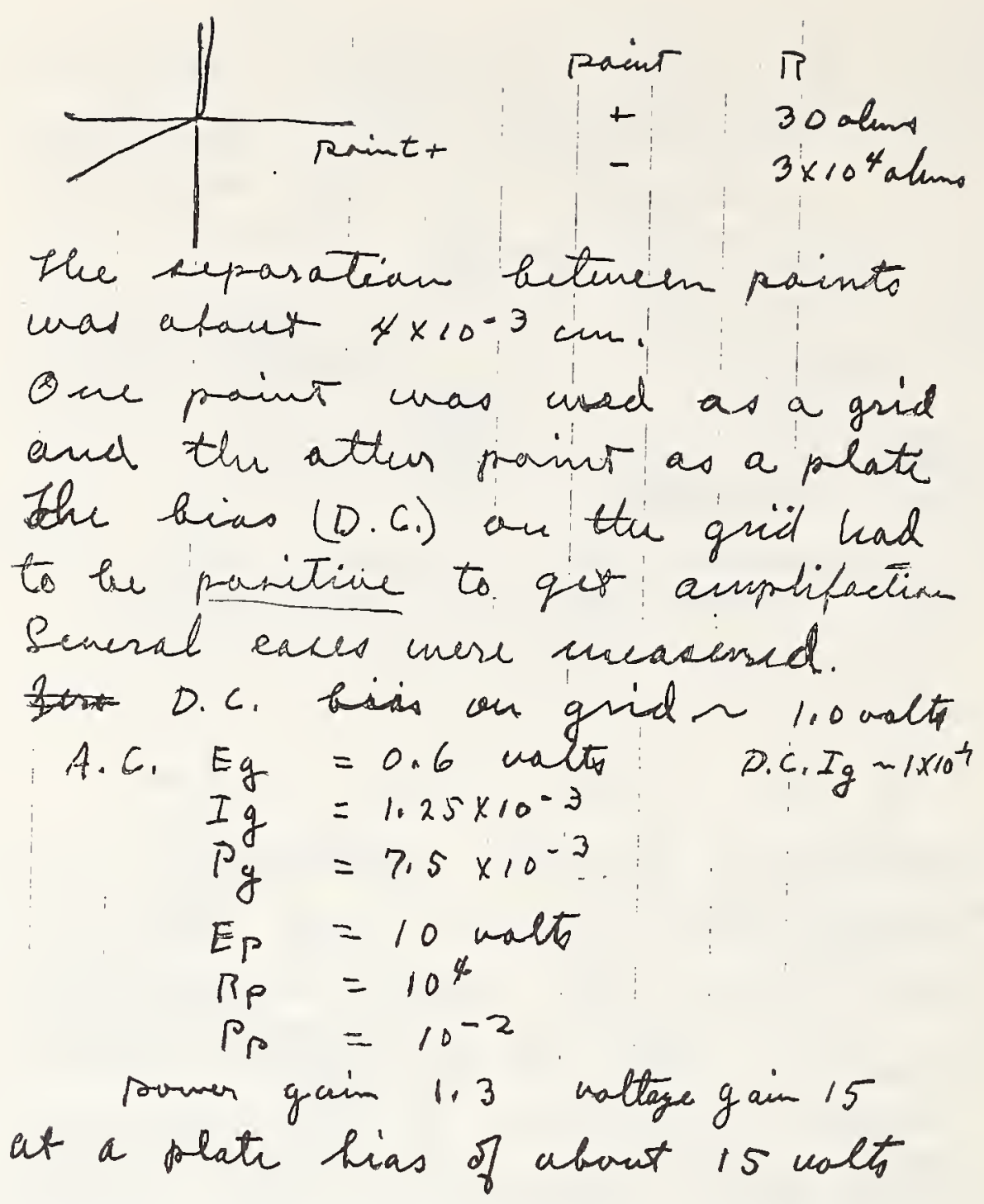

FIGURE 29. A continuation of the 16 December 1947 notebook entry reporting the first record of power gain with a point-contact transistor.

to practice." A test of reduction to practice in patent law is whether a businessman would be prepared to invest in development. There was, of course, no doubt about this at the Laboratories - or was there on 23 December?

I have a clear recollection that Harvey Fletcher did raise a significant question to this effect:

"How do you know you really have amplification in the telephone conversation demonstration? It may be simply matching of impedances? Making an oscillator would be a valuable confirmation."

Actually the input and output voltage measurements had already clearly shown true power gain. But it is noteworthy that Brattain's 24. December notebook entry continues after the report of the 23 December demonstration to record that an oscillator was constructed on 24. December and did, indeed, oscillate.
The identification of the exact date of the "invention" of the transistor is a legal matter. If "conception" is taken as the definition of "invention," then 15 December is a date confirmed both by my notebook research and by the Patent Department's records. First observation of amplification was 1 day later. "Reduction to practice" in a legally sound form was 23 December. In any event, it was a wonderful start for a 4-day Christmas weekend.

The Patent 3 Story. Patent 3 was conceived and reduced to practice in connection with the point-contact transistor. The surface treatments devised by Gibney played an essential role in making point-contact transistors at that time. I recall a most trying week somewhere in late December or early January when for some reason the treatments failed and no transistors worked. As discussed earlier in connection with figure 9, Gibney's patent dealt with the electrolytic processes used for preparing the surface 
and for cleaning-off the oxide products while preparing an inversion layer for use with contacts as shown in figure 9.

\section{The Invention and Realization of the Junction Transistor}

\subsection{Pre-Invention Explorations That Missed the Key Concept of Minority-Carrier Injection}

The completion of the invention of the junction transistor was accomplished with conception of an emitter junction to inject minority carriers into a sufficiently thin base layer. These injected carriers would then diffuse to the collector junction. Satisfactory collection efficiency and voltage gain would then result from reverse-bias on the collector junction-a concept already proposed as discussed in connection with figures 25 and 26 . All of these ideas had been considered in work that I had done before the point-contact transistor amplified - with one exception - the recognition of the importance of injection. It took exactly one calendar month after the demonstration of the point-contact transistor on 23 December 1947 before the missing piece was inserted to complete the concept of the junction transistor.

An aside is appropriate here. Frankly, Bardeen and Brattain's point-contact transistor provoked conflicting emotions in me. My elation with the group's success was balanced by not being one of the inventors. For the next 5 years, I did my best to try to put the Labs-and myself-in the lead for transistor patents. (Most of my 90-odd issued U.S. patents relate to the transistor.) Such efforts account for much of my "will to think" peak of notebook pages for the month ending on 25 January 1948 as shown in figure 14. One example is worth discussing as an illustration of how easy it was to miss the concept of injection while trying to invent transistors based on $\mathrm{p}-\mathrm{n}$ junctions.

31 December 1947. On New Year's Eve I was alone in Chicago between two meetings that came so close together that a return to New Jersey seemed impractical. I used this opportunity for uninterrupted efforts to invent new semiconductor amplifying principles. In 2 days I wrote enough to fill a bit more than 19 notebook pages. My notebook was at the Laboratories and I used a pad of paper and mailed the dis. closures back to my co-supervisor, S. O. Morgan, who witnessed them and asked Bardeen to do the same. Later these pages were rubber-cemented into my notebook where they remained available for study while writing this article.

The pages from which figures 30 and 31 were reproduced were three of the five which were written on New Year's Eve. The other 14 were written on New Year's Day.

The structure shown in figure 30 has two p-type regions separated by a strip of n-type formed by heating a thin film of germanium lying upon a plane formed by two ceramic insulators separated by a thin layer of antimony-bearing alloy. The antimony diffuses into the germanium converting a strip into n-type. I shall not consider the naivete of the fabrication scheme. I shall instead focus on a blind spot in the amplification concept. These notebook entries reveal that I missed an obvious opportunity to recognize the possibility of minority carrier injection into a base layer and did so even while considering a device containing a base layer and while drawing energy-band diagrams almost indistinguishable from those for true junction transistors.

Figure 30 shows the structure of the device and also contains an energy band diagram representing the variation along a line extending from the p-type emitter through the n-type base to the p-type collector. It looks precisely like the diagram for a true junction transistor. But that wasn't the idea at all.

How the amplification concept of this disclosure differed from that of a true junction transistor is represented in the lower diagram of figure 31 . The antimony was supposed to convert the germanium to strong $\mathrm{n}$-type near the antimony-bearing, metalcontact B, while barely converting it at all near the surface. Thus the barrier for hole flow was low near the surface and high near $B$, as indicated in the diagram. By applying negative voltage to $\mathrm{B}$, the barrier could be made so low that holes could easily flow over it to reach the reverse-biased collector. The disclosure also suggests using the structure as a junction, field-effect transistor with a superficial p-type layer channel lying over the n-type stripe gate.

What is conspicuously lacking is any suggestion of the possibility that holes might be injected into the n-type material of the stripe itself, thereby becoming minority carriers in the presence of electrons. Why this idea did not occur to me then or even much earlier is baffling. Eight months before in the same notebook I had written an analysis of thermal 


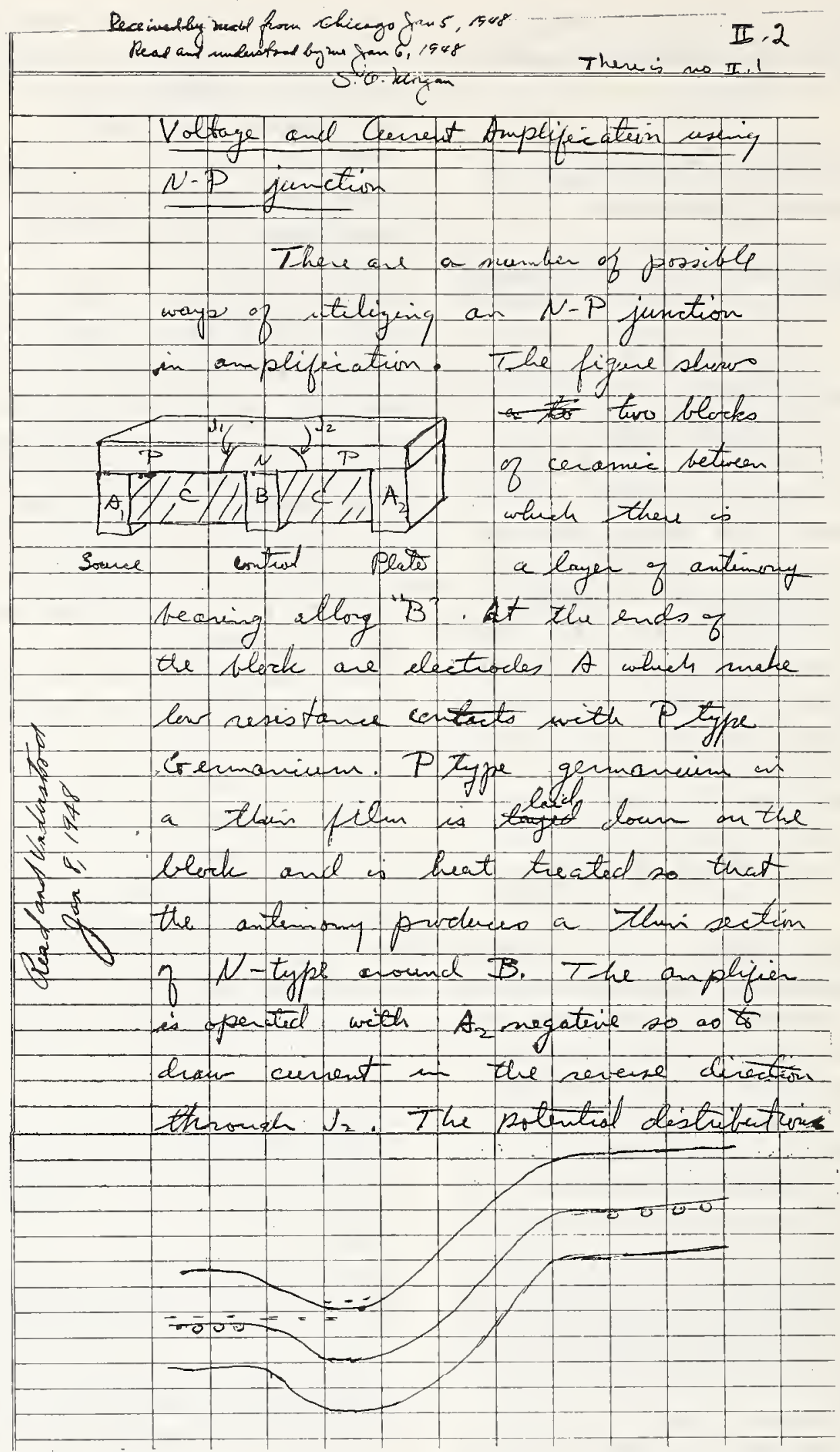

FigURE 30. How a disclosure of 31 December 1947 in Shockley's notebook should have, in spite of its practical shortcomings, suggested that minority carrier injection would be important in making transistors. 


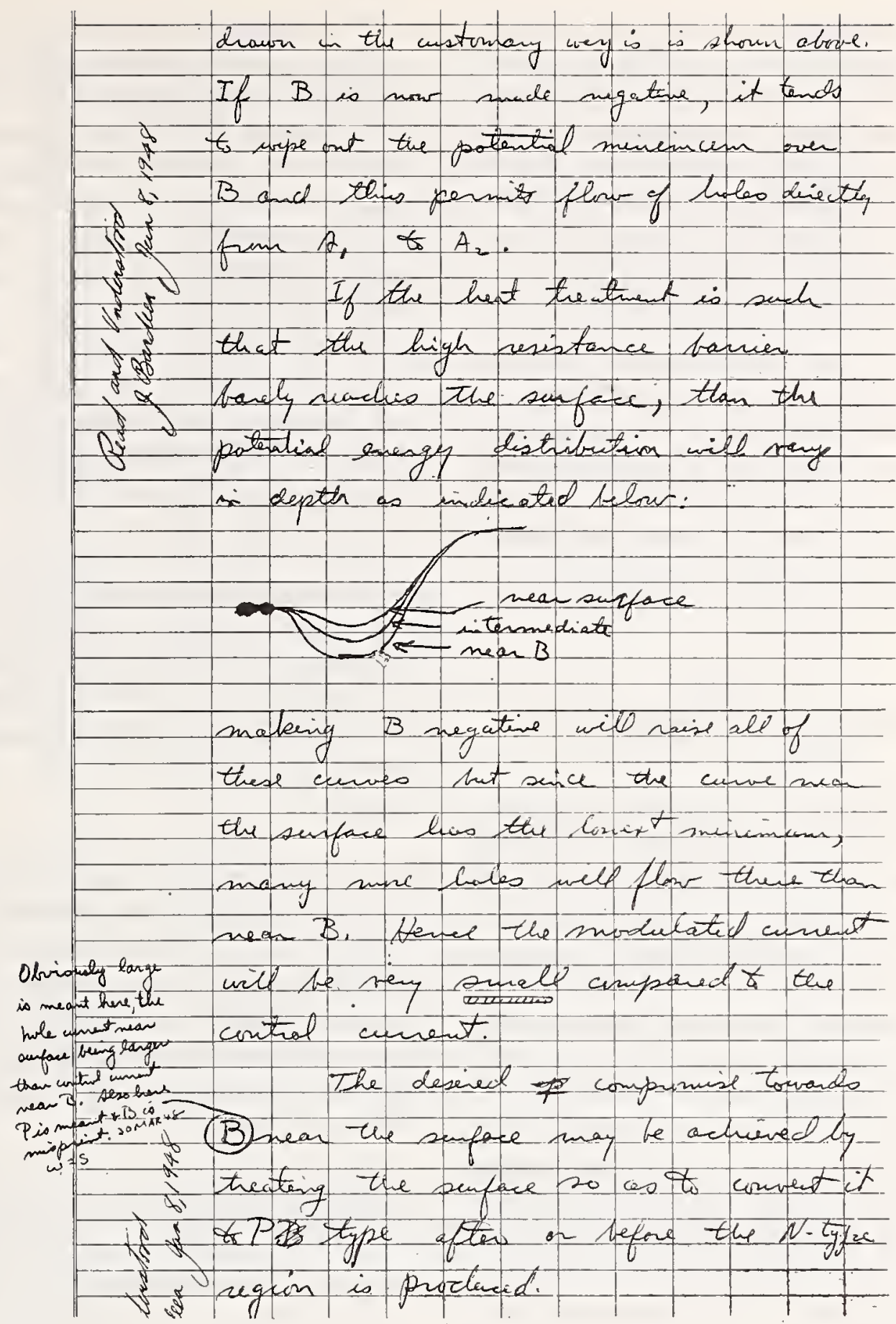

FIGURE 31. A description of the proposed mechanism of operation of Shockley's 31 December 1947 conception showing how it missed out on minority carrier injection from the emitter.

generation of minority holes in n-type material and how their contribution to the saturation reverse current of a p-n junction depended on their diffusion length. I then had the bum-hunch that the activation energy for reverse current would measure the energy gap. But in any event, in April 1947, I had in hand all the necessary mathematical machinery needed to derive the p-n junction current-voltage formula that would have included injection from a forward biased emitter junction but had simply done nothing about it.

There had been at least two other opportunities in 1947 for me to think of injection. In April, I had proposed a lightning arrestor composed of a sequence of very thin $p$-type and n-type layers in series. In a high electric field, the shallow potential 
hills would be flattened out so that carriers of either sign could go straight through: i.e., a form of electric breakdown would occur. In September, I had proposed a high speed thermistor that also involved minority carriers passing over the potential energy maximum for them in a layer of the opposite conductivity type. But for none of these ideas had the concept of injection of significant densities of minority carriers been singled out as potentially useful.

The completion of the basic junction transistor concept came about as an accident-one for which I had a prepared mind. It had features of respect for the scientific aspect of the practical question of how exactly the point-contact transistor works and also of creative-failure in the sense that what came out of the effort was not really what I had been looking for at the time. It all happened 23 January 1948.

\subsection{The 23 January 1948 Disclosure}

23 January 1948 was the day when I made notebook entries that disclused the basic conception of the junction transistor including several closely related inventions. I was not trying, as I was on New Year's Eve, to invent an amplifier. Instead I was trying to devise experiments to determine whether or not an inversion layer really played an important role in the point-contact transistor. I had speculated about placing an n-type contact on top of the assumed p-type inversion layer. I thought that this contact might adjust to the electrons of the underlying n-type body rather than to the potential of the holes in the inversion layer. This led me to think of a structure having three layers of semiconductor of alternating conductivity type. I had considered such structures before but not in terms of a three-terminal amplifying device. As soon as I became really familiar with the three-layer concept and the possibility of current flow between the two outer layers by minority carriers diffusing through the middle layer, my reservoir of orderly logical patterns, as represented on figure 1 , came into play and I had the payoff-hunch: I recognized that one of the p-n junctions could be reversed biased, as for my concept of 8 December 1947 of voltage gain, and that the minority carriers could control the reverse current. I recognized the structure for a $p$-n junction semiconductor amplifier-later to be called the junction transistor.
The resulting disclosure, written on a pad at home and later rubber-cemented in my notebook, is shown in part on figures 32 to 36 . Their content is discussed in the captions. They were witnessed 4 days later on January 27 by J. R. Haynes. Figure 37 shows the four corresponding figures from patent 5 including the electrolyte-junction structure, the "near miss" of figure 30 , the structure of the original disclosure of figure 32 , and finally a more orderly, three-layersandwich, junction-transistor structure. I have quoted above Claim 29 of patent 5 and discussed how it was so contrived as to read all the examples of figure 37 . In contrast, Claim 1 reads simply and directly on the sandwich structure:

"1. A solid conductive device for controlling electrical energy that comprises a body of semiconductive material having two zones of one conductivity type separated by a zone of the opposite conductivity type, said two zones being contiguous with opposite faces of said zone of opposite conductivity type, and means for making electrical connection to each zone"

Claim 1 is a straightforward definition of the junction transistor. A satisfactory reduction to practice of the Claim 1 structure was not achieved until the middle of 1950. I wonder how Claim 29 would have stood up in a patent suit if the teaching to achieve Claim 1 had been challenged. Actually by the time patent 5 had issued, techniques for fabricating Claim 1 structures were well along.

I have referred above to my conjecture that the junction transistor would probably have been invented later in 1948 by someone else at Bell Laboratories if I had not already disclosed it in January. The key item in my reasoning is an observation made and recorded in his notebook on 13 February 1948 by John N. Shive and subsequently reported by him in a conference that $I$ attended 5 days later. Shive had tried a new way to bring emitter and collector points very close together. He made a thin "sliver" of germanium and placed the points on opposite faces. He obtained good transistor action. This success was hard to explain if transistor action occurred through an inversion which in his arrangement would have required a much longer path over the surface from emitter to collector than would have resulted in power gain if the points had been on the same face of the specimen. Shive's notebook entries between 13 and 18 February included some 


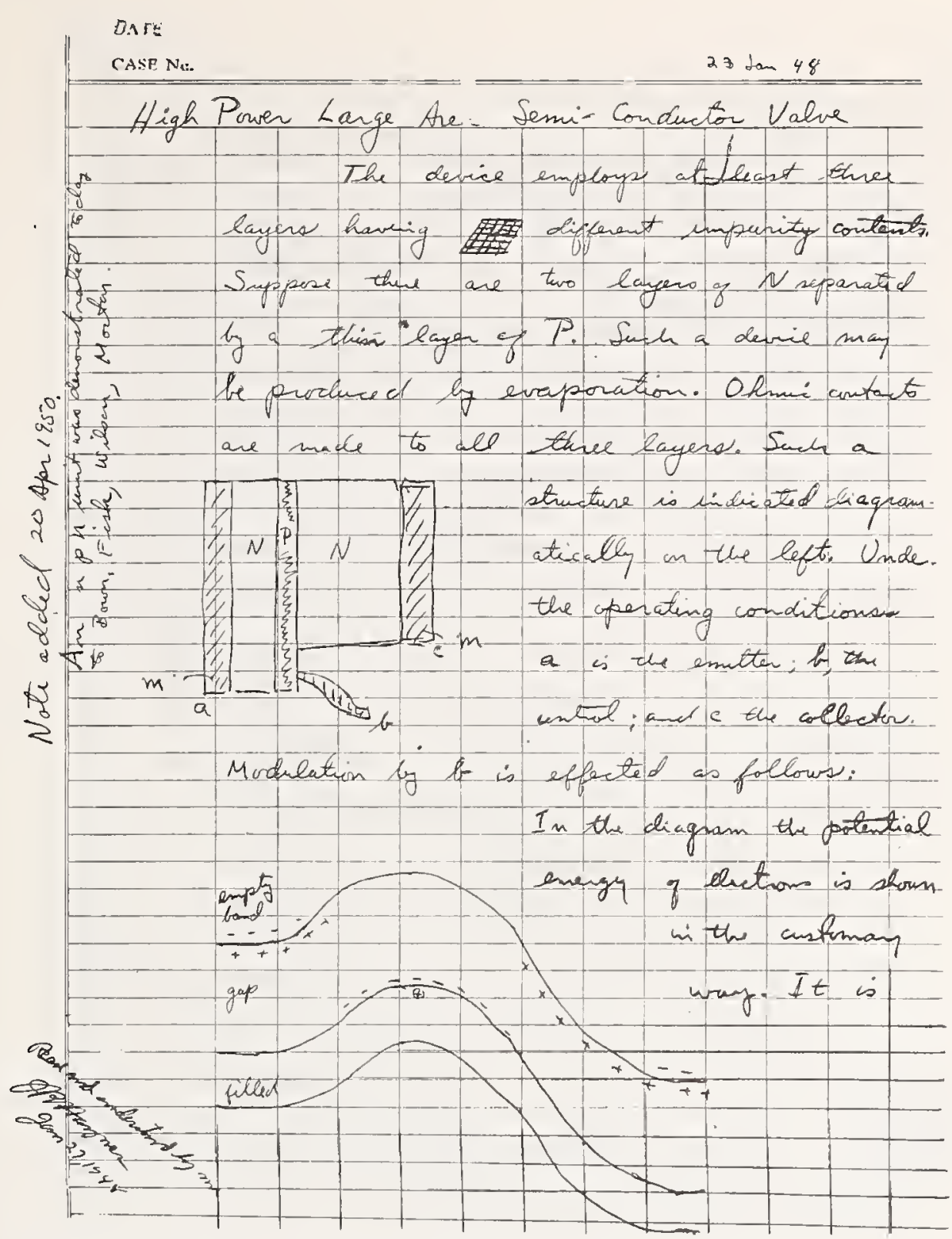

FIGURE 32. The first of five pages dated 23 January 1948 from Shockley's notebook containing the record of the conception of the junction transistor.

It proposes using evaporation for fabrication-a poor idea. But it does lead into the concept of minority carrier injection through a thin base layer.

speculations about mechanisms that would permit holes to flow through the thin specimen from emitter to collector. These mechanisms included the formation of p-type regions and the spreading of wide space charge layers - concept on a par with some of my bum-hunches, for example, figures 30 and 31. However, none of Shive's proposed mechanisms in. cluded injection of minority carriers that then diffused through the base layer until collected. Incidentally, it was Shive himself who later introduced the words "minority" and "majority" that have proven to be so convenient to describe such effects.
I recall being startled when Shive presented his findings at the conference on 18 February 1948. My junction transistor concept had been witnessed but had not been generally promulgated. I felt that I did not want to be left behind on this one much as I recall feeling that I had been on the voltage-gain idea of 8 December 1947; Bardeen had then effectively used creative-failure methodology by converting my very half-baked, voltage-gain idea into a big forward step towards the point-contact transistor that he and Walter Brattain achieved 8 days later. At the conference where Shive presented his observations, I 


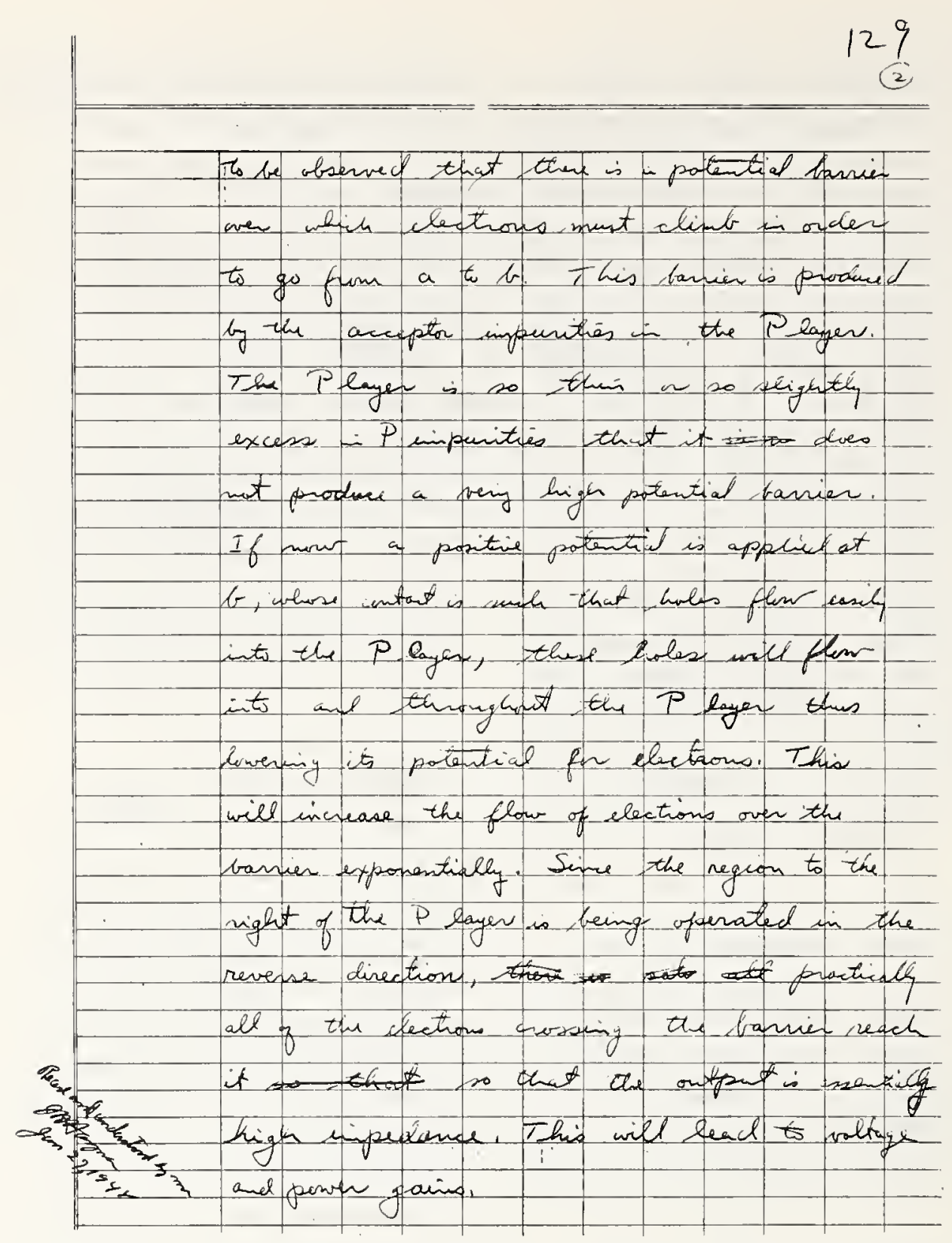

Figure 33. The second page of the 23 January 1948 disclosure of the junction transistor.

The basic amplifying considerations are clearly explained.

made it a point to explain how they could be interpreted by my carrier-injection model of an emitter junction. If I had not given this interpretation at once, I am sure that Bardeen or someone else would have proposed minority-carrier injection within a very short time-possibly even during the next 5 minutes. From that point on, the concept of using p-n junctions rather than metal point contacts would have been but a small step and the junction transistor would have been invented.

These observations suggest that the proof provided by the success of the point-contact transistor would have so stimulated "the will to think" that, after Shive had tried the radical experiment of points on opposite sides, the thinking needed to complete the invention of the junction transistor would inevitably have occurred and probably at most no more than a few months later.

The junction transistor, in one embodiment or another, was the amplifying device that played so large a role initially in solid-state electronics that it is fair to say that its realization was the development that did effectively launch the solid state era of electronics. It continues to dominate bipolar circuitry. 


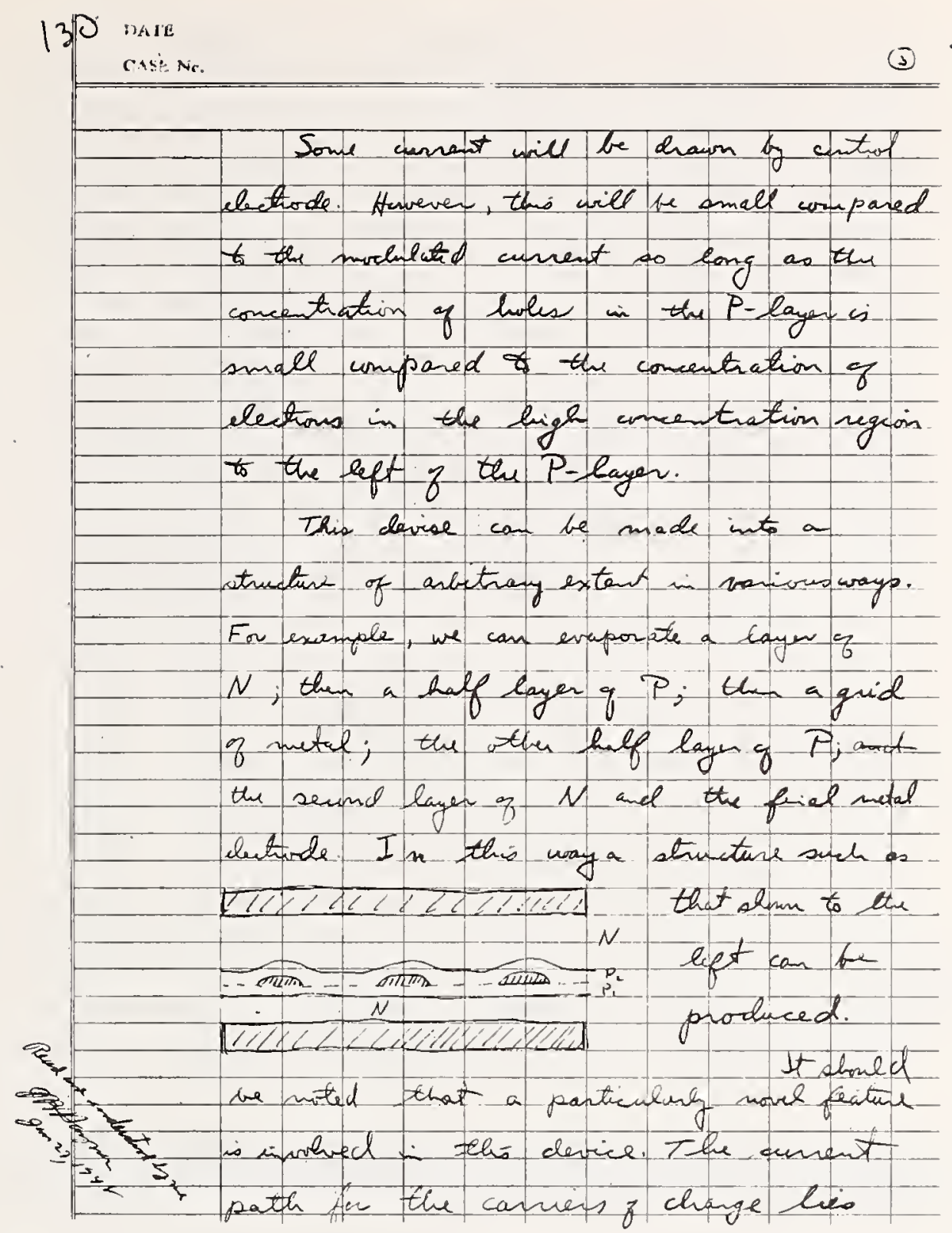

FIGURE 34. The third page of the 23 January 1948 disclosure including an appreciation of the importance of heavy doping of the emitter to reduce unwanted base-toemitter currents.

A half-baked idea about metal electrodes in the semiconductor to reduce base series resistance is discussed.

But this launching required much more than the concept disclosed in the junction transistor patent, patent 5 of table 1. The specification of that patent did teach those skilled in the art to make junction transistors-indeed before the junction transistor patent issued-but not until other inventions were made that permitted converting the concept of the junction transistor patent into a working reality.

\subsection{Making the Junction Transistor a Reality}

The tempo of the magic month was followed by a period of more gradual development. New technolo- gy needed to be developed to conquer the fabrication problems of the junction transistor. Morgan Sparks undertook a program of trying to make good p-n junctions. The first major effort consisted of dropping molten germanium of one conductivity type onto heated plates of the opposite type.

24 March 1949 dates the notebook entry of figure 38 describing how Robert Mikulyak, working under Sparks' direction, produced a form of junction transistor. A drop of molten p-type germanium fell onto a heated slice of n-type germanium. The solidified droplet was later polished down so as to make a slab structure. 


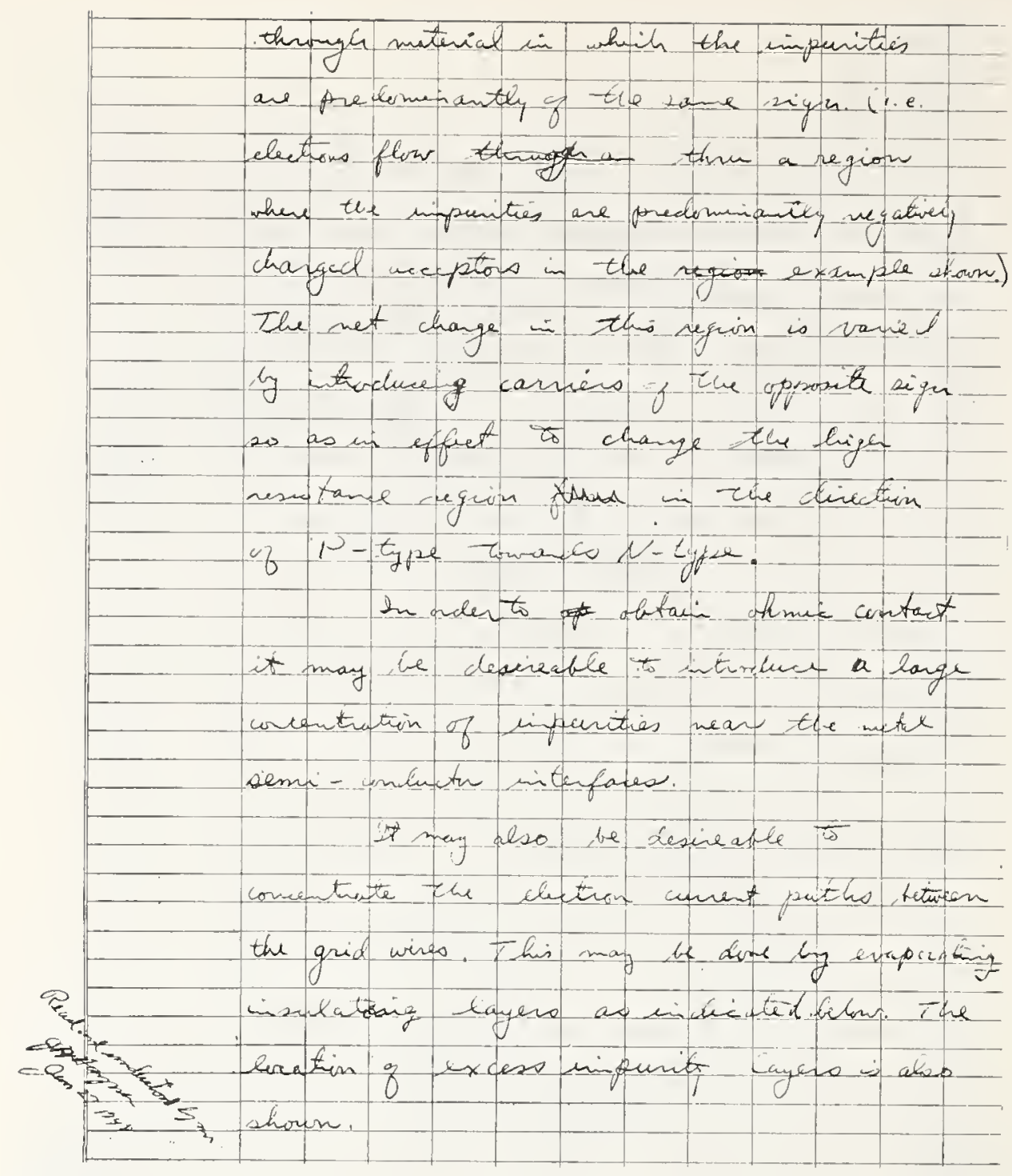

FIgURE 35. The fourth page of the 23 January 1948 disclosure containing one idea that became a division of patent 5 of table I: the importance of heavy doping under the metal contacts to reduce contact resistance.

6 April 1949 dates the notebook entry covering the resulting transistor. It was done as shown on figure 39 by sawing through the p-type drop with a thin wire so as to leave two parallel bars of p-type sitting on top of a large block of n-type. If a junction transistor of proper form is described as a sandwich with a base layer of cheese lying between emitter and collector slices of bread, then Mikulyak's transistor consisted of two fingers of bread lying on top of a cake of cheese. As his notebook entry shows, this device did give power gain. It may be the first example of a transistor with p-n junctions for both emitter and collector. It did not, however, achieve the structure of Claim 1 of patent 5 discussed above.

The essential missing ingredient needed to put the junction transistor across was good crystal growing techniques and the use of compensation of donors and acceptors through the technique of "double doping." The crystal growing story is an important one. Gordon Teal who had worked on semiconductor preparation towards the end of the war was enthusiastic about growing large crystals for purposes of both research and development. He was unsuccessful in selling this program in the chemistry department and to me. My position at the time was that we could do adequate scientific research by cutting specimens from the relatively large crystals that appeared naturally in the polycrystalline ingots resulting from solidified melts, Gordon Teal bootlegged on a shoestring basis a program of preparing a crystal grower without an official authorization. (Indeed, he reminisces about fears imparted to him by manage- 


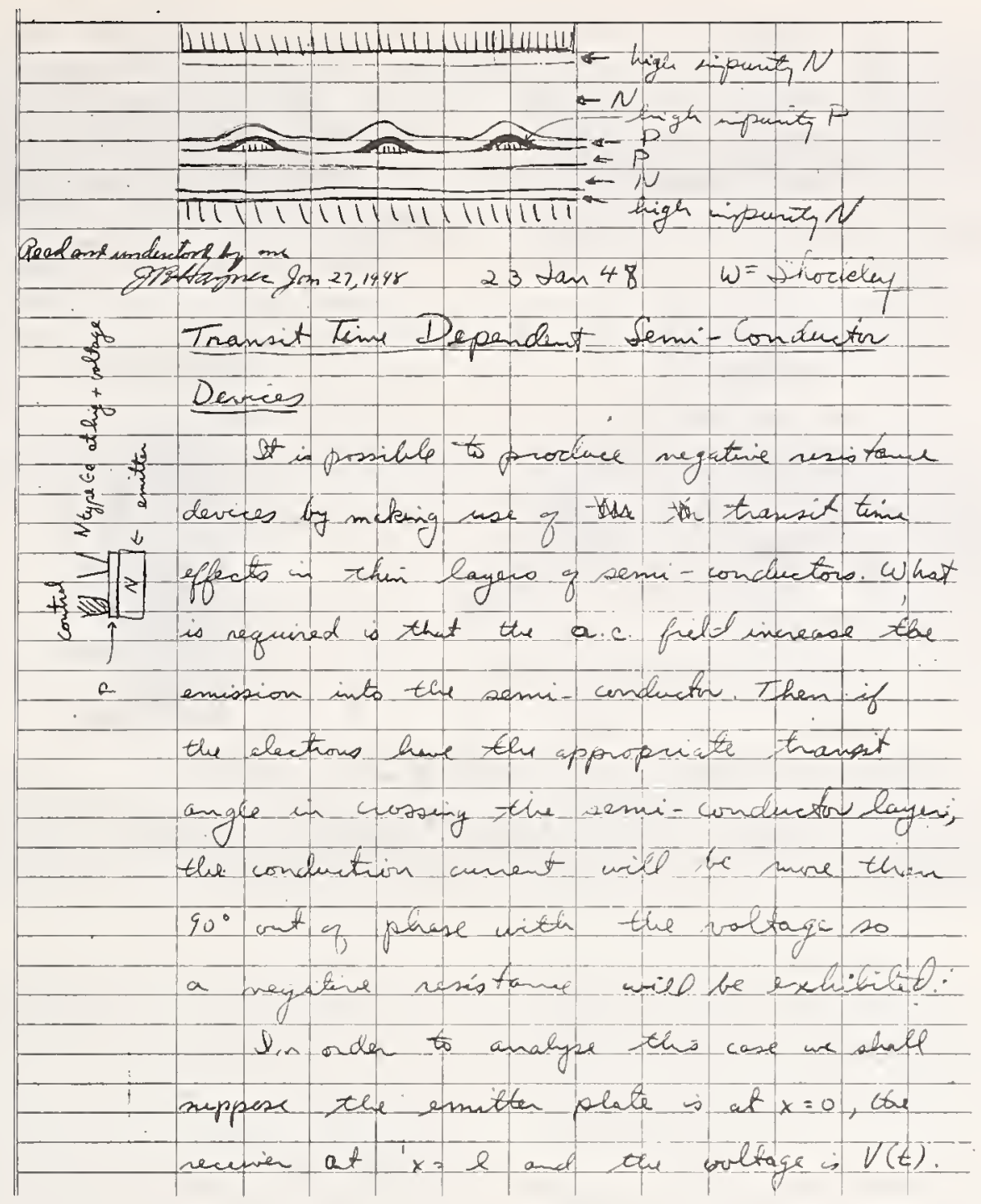

FIGURE 36. The ffth page of the 23 January 1948 disclosure discussing what might be called "ribs" of high doping in the base. This diagram does not appear to follow what was called for on the fourth page.

Also on this page is the start of a discussion dated 24 January 1948 of negative-resistance transit-time devices. This topic became a continuation in part of patent 5 .

ment that his obstinacy might cause him to lose his job.) Later, J. A. Morton, who had the responsibility of developing transistors for manufacture, bought Teal's program and supported it. Morton wished to avoid having grain boundaries cause variations in point-contact transistors.

Subsequently, the proper way to produce good p-n junctions was discovered by Sparks and Teal to consist of changing the composition of the melt as the crystals grew. Good p-n junctions were produced from apparatus like that of figure 40 .

12 April 1950 dates the notebook entry of figure 41 that shows how Morgan Sparks chemically etched a specimen made by double-doping so as to produce the desired three layers. The etch raised the base layer so that it could be contacted by soldering to it.

Figure $4 \dot{2}$ shows the first, large-area junction transistor that was made by this means in the late spring of 1950. It was embedded in wax and soldered to a large block of copper to provide cooling. It had a thick base layer that produced such long diffusion times that it would not operate above about $20 \mathrm{Kc}$. However, it did produce 10 or 15 watts of audio power. In the summer of 1950 , I discussed it at a semiconductor conference in Reading, England, and described its characteristics. These were in keeping with the theory that I had published in 1949 in the Bell System Technical Journal about p-n junctions 

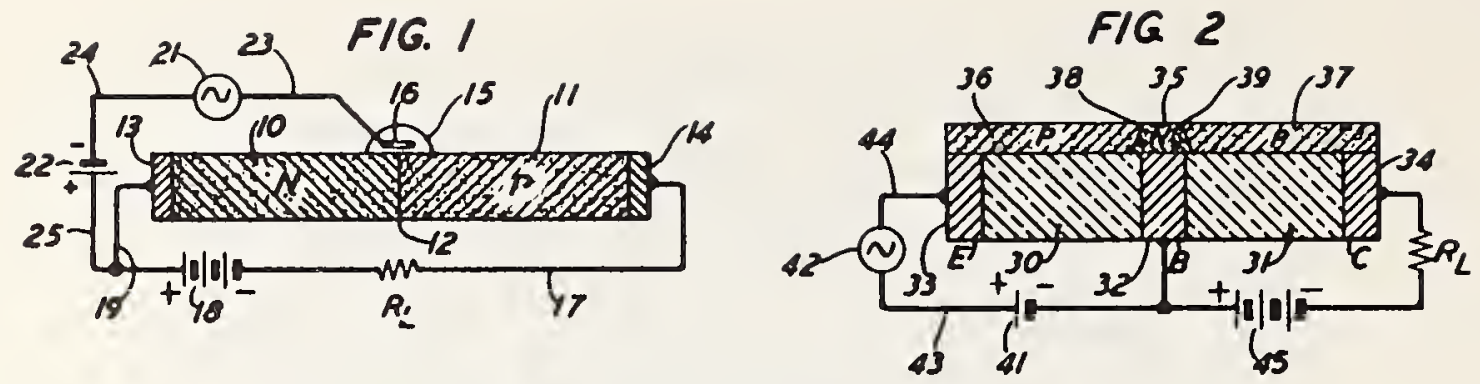

F/G. 3

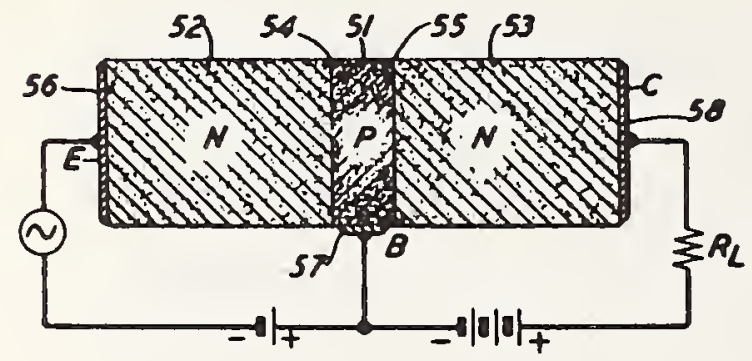

F/G. 6

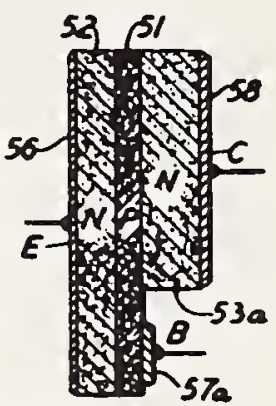

Figure 37. Figures from the junction transistor patent, patent 5 of table 1.

Figure 1 shows the drop of electrolyte across the $p-n$ junction, the structure discussed as Experiment II in Brattain's notebook entry of 4 December 1947 reproduced in figure 22. Figure 2 is the conception of 31 December 1947 reproduced in figure 30 . Figure 3 is a true junction transistor structure. Figure 6 is a close copy of the diagram of the first theoretically correct junction transistor disclosure as shown in figure 32 .

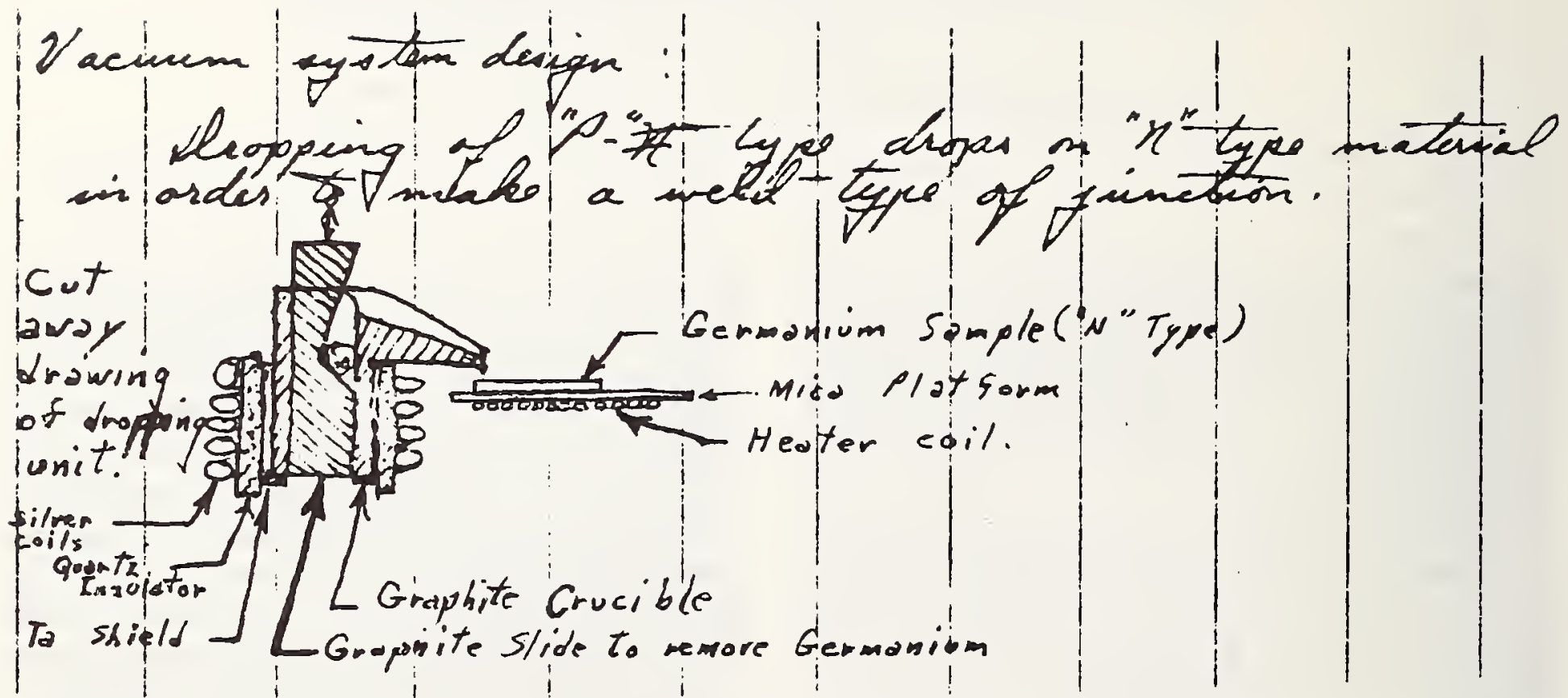

FiguRE 38. A 24 March 1949 entry from the notebook of R. M. Mikulyak illustrating how a drop of p-type germanium was made to fall on a heated $\mathrm{n}$-type slice in an attempt to make a $\mathrm{p}-\mathrm{n}$ junction. 


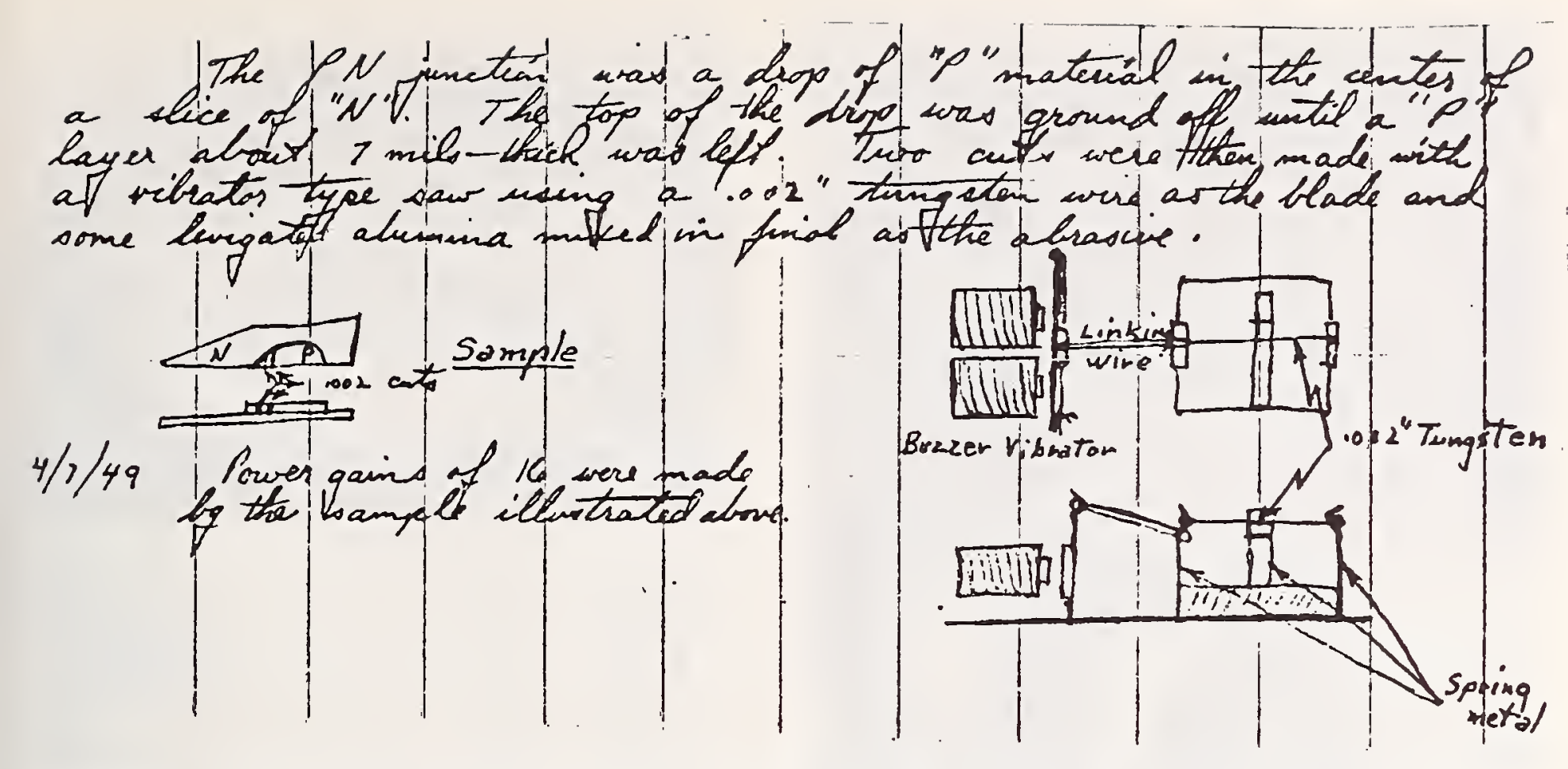

FIGURE 39. A transistor using p-n junctions made from a specimen prepared by letting a drop of molten p-type germanium fall on a heated n-type base gave power gain on 7 April 1949.

and junction transistors. This post-deadline paper that I presented at the Reading meeting was omitted from the report of the meeting. While giving lectures in London during the 25th Anniversary celebration of the invention of the transistor-one of the lectures upon which this presentation is based-I remarked on this omission. A member of the audience then reminded me that in $1950 \mathrm{I}$ had been unwilling to reveal how the transistor had been fabricated by double doping. This was probably why it was not included in the reports of the transistor conference at Reading University in 1950.

December 1950 was the date at which significant hastening of the junction transistor development occurred. Because of my experience in operations research during World War II, I had been called in the late fall of 1950 to consult on operations research on our combat forces in Korea. I found that proximity fuses were not in use in mortar shells. Proximity fuses would have been very important in fighting that limited war. After my subsequent contacts with the Quartermaster General as a member of another consulting group, I urged that transistors should be actively considered for use in proximity fuses. I made further inquiries at Bell Laboratories and was convinced by R. L. Wallace, who was an expert on transistor circuitry, that a good, small-area, high- frequency junction transistor would be far superior to point-contact transistors for proximity fuses. No such transistors had then been made.

This stimulated us to take up the double-doping program in which no one had shown any interest. In January of 1951, Morgan Sparks succeeded in growing new crystals with suitably thin base layers. These were cut into rods having snall cross sections and which were made into individual transistors. Figure 43 shows an example. True to Wallace's prediction, these had enormous technological impact. The public announcement of these microwatt transistors occurred in the summer of 1951. This is the date at which I feel the transistor era was really finally launched.

When I am asked how we felt about the transistor's future shortly after its invention, I reply by quoting a paragraph written in mid-1950 from my book "Electrons and Holes in Semiconductors":

"It may be appropriate to speculate at this point about the future of transistor electronics. Those who have worked intensively in the field share the author's feeling of great optimism regarding the ultimate potentialities. It appears to most of the workers that an area has been opened up comparable to the entire area of vacuum and gas discharge electronics. 


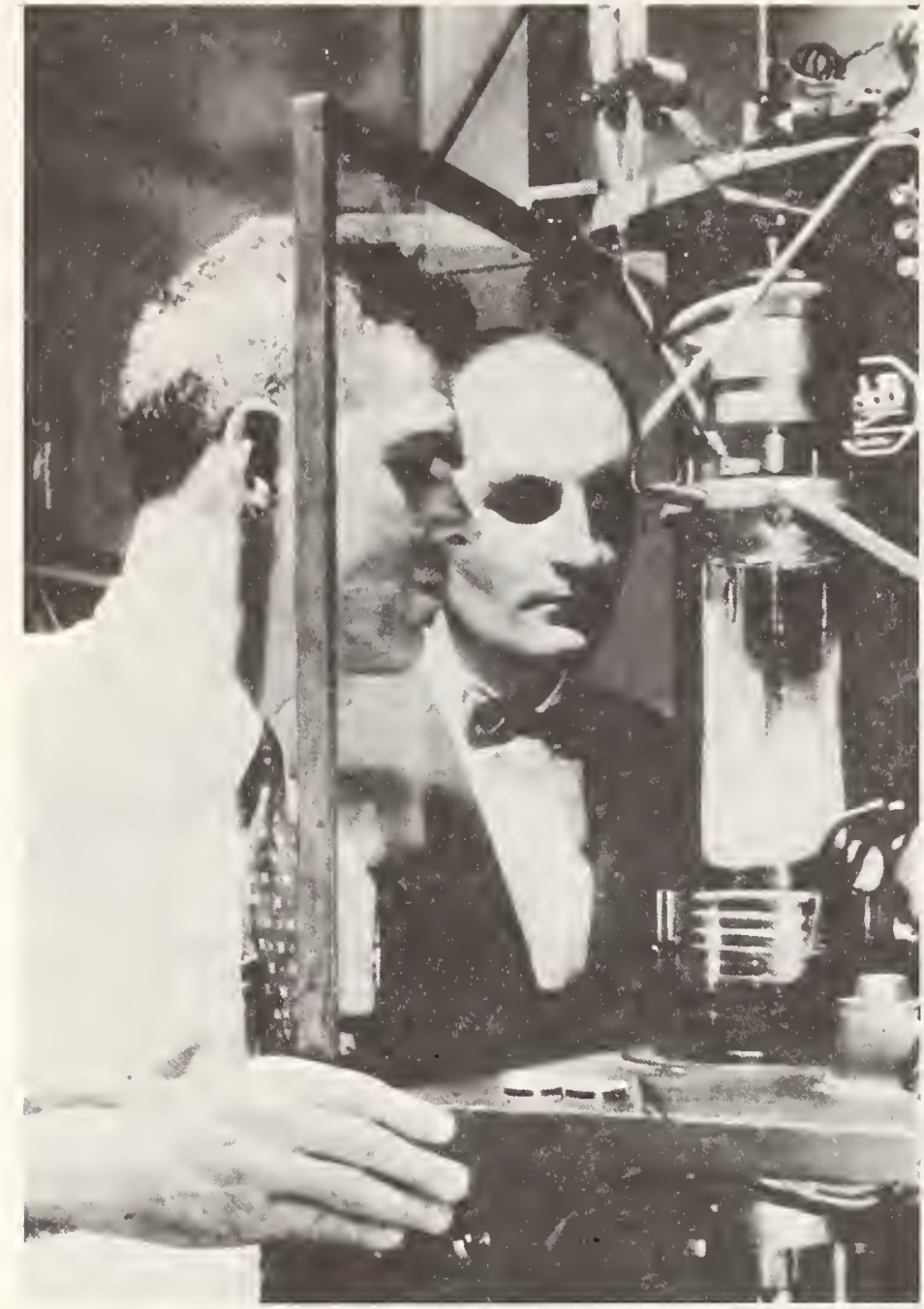

FIgURE 40. A crystal-growing apparatus of the form developed by G. K. Teal being observed by Mr. E. Buehler, who grew most of the crystals used in semiconductor development and research at Bell Laboratories for many years, and M. Sparks who fabricated the first of the good junction transistors.

Already several transistor structures have been developed and many others have been explored to the extent of demonstrating their ultimate practicality, and still other ideas have been produced which have yet to be subjected to adequate experimental tests. It seems likely that many inventions un. foreseen at present will be made based on the principles of carrier injection, the field effect, the Suhl ef fect, and the properties of rectifying junctions. It is quite probable that other new physical principles will also be utilized to practical ends as the art develops."

To speculate here about the future of solid-state electronics is not part of a presentation on the invention of the transistor.

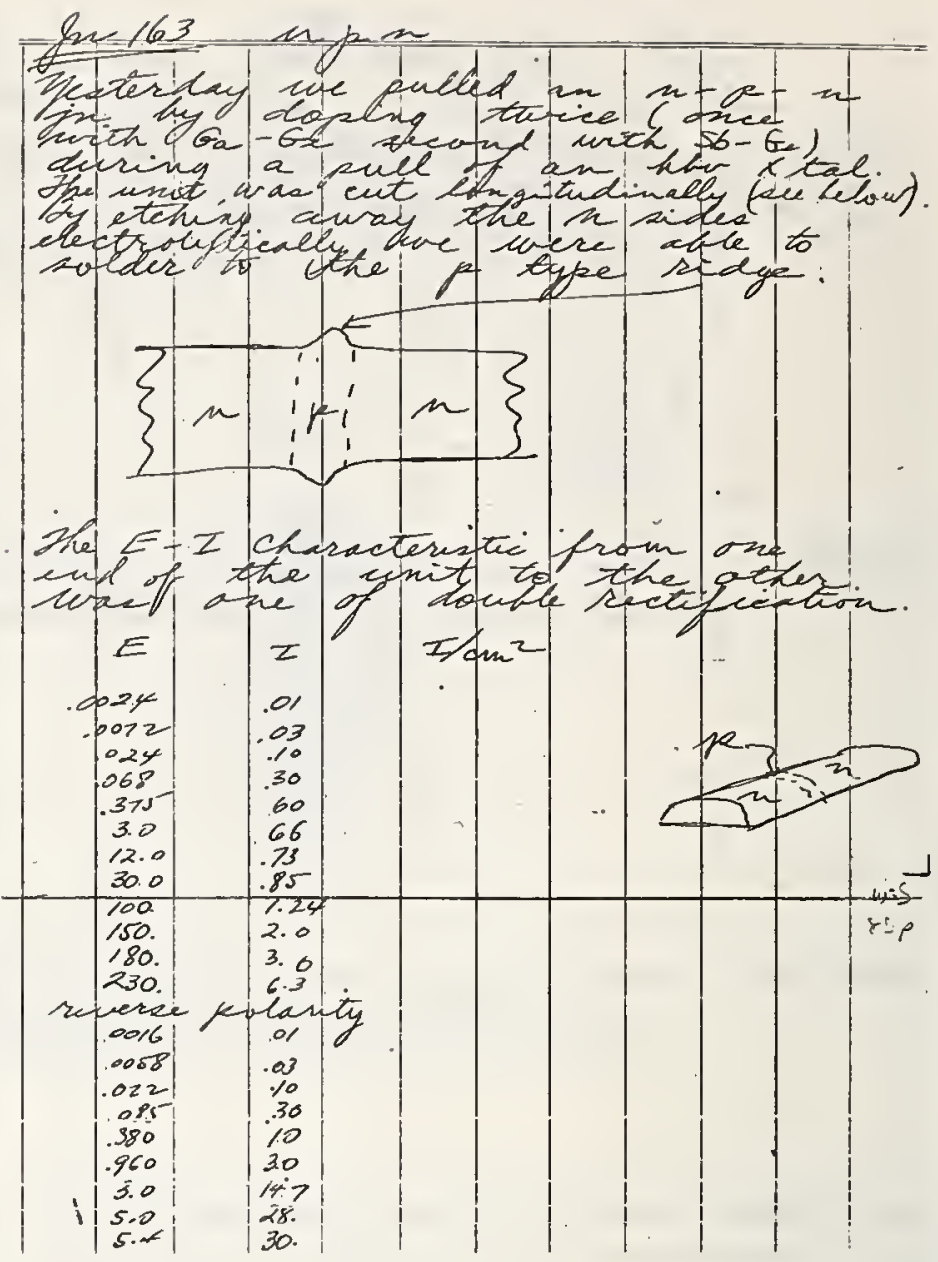

Figure 41. A disclosure of 12 April 1950 by Morgan Sparks of his technique for making a base layer for contact in fabricating a junction transistor.

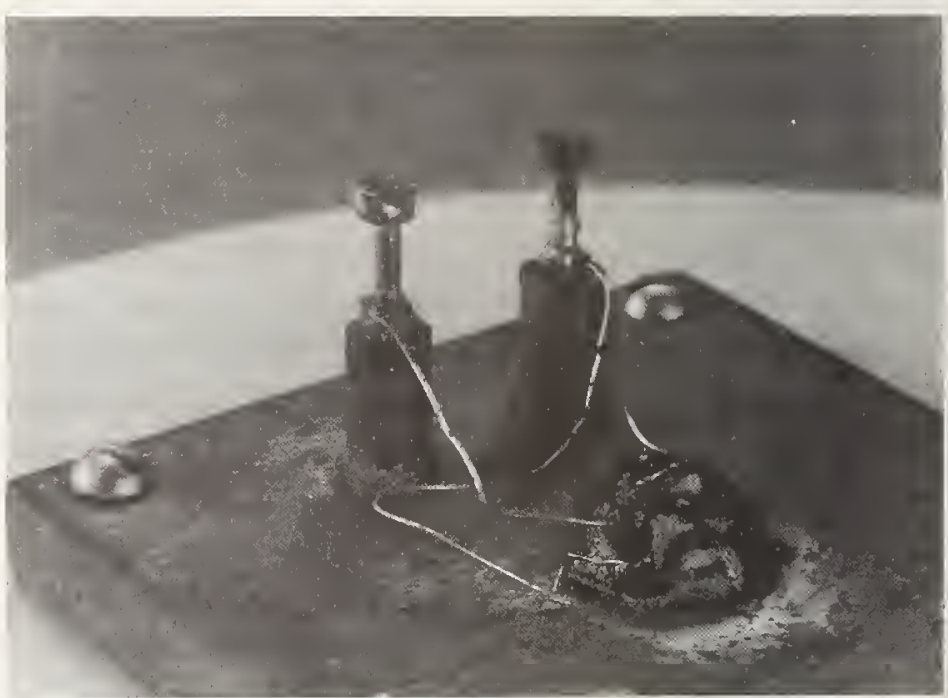

FIgURE 42. The first successful, sandwicl-structure, junction transistor. 


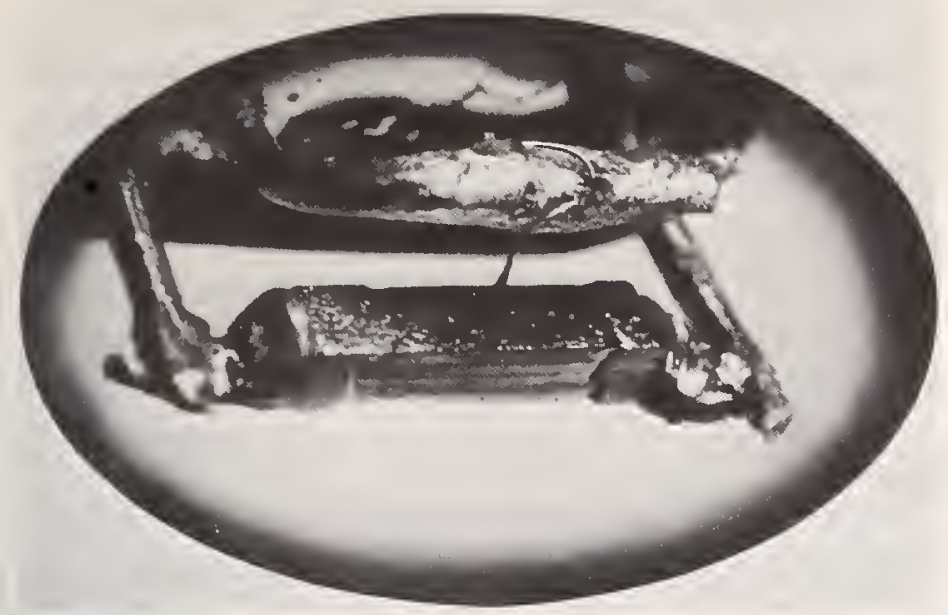

Figure 43. An example of the first micro-watt junction transistor, the device that may be said to have launched the transistor era.

\subsection{Conclusion}

I shall close the junction transistor story with an anecdote-actually still one more example of a form of creative-failure methodology. The original junction transistor of figure 42 would have been lost if Bob Mikulyak, who had helped to make it, had not retrieved it from refuse that had accumulated during a clean-up campaign. Consequently, he was later able to supply it in response to its need to appear in a transistor exhibit for display at the Murray Hill Laboratory. He requested that it be returned to him when the exhibit was taken down.

When the exhibit was opened, Mikulyak was surprised to find the label "replica" on the junction transistor as shown in figure 44. I suggested that the "replica" label was a device to protect this valuable original-a bum hunch as we were to discover.

When new building construction started at Murray Hill in 1972, the exhibit was removed and the transistor again disappeared. Mikulyak once more succeeded in retrieving it from refuse.

I learned this story while preparing lectures for the 25th Anniversary of the transistor. I talked to the Publication Department about preparing a slide showing this transistor being held by Mikulyak who had been involved in its original creation and twice in its subsequent preservation. I was disconcerted to be told that the original junction transistor was carefully preserved and known to be at the moment in the possession of AT\&T. Furthermore, it would not be made available to be photographed with

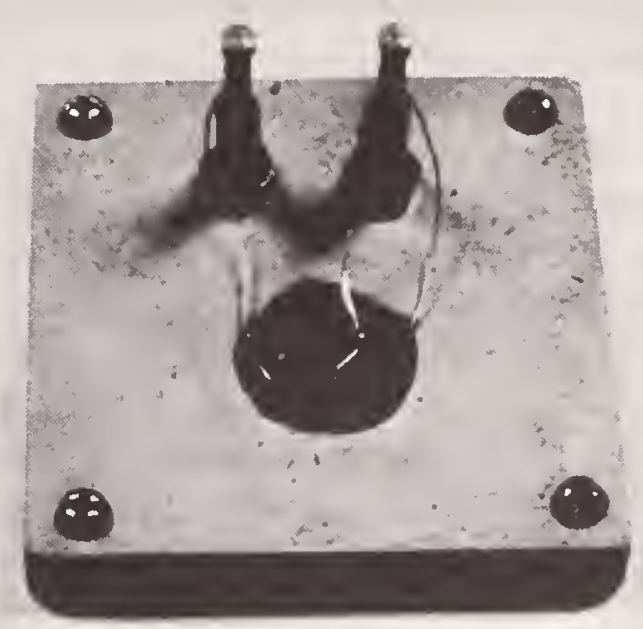

Figure 44. The junction transistor displayed for many years on the concourse at the Murray Hill Laboratory of Bell Telephone Laboratories.

Was it really the original junction transistor?

Mikulyak because it was being photographed in a movie about the 25th Anniversary.

To determine the fact about the "replica," I asked Mikulyak to give it an ohmmeter test. He called back to report that it was indeed a replica. He had not needed an ohmmeter. A fingernail test sufficed. The "copper block" of figure 44 was plastic painted with copper paint.

This anecdote is my closing example of creativefailure methodology - one of many which occurred in the history of the transistor program. The practical output was my persuading Bob Mikulyak to be photographed, as shown in figure 45, as I awarded him with the replica.

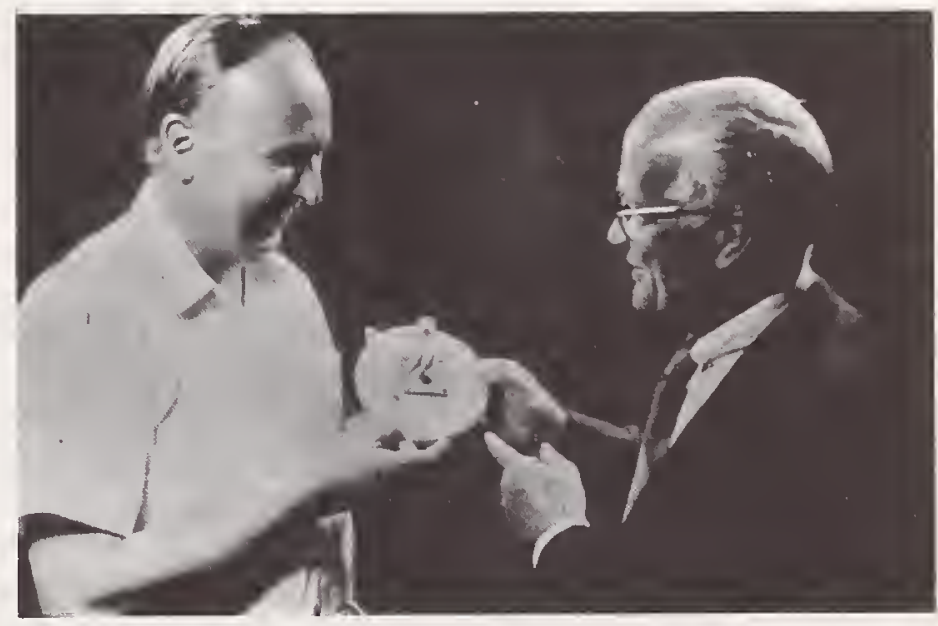

Figure 45. The presentation in September of 1972 to Robert Mikulyak of the junction transistor exhibit at Murray Hill. 
To summarize in a few words the intended impact that I hope this paper may have upon creativity, I use a picture that was given to me after I had rehearsed it at Bell Telephone Laboratories in February of 1973 by a member of the audience. He felt that this picture distills the essence of creativefailure methodology. It read:
"When life gives you lemons, make lemonade."

I have since found this quotation to be an applicable comment for me to make about other research areas in which I have worked as well as to transistor electronics.

\section{Discussion}

Question: Who owned the patents?

W. Shockley: Bell Labs owned them in the United States until sometime in 1956 or thereabouts, when I joined up with Beckman to try starting something. We paid them $\$ 25,000$ for patent rights, and then the consent decree came in and the patents would have been for free anyhow. I don't think I'd like working in a place where your rewards were so dependent upon the value of the patent.

J. Rabinow: I think this is a point that's worth taking up. I don't want to belabor this business of what an inventor deserves when he works for a company, but, Bill, I think that was oversimplified this morning, that if you invent you get so many dollars; I think any intelligent management would weigh all the other factors, like how secretive you are as against how cooperative you are.

As I listened to your story, which is a very fascinating thing, how haphazard inventions are made, even by intelligent people, I was wondering: were you aware of the commercial importance of it, in getting your names on the thing and rushing, as you were, because you knew this was scientifically very important? I don't question the motivation of the invention, but you were obviously very anxious to get it on paper, to document the exact dates. Was that because of commercial importance or because of the fact that you wanted your name on them for future glory? And I don't mean to belittle the glory.

W. Shockley: I think it was a mix of the two, and I'm not sure how well I could balance that out.

J. Rabinow: Did you realize it was going to be commercially very important?

W. Shockley: Well, certainly by 1950 , when I wrote a book. I think we felt it would be very important right from the start, simply because we knew we were doing something new and different. As soon as it had worked, the reaction of some of the managerial people at Bell Labs, of course, was very clear. This was really a well-held secret up until this public announcement.

J. Rabinow: When people talk about great inventions, you find that most of them come out of small laboratories; this is a special case, and the interesting thing about the transistor is that you had a readymade market, once you recognized how important it was. If you were in some little company and came up with a point contact transistor and tried to sell it to a big company, I think you wouldn't sell it. They would say, "Well, wait till it works right, wait till all the problems are licked." But because you had your own customer built in, a tremendous customer, and your own money, I think this is a most unusual combination. Almost no invention is made by the company that is its own user. Usually they sell it to somebody else, and that was a very special case.

I. Kayton: I joined the Labs in 1952, and at that time I was told a story given as the truth-perhaps it was apocryphal-that the patent department and management so fully realized the commercial importance of your contribution that in preparing the patent application they had three of their very best patent attorneys write applications independently of each other, and that they selected the ones that were best. This was told to me by a division patent counsel, and I was wondering if that were true.

W. Shockley: I don't remember that story; I doubt it, but I could be wrong. I wrote most of the disclosure on the junction transistor patent myself, and this may have been the first time I really worked closely with Rudi Guenther, but we did a lot of things otherwise. So I'm not aware of that on the junction transistor patent. The thing that impressed me on coming back to it was the ingenuity on that Claim 29, and some of the other claims. 
J. Stephens: Was the generality of that first patent application the work of the attorneys, or the inventors?

W. Shockley: You mean Claim 29? I don't remember having appreciated that; if I'd thought that thing up and realized what it was, I would have had no doubt that I had made a big contribution. It must have been that Guenther did it and I didn't even bother to read it.

A. Ezra: What led you guys to start doing research on semiconductors anyway? Was it a result of a market survey that said, if you invent a transistor you will nıake a lot of money?

W. Shockley: No, the work on the semiconductors was part of the really very wise and farsighted research policies at Bell Labs. The organization there was a concept of Mervin Kelly's, which he came to toward the end of the War. Brattain was away working on magnetic anomaly detectors, Bardeen had not been hired, and I was doing operations research in the Office of the Secretary of War. He visualized this group and set up two co-heads. This was a solid state physics group; the other fellow was S. O. Morgan, who had one ingenious patent worth mentioning; he was particularly concerned with dielectrics and piezoelectrics, and I think he had the first patent on using heavy hydrogen, deuterium, to alter critical temperature of a piezoelectric. There were several areas of this, all of which had to do with the properties of crystalline material which were relevant to phenomena that might be used to control electrical signals. And that's as closely defined as the work was. That's typical of the type of research emphasis they would have. Ferromagnetism was one, dielectrics was another; piezoelectrics was another, semiconductors. I think there were five; I seem to have left one out.

I remember at another time, myself, trying to sell Bell Labs on doing something in the nuclear physics fields, of getting some Van de Graaff generators. They weren't so interested in the nuclear pile business, because these were things in which other organizations might well have a much larger fraction of their interest, than the Bell system. But in terms of these materials, in influencing or controlling signals, which are so central to the whole communication business, there this was a very logical business. In that, the sort of freedom and support we had was high.

I remember one other thing that we were wise about; it has to do with respect for the scientific aspects of practical problems. I recall some people coming around and saying, "Well, you're working on silicon and germanium; those are really pretty well under control, why aren't you working on selenium or copper oxide or nickel oxide - those are the things we are using in the telephone plant?" Well, these we knew were relatively messy things; besides that, there were some gaps in the science of silicon and germanium, and they were pretty well understood. That, I think, is another sound research principle, that if you are trying to extend a field, sometimes one of the best ways of doing it is to find a place in which you are maybe most advanced, but there's another step, you don't know where to go. Well, the surface state was exactly that sort of thing. I remember before we had any low-temperature stuff, Gerald Pearson and I went down to the Bureau of Standards and borrowed low-temperature equipment and cooled off silicon and germanium specimens; and later on Bardeen and Pearson wrote papers on this. So the freedom to work on this basic stuff was very high. It fitted into a research principle that I haven't tried to quote for a long time that came from Ralph Bown, who was at that time Director of Research and later Vice President for Research, and was a very thoughtful, eloquent man. He wrote the foreword to my book on Electrons and Holes in Semiconductors. He talked about several freedoms: one was the freedom to do things, and another one was the freedom to refuse to do things. And we didn't have anything to do with these suggestions that we should look hard at these practical semiconductor materials.

J. Rabinow: I once heard Dr. Kelly speak, and he said that one of the things that he did when he became the Director of Bell Labs, was to shake the place up - that he reorganized it. He said that every laboratory should have a boss that comes in once in awhile and reorganizes and changes things, just because it's necessary to do it for the good of society. 



\section{SESSION II - June 12, 1973}

\section{Opening Remarks}

\section{Jaccb Rabinow*}

This is going to be a short session, I hope, although I expect that there'll be considerable debate today. We are going to discuss the basics of the patent system.

What we hope to get out of this meeting in general are several things: one, of course, is a book which will reproduce the wise and foolish things we've said and will say here. Another result will be a set of recommendations.

The last item will be the questions we are asking because the patent system, above all things, is a kind of mystery. It's a religious kind of thing with most countries of the world; everyone says that a patent system is good to have, but no one knows how good it is. I have asked many economists in Washington, "What is the patent system worth to the country?" and not one of them has the vaguest idea. It's time that we found out.

Today we shall have some discussion apout antitrust laws and the patent system. We'll hear Dr. Kayton, who is mild most of the time, discuss what the patent system is not to the inventor. We'll hear John Stedman, who believes that the antitrust laws do not really conflict with the basic patent ideas.

Tomorrow you will hear about the way inventors in large corporations look at the patent system, how Government inventors look at invention, and so on.

It is obvious that the patent system is in trouble. It's in trouble because when the Constitution was written, there were no large corporations. It did not take a million dollars to put a record player on the market, as it took in my case. Reading machines did not take half a million dollars per sample. Today there's no such thing as a local technological business. You're national and international even if you make can openers. Your business is large, in general; this means that the common tale of the inventor as a little guy who has a basement shop is no longer true. You're either big, or you're nothing. So the question is, is the patent system still working, and if it works, for whom, and how?

${ }^{*}$ Executive Director of the National Inventors Council
Searches in the Patent Office are getting much more difficult, both because the number of patents is very large and getting larger very fast, and because the subtlety is increasing. It does so for two reasons: technology is getting much more sophisticated, and the difference between patents is very often much smaller, because there are so many patents in the same field. What do we do about this? A simple answer would be to triple the size of the Patent Office and increase the salaries of everybody to $\$ 36,000$ and thus, maybe, get the best people. But Congress seems to have the opinion that this is not a practical solution.

You've heard that the courts often hold patents invalid, and the question is, why? No one knows why. There are a lot of questions we have to ask.

So I hope we'll get out of this conference a great many good questions, more than we are going to have answered, because the answers are not easy to come by. These questions will be relayed by means of the book and personal recommendations of the Inventors Council to Dr. Ancker-Johnson, whom you met yesterday. We sincerely hope that the Inventors Council will have a great impact, if not on changing the patent system, at least on preventing the patent system from being changed in the wrong direction.

An announcement I would like to make: there was originally a Patent. Trademark and Copyright Foundation at George Washington University, which for lack of funds went out of existence. But I'm glad to report that the PTC Foundation has been reinstituted; it is now at the Franklin Pierce Law Center somewhere near Boston-I think it's in Belmont. Those of you who are interested in the kind of work that the PTC Foundation did-and I think it was beautiful work-can contact them. The original Foundation was the first to look into the patent system and cut out some of the nonsense and fic. tions that were told about patents. For example, many years ago the PTC Foundation looked into how many patents are utilized during their lifetime, and it was amazing to learn that half the patents of the United States are used at least sometime during 
their lifetime. This was quite contrary to the popular fiction that only 2 to 5 percent of all patents are used. We would like to know, for example, what patent royalties are collected in the United States. How many dollars do we collect from foreign countries? It is said to be something between $\$ 1$ and $\$ 2$ billion, which is more than enough to pay for the Patent Office 50 times over, and yet no one is sure. I'm glad Dr. Neumeyer will be speaking tomorrow-maybe the way we find out about our patent system is to go to Europe and ask the Europeans-perhaps they know. 


\title{
Antitrust Doctrine v. the Individual Inventor: Friend or Foe?
}

\author{
John C. Stedman \\ University of Wisconsin School of Law, Madison, Wis. 53706
}

\begin{abstract}
The perennial conflict between antitrust and patents is currently reflected in the Scott (Patent Bar) and Hart proposals pending before the Senate. The Scott proposal would apply a "rule of reason," giving a patentee considerable freedom in imposing various restrictions upon licensees. The Hart proposal would apply a "reasonably ancillary" test, narrowly circumscribing the patentee's freedom in this respect. The question is: which is more advantageous to the inventor, independent or employed? Restrictions in patent licenses, while they may enable the patentee to maximize his return from the invention, may at the same time provide protection from competition and thus lessen the competitive fears and hopes of competitive advantage that provide the main economic force underlying inventive activity. Thus, paradoxically, the short-range advantages of restrictive licensing may operate long-range to the detriment of the inventor. Deeper research into the subject is urgently needed, but tentatively one may suggest that enactment of a law enlarging a patentee's freedom to impose licensing restrictions may prove, in the long run, advantageous to institutions that seek to minimize the forces of competition (including competition in research and innovation), but disadvantageous to small concerns and individual inventors, independent or employed, whose welfare depends upon competitive achievement and innovative activity.
\end{abstract}

Key words: Antitrust; Hart proposal; inventors; patent licenses; patents; Scott proposal.

\section{Introductory Comment}

The battle between Antitrust and Patents is almost as old as the battle between the sexes - if I may exaggerate somewhat - and almost as complex and inconclusive. It has been going on for ages - at least for $31 / 2$ centuries. It was in 1624, after all, that Parliament enacted the Statute of Monopolies which prohibited all monopolies in England, but made an exception in the case of patents for inventions with the important proviso, however, "that they be not contrary to the law nor mischievous to the state by raising prices of commodities at home, or hurt of trade, or generally inconvenient." Taking a leaf from that book, our courts and Congress have been trying for over 80 years to give meaning to and mark the limits of that proviso even though it is not stated in so many words in either our antitrust or patent law.

The issue is especially important today. It is frequently suggested that our antitrust laws stand as an impediment to invention and innovation, and just as frequently asserted, that they provide the major incentive to invention and innovation. The intensity of the controversy is evidenced by the sharply opposing approaches to the subject currently being offered for Congressional consideration. I refer to what are generally known as the Scott and the Hart amendments. Actually, neither proposal has been introduced yet in this Congress, but both are waiting in the wings ready to come on stage whenever it seems appropriate.

These are the proposals that I am taking as my text. I am not approaching them, however, from the usual point of view. The typical discussion in this area centers on the impact of the antitrust laws, or changes in the antitrust laws, upon the patent system, and vice versa - to put it in economic and industrial rather than legal terms, the interaction of competition and monopoly, respectively, with invention and innovation. My concern, as the title of my talk indicates, is with the effect of these respective proposals upon the individual inventor, whether independent or employed.

The issue is more complex than would appear at first glance. It is not solely a question of how free is the inventor-or the inheritor of the rights in his in- 
vention (typically, his employer) - to grant licenses and fix the terms of such licenses. There is the further question of what effect the licensing practices he is permitted to engage in may have upon the market for inventions. And there is the still further question of the long-range effect of given practices as compared to the short-run effects.

Before I get into details let me make explicit a couple of premises upon which I base my discussion. They are, I think, fairly obvious and require little more than a mere statement of the propositions.

First, innovative activity on the part of private commercial and industrial enterprise is induced by economic considerations - the push of the competitive threat or the pull of greater profit. There are exceptions, of course. One may innovate because the law requires him to-the introduction of an anti-pollution device is an example. Occasionally, no doubt, an innovator may be inspired by curiosity, pride, a sense of public service, etc. (whether he is indulging a luxury or being foolhardy depends, of course, on his Dun \& Bradstreet's rating). On the whole, how ever, the premise probably holds up quite well.

The second premise is that invention, for the most part, stems from the economic stimuli for innovation. While non-economic motives may play a more important and frequent role in the case of the inventor than in the case of the innovator, the old adage that "necessity is the mother of invention" still holds up well if we define "necessity" as the need or desire for economic gain. Certainly a major premise, even though not the sole premise, of the patent system is that one will be more disposed to invent if there is the promise of a pot of gold at the end of the rainbow.

\section{The Patent Bar-Hart Amendments}

The question is, what bearing do the proposed amendments referred to at the beginning have upon these incentives to innovate and the resultant incentives to invent? Before we can even attempt to answer this question-and the answer, let me emphasize, is not easy to come by-it is essential that we look briefly at these proposed amendments and what they do.

First, a quick comment regarding the origin of the present controversy. As I indicated at the outset, the history of patent-antitrust conflict goes back decades, even centuries. The immediate conflict begins with Recommendation 22 of the President's Patent Commission. Recommendation 22 urged the incorporation of a "rule of reason" in the patent laws. Explanatory comment made it clear that the Commission was not really seeking to cut back existing antitrust law application, but rather sought to provide a rationale for antitrust treatment and put a stop to further encroachment. Administration patent revision bills subsequently introduced did not include this recommendation. Later on, however, amendments considerably more detailed and sweeping than the Commission recommendations were proposed, originating apparently with the Philadelphia Patent Law Association. These suggestions were ultimately introduced by Senator Scott as amendments to the Patent Revision bill. Thereafter, these proposals were worked over and somewhat tightened up by the Department of Commerce and various patent bar representatives. Neither the original Scott amendments nor subsequent revisions were ever actually incorporated into the Patent Revision bill. The present version, involving only minor changes from the previous modified proposals, are currently being urged by the American Patent Law Association and the Patent Section of the American Bar Association for inclusion in a Patent Revision bill if and when one is re-introduced in the present Congress.

What about the Hart proposals? Heretofore, the opponents of the above suggestions - which I will refer to from now on as the Patent Bar proposals - have limited themselves to resisting the proposed amendments. This time they have gone further. Senator Hart, emphasizing that he continues to feel that no provisions concerning antitrust should be incorporated into the patent bill, nevertheless has publicly offered certain statutory proposals that he intends to introduce as a backfire in case the Patent Bar proposals are introduced. And there the matter stands, as of now.

Let me compare the two proposals, as briefly as I can considering their complexity.

Senator Hart and the Patent Bar are in agreement that a flat refusal of a patentee to license at all is permissible. They also agree that unrestricted, unlimited licensing of a patent is OK. These are about the only things they do agree upon. Everything else is a study in contrasts.

The Patent Bar bill (I will refer to both as bills although, as I point out previously, neither has actually been introduced) proposes its recommenda- 
tions as a part of the patent law - an authorizing, permissive statute. The Hart bill is offered as an amendment to the Federal Trade Commission Act - a regulatory act designed, among other things, to preserve competition. The Patent Bar bill, generally speaking, would tell a patentee what he can do; the Hart bill, in general, tells a patentee what he cannot do.

Both contain certain general provisions regarding restrictive licenses. The Patent Bar bill would apply a broad, general "rule of reason" test. The Hart bill adopts the approach the Antitrust Division has been urging for several years, namely, that the restriction be ancillary to a valid contract, that it be reasonable as such, and that it go no further than is reasonably necessary. The Patent Bar bill says that a limited license, i.e., one that licenses less than the entire patent, is permitted. The Hart bill permits a limited license only if it meets the ancillary test just referred to.

Turning to specific provisions, the Patent Bar bill states that price restrictions, restrictions upon the resale of patented articles, tie-in arrangements, ${ }^{1}$ a veto power in the licensee over the grant of other licenses, and restrictions on activity that lies outside the scope of the patent, are not legalized by the proposed amendments, presumably leaving the question of their legality or illegality to be determined by existing or other law. The Hart bill states positively, that all of these license limitations are illegal. Both bills permit the grant of an exclusive license, but the Hart bill requires that it carry with it a right to sublicense. The Hart bill prohibits the mandatory imposition of package licenses, though it permits voluntary package arrangements. The Patent Bar bill is silent on this point, though a royalty provision I will mention in a moment may implicitly permit such packages. The Hart bill prohibits exclusive grant-backs. The Patent Bar bill is silent on this point.

With respect to royalties - and royalties are a very important part of the picture since they can often influence conduct almost as significantly as express restrictions do-the Patent Bar bill again leaves the patentee with considerably more freedom than does the Hart bill. The Patent Bar bill permits post-expiration royalties provided they are based on pre-expiration activity. It permits both package royalties

1 There appears a certain inconsistency between the tie-in provision $\left({ }^{*} 271(\mathrm{~h})(2)\right)$ and another provision (*271(e)), that I will not take time to discuss. and royalties based on an end product of the patented invention. It permits discriminatory royalties. The Hart bill, though it expressly permits lump sum and minimum royalties, declares that a royalty not reasonably related to the patent is illegal. A running royalty (whatever that means), a royalty based on number of units, or a royalty based on usage after the patent falls into the public domain, is also illegal.

As for patent pools and cross-licensing, the Patent Bar bill permits these if they are non-exclusive. The Hart bill is silent on the subject.

I should add that both bills contain additional significant provisions not of immediate relevance to the present discussion. For instance, the Patent Bar bill contains certain provisions regarding challenge of patent validity. The Hart bill requires that licenses be filed with the FTC and, within limits, be available for public scrutiny.

So much for the detailed provisions. How do the two bills stack up as far as the inventor is concerned? Several significant points stand out: (1) As I said before, neither puts any limits on a patentee's freedom to refuse absolutely to grant any licenses at all, or conversely, to license freely and unrestrictedly. (2) The Patent Bar bill, also as I have previously mentioned, emphasizes what a patentee can do, whereas the Hart bill emphasizes what he cannot do. (3) The Hart bill tends to discourage-and by comparison, at least, the Patent Bar bill tends to encourage-the granting of licenses on restrictive or limited terms and the use of a patent as a leverage device to obtain advantages beyond the patent, for instance, through the imposition of certain tie-ins, through grant-backs, etc. (4) At the risk of overgeneralization, let me suggest that the Patent Bar bill tends to apply basically the old Holmesian approach, namely, that a patent gives the patentee a complete right to exclude within the scope of its claims, and anything he does with it that does not extend his control beyond that exclusion is permissible. The Hart bill, in contrast, tends to apply what seems to have become increasingly the Antitrust Division approach-and for that matter, the approach of most courts. This approach concedes the legitimacy of the patent monopoly, namely, the right to exclude, but tests all conduct other than exclusion by its effect on competition (giving due consideration, however, to the existence of the relevant patent or patents). This approach brings into issue such questions as validity, the presence or absence of competitive patents, 
the effect of a gang-up resulting from licensing some but not others, the effect of the licensing practice upon competitive research and the incentive to invent, and so on. In saying this, it is only proper to note that in some respects the Hart proposal goes further than this. In adopting the doctrine that only "reasonably necessary" restrictions may be imposed, for instance, it demands that the patentee be guided by public interest considerations rather than by his own judgment as to how he wishes to exercise his legal right of exclusion.

This, I think, gives a reasonably accurate picture of these two competing proposals. Let me turn now to the central question - central for immediate purposes, at least. Which of these approaches best serves the interests of the inventor, both short-range and long-range? In posing the question in these terms, I am bypassing the issue that usually enjoys the center of the stage in most discussions of this subject, namely, what approach is called for in the public interest? In dealing with that question, the advantage or disadvantage to the inventor is only one, albeit a very important one, of the factors to be considered. In my discussion today, I make this factor the central issue.

\section{Impact of These Respective Approaches Upon the Inventor}

In evaluating the respective approaches of the Patent Bar and Hart bills, we can start with a proposition I mentioned earlier, namely, that the reward to the inventor is determined by the worth of the protected invention in the market. This, in general, is true whether the patentee assigns it, licenses it, or keeps it to himself. It is also more or less true where the inventor is employed, although in this case compensation will be skewed by the supply and demand factor as applied to the labor market, and by the employer's guess as to what the value will be of whatever results from the employee's efforts.

What goes to make up this market value? There is, of course, the value that attaches to the simple right to use the invention, although this value becomes less and less as more and more are free to use the invention - a point that the patent bar and others point out in criticizing compulsory licensing proposals and governmental free-licensing policies.
The other value-indeed, the value that is created by the patent statute-comes in the power to exclude, whether asserted by the patentee incidental to entrepreneurial activity, transferred to others through assignment, waived in return for a valuable consideration through licensing, or used as leverage to obtain advantages with respect to other commodities or services (tie-ins), other patents (package licensing and grant-backs), or insulation from competition in other areas (agreements not to compete).

The important point to note here is that all of these values stem from competitive considerations. A licensee or assignee pays for patent rights to the extent that they give him a competitive advantage, either by strengthening his own competitive position or by weakening the position of his competitors. In short, a patent-and the patent system generally-has meaning and value only within a competitive system. Let me say that again, because it is crucially important: $A$ patent has meaning and value only within a competitive system. A patent gives protection against competition. That is all it does, all it was ever intended to do. But no one in his right mind is going to pay good money for protection against competition if competition poses no threat to him.

Once we recognize this fundamental fact, we introduce a new dimension into the licensing picture. The situation turns out to be considerably more complex, economically, than might have appeared at first glance. Every sale of rights under a patent, and I am including licenses as well as assignments, has a dual aspect. One is the immediate impact of the transaction in terms of the return received in exchange for the patent right; the other is the collateral impact in terms of the effect of this sale upon subsequent sales, whether the sale of additional rights under the same patent, the sale of other patent rights by the same patentee, or the sale of rights, now or in the future, by other patentees. There is nothing startling or unusual about this. It is the familiar story of supply and demand, the traditional operation of the market and the interaction of buyer and seller in that market.

With this elementary introduction, let's see how these market forces operate in the patent licensing area. It is essential at the outset to distinguish between the immediate, short-range effect of a given licensing transaction and its more remote, longrange effect. I will look at the immediate transaction first. 
It is a truism, I would think, that the more freedom the owner of a patent has in setting the terms of his license, the greater his opportunity to maximize his return from such licensing. As just pointed out, a licensee may pay, not only for the affirmative right to use the invention, but even more for protection against others using it. Actually, the process is often more complex than this. A license may be worth more to $\mathrm{X}$ than to $\mathrm{Y}$ and if a patentee is free to discriminate in the royalty rates he sets, he can take advantage of this fact. A patentee who is himself engaged in business can reap greater rewards if he can protect himself against competition, at the same time that he receives a return from a licensee. This he can do through price, quantity, field of use or territorial restrictions. $\mathrm{X}$ may desire only a narrow license and be unwilling to pay more for a broad one, but if the patentee can restrict $\mathrm{X}$ to his narrow area, $Y$ may be willing to pay more for a different area knowing $\mathrm{X}$ is not a potential competitor. A licensee will normally pay more for a license that is exclusive or semi-exclusive than for one that is non-exclusive.

What all this comes down to is this: There are three entities involved, namely, the patentee, the licensee, and other licensees. Each has a double interest in the patented invention, to wit, (1) the right to use it and (2) protection against others being able to use it. The patentee, of course, starts out with both of these rights by virtue of issuance of the patent, so his interest lies in getting as much as he can in the way of royalties or other benefits, without giving up any more of his exclusionary rights than he has to. A limited license does just this: it enables the patentee to grant a narrow right of usage, albeit a right as broad as the licensee really desires, reserving to himself the remaining areas, either for his own immediate advantage or for parceling out to other licensees. But a narrow grant to $\mathrm{X}$ licensee is, to that extent, a protection against competition to $\mathrm{Y}$ licensee-a protection for which Y may be willing to pay. The advantage to the patentee of being able to license in this manner is obvious - and it is freedom to do so that a flexible, generous licensing law gives him.

And so, one may reach without too much difficulty, the conclusion that the Patent Bar bill approach is likely to have real advantages to the inventor if one looks at the matter solely from the standpoint of licensing a given, existing patent. As I have previously suggested, this is likely to be true to some ex- tent for the employed inventor as well, since the greater value to the employer should sooner or later, and more or less, mean increased compensation for those who created the value.

But what about the other side of the coin? What happens to the market for inventions if widespread restrictive licensing is engaged in? Here, one is given pause.

It is familiar learning that my actions of today, undertaken quite soundly in my own best interests, may adversely affect what others, and I as well, do tomorrow. A load of fresh vegetables brought to market today may reduce the price paid for tomorrow's load. Profit-taking on the stockmarket depresses the price levels of stocks. In a more generalized examination of this phenomenon, Garrett Hardin has pointed out in "The Tragedy of the Commons" how cashing in one's rights today may pervasively reduce the rights of all, including one's self, tomorrow. So, I repeat, what does happen to the market for inventions?

I have suggested previously that it is the force of competition, whether in terms of the attraction of monopoly or semi-monopoly, or fear of what one's competitors may do, that provides the chief economic spur to invention. As for the role of the patent system in all this, I suppose there are two major situations in which patent licensing or nonlicensing practices can act as a genuine stimulus to invention-and thereby strengthen the demand for inventions and for the services of inventors. First, a flat refusal to license at all should act as a spur to competitive research, inventing around, or whatever you choose to call it. The patentee, with his monopoly, may be able to relax, temporarily, but others cannot if they are to stay in business. Second, unlimited, unrestricted licensing - in effect, writing off the patent system insofar as competition is concerned-retains product competition to the full, except as it may be affected by other factors, and again provides a spur for invention in the hopes of one's obtaining advantages over one's competitors. [I should mention a third and concededly rather common situation. This involves the licensing of complementary patents, i.e., patents on inventions that work together, so that failure to license results in blockage. Reluctantly, because of the pressures of time, I am going to pass over this area. It is too complex to deal with briefly. And under either proposed bill, reasonable licensing provisions will probably turn out to be acceptable.] 
But to get on with the discussion: In the limited licensing situations which are the subject of both the Patent Bar and the Hart bills, the effect of the limitations is invariably to permit the various parties, patentee and licensee as well, to use the invention in designated ways or on designated terms, and at the same time to insulate themselves to considerable extent against competition in their chosen fields. If it is true, as I believe it is, that the pressures or fears of competition are what stimulate invention, then it follows that removal or lessening of these pressures or fears will lessen the stimulation - in other words, reduce the demand for inventors.

There are indications that this does, in fact, happen. Schumpeter, one of the great economists, emphasized that competition through product differentiation was replacing price competition in oligopolistic industries (industries dominated by a small number of large producers) but as far as I know he did not follow through and explain why the members of such industries should be any less disposed to seek the quiet, comfortable, non-competitive life in the technology area than they were in the price area, provided they could find the means for doing so. The legalization of limited and restrictive licensing, including pools, provides such a means. In recent times we have seen the efforts of the automobile industry to mark time in the development of emission-control devices. There is the Antitrust Division action against the aircraft manufacturing pool based on an alleged solid front of disinterest vis a vis outside inventions. There is the current case charging United Aircraft with discouraging R. \& D. on the part of TRW. There are the continuing complaints about the "Not Invented Here" syndrome on the part of large concerns. I grant you that one swallow does not make a summer. Nevertheless, these are straws in the wind that should give pause to one who seeks a thriving invention industry and is concerned for the welfare of the inventor, independent or employed.

What I have suggested in this discussion is an in. teresting paradox: As the owner of an existing patent, it is to my immediate advantage to have max- imum freedom and flexibility to license or not as I choose, and to license on such terms as I see fit. But in the very act of licensing in such a manner $\mathrm{I}$, and the myriad other patentees who follow the same course, run the real risk of seriously weakening the market for further inventions by contributing to a structure of comfortable, instead of uncomfortable, monopolies, or to industry structures in which competitors are so few as to result in oligopolistic or shared-monopoly conduct.

I am fully conscious of the fact that I have been talking theory, and that I have not made a clear, iron-clad case for the proposition that inventors, as a body and in terms of long-range interests, are better off with the Hart-type proposals than they are with the Patent Bar-type proposals. But I see nothing to indicate that those who take the contrary position have made their case either. What is needed here is a close, hard, down-to-earth look at what actually goes on at the various levels, in terms of the forces and factors I have been discussing here this morning-a hard look that is needed at various levels. After all, the courts and Congress are driving blind just as much as we are.

Meanwhile, if I were a monopolist or a would-be monopolist, seeking to preserve my monopoly position, I would probably welcome a law based on the Patent Bar pattern. I would do likewise if I were an oligopolist. But if I were a small concern, trying to obtain or maintain a foothold in my industry, or if I were an independent inventor, dedicated to making inventions, and hoping either to exploit them or to find a market for them, or an employed or employable researcher looking for an employer who really wanted and needed my services, I think I would prefer to let the law stand as it is. If I had to take a position, I think I would opt for the Hart proposals - or, at least, a debugged version of them. At the minimum, I would want to take a hard look-much harder than has been taken to date-before jumping on the band wagon with those who would lead me down the garden path in the other direction. 


\section{Discussion}

J. Rabinow: I am not, by law, allowed to comment either on the Scott amendment or the Hart bill, but there are things I can say which are factual. The Hart bill, among many things, also proposes that the life of the patent will be 12 years from the date of filing, and the maintenance fee after 4 years becomes $\$ 1,000$. This will rise by 20 percent per year, which means that in 12 years the small company, which John and I both like very much, will have to pay some $\$ 15,000$ for each patent. The Scott amendment gives the patent owner certain rights which the Hart bill doesn't.

There is one fact that you people should know: The President's Commission recommended that the argument between the antitrust laws and the patent laws should be clarified, and they suggested this without any specific recommendation, saying that Congress has the duty to clarify this once and for all. When I testified before Senator McClellan, I said that $\mathrm{I}$ as an inventor have no strong feeling about what my patent rights are v. the antitrust, but I'd like to know what the rights are, once and for all. It should not be a matter of a man in the Department of Justice making the decision whether he is going to fight me or not fight me. I simply want to know what the law is. When that bill was finally written, that item was deleted. When we in the Inventors Council asked the counsel for Senator McClellan why it was deleted, we were told that the Department of Justice fought against this one item and said, "If this item is done in any form, the Department of Justice will oppose the whole bill and the bill will never get out of Congress." And the Department of Justice to this day insists that it, and not the law, decides which things are rule of reason, which things shall or shall not be opposed in court. John, I think it's your duty to tell us why the Department of Justice does not want Congress to clarify this very fundamental issue.

J. Stedman: Let me make two or three comments. One: it is important to distinguish between the Hart bill and the Hart bill. There are two Hart bills. One has actually been introduced, and that is Hart's own version of what the patent structure should be; in other words, his patent revision bill. The other one is the one which has not been introduced, which is a special amendment. He said, "I will introduce if it becomes necessary," but he hasn't introduced it yet, and it would be an amendment to the Federal Trade Commission.

On the matter of clarification, I think all I can say to what Jack has said is "Amen." There is a desperate need for clarification of the law in this area. I think I've made that perhaps both implicit and explicit in my discussion, and I emphasized the fact that 350 years of confusion is enough. But I think there were two questions that were left: one was whether it should be part of the present patent revision bill. This, for some rather complex reasons, I really don't think I ought to attempt to go into. I really think it should be handled separately. I thoroughly agree with Jack that this is a responsibility that Congress should have. As far as having a duty to explain what the Antitrust Division does, there was a time when I was in the Antitrust Division, and I considered probably at that time, if somebody asked me, I did have such a duty. I have not been in it for 15 years or more, and so I don't think I have any duty to explain why they take a particular position, and thankfully I don't, because I don't know why they do myself at times. I have a feeling in this particular instance that they have serious reservations as to whether the injection of a rule, just in terms of a rule of reason, really would clarify the law. And here I think I feel impelled to say that I agree; I think it would confuse the law rather than clarify it, as things stand at the present time.

I. Kayton: I'm aware that I'm speaking later today, and I would like to address myself now to Professor Stedman's comments in one area to which I will not be addressing you later. And I don't really want to let this opportunity go by, because Professor Stedman has, in a most gracious way, led you down the most pernicious garden path I have ever seen. He very beautifully referred to Schumpeter's exposition on the significant new kind of competition that's meaningful in our society; namely, feature or product competition, as being very significant alongside of price competition. What Schumpeter was suggesting by that is that the nature of the game has changed today because of technology, and that for the first time we can look to the introduction of competition into our industrial society because of technological innovation. Professor Stedman tells you that competition is lessened by various techniques, looked at after the patent has issued, 
which is totally beside the point, is irrelevant and immaterial to you and our considerations here. What is relevant is, how do you inject this competition into society? How do you get the innovation? How do you generate the incentives to innovate? The antitrust laws have never since the beginning of time, do not now, nor can ever inject competition into our society, and certainly not technological feature product competition. There is only one legal mechanism for doing that, and that is the patent incentive system used to induce people to invent. Now, if you think of a practical example in the form of a bathtub, with a stopper in the bottom, and a faucet at the top, and the water in the tub being the competitive factors in our society, the antitrust laws are the stopper in the bottom designed to prevent the competition from leaking out, and as a passive inactive device, cannot inject water into it. The patent system, on the other hand, is that active mechanism that introduces into our society the technological competition which today means more than anything else.

J. Stedman: Thank you, Irv, for making my speech much more eloquent than I possibly could. I think, actually, this is what $I$ was talking about all the way through; namely, the importance of the patent system; and what I was emphasizing at the last, and in my reference to Schumpeter I was accepting Schumpeter's approach, but I was pointing out that he had not given us a full answer to, in a monopoly or oligopoly structure, how you prevent people from stopping innovating, and ceasing to differentiate; and the main point I was trying to make was that there is a very important part that the patent system can play in this area of competition in the form of competitive research. My concern was that with the increased flexibility of licensing of this particular type, that the result of this is to write out of the market the competitive incentives that the patent system provides, instead of maintaining it. It's recognized that every time - this may be a slight exaggeration, but not very much of one- every time one licenses a patent, he is eliminating the competition that comes from innovation and new invention. This is what you are doing, exactly.

J. Rabinow: It isn't so, John. The fact is, every time I license a patent, and I have done this a few times in my life, someone wants to compete with me and starts inventing like crazy. Not only that, but he says, "If that jerk could invent, I could invent." This is one of the basic fundamentals of invention, that if Jack Rabinow could do it, a million guys could do it, and I'm not saying this to belittle my invention, I'm pretty good at it. But I do this to others: If I see that guy invent an improvement, I say, "I could do it better." I could give you fact after fact of how this was actually accomplished in the case of post office equipment, watches, and anything else you like. What happens is that when you invent, and give a license to one company, immediately their competitor comes to a couple of guys and says, "Hey, he's got an interesting new product; he's opened a whole new field." They begin to invent. It is simply not true that when you give a license you stifle competition. I deny this point of view; I can give case after case if you wish me to.

Question: Where have the Scott amendments been published so that we can look at them in detail?

J. Stedman: The Bar Association ones-I don't know that they have been published yet. They have been distributed in a printed form; I'm sure you could get them by writing the Chairman of the Patent Section of the American Bar Association, or the APLA; and the Hart amendments could be obtained, I suppose, either from Senator Hart's office, or they were published in the Patent, Trademark, and Copyright Journal, as put out by the Bureau of National Affairs in Washington.

M. Harris: Jack, both you and Professor Stedman are right on this point. My own experience is that when you take little gadgets and small developments and license them, people start inventing around them. But in the big developments, where a company takes a license to manufacture polyethylene and has to build a $\$ 2$ to $\$ 3$ million plant, they do a minimum of R. \& D., just enough to support that ongoing plant, but it really does stifle the innovation in those areas, so you have this whole spectrum. The generalizations are all wrong.

J. Rabinow: That's interesting, because in the case of Nylon - this would argue that once Nylon was invented, it would stifle competition. The fact is that there are more plastics now than there ever were. While it's true that Nylon may be a basic patent that Du Pont has and it stifles Nylon development, I argue, "What do you mean by stifle; they invented it." But the fact is that many other plastics were developed. 
M. Harris: People who took licenses on making fiber Nylon, mostly are just going along on the way they did it.

J. Rabinow: What's wrong with that?

M. Harris: I didn't say there was anything wrong; I was just saying that's what's happening.

J. Rabinow: Who is stifled? You invent Nylon, I buy a license and make Nylon stockings; just what is being stifled?

J. Stedman: I suspect the real answer is, you cannot generalize in this area; that in different situations you will have different things. Sometimes, if I can get a license, I may be inclined to go ahead and do something, whereas I wouldn't if I couldn't because I wouldn't be able to use it anyway. But the point I was trying to make is that in the very act of obtaining a license, and I think it's a valid point, I have substituted an invention that somebody else has made for the effort of trying to do something myself.

J. Rabinow: That's a very interesting point, that because I invented a watch regulator, it prevented somebody else from doing it. I deny this; watches had been built for the last 300 years, and I was the guy who said, let's make an automatic watch regulator. Are you saying that I stopped other people from inventing the watch regulator because I invented it?

J. Stedman: No, I said that they would invent more if you hold the patent to yourself.

J. Rabinow: But what stopped them from doing it for 300 years? Suddenly I developed a watch regulator. Now, other people say, "Well, there are other ways of regulating watches." How did I prevent anybody from inventing an art that's been in existence or how did some chemist prevent anybody from inventing Nylon because he invented it?

J. Stedman: That's the point I've been trying to make: that a person does make inventions but that if he can get the invention from somebody else he may be less inclined to make an invention than if he is forced to engage in inventing for himself.

J. Rabinow: I don't understand the argument. You mean if I can buy an invention from him, I won't invent it myself. That means I was going to invent it but because he did it first I'll buy it from him. I don't understand this kind of logic. This implies that inventions are much more rational than they really are.

J. Stedman: And inventors, too.

J. Rabinow: And inventors - that's correct.

H. Forman: There was testimony given before the McClellan Committee by representatives of a small group of independent inventors that called themselves the American Society of Inventors. I can recall a colloquy between their spokesman and Senator Hart, who happened to be presiding that day. These gentlemen said, "When we make an invention in a given field with our limited resources, about all we can do is hope to manufacture, if we can do it at all, in a single community, a state, or the east. We don't have the facilities to manufacture across the country. Now, this limits our opportunity to capitalize on our inventions and it also deprives other areas of the country of our inventions. If you deprive us of the right to grant licenses to people on a territorial basis we say, Senator Hart, this is anti-competitive. This is not introducing and adding to competition; this is destroying competition." Senator Hart said, "I think you may have something there." Now, why didn't he recognize this in his bill? We have good antitrust laws and we should keep them but there's no reason why they should prevent the Scott amendments from doing their job in promoting utilization of inventions.

J. Stedman: First, I'll refer you to Senator Hart rather than attempt to answer the question myself. I think we could recognize, Howard, that this is an incredibly complex situation. There may be situations where this kind of licensing may be perfectly permissible, where it is permissible under the present law, and that what is needed is a harder look and a closer examination to see in what circumstances some of these things should be permitted and in what circumstances they should not be permitted. This is exactly what I am saying when I say we need to take a much harder look than we've ever taken. My difficulty with the Scott amendments, and I must say I have the same difficulty with the Hart amendment, is that neither of them takes this position. They lay down and attempt at a flat rule and the situation you referred to may be fine in the case of the company you referred to. In another situation, it may be very bad. If two, three or four concerns, let's say, in an industry dominated by three or four con- 
cerns get together and engage in this limited type of thing, then you're in a mess.

J. Rabinow: I think that we agree it is time that Congress take a look at the antitrust laws versus patents.

J. Fulleylove: You made the generalization that, as I recall, patents only had meaning and value in a competitive environment. I wonder if you are not overlooking a certain situation where an invention is widely used and the patentee merely looks for a reward by broadly licensing any and all who may use his invention. A case comes to mind of the Townes patent which our Foundation has assignment of and has been licensing, a case where we can make no claim whatever to having contributed the use of the laser or the maser through our managing of the patent. All we tried to do is to bring about some return to Townes and to the scientific community through our receipt of royalties from companies which have been formed and gone into business making lasers. Is that not an exception to your generality?

J. Stedman: I guess I would say that if somebody is willing to pay for the license, it is because he is either concerned that he won't be able to compete if he doesn't have the license, or that if he gets a license this may give him an advantage that others may not have.

J. Rabinow: I would like to read a few statistics which are very interesting, just for your information. The United States applied for 85,000 patents in 1963 ; in 1965 we applied for 89,000 patents; in 1970 we applied for about 101,000 patents. Japan at the same time, in 1963 applied for 36,000 (we applied for 85,000 at that time); in 1965 we applied for 89,000 ; they applied for 60,000 . In 1970 we applied for 101,000; Japan (natives applying for native patents, not for foreign patents) applied for 101,000 patents exactly equal to us in 1970 , with a smaller population. Plus, in "utility" patents they applied at the same time for 140,000 more, so their total filing in 1970 was 241,000 patents, which is $2-1 / 2$ times the patenting effort of the United States in 1970. This is very important; Japan is now filing, with a smaller population, 2-1/2 times as many patents (you can argue that utility patents are not equal to our patents; this I leave to the patent lawyers; I think essentially they are). I could give you other statistics, which I'll do during the day, about how the foreign companies are doing in certain specific fields. And this is worrying our Congress, and this should worry us. Should we increase the rewards to wise guys like me, or should we not, quite aside from what it does to the antitrust laws? 


\title{
The Inventor in a Changing World of Patents
}

\author{
Arthur R. Whale \\ The Dow Chemical Co., Midland, Mich. 48640
}

\begin{abstract}
It's time we overcome our collective hardening of the attitudes about changes in the patent system. The simple choice is whether the design of change will pass by default to those in the courts or Congress who march to different drummers, or whether those who use and understand the system will meet the challenge of change.

The patent system faces an identity crisis. Three positive approaches would help set thinking straight:

1. Emphasize the patent system's effectiveness in areas of its intended operation in the useful arts.

2. Foster understanding of the interdependence of invention and innovation in making the patent system work in the public interest.

3. Work for a no-fault divorce between patents and antitrust to rectify the subservient status now assigned to patents.

At the same time, we should move to reconstruct the patent system rather than repair it. Recognizing that the concept of patents remains sound, we should give consideration to carefully circumscribed adversary proceedings made practicable by deferred examination and maintenance fees and administered by an independent Patent Office. Thorough discussion of the possibilities and pitfalls of these approaches should lead to a patent system of increased vigor and the restoration of confidence in the patenting process without distress to the substantive aspects we seek to preserve.
\end{abstract}

Key words: Adversary proceedings; antitrust; deferred examination; independent Patent Office; innovation; inventor; patent system; useful arts.

There is no doubt that the inventor's world of patents is changing in many ways. For one thing, he's finding it increasingly difficult to go it alone, considering the expense of getting and enforcing patents and, indeed, of making inventions of interest in today's sophisticated technologies. But the system, fundamentally, must recognize the importance of individual inventors, regardless of how or where their work is done. At the same time, it must recognize the public's interest in enjoying the fruits of inventions for which the public grants the patent privilege.

At this particular juncture in history, we are seeing a concert of attacks on the patent system. These demand our attention. They override, in my view, the parochial interests of individual inventors and patent lawyers and corporations. For that reason, I'm going to direct my comments principally to what I consider the most urgent matters I could bring before you. I'd like to discuss some attitudes and factors which I believe are implicated in the problems facing the patent system, and I'll venture some sug- gestions for basic changes in the machinery of patenting.

To begin with, consider the following: the Patent Office and the courts disagree about 70 percent of the time as to validity [1] ${ }^{1}$. One Government agency has received a hunting license to shoot down the patents issued by another Government agency [2]; and a typical antitrust appraisal of patents was expressed by a court recently when it said: "Monopolies-even those conferred by patents-are not viewed with favor [3]."

Consider also a decision of May 10, 1973, from the Sixth Circuit Court of Appeals. The Court held, in Kewanee Oil Company v. Bicron Corporation, that a trade secret in commercial use for more than 1 year could not be protected under a state trade secret statute if the subject matter was appropriate for patenting [4]. This would seem to effectively foreclose inventors from the trade secret option. The decision is monumental in its implications. It's in

\footnotetext{
'Figures in brackets indicate the references at the end of this paper
} 
direct conflict with those of several other Circuits, and it has been appealed to the Supreme Court.

The Kewanee decision may be good business for patent lawyers, but I predict it's going to be opposed by the Patent Bar because it's bad law. In any event, it puts an added premium on dependability of the patent system. Indeed, the whole concept of patenting is only viable if it is reasonably dependable in its implementation; and dependability means nothing more than the issuance of patents by the Patent Office that will stand the threshold test of novelty and be judged as to validity in the courts by consistent application of the law.

Unfortunately, the fact that less than 1 percent of patents reach the courts does not properly suggest the dimensions of the problem. This was generally referred to yesterday by Dr. Ancker-Johnson. But what is often missed is the fact that the uncertainties as to what a court will do with patents influence all kinds of transactions involving the inventions.

We are, indeed, at a "crisis in the law of patents," as Professor Kayton has observed in a recent study of the validity of patents in the various judicial circuits [5]. It is, however, and I think this is extremely important to bear in mind, a crisis of confidence in the patenting process, and not in the patenting concept.

Nevertheless, tinkering with the process will not be enough. We should see that the patent system is viewed for what it is: a positive and independent force for progress, and not a miscast remnant of the past, or an unfortunate exception to the antitrust laws.

\section{Directions of Philosophic Change}

It seems to me there are three faulty premises that have been grinding away at the patent system for some time. These have contributed to an underlying distrust of the so-called "patent monopoly." We need to urge a better understanding of the philosophy of patents in order to create a more favorable and realistic climate for evaluating the system.

\section{Science v. Useful Arts}

The first faulty premise is that the patent system is not doing its job because it is not encouraging "science," as distinguished from the "useful arts"
[6]. We hear this most often from the scientists, which is particularly unfortunate because the influence of the scientific community has increased dramatically in recent years. This has been due es sentially to the emergence of science as an instrument of national policy through the reaches of the space program and the fallout technology it has produced.

I suggest that the patent system was never intended to promote the progress of science, in the sense of the quest of knowledge for its own sake. Scholars have demonstrated, I think rather conclusively, that Article I, Section 8 of the Constitution, from which the patent system derives, associates "useful arts," "inventors" and "discoveries" in one class, and "science" (in the sense of general knowledge), "authors," and "writings" in another [7]. This separate classification gives rise to separate systems of patents and copyrights.

Indeed, in 1790 the first patent law was passed by the Congress. It was called "An Act to Promote the Progress of Useful Arts." Shortly thereafter, the first copyright law was passed; it was called "An Act for the Encouragement of Learning." The two systems were not confused in the Constitution, and we shouldn't confuse them today in testing the effectiveness of either to do its job.

\section{Invention v. Innovation}

The second faulty premise is that the bundle of rights comprising the patent grant is not equally operative in encouraging invention and innovation. Such reasoning makes it easy to justify restricting the ways in which a patent may be used; but it denies the attributes of personal property to patent ownership, despite plain language in the statute that says patents are personal property [8]. Moreover, the conceptual separation of invention and innovation is damaging to the public interest served by patents and is contrary to the Constitutional purpose behind the patent system.

No progress, in terms of the public interest, comes from invention alone. The act of inventing, however rewarding to the individual, is nothing more than an act of self-gratification unless the invention is brought to public use, if not by the inventor, then by his designee during the life of the patent, or by someone who reads the patent and does something with what it teaches. 
Public notice of the invention through the publication of the patent discharges the patent owner's obligation in exchange for his grant. But that does not exhaust the right of the inventor to bring the public the fullest benefit of his work in the form of an innovation, which Mr. Webster defines as "the introduction of something new," and which Mr. De Simone, in his report on technological innovation, defines as "a complex process by which an invention is brought to commercial reality" [9].

I cringe when I hear the patent system defended on the ground that it encourages invention, without hearing the other shoe drop. You and I know that a man with an inventive turn of mind will invent, no matter what. But whether he will invent in areas requiring heavy investment of time and capital, and high degrees of risk, or be able to innovate from what he has invented, may well depend on whether he can look to reasonable prospects for patent coverage on the results of his work. Perhaps we should explain this more carefully to some of the critics of the patent system.

The point at hand is that the patent system must be justified or condemned for its effects on innovation as well as on invention. And if innovation is elevated to such an important consideration in the functioning of the patent system, as it should be, the patent owner's use of his patent in the innovative process should be given all the latitude the patent grant permits. In short, if implementation of the patent statute is to be responsive to the Constitutional mandate, it must encourage the patent owner to innovate as well as to invent.

\section{Antitrust v. Patents}

The third faulty premise is that the patent laws must always give way to the antitrust laws in any apparent conflict [10]. Now, Professor Stedman has tried to swear back of the patent system by about 300 years, but I would confine myself to the existence of the patent statutes and the antitrust statutes in this country. We sometimes forget that the antitrust laws are junior in origin to the patent laws in the United States by some 90 years, and that they developed from circumstances totally unrelated to the use of patents. It was no less than Justice Douglas, a man not frequently identified as a friend of the patent system, who wrote [11]: "The patent laws which give a 17-year monopoly on 'making, using or selling the invention' are in pari materia with the antitrust laws and modify them pro tanto."

Nevertheless, in 1969 the Department of Justice announced that patent license provisions would be tested for antitrust compliance according to two principles: first, whether a particular license provision was necessary to the patentee's exploitation of his lawful monopoly, and second, whether less restrictive alternative provisions were available which would more likely foster competition [12]. There followed an intensive period of "luncheon legislation" by members of the Patent Unit of the Antitrust Division, in which they espoused their view as to what was right and wrong in patent license provisions. Professor Oppenheim, an eloquent and widely respected voice within the antitrust bar, was moved during this period to express the lawyer's lament: "Shall [the Bar] advise [clients] on the basis of what the law is, or on what the Antitrust Division believes the law ought to be?" [13]

Where, indeed, is the requirement in the patent statute that a patent owner only license on terms necessary to exploit his invention? Or that he select terms that are the least restrictive of available alternatives? Where does it say the patent owner has an obligation to use his patent only in a way that fosters the kind of competition with which the antitrust laws are concerned? Certainly not in the Constitution, which speaks in Article I, Section 8, of promoting the progress of useful arts, not of competition.

I believe, however, that patents do foster competition, but a special kind of competition-competition in value, as distinguished from price. As Professor Stedman pointed out, patents encourage inventing around a patented invention to obtain something entirely new. not merely the old thing made cheaper. I know of no greater stimulus to invent than a valid patent blocking the way to copying a successful invention.

Unfortunately, the incursion of antitrust in the normal functioning of the patent system has become so pervasive that an antitrust counterclaim is almost automatic in suits by patent owners for infringement. The theory is that probably, in today's climate, some conduct or practice of the patent owner can be found that would offend the anti-patent sensitivities inherent in today's antitrust philosophy, and thereby aid the defendant's cause. So you can see that uncertainties and opportunities to intimidate prevail in abundance. 
Former District Court Judge Rifkind has called for what he termed a "divorce between patents and antitrusts" [14]. He suggests that patents not be subject to an antitrust defense. If the defendant really wants to press an antitrust claim, Judge Rifkind urges that he should do so by independent action in order that litigation on the patent can proceed, with the merits of the patent alone at center stage.

We are already fixed with the stigma of "monopoly" as a description of the patent grant. We even take the bait and try to argue that it really isn't a monopoly. I used to go to bed at night worrying about people who were talking about the patent "monopoly," and you see what happened to me. So I finally gave up. I now think, Professor Kayton to the contrary notwithstanding, that we should face the fact that it is a monopoly, and we shouldn't be embarrassed to say so! But when we speak of the patent monopoly, we should also make sure that people understand how fragile and purposeful and conditioned that monopoly really is.

It seems to me it serves neither the purpose of antitrust nor of patent concepts to assign dominant and subservient status to these vitally important instruments of our competitive economy. Rather, both should recognize their functions as complementary, and each should go about its separate business.

The philosophic changes to correct the faulty premises I have outlined would go far to building a more dependable patent system, but they are not enough. We need also to take a critical look at the time-honored procedures for patenting, and see if perhaps their time has ended.

\section{Directions of Procedural Change}

In my view, many courts have reacted with a distinct anti-patent bias in the patent disputes before them. This has been due partly to the climate of suspicion created by overly zealous antitrust pronouncements and intervention, partly to a lack of understanding of the legitimate function of patents in the rcal world, and partly to the readiness of members of the Bar, and of the clients that hire them, to exploit the intimidating character of an antitrust defense or counterclaim.

But more is obviously involved. Remember, the attitude of the courts has grown out of many years' experience with the present system. I've not joined those who advocate special patent courts, or special judicial handling of patent matters, as the solution to the problem. Rather, I suggest we first look carefully at what seems to trouble the courts the most. Instead of changing the judges, maybe we should change the system.

If we do this - if we look at what's troubling the courts-we find as a recurring theme in judicial criticism the absence of adversary proceedings in the patenting process. By this is meant the lack of opportunity for third parties having specific interest in the subject matter under consideration for patenting to produce the art and the arguments as to why a patent should not be granted. Former Supreme Court Justice Fortas has said [15]:

"The skepticism about the Patent Office procedure, perhaps stemming largely from its differences from familiar judicial and quasi judicial proceedings, is, in my opinion, the fundamental stumbling block in the way of obtaining more sympathetic treatment of patents in the courts. Until we can materially reduce the vast differences between Patent Office procedure and conventional quasi judicial proceedings, I do not believe much progress will be made in reducing judicial hostility to patents."

Similar views, sometimes much less kindly put, have come from other judicial sources [16].

Another irritant is what the courts interpret as a lack of cooperation on the part of inventors and attorneys in bringing knowledge of the prior art to the attention of the Patent Office. In truth, this has been parlayed far out of proportion to the facts. Seldom is the examiner not informed of prior patents or literature, of which the attorney has knowledge and which he believes to be revelant to patentability. The trouble is that in some circuits the permissible dimensions of attorney judgment in such matters have shrunk to the point where the attorney must be a virtual insurer that the court will agree with him as to what is relevant-under penalty of being guilty of some degree of turpitude ranging from fraud to lack of candor.

There's also the practical problem, however, of the continuing increase in the publication of technological information in the United States and, particularly, abroad. The Patent Office search files now contain some 12 million patents and are increasing by about 450,000 new patents and about 25,000 
non-patent documents each year [17]. So the burden on the Patent Office, as well as on the inventor and the attorney, to cover the pertinent literature in the field of an invention is apparent. Help is obviously needed.

\section{Adversary Proceedings}

I suggest we consider some form of adversary proceedings in the Patent Office. This would be directly responsive to the expressed judicial concerns. It would also be responsive to the prior art problem. The facilities and abilities of the Patent Office have simply been inadequate, within the limitations of budget, space, personnel, and retrieval technology, to handle the job alone. Inputs from other interested parties would improve reliability of the examining process and the confidence of everyone in the patent system.

Now, implementation would not be easy. The two principal elements of such proceedings would be publication of pending applications and limited participation in the examining process by parties other than the applicant. Applications could be published a designated time after the first Office action or after filing. Following publication, third parties could submit art and arguments concerning patentability. But-and this is essential-no such procedure should give third parties the chance to shorten the life of any patent that issues, or give them access to records of the applicant outside the Patent Office.

It's of interest to note that the Commissioner of Patents, in a talk on May 10, 1973. announced a new procedure for the Patent Office [17]. This would, within existing law, introduce a limited form of adversary proceeding. An applicant whose application is allowed will soon be permitted to request that it be published. Interested parties can thereafter, for a limited period, submit art or information for consideration by the examiner before the patent goes to issue. We will follow the Commissioner's innovation with interest.

\section{Deferred Examination}

But how can a change so drastic, and one that will occupy additional time of examiners in evaluating the submissions of outsiders, be handled by a Patent Office staff of reasonable size? I suggest we consider a system of deferred examination. Now, under deferred examination, an applicant could elect within a specified period of years when to subject his application to examination. Thus, he would enjoy a period after filing in which to decide whether or not he wished to proceed with the expense of examination and prosecution, and the Patent Office would be spared the time of examining applications in which the applicants lose interest. Such a practice would not be without its difficulties, particularly if coupled with publication and the right of third parties to ask for examination [17]. But in my view the difficulties are not insurmountable, and there might be offsetting gains for everybody.

Experience in Holland indicates that about 60 percent of applications are never called up under their system of deferred examination [18]. One might argue the relevance of the Dutch experience to the U.S. picture, but it certainly is indicative of the direction, if not the degree, we could expect from such a practice. I believe it merits our study.

\section{Maintenance Fees}

If we enact such innovations, are we in danger of pricing patents out of the reach of many inventors? I think quite probably the answer is "yes," particularly under present prospects for extracting proportionately more money from the Congress, and certainly under the schemes I've seen for recovering fixed percentages of Patent Office expenses from fees. So $I$ believe we should consider a system of maintenance fees.

For years I've been in a lonesome minority favoring a system in which payment of Patent Office fees could be deferred for several years. then presented annually as a condition of maintaining patents in force. It seems to me that individual inventors and corporations alike would benefit by delaying payment until there was money coming in, or at least the prospects of it, to cover the fees. If a patent were not of sufficient interest to justify its upkeep, the public would receive the free right to use the invention at a date earlier than the normal expiration of the patent.

\section{Separate Agency}

But what about the Patent Office itself? For years the Patent Office has had to justify its budget to the Congress on the material balance between what it takes in and what it puts out. Dr. Ancker-Johnson mentioned yesterday that this again had happened in the 1973 hearings. 
Quality is difficult to measure, but one of the least reliable parameters of quality is quantity. But quality underlies validity, and there's the problem. With the number of patent applications and the Patent Office search files growing steadily each year, consider the effects of searching more and more documents in shorter and shorter times to increase that output, and yet issuing intelligible, thoroughly considered Office actions with inadequate staff. Something has to give, and unfortunately that something is often quality.

The Patent Office has many dedicated and highly competent employees. Much has been done lately to increase its mechanical efficiency. But the Patent Office is an old-line Government agency, with perhaps more than its share of entrenched diverse philosophies, interpretations, and procedures. In some respects it's a bundle of little patent offices pulling in different directions, and the Commissioner of Patents is virtually without authority to fire incompetent and insubordinate employees in either the professional or service arm of his organization.

To compound these difficulties, it appears to this outsider that the Patent Office is a stepchild in the Department of Commerce. The Patent Office periodically suffers from the paralysis of political uncertainties in the Department of Commerce, and it's doing so today.

I suggest the Patent Office be made a separate agency. This would give the Patent Office greater authority in implementing the patent statute and handling its administrative problems. It's true that the clout of a major government department would no longer be available in dealing with intergovernmental matters and with budget problems. But residence in Commerce has not brought, in my judgment, the advantages of belonging that outweigh the burdens.

For example, one might have expected more consideration for the needs of the Patent Office in spending the money appropriated to the Commerce Department last year to find ways of stimulating the innovative process, pursuant to the President's Message on Science and Technology [19]. At this meeting we've heard much about the Experimental R. \& D. Incentives Program and the National R. \& D. Assessment Program. Although Mr. De Simone indicated they were finally funded at considerably lower levels, they were established with something like $\$ 18.5$ million and $\$ 2.1$ million, respectively, for studies and recommendations.

I can't help but feel that some of this money (except the money spent for meetings like this!) could have been better committed to expanding the search capabilities of the Patent Office. The Commissioner has noted that some $2,340,000$ U.S. and foreign patents need reclassifying [20]. This would have been another worthwhile project, and these investments would have contributed in a very tangible way to the objectives of the President's program. Perhaps the Patent Office would have fared better by stating its own case. In any event, operating as an independent agency, the Commissioner should be more his own man to shape the Patent Office more closely to the dimensions of its mission.

\section{Pending Legislation}

It's prudent to note, as Professor Stedman has already mentioned, that the only patent legislation now pending before the Congress is S.1321, introduced by Senator Hart [21]. You may recall that Senator Hart led a 3 to 2 majority in defeating last year's administration-sponsored bill, S.643, which enjoyed fairly wide support among inventor and Bar groups. It would be well for us to assume that he could muster the same majority in support of S.1321. A corresponding bill has been introduced in the House by Representative Owens, along with a catalog of quotations unfavorable to the patent system and to the Patent Bar [16].

Despite one's immediate reaction to proposals from such unfriendly quarters, I note with interest the inclusion in S.1321 of provisions for adversary proceedings, deferred examination, maintenance fees, and the Patent Office as a separate agency. Except for the broad proposal with respect to the Patent Office, however, I object strenuously to the specific implementation described for these proposals. Nevertheless, if the basic concepts should meet with the approval of the Department of Commerce, inventors, and the Bar and of other groups working within the patent system, we may have common ground for patent reform legislation. I hope that passions have cooled sufficiently with respect to antitrust legislation that patent matters can move forward with or without the Scott Amend. ments or its substitutes. 


\section{Summary}

What I've been saying is that it's time we defended the patent system in terms of its intended operation and not be drawn into disputes as to whether it promotes science in the same manner it promotes the useful arts.

I suggest the same concern for the tendency to exclude innovation from a proper part in implementing the patent system. We must think of invention and innovation as a necessary duality in making the system work as it should. Otherwise, the system will diminish in scope and in effectiveness, and the public's interest, as expressed in the Constitutional purpose, will not be fully served.

Fostering the concept of divorce between patents and antitrust will untangle much of the philosophic confusion. Legislation in that area, however, should not delay patent legislation.

My personal view is that the time has come, to borrow language from a famous infringement case, for the patent system to undergo reconstruction rather than repair. I'm suggesting attention be given to a carefully circumscribed system of adversary proceedings, made practicable by deferred examination and maintenance fees, and administered by an independent Patent Office. I believe such a combination would increase confidence in the patenting process and restore dependability to the patent system, without distress to the substantive aspects we seek to preserve.

Finally, I want to convey a sense of urgency that we get on with the job and overcome the hardening of the attitudes that's marked some of our activities in the past. We face the question of whether the design of change will pass by default to those in the courts or in Congress who march to different drummers, or whether inventors and others who use and understand the system will meet the challenge of change. Thank you.

\section{Bibliography}

[1] Address by Honorable Robert Gottschalk, Commissioner of Patents, before the Patent, Trademark and Copyright Sec. tion of the State Bar of Texas, Houston. Tex. . July 7, 1972.

[2] United States v. Glaxo Group Ltd., 176 U.S.P.Q. 289 (1973). The Court specifically said it is not giving the Government "a roving commission to question the validity of any patent lurking in the background of an antitrust case." But the
Court also indicated how easy it would be to put the patent on the line. There need only be a challenge to the "basic as. sumption" that the patent is not valid.

[3] Deepsouth Packing Co., Inc. v. The Laitram Corp., 173 U.S.P.Q. 769. 772 (1972). Quoted with apparent approval from the decision of the District Court, 165 U.S.P.Q. 147, 149 (D.Ct., E.D. La., 1970).

[4] Kewanee Oil Company v. Bicron Corporation, et al., 178 U.S.P.Q. 3 (C.A. 6, 1973).

[5] Irving Kayton, "The Crisis of Law in Patents," Patent Resources Group, Washington, D.C. (1970).

[6] Arthur R. Whale, "The Scientist and the Patent System," Am. J. Hosp. Pharm. 22:311 (June) 1965.

[7] Karl B. Lutz, "Patents and Science-A Clarification of the Patent Clause of the U.S. Constitution," Geo. Wash. Law Rev. 18:50 (Dec.) 1949.

[8] 35 U.S.C. 261. "Subject to the provisions of this title, patents shall have the attributes of personal property."

[9] "Technological Innovation: Its Environment and Management." Report of the Panel on Invention and Innovation to the Department of Commerce (1967). Superintendent of Documents, U.S. Government Printing Office.

[10] Arthur R. Whale, "Antitrust Encroachment on Patent Im peratives," Chi.-Kent Law Rev.47:125 (Spring) 1970.

[11] Simpson v. Union Oil Co., 377 U.S. 13, 24 (1964).

[12] Address by Assistant Attorney General (now Federal District Judge) Richard W. McLaren before The Patent. Trade. mark and Copyright Institute of The George Washington University, 161 U.S.P.Q. II, III (No. 11, 1969).

[13] S. Chesterfield Oppenheim, "The Patent-Antitrust Spectrum of Patent and Know-How License Limitations: Accommodation? Conflict? or Antitrust Supremacy?" Idea 15:1 (Spring) 1971. Professor Oppenheim concludes that "the patent laws do not obligate the patentee to promote the kind and extent of competition demanded by the antitrust laws."

[14] Simon H. Rifkind, "Patents and Antitrust-Time for a Divorce," Bull. Am. Pat. Law Assn. 695 (Oct.-Nov.) 1972.

[15] Abe Fortas, "The Patent System in Distress," Idea 14:571 (Winter) 1970-1971.

[16] Floor remarks of Representative Wayne Owens on introducing Patent Reform Act of 1973 (H.R. 7111), P.T.C.J. 125:D-1 (Apr. 26) 1973. See also, Judge Hubert L. Will, "The Patent System-One Man's View," APLA Quart. J. 1:49 (Dec.) 1972.

[17] Address by Honorable Robert Gottschalk, Commissioner of Patents, before the American Patent Law Association, St. Paul, Minn., May 10, 1973.

[18] Netherlands, Report of the Octrooiraad, "Deferred Ex. amination." Ind. Prop. 12:369 (Dec.) 1972.

[19] President's Message to Congress on Science and Technology, Mar. 16, 1972, P.T.C.J. 70:D-1 (Mar. 23) 1973. The Pre. sident declared that "a strong and reliable patent system is important to technological progress and industrial strength" and that "we must make the most effective possible use of the incentives which are provided by our patent system."

[20] Address by Honorable Robert Gottschalk, Commissioner of Patents, before the Patent Resources Group, Bahamas, Mar. $29,1973$. 
[21] Senate Bill 1321, 93rd Congress, lst Session (Mar. 22, 1973), Senator Hart. In his introductory remarks on the floor of the Senate, Senator Hart said: "the evidence is strong that our system tends to frustrate invention and tie up technology so the public cannot benefit from it." To the extent this is true. it is a consequence of excessive antitrust zeal against the licensing of patents in ways best suited to moving inventions in commerce.

(Combined discussion follows next paper by $E d$ wardJ. Brenner.) 


\title{
The Role of the Patent Office in the Process of Invention and Inmovation
}

\section{Edward J. Brenner}

\author{
Association for the Advancement of Invention and Innovation, 2001 Jefferson \\ Davis Highway, Arlington, Va. 22202
}

\begin{abstract}
Examines how well the U.S. Patent Office is doing its job now, and presents some suggestions that might enable it to do a better job in the future.

Within the financial limitations under which it must operate, the Patent Office performs an efficient screening operation, rather than a validity proceeding, which would take far more time and money.

Two general suggestions are given for future improvement: first, that an Assistant Secretary for Invention, Innovation, and Intellectual Property be appointed in the Department of Commerce, to serve as a focal point for these activities; and secondly, that a systems analysis approach be taken to weigh the merits of various ideas for reforming the patent system.

Specific suggestions are also made for consideration: adoption of deferred or selective examination; a system of petty patents; a greater role for the Patent Office in litigation; continued efforts to improve mechanized searching; the institution of satellite search centers and a system of advisers to inventors; and a review of the patent system to eliminate some of the technicalities that may invalidate patents.
\end{abstract}

Key words: Advisers to inventors; deferred examinations; innovation; invention; mechanized searching; patent litigation; Patent Office; patent system reform; petty patents; satellite research centers.

I'm very happy to be able to participate in this conference. Unfortunately, when the Woods Hole Conference was scheduled I was out of the country at some other meetings and was unable to be there, but I remember the first conference like this. I think it was about 1965; it resulted from a recommendation of a panel of the National Inventors Council suggesting they get together people from different areas that would be interested in the patent system, and I chaired that conference. We had speakers from the business community, the scientific community, inventors, judges, Congressmen; and I thought I must be in the wrong place, because nobody seemed to be talking about the same subject. But I think maybe it was a first as far as getting people together in sort of a public forum. However, yesterday I thought maybe I was back there again, when I heard somebody from the Executive Branch of the Government at the White House proposing that it would be a good idea to institute a system of oaths in filing patent applica- tions, to eliminate fraud. Now, honestly, I think we all know that all patent applications filed in the United States require oaths, and have for decades, as far as I know; but I think it helps to point out one of the problems of communication in this business, and how little the average person knows about this subject. This includes many influential people in the Executive Branch, as well as in the Congress and in the Judiciary. They know very little about invention and innovation, and I think this is what a conference like this is intended to do: to help bring out some of the problems we face in this regard.

Now, as far as the program goes, you will note that I plan to speak on two subjects; namely, how well the U.S. Patent Office is doing at the present time; and secondly, whether it could do things differently or better in the future of the patent system and for inventors.

Very briefly, my position on these two points is that in regard to Patent Office operations, I may be 
biased, but I think it's doing quite well; it's not perfect, but really doing a pretty good job, within the limitations under which it must operate.

As to what could be done in the future, I think there are many things that could and should be done, and I'll just mention a few of these. I think it will be interesting to note how closely in some of these respects I'll be tracking along with Dick Whale in his earlier remarks, and we both prepared these remarks completely independently.

Considering the Patent Office's present operations, I think if you figure that under the budget limitations imposed by Congress, and considering that the world is changing constantly and getting more complex, as Jack points out, I think the Patent Office is doing quite an efficient job. Furthermore, I think one important point to keep in mind is that any system operated by human beings is not going to be perfect, so if anybody is looking for a perfect patent system, it just isn't in the cards, in my judgment.

One of the major operations of the Patent Office is to examine patent applications, and to grant patents or refuse to grant patents. I think, considering there are over 100,000 applications each year, on all kinds of different subjects, they make a great contribution to the matter of certainty with regard to the way the system operates. About 30 percent of the patent applications filed become abandoned because they're not patentable, in the judgment of the examiner. In most of the other cases, the scope of the claim is usually trimmed down to something more reasonable in terms of the contribution that's made; and I think that that is a great contribution to the certainty of the system. I think that they do a remarkably efficient job, as Jack says, in this sort of screening operation; it's not a validity proceeding in any real sense of the definition; there just isn't that much time available or that many resources available. But as I say, I think they make a great contribution for what they do.

I think things have improved in some respects in the Patent Office over the last 10 years, when you consider the magnitude of the job that must be done. About a decade ago there was talk about the crisis in the Patent Office; the Patent Office was going to collapse, and the period of pendency was over 3 years, aiming towards 4 years, with a great deal of difficulties. Well, due to the efforts of a lot of people, this pendency has been reduced now to 2 years, and is aiming at its goal of 18 months. I think once the office gets there, this is going to make an important contribution to get this technology out earlier, and to let people know what the patent situation is relatively early in the game.

The Office, I think, has gotten in the habit of recognizing they have a twofold responsibility: one, to grant patents on meritorious inventions, and secondly, not to grant them on inventions that don't meet the standards.

The cost per case runs in the hundreds of dollars; this is the cost in the Patent Office, as well as probably the patent attorneys' costs in handling most of these cases. Now, this contrasts with figures that have been quoted for validity reviews in the court. I quote a report of the American Bar Association, that says, "Any litigation, even the simplest, that must go all the way through the District Court and the Court of Appeals, will cost a minimum of $\$ 50,000$." Now, this is over a hundred times more than the resources that the Patent Office is receiving. So, when I hear people say, and there are many influential people that will say this, including present and past members of the Supreme Court, that the Patent Office has got to carry out a proceeding which is equivalent to what we have in litigation in all the cases, I just say it isn't in the cards, because I don't really believe that the Patent Office is ever going to have a budget of $\$ 2$ or $\$ 3$ billion and have a staff of 50,000 or more. It just doesn't make sense. I agree with Dr. Ancker-Johnson: it's a question of balancing what reasonably can be done under the circumstances, what are the needs of the system.

But there are many programs under way. In the international area there is the Patent Cooperation Treaty, which would mean more value per dollar for the inventor. The Patent Office instituted a disclosure document program, which proved quite popular with independent inventors as well as some foreign inventors. There are many things that have been done that I think have improved the system. But the system really gets back, basically, to Congress. The question of what kind of system you have depends upon the substantive patent laws of the United States as enacted by Congress. The question of how this system operates, including the Patent Office, is very much controlled by the budgets that have been approved by Congress. I think probably most Commissioners of Patents in their annual budget have 
had proposals for increased numbers of examiners. I did, too; but we never got them. One year, out of the 150 more we requested, we got 75 positions approved, but then there was a salary increase, and the amount of money we had to pay in additional salaries was equivalent to the dollars that we got for the additional examiners. So we got 75 more positions, but no examiners. I think, realistically, that you can't expect any order of magnitude of increase in the examining corps; you've got to figure out other ways of improving the system.

Now, what can be done in the future? Well, there doesn't seem to be any shortage of ideas. The Presidential Commission had a lot of them. Senator McClellan's Bill S.643 had ideas. Senator Hart's Bill, Congressman Owen's Bill, the ABA, the APLA, and even the Justice Department have some ideas. Justice Clark and Justice Fortas have ideas. There's no shortage of ideas. The question, though, is specifically what can and should be done for the future? How do you mold together all of these ideas?

Well, I would like to first mention two general points that I think would help in the future, and then a half dozen or so specific ideas that I think should be given serious consideration.

The first major point I'd like to make is that I think we're not going to get any place with a substantial improvement in the area of invention and innovation in the patent system until the Executive Branch of the Government recognizes its importance and establishes an organizational structure accordingly. Now. Dick mentioned his views about an independent agency; I personally, based upon my experience, don't think that would particularly help. and it could create some problems. My particular approach is that, as a minimum, I would think that in the Department of Commerce we ought to have an Assistant Secretary for Invention and Innovation and Intellectual Property. In other words, within the Government, someplace, sombody's got the ball. Like Dick Morse said the other day, who is it? Where do you go? Actually, there's no place; there are all kinds of different islands, you might say, where you can go and talk about a piece of the total picture, but no one person that speaks with authority or carries the authority in the Executive Branch of the Government. We ought to have a position, I think, at least the equivalent of the Assistant Attorney General for antitrust.

The second general point I would make is that for the future, I think we need to take a professional approach v. what I would call sort of an amateur seatof-the-pants approach. I think there's enough information in the picture now, or information that could be generated, to make a systems analysis approach to the operations of the patent system, and from that to be able to weigh better the pros and cons with regard to these various proposals.

I think that this is one way of dealing with all kinds of different types of people, including economists. I guess my greatest claim to fame is that for 3 years I worked as an economist. I probably made more economic calculations than I think a lot of the other economists have that speak very much on the subject because apparently they're too busy writing books and giving speeches and things like that. But it's an important point, I think, as to whether changes make sense or not. I would hope that under these technology incentive programs in the Department of Commerce and the NSF, that some of these programs would be directed to getting experience or data which would help with regard to the future operation of the patent system.

Now, Dick mentioned quantity and quality, and these are words that always come up in the operation of the patent system. I think we have a pretty good handle at this point on the quantitative aspects of the operation of the Patent Office, although, would you believe it, 10 years ago when I came in the office and said, "How long does it take to examine an application?" people said, "We don't have any idea." But also, in addition to the quantitative aspects, the quality is very important. We did start an extensive study and analysis of what makes quality, and we were starting to generate some very interesting information when I left and this program was dropped. I think this was unfortunate, because otherwise by now there would be a considerable amount of quality information in the picture. Quality is a very interesting subject. What the heck do you mean by quality? Let's say we talk about a particular invention here. and let's say everybody in this room agrees unanimously that it's a meritorious invention and the patent was valid on it. That doesn't make a bit difference if the Supreme Court votes nine to nothing that it's invalid. That's the way the game goes.

If you look at the operation of the courts, they will frequently criticize the judgments in the Patent Office, but they seem to totally ignore the fact that in the judiciary everything doesn't come out 100 per- 
cent clean-cut. In fact, nearly 20 percent of the cases decided by the District Court are overturned by the Court of Appeals on the same record, on the basis of a clear error. I think this is one of these human factors. Also, how does the Supreme Court explain a 5-4 decision? I mean, what about those other four judges? It's very much a question of judgment in this matter of patent quality; and reasonable men can differ, and I think we just have to accept that. So. in other words I think there is too much theory and maybe not enough facts in the picture and that these should be obtained.

Now, moving to specific ideas, I'd like to mention a few that I think should be given serious consideration. I think the facts would help to judge what impact they might have with regard to benefits as well as problems that are created. Also, I think there's a little bit of market research in here. You can propose a new program and you can figure that it'll be accepted to a certain extent. You try it out and it doesn't work that way at all. The patent system is not cast in concrete. If a new idea looks like it has reasonable chance of success, you've got to try it and then learn from experience as to whether it works or not, or whether it requires future modification.

I think we ought to take a close look at deferred or selective examination, as it is called. However, I think it has to be carefully evaluated, not only with regard to its benefits, which seem to be quite apparent, but also with regard to its problems. There are a lot of problems in the Patent Office. I remember we made a close analysis of this - all the pros and cons. Relative, say, to the Dutch system, it looked like it would be about a standoff in the United States if you figured in all the pluses and minuses. True, you save for a while some examining manpower, but eventually things will catch up with you and then you have a lot of the disadvantages. Anybody that has to cope with all this tremendous number of publications in foreign languages under these deferred systems would know what you're talking about. The Japanese situation is almost impossible right now in trying to cope with 250,000 documents a year being published, all in Japanese. But, nevertheless, I think that perhaps a proposal like the new European patent system, which maybe will have only a 2 -year deferment, might give a more clean-cut resolution here and provide greater benefits.

Secondly, I think the United States ought to take a look at the matter of petty patents which are now used in a number of foreign countries, although I would really call them more of a utility copyright. In other words, this protection might be granted for new inventions or devices, which might not necessarily be unobvious, but protection would be limited in terms of years and would give protection just against copying. Thus, I think petty patents are something you should take a close look at as a means of taking a little pressure off some of the marginal inventions while maintaining, as the Supreme Court says, an extremely high standard of invention for regular patents.

A third area I think that should be looked at very closely is a greater role for the Patent Office in the area of litigation. There are all kinds of possibilities here such as in the area of pre-litigation, including the reexamination proposals that are in S.643. The Commissioner is now proposing this on a trial basis, as published in the Federal Register, and is looking for written comments anytime up to October or so of this year. I used to be in favor of specialized patent courts but I have sort of given up on that because I just don't think it's in the cards from a political standpoint in view of the opposition by the American Bar Association and probably the Federal judiciary. Rather, I think we'll have to figure out ways of using the Patent Office in an advisory role to the court. My favorite proposal at the moment is in case of litigation, or incipient litigation, either one of the parties could request the Patent Office to make a decision on validity and perhaps on infringement, presenting to the Patent Office any new evidence in the picture. I think this could provide a missing element. At the present time the Patent Office does a pretty good job based on the information it has available, but it doesn't have all of the prior art that's available and some mechanism has got to be devised to bring this prior art to the attention of the Patent Office. I, for one, think that when you have to make a judgment on a question of unobviousness, it is particularly difficult. A lot of you probably will be surprised to find it is a question of law to be handled by lawyers and judges. Thus, I think that administrative judges such as you could have in the Patent Office, who have backgrounds in science and technology and experience in the patent law and with the process of invention and innovation, should be able to make pretty sound judgments. In fact, I think the Federal Courts would be happy not to have to cope with some of this tremendously complex technology that obviously, and the judges will adnit this, they don't 
understand, for example, computer technology, high powered organic chemistry, etc.

Another area where the Patent Office could improve, I think, is in the area of patent documentation. There are presently programs underway, particularly in connection with the Patent Cooperation Treaty, to provide English language abstracts of the world's foreign patents and the technical literature relating to patentable subject matter. Mechanized searching, I think, is something that's way off in the future as far as providing any help to the Examiner, but I think work has got to be continued on this.

I also think serious consideration should be given to instituting what I call satellite search centers where classified sets of U.S. and foreign patents would be available to inventors and members of the public. Also, I think the system could use in major cities some invention advisers or counselors to provide general advice to inventors. They now turn to disreputable people who usually con them out of a lot of money so that they become very disenchanted with the whole invention process.
Finally, I think the whole patent system should be reviewed to eliminate some of the technicalities that now invalidate patents. I think that in the case of an inventor who has a meritorious invention, the system should work to protect that invention rather than the present situation where there are innumerable technicalities that may trip up and invalidate the patent. I don't think this is the way the system should work.

So, in conclusion, Jack. I am pleased to be able to participate here because I agree with Stark Draper and you that invention and innovation are important to the country. The patent system plays an important role in the process of invention and innovation. The Patent Office has an important role to play in the operation of the patent system. I don't think there is any single solution, but rather the situation requires a lot of things to be done and a lot of effort on different people's part. I believe the Patent Office has played a key role in the past and has an even more important role to play in the future. Thank you very much.

\section{Discussion}

N. Parrish: Mr. Whale indicated that the inventor will continue to invent without reward. I wish to take exception to that. I speak for myself because from 1952 to 1955 , I got 7 patents granted and 15 disclosures. When I found that I was getting nothing but certificates, a dollar and a pin. I ceased to turn out the patents and it was over 5 years before I even considered turning in another one.

Also, you suggested ways to fine or penalize the inventor by pushing for a delayed charge to maintain his patent. He may find that he cannot pay this charge; therefore, his opportunity to profit from his innovative ideas is dead.

A. R. Whale: Maybe there's some misunderstanding as to what I intended to convey. I see maintenance fees as being a device for payment that I think should appeal most particularly to the individual inventor and to the small companies. It's a way of deferring the immediate charges, which I think are going to continue to increase in the future, until there is some money coming in or at least a patent which can be offered to the bank as collateral. Question: Might I make a suggestion on this maintenance fee that possibly could help? Let us consider an anti-shelving clause that would be put in for the small inventor assigning his patent to a large corporation so that if his patent is shelved, then there would be enough fines involved, if it is maintained and kept shelved, that this will help on your maintenance program.

J. Rabinow: As the Chairman, I would say that the shelving argument should be separated from the fee argument because the fee has been experienced in Europe, but the shelving is a very difficult question. Ed, would you like to comment on the fee system? That's a very fundamental question to come up here.

E. Brenner: I think I've always been in favor of giving strong consideration to maintenance fees. When I started out as Commissioner. I was in favor of close to a 100 percent recovery by fees, because if the Patent Office were essentially self-sustaining, we ought to be able then to staff and operate in an effective way and have a minimum of negative action by Congress. But I've changed my ideas considerably in the last decade. Now I feel that we need low fees in the patent system because it operates in the public interest. I think we've got to make a case that the patent system generates much more than its value. This may be difficult to sell, but I think that it's a disincentive to have any substantial fees in the patent system. If we have to have them, then I think it should be on the tail end of those inventions that can pay for them. 
J. Rabinow: I would like to make a statement about the fees since I have paid them. I have something like 100 patents in foreign countries. What happens to me is that I abandon patents when I don't sell them, and I would like to suggest that this is a terrible thing to the inventor, particularly the small inventor. In the United States it took me 9 years from the time I got the patent to sell the watch regulator, which did make me a third of a million dollars so far. I got the patent issued in about 8 to 9 months; it took 9 years to sell it. If I had had to pay fees. I would certainly have abandoned it. The fiction that the fees are a simple substitute for the initial fee, which is going to get larger and larger, is the fiction that taxes which are hidden are equal to outright, single taxes. If the fees can be spread out they invariably add up to much more than a single fee. Because inventors usually are ahead of their time, I think that maintenance fees are a hidden trick by which patents are destroyed. Certainly they will hit the small man much harder than the big companies who can afford them.

By the way, you did ask one question that Dick did not answer: "that inventors will invent anyway." Would you like to comment on that?

A. R. Whale: Well, I've been an inventor in a small way as a pilot plant engineer. But we're not talking about that kind of invention. I'm talking about the individual with the inventive turn of mind. He's going to-I think - perhaps not in your case, but in most cases, invent. Now whether he's going to invent the kinds of things that involve money, investment, is another question. But it's just like an old ball player retiring; he's going to keep throwing the ball around for a long, long time.

J. Rabinow: About this I would like to give some facts, gentlemen. I have in my notebooks now some 1800 inventions - good, bad, many indifferent. I have 205 U.S. patents, which is a statistic all by itself. I say this to you, not because I want to brag, which I don't mind doing, but because what is important is this: I have plotted over the years what I invent, how many inventions I make, and what happened to me at the time. And I don't invent automatically. When I worked for the Bureau of Standards and calibrated water current meters, I invented nothing. I would have, maybe, one idea in my notebook during 1 year. Then I was thrown into war work under Dr. Ellett, who is sitting here today, and my inventing shot up tremendously because I was given an environment where they wanted inventions; there were problems thrown at us. I invented like crazy. That went on until the Bureau of Standards got involved with the battery additive. We were accused of being a bunch of crooks; the Director was fired; my invention rate dropped to zero for 6 months, because I was so busy fighting this battle; they were going to split the $\mathrm{Bu}$ reau, which they eventually did; I was very unhappy about this. I quit the Bureau of Standards and opened my own company and became a consultant. Suddenly the invention rate went up to some six times higher than it was at the Bureau of Standards. I worked for many companies with many more problems of various types, and I invented like mad. Then I sold some stock in my company, and the invention rate went to near zero because I was busy with Wall Street; and when you are busy with Wall Street you don't invent.

It's not true that you invent "anyway;" you invent when you are busy inventing, and you don't invent when you are selling stock.

Then I sold my company to Control Data; the invention rate went down to about a third, because Control Data limited my field of work to reading machines only; they did not want many inventions because they wanted to improve the old machines.

Then I got a job at the Bureau of Standards a year and a half ago, a position where I don't have any need to do technical work, and my invention rate is almost zero again. Now you could say that I got stupid suddenly last year; that's not very easy to justify. I admit that I get stupider as I get older, but not all in 1 month. And I didn't get smart suddenly when I opened my business either, but the fact is that when you plot these curves, I'm willing to bet that if I take Mr. Zepell here, or any of the inventors-Sam Ruben, Costas, anybody else-I will bet that there is a correlation between what they invent and what they are doing. It is not true that you automatically invent. I think that if you hang me by the heels, I'll invent, and the invention will be how to get out of that situation. But I doubt that I'd be inventing magnetic fluid clutches when I am hanging by the heels.

S. Yerazunis: Mr. Brenner, do I interpret your remark with regard to mechanized searching being far off in the future to indicate that the Office does not now use a computer system for searching, and does not anticipate computer information systems for this purpose?

E. Brenner: Well, sir, yes and no. The Patent Of- 
fice does have a couple of systems that work either by mechanized sorters or computers, but they are an infinitesmal amount of the total search base. Actually, one of the problems you find after you've worked on this for many years is that the Patent Office's human system is quite efficient; the files, despite the millions of documents, are organized pretty efficiently, and a person can make a pretty skilled search, particularly when he's worked in this field for many years. It's tough for computers to compete with that, and I know Jack, who's got a lot of experience here, personally doubts whether your computer can do the quality job that a human being can.

I personally think eventually the magnitude of the documents is going to increase so much in the future, you're going to have to have a way of computer selection, to select a limited number of documents, 25 or 50 documents out of a bigger mass, but this computer system is competing with human classifications, so the answer is that it's going to be a long, long time; I think it will be a decade or two before you see any significant improvement from a computer stand point.

J. Rabinow: There are things a computer can do; but if they can search, they can also invent - it's of about the same difficulty. If you catch me later I can give you the history; I was on committees working on this.

J. Rajchman: Mr. Brenner mentioned that the Patent Office has already, in March of this year, instituted a provision whereby prospective litigants can come to the Patent Office to ask advance clarification in a case; and later, he proposed that this could be extended. Now, my question is, to what degree can the Patent Office do all of this on its own, without any Congressional action? It would seem to me that this would be an extremely constructive way to lessen the burdens of the judicial process. I was involved myself in many of the judicial problems, and I think that if the Patent Office could come in as an expert party, in some reasonable, practical, constructive way, this would be very helpful. If this could be done without involving Congress, on the discretion of the Commissioner, that much the better.

E. Brenner: The program I think you're referring to is presently a proposed program; it's published for comments, to see whether people think it's a good idea or not, and it might be changed if it's got any shortcomings. I think it's a very ingenious way to get a little experience. I'm not so sure how many people will take the opportunity, but I think you've got to try. If this doesn't work, maybe there are some other ways.

Actually, a lot of foreign countries have post-examination proceedings, like the Netherlands, England, Germany, Japan. I remember, when I was on the Presidential Commission, we looked at those, and we shied away from any inter-parties sort of opposition because these get to be very costly. I know in Esso, every time a Shell case issued, we automatically opposed it; every time an Esso case issued, they opposed it. We had hundreds of cases in which we were opposing each other, and we really didn't know why we were doing it. So the Commission recommended sort of an ex parte affair-a reexamination where third parties could cite prior art to the Patent Office. This is in the present patent revision bills, and I think would be a good step forward. The Commissioner is going to try to see whether maybe some applicants might not volunteer. Under the proposed Patent Office system, it's up to the applicant to decide whether he would like to publish his application and allow other people to cite art against it. It's different from the reexamination proposal, where anybody would have the inherent right to cite art against any granted or published application.

J. Sutton: I would like both Mr. Whale and Mr. Brenner to comment on the problem of prior public use of an invention, because I think that even after you have this proposed program of an ex parte application at the Patent Office to cite prior art, you don't have anything about the prior public uses; that is to say, the acts which have taken place as contrasted to the documents that have been published. In at least half of the cases that I'm involved in, where the patents are held invalid, they are done so because of a prior public use, which invalidates; and at least in the Ninth Circuit, that seems to be the way it is. I think in the procedures that are proposed, even in the Bills that are pending, and also in the proposed Commissioner's solution, we have no facing up to that problem of prior public use.

A. R. Whale: That leaves, though, at least 50 percent of the cases that could benefit by such a proceeding - those that involve issues not related to prior public use. There are public use proceedings, 
which perhaps Ed will touch on, available in the Patent Office even today, very seldom used. I think probably the answer is going to come from the increased alertness of attorneys specifically to pursue the evidence of existence of uses that could be construed as public. Because it is such a personal thing within the knowledge of the individual, I don't see that it's going to be reached by anything that I've seen on the horizon.

J. Sutton: Well, if I recall S.643, it did have a provision for calling the attention of the Patent Office to prior public use, and actually provided for a proceeding along that line. It's true the present public use proceedings are used very seldom, about once a year. The problem is that this can only be against pending applications. Usually you don't know about what's pending, and furthermore, the Patent Office has been very reluctant to get into that, because it really isn't particularly expert in this type of proceeding. But I don't see, under proposed new litigation, or even in this proposed approach by the Commissioner, why you couldn't go all the way with public use proceedings. Some people have argued that there's an advantage in doing it early in the game where the evidence is still around, rather than 20 years later. I remember, for example, this Eniac case, talking about prior public use, 25 years ago, you know, witnesses trying to remember, I don't know how they remember way back that far.

J. Rabinow: They don't; I know that case. I read the original application, and the case was a mess.

B. Walker: Has there been any ruling on electronic printing, i.e., Xerox, constituting a printed disclosure to invalidate a patent by the inventor or by somebody else, if more than one year before the filing, even if the sheets are produced in limited number?

E. Brenner: That seems to me to be posing a legal question, and I don't know whether there's enough information to answer it.

B. Walker: I think it's getting to be very important, because there are so many people making Xerox co- pies of all kinds of things, and Xerox is, I understand, electronic printing, so technically it is a printed publication; and how many do you have to get out to invalidate your patent, either by the inventor or by somebody else?

E. Brenner: I know on the Presidential Commission we struggled tremendously with the impact of new technology, including microfilm. I think we finally wound up with a disclosure in tangible form as distinquished from oral or verbal. But it is a very ticklish subject and has quite a legal impact.

J. Rabinow: I think that is too technical and legal a question, and should be left to Congress.

L. Shaffer: This question is directed to Mr. Brenner. You mentioned that some thought had been given to satellite search centers. Would the satellite search center be located where the patent libraries are now; and has any thought been given to the possibility of expediting the work involved in examining patents by utilizing the inventor and his time, or possibly his agent? In other words, would it be available to the public, too? To help get the backlog down?

E. Brenner: Satellite search centers have been proposed for about 15 years, and I personally think it's now time to take some action. I would hope under this Technology Incentives Program, from either in the NSF or the Bureau of Standards, that the money would be available to try this out on an experimental basis, probably in these libraries where you already have U.S. patents. These would be in classified form, probably on microfilm, U.S. and foreign patents, and maybe in certain fields of high public interest, like environmental protection. I think that this could help in the whole system; the more the people know about the prior art, the less time they waste in reinventing the wheel, and fewer patent applications come into the Patent Office that are obviously unpatentable.

J. Rabinow: There have been many other suggestions, that a special group be set up in Washington by the Government to do searching only. 


\title{
United States Patent System: Fraud on the Inventor and the Public (And What Can Be Done About It)
}

\author{
Irving Kayton
}

\author{
Patent Law Program, The George Washington University, 2011 I Street, NW., \\ Washington, D.C. 20006
}

\begin{abstract}
The inventor is the creator of progress, and our main hope to solve most of society's problems. In order for him to be motivated to continue inventing, he needs to have his property rights protected. By and large, the United States patent system no longer affords that protection.

There are some Federal circuits where, because of the rules of law enunciated by the United States Court of Appeals, a patent cannot be held valid, irrespective of the merit of the invention.

The law of expected return dictates which patents get litigated-there's no such thing as a per se good patent. The reason is the legally outrageous proposition which has been imposed on the public, the bar, and the bench, either fraudulently, through arrant ignorance or simple misconception, that all patents are monopolies. Monopolies are bad-therefore, patents are bad.

The truth is that practically no patents are monopolies. Patents are property-and where there is competition, either by product alternatives or by licensing, you cannot control price and you do not control a relevant market and you do not have a monopoly.

A revision of the patent statute is suggested which would reverse the alienation of the small inventor from the patent system and restore the system to its earlier effectiveness in promoting the useful arts.
\end{abstract}

Key words: Inventor; monopoly; patent system; property rights; validity of patents.

Ayn Rand, speaking through her protagonist in The Fountainhead, said, "Men have been taught that the highest virtue is not to achieve, but to give. Yet one cannot give that which has not been created. Creation comes before distribution, or there will be nothing to distribute. The need of the creator comes before the need of any possible beneficiary. Yet we are taught to admire the second-hander who dispenses gifts he has not produced above the man who made the gifts possible. We praise an act of charity; we shrug at an act of achievement."

My friends, I have not come to praise Caesar; I have come to bury him. I've come to read the epitaph, symbolically, of the people in this audience who kept their hands up in response to my request for a count of those who view themselves as inventors and either do not work for a company or do work for a company with gross annual sales of less than $\$ 75$ million. I consider that my obligation to those of you who kept your hands up, to Dr. Schockley, ${ }^{1}$ to

'Nobel Prize winner for his invention of the transistor and the development of transistor theory.
Dr. Kapany, ${ }^{2}$ to Jack Rabinow, ${ }^{3}$ requires that I point out to this audience certain fundamental, elemental truths.

It is the inventor who is Ayn Rand's creator, the first-hander. The patent lawyers, the judges, and the businessmen who bring the already extant creation to market, are the second-handers. They do not create; they are necessary, but they do not create. There are thousands of investment bankers; there are thousands of patent lawyers; there are hundreds of Federal judges; there is only one creator for each invention, except in rare instances. The second-handers may keep moving continuously but without the inventor it is a treadmill exercise productive of nothing but remaining in place. The process of creation and its commercialization stop at top dead center without the inventor.

Having said that, it is nonetheless the case that the things that are necessary to nurture the creator

\footnotetext{
${ }^{2}$ Prolific inventor in the fiber optics field.

${ }^{3}$ The inventor of several hundred patented inventions, many of which have formed the basis for financially successful entrepreneurial activities.
} 
are also necessary to nurture significant second-han ders, such as the people who bring the product to market.

What is required for this process of creation and commercialization from the point of view of the inventor (including his wife and children) as well as the second-hander? I'm convinced that Jack Rabinow would not invent if inventing meant his wife would go hungry; he would sell shoes. What is it that's necessary for the innovator who brings the product to market? Even a thief, let alone a creator, can tell you what that is. Simply put, once you have stolen something, or have created something, you want law and its reputed order to protect it for you. No thief will go through the effort of stealing if he does not have a safe-deposit vault that will protect the products of his theft. No businessman will go through the effort of investing, working, sacrificing, and making his money vulnerable to loss unless he has some reasonable assurance that there is an orderly property system which will guarantee that that for which he worked will be protected for him.

Inventors need that protection as well since they too are human beings. Risk capitalists, absent that established, orderly property right, simply will not invest. What in heaven's name is so complicated about this self-evident truth? In the jungle, without property law, the biggest and the strongest apes take the bananas. In our civilized society, with a breakdown in property law, the biggest and the strongest institutions take the property. It doesn't take much to understand that if a viable property system for invention breaks down, then, to the extent that invention continues by the compulsive few who must spew forth inventions despite the fact that their families are starving, those inventions which are spewed forth will be taken by the strong.

Who are the strong? They are the large corporations with the most effective merchandising capability, the most efficient production capacity, the best financial resources, and perhaps the most political clout. And so, as in the jungle, this property will be taken away.

Now, it has been argued, that's not so bad, because those large apes or corporations are efficient. Is there not, in fact, a benefit to society to stepping on Jack Rabinow's neck and having a large corporation take his inventions free of charge and use them to the advantage of society?

Well, there is a serious problem with the approach posed by the question. It is that without the property right that will enable the inventor to protect that which he created, he will in fact stop inventing. This does not mean that a society without the orderly arrangements of property in invention will not function. It will function. There is no reason why we cannot give all inventors salaries, or give them inventors' certificates with a stipend from the central presidium, and have them function that way. The Soviet Union does precisely that. There are a lot of good inventions in the U.S.S.R. I'm not opposed to that approach, if it works. But that approach happens not to be the mechanism that the framers of the Constitution thought was the most effective for us. The mechanism that we have is an exclusionary right for a fixed period of years. That exclusionary right is the means that is supposed to, in our free enterprise system, generate that excitement of activity for a "piece of the action" that's going to do more than just a salary as motivation for creation.

Now, that's not true for all people. A lot of people much prefer an orderly, quiescent, economic situation with a regular and good salary. They work better that way. But, as we now know, from the work done by Professor Jewkes ${ }^{4}$ and others, half of the significant inventions during this century came from people outside that environment. They came from individuals and from inventors in small companies. Great inventions often come from the minds of the inexpert because they are too untutored to know that what they invented couldn't be done.

Now the fact of the matter, my friends, is that I don't want to lose those inventions for the future. I do not believe that the major problems of society will be solved by political institutions. I do not believe that any of our real problems will or have been solved by lawyers, or judges; but I know, based on inductive logic, that most of society's problems will, or can be, solved by technological innovation and in. vention.

That is why as a lawyer and second-hander, I am in love with people like Jack Rabinow and Dr. Shockley, who happen to be lovable human beings anyway. But I am also in love with the inventors who are garrulous, ill-dressed, smelly, dirty, but who create. They, my friends, perform the function that we second-handers are incapable of performing, and without which we are bereft of any hope for the future. The creators are, in fact, the salt of the earth!

\footnotetext{
4Jewkes et al. The Sources of Invention, pp. 82.85 (St. Martin's Press, 1958).
} 
The property concept that I have defined and explained is simplicity itself. Property as a legal concept requires as indispensable the right to exclude others from the enjoyment of the thing which is the subject of property. That is what property has always been; that is the jurisprudential definition of property; and that is what property always will be for so long as we have it.

The question, then, is: Does the United States patent system purvey and convey a protectable property right to inventors and to those who must invest capital to bring the invention to the marketplace? The answer is, by and large, it does not. There rarely has been a group in society that has been as duped, deceived, taken advantage of, and misused, as that group known as inventors. And it's always done by us second-handers; i.e., by the people who take the invention to market, by the patent lawyers, and by the judges.

More recently, totally confused politicians and illinformed consumer advocates have joined the deceivers and destroyers.

It is the case that top managers of large corporations, aware of what I am going to tell you about in the next few minutes, know patents to be what they are-an expensive and tragic joke in the scheme of the property system of the United States. I have spoken with the heads of some of the largest corporations in the United States who, after reading my analytic materials and data on holdings of patent invalidity and noninfringement, ${ }^{5}$ as well as resorting to their own in-house experiences, realize that as an institution patents are so rarely, expensively and unpredictably enforceable that they are more burden than help to the advancement of industry and the useful arts.

I spoke at the Licensing Executives Society's annual meeting not long ago, where I was asked to comment for the assembled Society on the reputed practice of some corporations which license trade secrets and sell show-how and start up capability, but throw the patents in free. When corporations either do or think of doing that they are recognizing and trying somehow to cope with reality. You cannot condemn a business organization for doing what the law forces it to do. By the same token, you can recognize that no competently advised large corporation today is going to take a license under a bare patent,

\footnotetext{
${ }^{5}$ Kayton, The Crisis of Law in Patents (Patent Resources Group, 1970).
}

where that's all that you have to offer, unless the patented invention falls into certain fantastic categories such as a cure for cancer or the $\mathrm{W}$ ankel rotary engine. Almost always what they are willing to buy is a capability for establishing the business or product line. The bare immunity from suit which is all a patent license nowadays provides is simply not enough to justify expending financial resources.

I want to recount for you now a representative tc.ephone conversation which I must have had 40 or 50 times a year for the past 3 or 4 years with people whom I've never seen before, and don't know. Typical phone conversation: Ring, ring, ring. "Professor Kayton?"

"Yes."

"I have an invention, and I want to get it patented. I want to do something with it."

My first question, then, is: "Why? Why don't you just give it to the world?"

He answers, "Well, I want to make some money."

Now, if that's the answer, which it always is (believe it or not, even inventors want to make money-not just investors in greasy chicken franchises, but inventors, too, want to make money; for some biological reason there's this compulsion to eat, and clothe themselves) I say,

"OK, if you want to make money, then I will talk with you. The question that I must ask you first is: Can this invention be kept secret?"

Now, if the answer is, "Yes, it can be kept secret," and very few answer, "Yes," I say, "Excellent. Keep it secret, do not file a patent application, do everything necessary to maintain the secrecy, and manufacture or carry out the process yourself. You will stand a good chance of being materially rewarded. If you cannot keep it secret, if you cannot manufacture it yourself, then you are in almost hopelessly serious trouble, unless you can answer 'Yes' to a couple of more questions." The question that follows is: "Are you independently wealthy?" If the answer is "No," and it is always "No," the next question I ask is, "Is your invention such that you can reasonably expect a manufacturer of that invention to make at least several million dollars a year by bringing your product to market?" And I'll tell you the answer to that is almost always, "Yes." That's based on the well-nigh universal wishful thinking of inventors and love of their intellectual products. Then I say, "If the answer is yes, then you must be sure that you can raise sufficient capital, not merely 
to file and prosecute your patent application, which comes typically to only a few thousand dollars; but you must raise enough money, if you're going to rely on the bare patent rights and nothing more, to litigate your patent. This is so because if your patented invention is worth anything substantial, as surely as day follows the night, it will be stolen from you by an infringer under the euphemistic banner and crusade that you are a monopolist and the patent is invalid. This is in lieu of the often actual and correct statement that the infringer is a thief and pirate. And you have to raise that risk capital for that purpose alone."

"W ell, how much is that?"

"Well, if it's a really good invention, that is, commercially valuable, you can expect effective litigation to cost you between an absolute minimum of $\$ 100,000$ and up to as much as $\$ 1.5$ million for the first time around up to a U.S. Court of Appeals."

"All right, I'm going to go get the risk capital; I'm going to go and talk to people."

I say, "Of course, you can't talk to anyone without a patent application, and more often than not you cannot talk to anybody, anyway, even with a patent application."

"Why?"

The answer to this is simply that a risk capitalist won't invest anything in an invention, where the invention is in an unenforceable property system. Why should Lehman Bros. or any investment banker invest $\$ 5$ million to commercialize a patented invention when the moment its marketability is proven a large corporation which had no research and development costs nor risks when undertaking tests or marketability, will steal it and knock them out of competition. All the inventor and banker will get is expensive litigation, as a general proposition. One other possibility does, however, exist. The potential infringer may take a license from the patentee while he is getting ready to compete. With the present posture of the law, however, he may never have to pay anything. To begin with he need pay nothing at the outset since most licenses require payments as royalties based upon production and during tool-up time the licensee is not in production. When the day of full production arrives and royalties start accruing, the licensee may and often does say, "We repudiate the contract; sue us." If the economics of the situation justifies, the patentee will bring suit and will lose 80 percent of the time. ${ }^{6}$ In the Eighth Circuit the patentee virtually always loses. There have been no patents, but one, held valid in the Eight Circuit since prior to 1966 in a series of cases which demonstrate, in the speaker's view, a profound lack of understanding of the law on the part of that Circuit.

I am now going to tell you exactly what the problems are that have produced this tragic (for society) state of affairs. I will explain the philosophical and practical reasons for them and what the single most effective and practical real solution to them is, in my view. I will also point out why there is no real hope of our ever achieving this solution, although we may try as long as we are alive. The actual data on holdings of invalidity and of noninfringement, show that there are at least two or more patent systems in the United States. There are some Federal circuits where, because of the rules of law enunciated by the United States Courts of Appeals, a patent cannot be held valid, irrespective of the merit of the invention. Those rules of law say the following: If an invention involves a combination of elements such as three layers of doped semiconductor material with three electrodes connected at different points, then that invention is a combination of old elements; and a combination of old elements cannot be much of an invention. Therefore, if you can find one printed publication that shows three electrodes hooked up somewhere and another printed publication showing three pieces of germanium doped in various ways, the patent is automatically invalid for obviousness.

Now, this rule of law enunciated that way is used most of the time in the Eighth and the Ninth Circuits of the United States. Fortunately, in the Ninth Circuit of the United States, there is also a case styled Reeves Instruments v. Beckman Instruments, ${ }^{7}$ that says the equivalent of the speaker's oft-repeated exhortation to reason: "You damned fools; don't you know that all inventions are combinations and all combinations must be made of the building blocks at hand and thus must be of already known elements? No human being is capable of inventing a

\footnotetext{
${ }^{6}$ The reasons for this high percentage have little to do with the merit or lack of merit of the patent as I have documented in conjunction with the statistics in The Crisis of Law in Patents, supra. A detailed breakdown of my data on holdings of invalidity and noninfringement is presented in the two statistical tables which are appended.

${ }^{7}$ Reeves Instrument Corp. v. Beckman Instruments, Inc., 444 F. 2d 263. 1970 USPQ 74. (9th Cir. 1971), cert. denied, 404 U.S. 951, 171 USPQ 641 (1971).
} 
combination, the elements of which are new and of which he is ignorant. Only God can do that."

With less despair and frustration than that of the speaker, Judge Learned Hand similarly said, some 30 years ago, "It is idle to say that combinations of old elements cannot be inventions; substantially every invention is such a "combination." He then presented a rational real-life approach to understanding when a novel invention is worthy of patent protection.

"In appraising an inventor's contribution to the art, as we have often said, the most reliable test is to look at the situation before and after it appears.... Courts, made up of laymen as they must be, are likely either to underrate, or to overrate, the difficulties in making new and profitable discoveries in fields with which they cannot be familiar; and, so far as it is available, they had best appraise the originality involved by the circumstances which preceded, attended and succeeded the appearance of the invention. Among these will figure the length of time the art, though needing the invention, went without it: the number of those who sought to meet the need, and the period over which their efforts were spread: how many, if any, came upon it at about the same time, whether before or after: and-perhaps most important of all - the extent to which it superseded what had gone before. We have repeatedly declared that in our judgment this approach is more reliable than a priori conclusions drawn from vaporous, and almost inevitably self-dependent, general propositions." 8

This standard was followed in Reeves v. Beckman.

Within the Ninth Circuit, therefore, we have the two opposite rules of law, although the Reeves $v$. Beckman view is followed only rarely. In those jurisdictions in which the statistics on validity are rational and reasonable, i.e., the Sixth and Seventh Circuits and the United States Court of Claims, where the holdings of validity may average 45-50 percent, the patentee clearly doesn't get his patent held valid automatically. He has to split his viscera to prove that his invention is great and his patent valid, but at least in those circuits he is given a reasonable chance to do that. He can win.

And so that's the posture of our situation. Now, there are some people including some very informed and knowledgeable people who say, "Oh, well, after

\footnotetext{
'Safety Car Lighting Co. v. General Electric Co., 155 F. 2nd 937 (2d Cir. 1946),
}

all, only the doubtful patents are litigated. Strong patents (and weak patents) are never litigated, never." That statement is categorically incorrect. Whether a patent is litigated is determined in real life by the solution in each instance of the following equation: $\mathrm{E}(\mathrm{X})=\mathrm{P}_{x} \cdot \mathrm{f}(\mathrm{X})$. This is the "law of expected return." It tells you whether you're going to litigate in the following way: "The expected return of any given situation (i.e., that which the situation is worth to you or that which you should be willing to pay to have the situation or that for which you would be willing to put $\mathrm{X}$ dollars down in a bet) is equal to the probability that you will succeed $\left(\mathrm{P}_{x}\right)$ in the venture (whether it's a flip of a coin, a horse race, or patent litigation), multiplied by the total amount you will get, $(\mathrm{f}(\mathrm{X}))$, if you do succeed. If $P_{x} \cdot f(X)$ is an amount substantially in excess of the costs of litigation, no rational businessmay may properly refuse to litigate. Suppose the total value of the infringement over the life of the patent (e.g., the infringer's profits) is $\$ 60$ million, and the probability of the infringer winning the infringement suit with the particular facts in the case is only 10 percent. Nonetheless, this means that even with such a poor probability of success it's well worthwhile for the infringer to litigate if the litigation expenses are substantially below $\$ 6$ million. Now, I have been in situations where I have said to my opposing counsel, "You know you don't stand more than one chance in 10 of winning even in this unpredictable court." And he responded, "Yes, but the lawsuit's going to cost my client half a million dollars, and he sees a potential profit over 17 years of something like $\$ 64$ million. The difference between half a million and one-tenth of $\$ 64$ million is substantial." Of course it is, and if I were in his situation I would have done as he did; and if I were the head of the client corporation I would do exactly what the president did. Businessmen do and must function that way.

The law of expected return dictates which patents get litigated. As in the above example, strong patents are often litigated. Whether a given patent is good, bad or indifferent in a given situation simply cannot be determined by whether or not it is litigated. There's no such thing as a per se good patent. The question is, is it a patent that will be enforced in a court of law? On balance, 80 percent of the time it will not. 
Another critical patent problem deals with the law relative to licensing patents. In a heartrending situation, Lear v. Adkins ${ }^{9}$ was a case in which an individual inventor licensed his gyroscope invention to a corporation. After taking the license the corporation refused to honor it; it refused to pay the royalties due. Until then it had been the rule that if you get benefits under a license, you're not allowed to attack the validity of the patent. In fact, this is a basic principle of all contract law. But the Supreme Court held that would-be monopolists (e.g., the little inventor, Mr. Adkins, whose contract called for some royalties from Lear, Inc.) must be kept in check. In express violation of basic contract law, the licensee was freed to attack the validity of the patent at any time after the license contract is executed irrespective of how valuable the contract had been to the licensee until then. ${ }^{10}$ There was no concomitant statement that there is some social good involved in making sure that valid patents owned by small patentees are not litigated so as not to legally harass those patentees into bankruptcy by large corporations. No such statement was made and there is no such Supreme Court policy!

Why are we in this abysmal condition? I submit that there is one major reason. That reason is the legally outrageous proposition which has been imposed on the public, the bar, and the bench either fraudulently, through arrant ignorance or simple misconception, that all patents are monopolies. The term monopoly in this country, rightly or wrongly, is akin to a loathsome disease. Irrespective of anything good in the patent system, if "all" patents are monopolies, then patents must inherently be bad. The logic is simple. Monopolies are bad. All patents are monopolies. Therefore all patents are bad and more particularly this patent is bad and must be held invalid in order to protect the public. No matter what the patent statute says, therefore, about validity, I, as a member of the judiciary, must interpret it in such a way so that it is held invalid.

Look at Lear v. Adkins or virtually any patent case today and you will see the words "patent" and "monopoly" used either interchangeably or in apposition. In Columbia Broadcasting System v. Custom Recording Co. (171 USPQ 502,509) the court pointed out:

${ }^{9} 395$ U.S. 653, 162 USPQ 1 (1969).

${ }^{10}$ Note that it had always been the law that the rest of the world, i.e., everyone other than a licensee, is always free to attack a patent's validity.
"It is well recognized that "monopolies in trade or business in this country...are generally denounced as odious, intolerable, and contrary to public policy and common right.' 36 Am. Jur., Monopolies, Combination, and Restraints of Trade, *4."

This view is part of the air that we breathe, we virtually take it in with our mother's milk. Is it any wonder therefore that in determining the question of validity, courts have gone through the following reasoning, as did the Ninth Circuit in Ashcroft v. Papermate Manufacturing Co.?

"The history of the American patent system is replete with the continuing tension between a strong public policy against monopoly and a desire to encourage inventions which will benefit the public. This tension has been resolved by the courts setting a high and exacting standard for patent validity."

The pathetic thing of course is that practically no patents are monopolies. In order for anything to be a monopoly, it must meet the definition of monopoly which in its simplest and most meaningful form is:

"Exclusive control of the supply of any commodity or service in a given market; hence, in popular use, any such control in a given market as enables the one having this control to raise the price of a commodity or service materially above the price fixed by free competition."

This definition appears in Webster's New International Dictionary, Second Edition. I do not cite the dictionary for the purposes of using it as authority, but rather because this definition is the one that most reasonable lawyers, economists and men understand when they use the term monopoly. In this definition we are constrained under our law to interpret the word "market" to mean "relevant market," as the Supreme Court of the United States has expressly required in Walker Process Equipment, Inc. v. Food Mach. \& Chem. Corp.

Clearly patents are property. That is, there is the right to exclude others from the use of the rest as there is for all forms of property, such as Black Acre, your automobile, a book or your wristwatch. These things which are property are rarely monopolies although any form of property may be used in a monopolistic way.

If your use of the property results in extensive control of a commodity or service which defines a relevant market, then you have a monopoly. A patent 
almost never gives such control. Why? It is rare to have a patent which is so dominant that it controls a relevant market. That is to say, it is practically never the case that during the 17 years of a patent there are not sufficient technological alternatives so that whatever it is that the patent controls, it is not a relevant market. The patent on the Accutron watch is a valuable piece of property, and as all property it carries the right to exclude others from making and using the tuning fork type of watch mechanism. Is it a monopoly? Of course not, because the relevant market, if it is not all time pieces, is certainly all wristwatches; but the Accutron share of the market is probably not more than 4 percent. Even if the technology which the patent controls does define a relevant market, there can be no monopoly if the patentee either licenses widely or is willing to license to competitors. Where there is competition either by product alternatives or by licensing, you cannot conìrol price and you do not control a relevant market and you do not have a monopoly.

As defined above not one patent out of 10,000 either controls a relevant market by the nature of the invention, or if it is inherently capable of doing so, is not licensed to others, thereby destroying the monopoly effect. I have said publicly on several occasions that I will give anybody $\$ 1,000$ for every patent since 1790 which he can produce which in fact has constituted a monopoly if he will give me one dollar for every United States patent which is not a monopoly. With some four million issued patents I would be instantaneously independently wealthy if anyone should accept the challenge.

The fact remains that there is no way in our society to make the pejorative word "monopoly" less than loathsome even if anyone were disposed to try. As long as patents are verbally equated in one-to-one correspondence with that "unmentionable" term, good and valid patents designed to reward and encourage the small inventor will regularly be held invalid.

There is one significant way to reverse the alienation of the small inventor from the patent system and restore the system to its earlier effectiveness in promoting the useful arts. It alone will, in my view, do more in this regard than all the other solutions, panaceas and proposed patent reform bills put together. I suggest only that one short paragraph replace the first sentence of ${ }^{*} 261$ of the patent statute which says; "Subject to the provisions of this title, patents shall have the attributes of personal property." Instead, it should read,

"*261. A patent is personal property and shall be treated as such subject to the provisions of this title. Like all property, a patent may constitute a monopoly through control of a relevant market. Control of a relevant market is not possible where a significant alternative to the patented invention exists in that market or where the invention is widely licensed or offered for license. In the instance where a valid patent does control a relevant market and thus is a monopoly for a period of years under this title, it is expressly exempt from the antitrust proscriptions of any statute of the United States as a partial incentive to promote the progress of science and useful arts."

There is nothing in this proposed paragraph that is untrue. Everything is legally sound. It conforms perfectly with the law as it is! It does, however. fly headon into the prejudices and irrational biases which most judges, lawyers, politicians and consumer advocates hold. These biases have been absorbed at least as early as their freshman college course in economics, if not with their mothers' milk.

Confronted with the pristine truth of this proposed paragraph, however, judges - and all of us - will be forced to think rather than to automatically react. It is my belief that confronted with this truth the Supreme Court could never again cite with favor, as it recently did, ${ }^{11}$ the district court's words that "monopolies-even those conferred by patentsare not viewed with favor."

What is the prospect for such a statutory statement of legal truth being passed? Very little. The main beneficiaries, i.e., the public and the small in. ventors and small inventive corporations don't understand and therefore cannot become a viable political force for its passage. The others, such as the Patent Section of the Antitrust Division, most lawyers and politicians and more recently consumer advocates are apparently so committed to sacrificing the patent system and its socially beneficial role in the misguided belief that this will in some way control illegal monopoly of the giant corporation variety. that they probably cannot be looked to for support or even much objective evaluation.

\footnotetext{
"Deepsouth Packing Co, Inc. v. Laitram Corp., - - _ - U.S. _ _ _ 173 USPQ 769 (1972).
} 
But you, whoever you are, having heard this analysis and solution can do something to correct the headlong race toward destruction of what should be a socially valuable institution. Only you know what that something is. Whatever it is, won't you please do it?

\section{Discussion}

J. Rabinow: I would like to add one comment: I will read the comment first and then the man who said it. "I have made very little profit from my inventions. In my lifetime I have taken out 1,180 patents up to date. Counting the expenses of experimenting and fighting for my claim in court, these patents have cost me more than they have returned to me in royalties. I have made money through the introduction of sales of my products as the manufacturer, not as an inventor. Signed: Edison, Saturday Evening Post. September 27, 1930."

The other comment I would like to retell is from another inventor by the name of Sherman Fairchild, who owned Fairchild Camera, Fairchild Semiconductors, Fairchild Recording, half of Long Island, and the largest block of IBM stock in history. We were discussing inventions. He had patents of his own, and he said, "Jack. inventions aren't worth a damn but inventors are very valuable people." And this, of course, agrees with what you say.

A. Ezra: This is not a facetious question, it's a serious one. Is there a fundamental conflict of interest between the legal profession and a simple law, which requires an army of lawyers and judges to interpret?

I. Kayton: I believe that there is always a conflict between individuals and institutions. The perfect institution invariably gets fouled up because it must be inhabited by and implemented by human beings.

W. Johnston: In reviewing all the cases which have been held invalid, do you notice any one characteristic: were they weak in any way?

J. Rabinow: Dr. Kayton said very clearly that when the money is large they will be tried. I would like to add one specific case. I have 205 patents; only one was ever in court. Let me use fictitious names. Company A has my exclusive license on the watch regulator. They licensed a Company B. Company B pays them about 5 cents a clock. The amount of royalties that Company A collects is on the order, then, of about $\$ 150,000$ a year from Company B. I get much less than that. Over 17 years, this amounts to something of the order of $\$ 2$ million. Company B de- cided, therefore, not to pay that royalty, and to say that they were not infringing the patent. They did not want to try it for validity; they simply said, "We're making something else, not covered by Rabinow's patents."

I said to the attorneys, "Their clock clearly infringes; I don't understand what argument they can possibly raise." The attorneys said, "Look, it's two million bucks, it's worth a hundred thousand to find out." They took it to court, the court held that they were infringing, they paid us the hundred thousand they owed us. By keeping the license in effect, they did not risk anything if they lost, because if they lost, they lost a hundred thousand, and if they gained, they gained $\$ 2$ million. This is a perfectly good illustration of what a sensible businessman would do.

I. Kayton: I would also like to respond to the question about the characteristics of the patents. It is literally not possible to tell whether a patent is a strong or a weak patent by looking at a reported judicial opinion. The only way you can do that is to read the entire record of the case, and I have done that under certain circumstances where I've studied fraud in the procurement issue cases. But I can tell you one other item of information which I did not develop, but which was developed at New York University School of Law as part of a doctoral dissertation. And it was this, for those of you who are interested in improving the patent system and the Patent Office. Over a period of 6 years where the data was analyzed, it was the case that when you had litigated patents wherein, in the litigation, the prior art set up as a defense was the same as the prior art that was in the Patent Office prosecution. the patent was held valid 75 percent of the time, which is a very strong indication that the Patent Office standards are quite reasonable when gauged against the judiciary's standards. That is to say, if they all considered the same prior art, there is only that 25 percent difference between the two, and that can be accounted for in many ways. But I don't consider that a significant difference, and I for that reason really get upset when the really ignorant federal judiciary in this area talks about the outrageous standards in the Patent 
Court of Appeals Patent Validity Holdings as Reported in U.S.P.Q.

\begin{tabular}{|c|c|c|c|c|}
\hline Circuit No. & $1961-1965$ & After the Trilogy* & $\begin{array}{l}\text { After the Trilogy and } \\
\text { before Anderson's- } \\
\text { Black Rock** }\end{array}$ & $\begin{array}{c}\text { After } \\
\text { Anderson's- } \\
\text { Black Rock*** }\end{array}$ \\
\hline $1 \ldots \ldots \ldots$ & - & $33.3 \% \quad(3 / 9)$ & $37.5 \% \quad(3 / 8)$ & $00.0 \% \quad(0 / 1)$ \\
\hline $2 \ldots \ldots \ldots \ldots$ & - & $25.0 \% \quad(7 / 28)$ & $26.0 \% \quad(6 / 23)$ & $20.0 \% \quad(1 / 5)$ \\
\hline $3 \ldots \ldots \ldots \ldots \ldots \ldots$ & - & $26.4 \% \quad(5 / 19)$ & $25.0 \% \quad(4 / 16)$ & $33.3 \% \quad(1 / 3)$ \\
\hline $4 \ldots \ldots .$. & - & $13.6 \% \quad(3 / 22)$ & $16.6 \% \quad(3 / 18)$ & $00.0 \% \quad(0 / 4)$ \\
\hline $5 \ldots \ldots \ldots . .$. & - & $45.9 \% \quad(16 / 35)$ & $40.0 \% \quad(8 / 20)$ & $53.2 \% \quad(8 / 15)$ \\
\hline 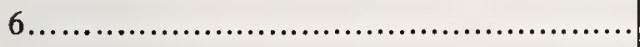 & - & $47.8 \% \quad(10 / 21)$ & $41.6 \% \quad(5 / 12)$ & $55.5 \% \quad(5 / 9)$ \\
\hline 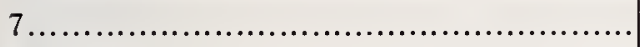 & - & $46.1 \% \quad(35 / 76)$ & $50.8 \% \quad(30 / 59)$ & $29.4 \% \quad(5 / 17)$ \\
\hline $8 \ldots \ldots \ldots \ldots \ldots$ & - & $00.0 \% \quad(0 / 18)$ & $00.0 \% \quad(0 / 17)$ & $00.0 \% \quad(0 / 1)$ \\
\hline $9 \ldots \ldots \ldots \ldots \ldots \ldots$ & - & $15.0 \% \quad(8 / 53)$ & $19.0 \% \quad(8 / 42)$ & $00.0 \% \quad(0 / 11)$ \\
\hline $10 \ldots \ldots \ldots \ldots \ldots \ldots$ & - & $14.3 \% \quad(1 / 7)$ & $20.0 \% \quad(1 / 5)$ & $00.0 \% \quad(0 / 2)$ \\
\hline D.C $\ldots \ldots \ldots \ldots \ldots \ldots \ldots \ldots$ & - & $16.7 \% \quad(1 / 6)$ & $33.3 \% \quad(1 / 3)$ & $00.0 \% \quad(0 / 3)$ \\
\hline Totals and averages. & $38.4 \% \quad(121 / 315)$ & $30.3 \% \quad(89 / 294)$ & $30.9 \% \quad(69 / 223)$ & $28.2 \% \quad(20 / 71)$ \\
\hline
\end{tabular}

*After February 1966, and up to and including U.S.P.Q. of March 8, 1971.

**After February 1966, and up to December 8, 1969.

***After December 8, 1969 and up to and including U.S.P.Q. of March 8, 1971.

\section{PATENT RESOURCES GROUP}

Washington, D.C.

April 10, 1971

Reproduced with permission from:

Kayton, The Crisis of Law in Patents (Patent Re. sources Group 1970) as updated to U.S.P.Q. of March 8, 1971.

Court of Appeals Patent Validity and Infringement Holdings as Reported in U.S.P.Q. (After Trilogy February 1966 and Up To and Including U.S.P.Q. of March 8, 1970)

\begin{tabular}{|c|c|c|c|}
\hline Circuit No. & Valid & $\begin{array}{l}\text { Valid and } \\
\text { infringed }\end{array}$ & $\begin{array}{l}\text { Valid but } \\
\text { infringement } \\
\text { not yet } \\
\text { decided }\end{array}$ \\
\hline $1 \ldots$ & $33.3 \% \quad(3 / 9)$ & $11.1 \% \quad(1 / 9)$ & - \\
\hline $2 \ldots \ldots \ldots \ldots$ & $25.0 \% \quad(7 / 28)$ & $17.9 \% \quad(5 / 28)$ & 一 \\
\hline $3 \ldots \ldots$ & $26.4 \% \quad(5 / 19)$ & $5.3 \% \quad(1 / 19)$ & $17.6 \% \quad(3 / 18)$ \\
\hline $4 \ldots$. & $13.6 \% \quad(3 / 22)$ & $9.1 \% \quad(2 / 22)$ & - \\
\hline $5 \ldots \ldots \ldots$ & $45.9 \% \quad(16 / 35)$ & $37.2 \% \quad(13 / 35)$ & 一 \\
\hline $6 \ldots \ldots \ldots \ldots \ldots \ldots$ & $47.8 \% \quad(10 / 21)$ & $28.6 \% \quad(6 / 21)$ & $4.8 \% \quad(1 / 21)$ \\
\hline $7 \ldots \ldots \ldots \ldots \ldots \ldots$ & $46.1 \% \quad(35 / 76)$ & $34.1 \% \quad(26 / 76)$ & $2.9 \% \quad(2 / 68)$ \\
\hline $8 \ldots \ldots$ & $00.0 \% \quad(0 / 18)$ & $00.0 \% \quad(0 / 18)$ & 一 \\
\hline $9 \ldots \ldots \ldots \ldots \ldots \ldots \ldots \ldots \ldots \ldots$ & $15.0 \% \quad(8 / 53)$ & $5.7 \% \quad(3 / 53)$ & - \\
\hline $10 \ldots \ldots \ldots \ldots \ldots \ldots \ldots \ldots$ & $14.3 \% \quad(1 / 7)$ & $14.3 \% \quad(1 / 7)$ & 一 \\
\hline 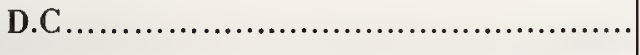 & $16.7 \% \quad(1 / 6)$ & $16.6 \% \quad(1 / 6)$ & - \\
\hline Totals and averages. & $30.3 \% \quad(89 / 294)$ & $20.0 \% \quad(59 / 294)$ & $2.0 \% \quad(6 / 294)$ \\
\hline
\end{tabular}

Reproduced with permission from:

Kayton, The Crisis of Law in Patents (Patent Resources Group 1970) as updated to U.S.P.Q. of March 8, 1971.
PATENT RESOURCES GROUP Washington, D.C. April 10, 1971 
Office, failing to keep in mind that when the same art is considered, the Patent Office comes off pretty well. It's only when the infringer puts in $\$ 2$ or $\$ 3$ million finding prior art that the examiner did not find in his 4-hour search, that there is a real difference.

B. Walker: How about inventions where the proposed royalty is less than the cost of litigation? Suppose the proposed royalty were $\$ 100,000$ or $\$ 500,000$; your estimate of litigation is a half a million to a million and a half. A great deal of money can be made with patents on which you get less than half a million dollars; I had one on which I got $\$ 400,000$, had 17 interferences that I had to pay for, plus taking it to the Supreme Court, and that cost $\$ 160,000$, quite a bit less than you recite, and I still made money on it.

I. Kayton: I'm very glad that you raised that question because it gives me an opportunity to bring out a critical thing that I couldn't get into my speech, and that we must keep in mind. If the patent system is as putrefied as I say it is, not the concept of property rights in patents, but the way it's being handled now, why in heaven's name are so many patents being taken out by large corporations? Seventy thousand were issued. The answer is very simple: the body is dying and decayed, but the cost of burying the body is far greater than the inconvenience of standing the stench. What I mean by that is, if you don't maintain a strong patent position by taking out patents, you are vulnerable to litigation costs. The one thing that's keeping the patent system alive is the astronomical cost of litigation. Because of that defect in our legal system, patents remain significant, and the patent system is utilized.

Specifically, with respect to your question, as these statistics go on and on, the amount that companies are willing to settle litigation for goes down and down, and believe me, I've been in all of those situations and have expressly negotiated for small inventors and said to opposing counsel, "Now, cut out the baloney, you guys; I know exactly what this is going to cost you; I know exactly what I can pry out of you in discovery," and in fact, I exploded one case with discovery that would have tripled the costs for the other side. I'm not proud of it; it's just the way it was.

B. Kemp: I would like to know what your explanation is, Dr. Kayton, of the fact that so few patents ac- tually go to court to challenge their validity.

I. Kayton: Why are so few litigated, you mean? What expectation would you have? Do you know how many are litigated? There are approximately 650 infringement suits brought every year; approximately 150 go through final judgment; and approximately 250 go through some significant stage of litigation. That's a lot, to me.

J. Rabinow: This is one of the items that we would very much like to know, and one of the things I would like to have the ETIP program find out: how many important patents are litigated, those which are important in dollars. By the way, many patents are not litigated now for quite another reason: companies do make cross-licensing deals, and they don't bother litigating. For example, the large automobile companies don't sue each other, and airplane companies, computer companies, all have made crosslicense deals. So, it's a little hard to say whether important patents would be litigated or not, when you have so many cross-license arrangements.

B. Kemp: Even aside from cross-licensing arrangements, if a company gets challenged and the whole patent declared invalid, anybody can get into that area.

J. Rabinow: There are many reasons why you would or would not sue another company, as you say, third party interests, fifth party interests, etc., so it's a very legal problem, as any lawyer knows, and it's not a simple thing to debate here.

C. E. Anagnostopoulos: Do you know what percentage of the patents that are litigated are between a large corporation and a small inventor?

I. Kayton: I have not the slightest idea, but just names come to my mind like Beckman Instruments v. Comtronics, Lear.v. Adkins, etc., but I have no data, at all.

C. E. Anagnostopoulos: I think that's important, in view of what you have said.

J. Rabinow: What keeps coming out in this meeting, and in all the meetings I've attended for many years, is that there's so little data of how the patent system operates. It's amazing, and Dr. Ancker-Johnson is trying hard to correct this. The answers to questions that one asks, like this, simply are not known. 
R. Kuntz: We are living in a society that's somewhat swayed by public opinion. We see now an anti-technology movement in the country; why go to the moon when there are riots in the streets? I submit that this is a hazardous public attitude, and then we find that patent legislation doesn't have a breath of a chance of getting called up for hearings in Congress because our representatives know that the public just couldn't care less. How in the world do we stimulate the public to become the forcing function on our representatives in government to see the intrinsic importance this whole field has on our economy and our nation?

I. Kayton: Senator Hart, in introducing his bill to the Senate, said, "Mr. President (of the Senate), the most boring subject in the world is patent law. There's probably no subject that's more boring, and
I apologize for introducing this patent reform bill, because I know it's death." He then went on to point out that there's nothing more important in society than this bill, and completed his statement by saying, "I apologize for boring you." I don't know the answer to your question.

J. Rabinow: This is why this kind of a meeting has to be held: because you do scratch history, and maybe the scratches sum together into something that changes it; if you don't try, you certainly won't get it. So you cast bread upon the water, you publish books, you make speeches, and if you don't do this, what can you do? This is the way democracy operates-sometimes it doesn't move, but sometimes it does move. I've been in Washington since 1938; now and then somebody catches fire - this is very important. 



\title{
NBS and the Inventive Process
}

\author{
Richard W. Roberts \\ Director, National Bureau of Standards
}

\begin{abstract}
If we are to compete for international markets, we need more and better science, and we need a continuing supply of marketable inventions. The role of the inventor at the National Bureau of Standards, and the services offered to the outside inventor by the Bureau, are described. The aims of a major new NBS effort-the Experimental Technology Incentives Program-are explained, and suggestions are requested for additional experiments that ETIP could perform.
\end{abstract}

Key words: Experimental Technology Incentives Program; inventors; National Bureau of Standards; Office of Invention and Innovation; technological innovation.

The United States has achieved the highest standard of living in the history of civilization. Material goods abound, we are fed and overfed through the efforts of a very small number of farmers, the wonders of applied medical knowledge have increased our life expectancy dramatically, and there are opportunities for travel, leisure, and recreation undreamed of by previous generations.

We attribute these blessings to a combination of factors: abundant natural resources, a people dedicated to achievement, and the vast contributions of science and technology. It is unfortunate that many tend to overlook the vital contributions of the inventor. True, certain names such as Edison and Bell are familiar to every schoolchild, but the efforts and successes of thousands of others, to whom we owe so much, are lost in the mists of time.

Today many inventors are scientists and engineers who create as part of their iob, but thousands of others are barbers, lawyers, laborers, housewives, and students, who tinker and create with the hopes of turning a profit in their own time.

And, let's face it, inventors were contributing long before science was an established profession. Thousands of processes and devices, from glassmaking to the steam engine, were developed before there was a National Bureau of Standards or corporate R. \& D. laboratories.

We all recognize that the world today is extremely complex. Knowledge grows faster than we can assimilate it, and the costs and problems of marketing an invention are vast impediments to the innovative process. But despite the difficulties, we need invention and innovation more today than at any time in history.
Let me show you why. Despite our present affluence, our position in world markets is deteriorating. In 1971, for the first time in this century, the United States had a negative balance of trade, and in 1972 the negative balance was $\$ 6.3$ billion.

Exports of American goods rose 110 percent over the past decade; Japanese exports quadrupled. Since 1960 our productivity has risen 32 percent; Japanese productivity tripled over the same period. And many nations, including West Germany, France, and Japan are investing a greater proportion of their resources in R. \& D. than we are.

There are other causes for concern. The number of foreign patents taken out in this country is rapidly increasing. In some areas, the majority of new technology is foreign based. In textile weaving, for example, about 70 percent of recent patents were foreign, in tunneling, 69 percent, and in tracked air cushion vehicles, 49 percent. If the trend continues, we will end up dependent on foreign technology in many areas.

And, of course, there is inflation. One of my friends has suggested that if we devalue the kilo. gram as we have devalued the dollar then we would get more food per dollar. I'm not so sure that's the answer!

One of the answers, of course, lies in more and better science, technology, and invention and innovation in this country, coupled with Government policies and initiatives to foster such progress. And that's one of the reasons we're here today.

The United States has always recognized the need to nurture the growth of invention. That need was formalized by the dedicated group of radicals who invented our form of government. They included a 
section in the Constitution "to promote the useful arts, by securing for limited times to authors and in. ventors the exclusive right to their respective writings and discoveries."

Benjamin Franklin, one of the architects of the Constitution, was himself an inveterate inventor. His creations, more than those of most inventors, have stood the test of time. The Franklin stove is still widely used, and probably half of this audience wears another of his inventions, bifocal spectacles.

American inventors have long played a major role in the feeding of our growing population. Lately, the phrase "green revolution" has caught the public fancy, or at least the fancy of the press. This revolution refers to the development of new strains of rice, wheat, and corn that give greatly improved yields. But I believe that we had an earlier "green revolution" in this country when Eli Whitney invented the cotton gin, Cyrus McCormack perfected his reaper, and a dozen others developed ploughs, seed planters, grain threshers, and corn huskers.

The impact of some of these inventions is impres sive. In 1791, the United States produced 138,000 pounds of cotton. In 1795,3 years after Whitney developed the cotton gin, we produced $6,000,000$ pounds. That's what I call rapid economic impact!

Before you jump to the conclusion that American farmers readily accepted every new invention that came along, though, consider the story of Charles Newbold. Newbold took out a patent in 1797 on a cast iron plough with which a team of two oxen could turn a straight, even furrow. But suspicious farmers believed the iron would somehow poison the soil, so they went on using their wooden plough and a team of 8 to 10 oxen. Newbold, after investing $\$ 30,000$ and remember this was 1797 , when $\$ 30,000$ was a massive investment, gave up in disgust. Goes to prove that you can't sell that better mousetrap if the market isn't ready.

Over the years, American inventors have contributed in many areas. There's no need for me to chronicle the achievements of Thomas Edison, Alexander Bell, George Westinghouse, and a host of other American inventors, including such contemporaries as Bill Shockley and Edwin Land. But there is a need for me to re-emphasize that if we are to compete for international markets, we need more and better science, and we need a continuing supply of marketable inventions.

During my career I've been very conscious of the role of the inventor.
Before coming to NBS just 4 months ago, I had spent over 12 years at the General Electric Company, Research and Development Center in Schenectady. GE has always encouraged invention. Thomas Edison, one of the company's founding fathers, was an inventive genius, and his traditions if not his methods are carried on today. Let me give you a recent case history involving man-made diamonds.

Ever since 1797, when diamond was first shown to be a form of carbon, man has dreamed of making, rather than mining, his diamonds. In 1951, GE launched a major program to produce diamonds in the laboratory. A team of four scientists, Bundy, Hall, Strong, and Wentorf, was assembled and several approaches were explored. The one that paid off involved a great deal of inventiveness in the field of superpressure and temperature control. By 1955 , using a process in which graphite is dissolved in molten metal and subjected to pressures of nearly a mil. lion pounds per square inch (36.9 megapascals), small quanitities of industrial-grade diamonds were produced in the laboratory. This process was patented, and in 1957, man-made abrasive diamonds were introduced to the marketplace. This particular invention had several results, one being the creation of a whole new enterprise for General Electric. Today, the GE production facility is one of the largest sources of industrial diamonds in the world, and American diamonds are now used by every industrial nation. Furthermore, the creation of a domestic supply reduced our dependence on a single, overseas source for a strategic material. Finally, the ability to tailor the properties of industrial diamonds to specific uses has resulted in an abrasive tool today that will perform 5 to 10 times better than its 1957 natural counterpart.

The industrial stones, small and unattractive by esthetic or jewelry standards, are used today for cutting, grinding, and polishing the hardest of metals, ceramics, glass, stone, concrete, and gem diamonds themselves.

Following the commercial success of abrasive diamonds, two members of the original team, Strong and Wentorf, pushed on in the quest to produce gem-quality diamonds. The process they developed involves the dissolution of a small mass of man-made diamonds in metal at about $2500^{\circ} \mathrm{F}\left(1370^{\circ} \mathrm{C}\right)$ and at 900,000 psi (33.2 megapascals). The metal is held in a tube that is about $50^{\circ} \mathrm{F}\left(28^{\circ} \mathrm{C}\right)$ cooler at the ends than in the middle. The carbon dissolves in the metal 
and diffuses toward the cooler end zones of the tube, where it crystallizes out of solution around small seed crystals of diamond. This process takes several days, and holding the temperature and pressure constant is quite an accomplishment. The stones produced by this process are indistinguishable from natural stones with one exception - price. The manmades are much more costly, and a major breakthrough will be required to put them on a competitive basis.

While at GE I had the privilege and pleasure of associating with Dr. William Coolidge. Dr. Coolidge, the inventor of the $x$-ray tube, was a charter member of the Inventors Council, a group on which he served until 1963.

In the last 4 months I've learned a great deal about the Bureau's famous inventors. One of them, of course, is with us today, and that's Jacob Rabinow. When Jack first came to NBS he was assigned to the calibration of fluid meters. Almost immediately he began improving on the equipment in use, and he's never stopped inventing. When the second World War broke, Jack was switched to Ordnance work, as were many others at NBS. One of his major developments was the acceleration integrator which determines whether a shell has been fired, in which case it will be allowed to arm, or has been dropped, in which case it won't arm.

Shortly after the war, Rabinow was asked by the NBS computer development group to devise a rapid acting clutch for use with computer input/output devices. What he came up with was a clutch based on a new physical principle - the control of frictional forces between solid surfaces and a magnetic fluid by application of a magnetic field. The magnetic fluid, consisting of a suspension of iron particles in a lubricant, becomes solid and transmits torque within milliseconds after a magnetic field is applied. This device caused a new sensation-literally thousands of industrial engineers contacted NBS for details, and several hundred came to see the device and get first-hand information. The clutch went into widespread commercial production, being used in a variety of control devices, servomechanisms, and even automobile transmissions, with the French Renault still using the principle.

Another development for which Jack is justly famous is his optical reading machine. In this device each character being read is matched with each letter of the alphabet and the closest match is selected. In this way broken or degraded letters can be handled with ease. A model of his machine is on display in the Smithsonian Institution, and the principle is now used in most optical reading devices.

In all, Jack holds over 200 patents, and while not all of them were taken out while he was at NBS, he still developed more patents while in Government service than any man in history.

But don't let me give you the impression that NBS has had only one famous inventor. Far from it. For example, in 1947 Abner Brenner developed a chemical method for plating nickel on a metal surface-electroless plating he called it. In his process the metal to be plated is merely dipped into a hot solution of nickel chloride and sodium hypophosphite. No electricity is applied, and nickel of up to 97 percent purity is deposited on the object at about the same rate as in conventional electroplating. The process is now a multimillion dollar industry, and while the patent was in force over 200 companies were licensed to use the process. More than that number are probably using it today.

During World War II a Bureau team, including Harry Diamond, Allen Astin, and Wilbur Hinman, developed the radio proximity fuze for use in bomb detonation. The proximity fuze is essentially a tiny radio transmitting and receiving set contained within the bomb. When the radio waves reflected back to the receiver reach a sufficient intensity, indicating proximity to the ground, an electronic switch detonates the projectile. A host of problems had to be overcome in developing this device, including operation at $-40^{\circ} \mathrm{F}$, miniaturization to fit into the bomb, and development of a tiny wind-driver generator to power the device. At the end of the war over 8 million fuzes had been built commercially, using at peak production 25 percent of the total facilities of the electronics industry and 75 percent of all plastic molding firms.

I mentioned Harry Diamond in connection with the proximity fuze. He was involved in many other Bureau inventions, one of the most interesting being the development of radio navigation devices for aircraft. Using a ground-based transmitter and instrumentation developed by Diamond and associates, a Bureau-equipped plane made history's first completely blind landing in 1931. In 1933, the first point-to-point flight in zero visibility was made from College Park, Md., to Newark, 'J.J. Showing the courage of his convictions, or faith in his inventions, 
Harry Diamond went along on that historic flight. Even Charles Lindbergh tested the system, making two blind landings in 1933. The whole object of the NBS work in the early thirties was to put radio navigation and landing on a routine basis, something we haven't accomplished yet.

But enough about NBS inventors. Let me turn now to the subject of what NBS has done for inventors generally. In a very broad sense, the Bureau and its work are resources to all inventors, big or small. Our staff is expert in topics ranging from activation analysis to Zener diodes, and provides consultation to those having problems in our areas of competence.

New knowledge generated at the Bureau is made available to all inventors through scientific publications, and our volumes of Standard Reference Data are often the key element in a decision as to whether a proposed process is viable or not.

Other NBS services to inventors are much more direct. In 1964 we created an Office of Invention and Innovation under the direction of Dan De Simone. One of the functions of this office is to work closely with the National Inventors Council. We are fortunate to have Len Hardland on our staff, as Len has been involved with the Inventors Council from its inception in 1940. One of Len's functions is to direct to the proper Government agencies those proposed inventions that still come rolling in. And come they do! In a recent 4-month period we answered nearly 800 letters concerning inventions and another 1,000 requests for publications. Now in charge of the Office is our friend Jack Rabinow, who returned to NBS a short time ago after a successful industrial career.

We were a major participant in the Woods Hole Conference on Creative Engineering Education in 1965. The principal aim of this conference was to explore the opportunities for teaching the techniques of invention and innovation in engineering schools. The consensus of the conference was that creativity could be taught to college engineering students. As a direct result, many curricula were modified to include courses in creative engineering, including those of Stanford, MIT, Santa Barbara, Dartmouth, Georgia Tech, and others.

A few years later Dan De Simone served as the Executive Secretary of the Commerce Panel on Invention and Innovation. The Panel Report, "Technological Innovation: Its Environment and Management," also called the Charpie Report, after the Panel Chairman, is a classic statement of the problems encountered in innovation, together with recommendations for smoothing the way for commercialization of inventions.

The Office of Invention and Innovation has also been a key factor in the spread of State invention expositions. These affairs, which with Bureau encouragement have now been held by 27 States, bring together inventors and firms who are looking for new technology. Some notable success stories have resulted, such as the contacts made at the Minnesota Exposition that led to formulation of the Rolite Company to manufacture camping trailers.

There is a major new NBS effort - the Experimental Technology Incentives Program, or ETIP - that we hope will have quite a positive impact on inventors and small R. \& D. firms.

ETIP, proposed by President Nixon in his 1973 budget message, seeks to increase the application of technological invention and innovation to such problems as productivity, employment, pollution, energy conservation, and the negative trade balance. ETIP will not seek to foster the development of specific new technology, rather it is aimed at the development of Federal policies to stimulate the flow of technology to the marketplace.

Before policy can be shaped in a meaningful way, we must have knowledge and experience concerning factors that influence invention and innovation. And developing that knowledge is the task of ETIP.

ETIP assumes that invention and innovation in the private sector is strongly influenced by Federal policies and programs. The program will start by testing this hypothesis in three broad areas: procurement, regulation, and invention and innovation by lone inventors and small R. \& D. firms.

We will look at such questions as:

- What cost-effective Federal actions can be taken to facilitate the commercialization of the technical inventions of inventors and small R. \& D. firms?

- What alternatives in Federal or Federallyassisted procurement policies and practices would be cost-effective in stimulating technology, invention and innovation and thereby increasing productivity and improving the U.S. competitive position?

- Can Federal regulations issued to protect public health, safety and well-being by controlling goods and services offered to the public be used to provide a positive stimulant to technological invention and innovation? 
ETIP has defined the desired experiments and statements of work for each of the three major policy questions, and participation has been solicited from the private sector. Most of the experiments will be performed in cooperation with technologicallyoriented private organizations and other Federal agencies, with NBS monitoring progress of these investigations.

The Federal Government has for many years provided assistance to small businesses. This assistance has been in the form of loans, loan guarantees, or management advice and assistance. Unfortunately, in qualifying for such assistance, firms associated with new technological products and services and lone inventors have been at some disadvantage because the Government has avoided the risks involved in making loans to firms that produce new technology.

To improve this situation experiments are now being developed that will identify those policies or programs that may facilitate technologicallyoriented small businesses. The validity of the experiments will be judged on the basis of whether or not inventors or small R. \&. D. firms are able to accelerate the commercialization of new products or processes.

In developing plans for these experiments, the following general assumptions have been made:

- The historic role of the inventor and small R. \& D. firm as a prolific scurce of technological innovations will continue.

- The relative value and probability of success of inventions can be compared.

- The cost-effectiveness of revised policies to stimulate innovation by lone inventors and small $R$. \& D. firms can be compared.

- The results of a systematic set of experiments aimed at improving the commercialization of the inventions of inventors and small R. \&. D. firms would permit the identification of better policies or programs.

Let me give you a few examples of what we mean:

- At present, the Small Business Administration provides support to small businesses primarily on the basis of their managerial competence and financial soundness. In conjunction with SBA, procedures could be tested so that decisions to support new ventures are extended to those that are especially technologically attractive. The experiment would be to provide SBA with the technical expertise needed to make sound technological judgments either through funding private engineering consultants or through making available technical consultants in Federal laboratories. If, by this means, a significant increase in technological innovation is stimulated, more permanent institutional arrangements would be proposed.

-A series of experiments could be conducted in cooperation with SBA to examine the effectiveness of providing objectives and accurate market information to small businesses concerning their advanced technological products or services. Assessment of the market potential for the product would be provided by funding technical market analyses. Results would be furnished to appropriate entrepreneurs when it is anticipated that a commercially viable innovation is found. The ability of the firm to use this information to gain needed financing will then be followed to examine whether market surveys or market development assistance might be provided by SBA as an additional service to small technologically-oriented firms.

-In conjunction with State-sponsored product development corporations such as those recently established in several States, means would be developed to provide managerial, marketing, financial and other assistance to inventors and small R. \& D. firms with promising technical inventions. Such assistance will be directed towards bringing together the entrepreneurship, financial backing, and market know-how needed to carry technical inventions through to successful commercial application.

These examples are illustrative and are by no means exhaustive.

So let me close with a request. We are actively seeking suggestions for additional experiments. I look to this audience for a good deal of input. Most of you are familiar with the processes and problems of inventions. You are aware of those barriers to invention that government action can overcome.

I encourage you to apply your inventive skills to the ETIP program, helping us design and test technology-transfer mechanisms. 



\section{SESSION III - June 13, 1973}

\section{Opening Remarks}

\section{Myron S. Coler*}

It might be appropriate in these opening remarks if I made one or two rather personal comments. Unlike the members of the morning panel who come from large organizations such as the Government, Monsanto, IBM and RCA, I have been a so-called small inventor and a small entrepreneur. However, I am not one of these people who think that there is a great mythological contest going on between the great companies and the little companies. Certainly there are some very rough individual moments!

In terms of the larger purposes of this meeting it is well to note that when we talk of affecting the international balance of trade, we are talking of units in the neighborhood of $\$ 100$ million. We are not going to affect $\$ 6$ billion shifts in an economy with just a handful of roughly $\$ 1$ million enterprises. So, sooner or later the development has to be big to be significant for the National economy. For major growth developments must either go over to the larger companies or less frequently, the small developmental company grows to be larger as in the case of Xerox or Polaroid. Hence, for present purposes we should not consider the individual small inventor or enterpreneur in isolation.

Similarly, if a public corporation, in which a family or an institution holds stock and counts on dividends were to announce suddenly that for the next 10 years they were cutting dividends in order to help and reward the small inventors employed by the company, there might be a rather fast shuffle of stock portfolios. Obviously, the value of inventions and hence the value of inventors are not intrinsic but depend increasingly on the marketplace.

I do want to call attention to the fact that we often tend to be a bit careless in our use of such words as "invention" and "patent." We often act as if the terms were unique; when you get stuck, you go to the dictionary. Unfortunately, the dictionary does not deal with many nuances and important legal and marketplace distinctions. Thus, for example, there are real inventions which are not patentable. Again,

${ }^{*}$ Member of the National Inventors Council there are inventions which are not suitable for patenting but which are patented because someone wants to negotiate with a block of 30 patent applications instead of 25. Contrariwise, certain inventions which may be very appropriate for patenting may, because of trade practices, be carried out as trade secrets.

Despite their generality, observations of this kind may lead to important distinctions in the way different so-called inventions will be handled and the real local meaning of such terms as "environment" and "incentive." Let me give you two extreme examples. If we have a mechanical device, it is usually self-evident (although it may require careful examination) how the device is or may be constructed and operated. Infringement tends to be readily detected.

On the other hand, let us take an example from the chemical industry: the area of catalysis. Even among companies which patent very extensively, certain details of catalysis, the manner of making the catalyst and incorporating it, and so forth, may be treated as "secret art." That is why "know-how" is often just as important as the related patents - technically if not legally.

I would at this time add my emphasis to a point which has been mentioned by several people. In many cases we do not sell the invention. We sell the know-how, the entree, the customer list and many other intangibles. However, the best legal instrument is the patent. So people may appear to negotiate and fight only about the patents. But it really is not that simple.

Thus, such a court decision as maintaining that the licensor can no longer require that the licensee not challenge the validity of a patent will, I predict, lead to more licensing which requires "all cash on the barrel head," and hence some very difficult pricing problems.

Inventors-especially of limited resources-are not going to go through the hard years of researching, developing and marketing only to find that their "winnings" are in complete jeopardy 
because the licensee finds it convenient to raise validity questions even without merit.

There can be invaluable legislation on patents and judges can make decisions of profound importance, etc. But, I submit, that to the extent that we are in- terested in methods of providing incentives, we cannot legislate inspiration, and we cannot simply argue incentives. We must find a different approach. I think that many of us here might contribute to that need. 


\title{
The Inventive Process - Where Does It Need Stimulation?
}

\author{
William B. McLean
}

\author{
Naval Undersea Center, 271 Catalina Blvd., San Diego, Calif. 92132
}

\begin{abstract}
The patent system is crucial for the development of our national economy. Its influence is exerted by providing a period in which risk capital needed for development can realize a return through production. The inventor and his returns are only incidental to this process.

Many areas of new development exist where the returns to the economy would be great but the Government is the only organization capable of starting the development. These include: (1) Satellite communications; (2) Two-way cable TV; (3) Floating cities; (4) Undersea cities and oil and mining operations; (5) Submarine tankers. Government ownership of patents is inconsistent with the purpose for which the patent system was created because it has no reasonable means to grant exclusive licenses.
\end{abstract}

Key words: Government help to innovation; Government ownership of patents; innovation; inventor; patent system.

Ladies and gentlemen, one of the advantages of being changed from the first day to the third day is that you learn a lot about the things that you don't need to say, particularly with this group. I was going to talk about the importance of innovation and invention to our total problem of balance of trade and the decline in the number of patents, and I was going to remark about the fact that we were now beginning to understand what Kruschev meant when he was over here and said that they were going to bury us in economic competition; the world is starting to do that. But I think Dr. Ancker-Johnson and Dr. Roberts both said plenty about the fact that we need more innovation, and I believe I can skip over that.

Then I was going to talk about the inventive process, and the at least 21 steps that we go through in order to get from an invention to a product; and as far as I'm concerned we should really start back with the conception of the inventor at the time the DNA molecule is first put together, which later will result in a man with an inventive pattern in his mind, but this process of how the individual then has to be trained, and how he has to have a pattern that allows disorder, how he has to get random combinations, was pretty well covered by both Dr. Kapany and Dr. Shockley; so I probably can skip through that, too. They also spoke about the need for artistic talent. and how to put things together, and that you needed one individual who could form an integrated whole. and could finally bring it together and demonstrate that something would work.

I also thought it would be useful to talk about why the patent system wasn't working, but after listening to Professor Kayton's impassioned speech yesterday, I think that anything I could add to that would be well in the form of an anticlimax. I certainly agreed with the things that he was saying, for the record.

One of the things that I did disagree with, and I'm not sure who said it, was that we really didn't need very much Government money to start the economy going, or to make a change in the inventive process, the innovative process. It seems to me that we have a lot of important areas that we could advance towards, where the initial investment is so large that I doubt that any single company or group of companies can take the risk involved. One of these, where the Government has already helped, is in the area of satellite communication. I think the fact that we now have synchronous satellites with communication systems operating will improve our total worldwide communication net, and will certainly involve a lot of new innovations and new inventions.

I think, closer to home, the next big step in communications is the installation of two-way cable TV. I think this is an area where the Government has 
been detrimental rather than helping; the few companies who have tried to get it started have been opposed by Government regulations. I think in the State of California we have an outstanding example of that, in which a company which had invested about $\$ 25$ million in cables in the Los Angeles area was legally, by an initiative in the State of California which received the support of 60 percent of the people, was enjoined from carrying out their operation. This obviously was illegal; the initiative is poorly written, and it wasn't something that should have been done in the first place; but because it is possible to manipulate a democracy, they did get 60 percent of the people voting against something which ought to be a very important public good. I think the cable TV makes possible an educational system; it makes possible sales; it can be important in training and entertainment; it even has a very frightening thing to the politicians, it would get an instantaneous expression of opinion on what they were saying. I think if we had a system of two-way communication throughout the country, we also would have a change in the transportation problem; we wouldn't have to drive so many automobiles down to the corner grocery; we could send things on a one-way trip instead of a two-way trip.

Now there is another area that I think is important, and which will require considerable initial investment. Dr. John Craven has been trying to work with our Government, and with the Government of Japan, to get the financing to build a floating island for demonstration that such a proposition is valid, and he was proposing that they build a floating island that would first be used as an oceanographic exposition in Okinawa, and then would be towed over to Hawaii, where it could serve as an exposition for Hawaii. The cost for such a device is about the same price, about $\$ 50$ per square foot, as property in downtown Honolulu; and in a floating island you get the buildings as part of the structure, and they come for free. So. economically it shouldn't be a very hard problem. But I think if we had such cities available, or had demonstrated that this is a possible concept, we would have an opportunity for a whole host of other innovations which would start the economy going again. Well, fortunately Japan has decided they'll go ahead with the project, and they're going to build such an island for Okinawa, but the U.S. Government has not decided to help with the project.
We've also located, on the north shore of Alaska, a large deposit of oil. This would help us in the problem of Saudi Arabia cutting off our supply of oil, but it's a very inhospitable area to set up the operation to recover oil, because it's awfully cold. We have in the ground a large thickness of permafrost, and the buildings that you build tend to sink into it; but just offshore, about 50 miles out, you have a lot of water at $30^{\circ} \mathrm{F}$ and it can't get any lower than $30^{\circ}$; there's no wind; the weather is an asset at that point; but what you need is an undersea city. Now this is not a case where we need to develop new technology, we just need an investment to build a city under the floor of the ocean. We started to look into it to see what technology needed to be developed about ten years ago. We found at that time there were about 10,000 miles of tunnels underneath the sea floor, and that there were daily about 4,000 people working below the sea floor. All these tunnels had a termination on the ground, but nevertheless they had to face all the other problems of supporting the ocean pressure, of construction, etc. We have some beautiful pictures of undersea mines in Sweden, with whole machine shops below the ocean floor. Again, I think that if we had such a city, then the technology necessary to make it lower cost would immediately develop. This would lead to the design of submarine tankers, because the only way to get to such a city without coming through the ice interface is by submarine; and I think the submarine tanker would open up the northern trade route that was the thing that Columbus was trying to find. The ocean in the Arctic is reasonably deep; it is $2-3,000$ fathoms, and except for the narrow straits at one end, you have a path for international commerce across the top of the world which would be opened up by the provision of a submarine tanker. I've asked some of the people in the oil companies why they don't do this, and they say: well, the Government has all the technology on submarines in general, and the initial investment in such a project is too much for any one company to undertake. General Dynamics has done the study of a good submarine tanker, has it available to anybody that wants to look at it, but I don't think it's a project that will get off the ground unless the Government is willing to help support it.

Well, Jack Rabinow asked me to talk about the role of the inventor in the Government, and before 1952, when we both went to work, the role of the inventor in the Government was very favorable; that 
is, we could retain all commercial rights to a patent, and we could retain all foreign rights. The $\$ 25,000$ award that Myron Coler mentioned that I got for the Sidewinder I used to file for foreign patents in the other NATO countries, and I was real lucky, because the filing in the foreign countries eventually ended up with about $\$ 1.5$ million return on the units manufactured abroad. It isn't very often that that happens to a Government employee.

I believe that the Government is being very selfish. After 1952 the Government changed its policy; people began wondering why the Government was funding all this research and development, funding up to 70 percent of the research and development in the country, and not taking title to all the inventions which they were producing. Well, of course the reason the Government wasn't taking title was because it had no possible way of utilizing patents. The patent system was set up to provide an incentive to produce new things and to cover the costs of producing new things; and the Government just doesn't want to get into that business. If it did, I'm sure that all the people in industry would be very unhappy if suddenly the Government started competing with them relative to the inventions which they hold. And I can't see Congress funding the capital investment that is needed on some of these wild schemes that we would like to propose. So the Government is really holding on to something, both from its own inventors and from the inventors that work on contracts with the Government, which it can't possibly use.

I also had some recommendations on Monday that I haven't heard anybody else propose, and I'd like to just end with those. I'd like to first suggest that Dr. Ellett, after listening to all the problems of how to fund the Patent Office, said, "Well, why don't you just put them on a percentage of the take?" and it seems to me that would be a very important way of funding. The inventors would much rather have a percentage of the gross income than they would a flat payment, because I don't think anybody at the start knows how to price a patent. If we put the Patent Office on a percentage of the total income from their patents, I think both the legal attention and perhaps the Patent Office attention would shift around to the point of trying to get more valuable and more valid patents. So I would agree with the recommendation that Dr. Ellett made.
I have another feeling, and that is that patenting and development really is an individual matter until you have your first working model. I think if the Patent Office could return to the system they had originally, when they first set up the patent system, of not granting a patent until you have a working model, then we would eliminate a large number of patents that are taken out just for nuisance value; you'd eliminate the patents that just plain won't work, like the perpetual motion machines, because you really can't demonstrate a working model. We now have gotten to the point where we have storage mechanisms which would eliminate the original problem, which was that there wasn't any place to store all the models that people made. We could now store videotape or demonstrations of the models working in a form where people could look at them and see how they were working. Also, if you had a model of a patent before you granted the license, you could include in the certification of the model some of its characteristics on how it works, and we then could have a system that requires that nobody can produce something with a different trademark unless it meet the minimum specifications that you have for your model. At the present time there is nothing in the broad language that says how well a system has to work, and yet one of the things we are faced with is that a lot of our systems don't work very well. We can get one good unit and then everybody copies it, and it's very hard for the consumer nowadays to tell the difference by just looking at them, as to which units work and which units don't work. It's particularly true in the area of plastics. where they all look alike, but they are tremendously different in their strength, their resistance, their wear capabilities, etc. I think we need something like the Japanese "Passed for export," which means that it's a good product. Certification of quality really ought to be a Government function similar to the patent function.

My last recommendation is that we need to revise the tax structure, and probably this body won't have much influence on that; but it seems to me we have a tax structure whose main objective is to equalize the income of all people in the country. If you were able to accomplish equalization, there would be no capital to do anything imaginative, anything new. You don't build pyramids in a society where all the income is equal, and I think we need some 
mechanism where people and companies can accumulate enough risk capital so that we can get major projects started; otherwise, the Government has to do it. And in some countries the Government is doing it, and those are the ones that are competing with us most effectively, economically.

One of the other things I learned in the last 2 days is that if you stop talking, then everybody else will start.

\section{Discussion}

J. Jancin, Jr.: Would you elaborate on the percentage of take; I'm not familiar with that idea.

W. B. McLean: I'm not sure that I could give a percentage other than that you ought to be able to set it at such a value that the Patent Office would become self-supporting, if that's an objective. It ought to be easy to take the total income from patents and divide it into the cost of running the Patent Office. I suspect that it is not a very high percentage: I'd guess $1 / 10$ th of 1 percent.

J. Rabinow: Dr. Ellett, who was Bill McLean's and my boss many years ago, suggested that instead of giving a fixed fee to the Patent Office that the fee be based on the royalties you collect. This, I think, could be done. In other words, the income tax form could have a special line of royalties collected and a certain percentage could be assigned to the Patent Office. The difficulty is that many patents do not collect royalties, because many of them are used by companies where it goes into their general pool of profits and there's no way, in General Electric, for example, or Control Data, where I worked, to assign a dollar value to the value of the patent. It's easy enough when it is licensed to somebody else but the difficulty, even in cross licensing, for example. is. again, there's no cash. Control Data took my patents on reading machines, for example, and cross licensed them with three companies and nobody would be able to put a dollar value because there were no dollars exchanged. We just cross licensed 45 patents against 150 . It could be applied, however, to individual inventors.

I'd like to suggest this for your consideration, that the patents should be treated differently when they are gotten by corporations as against private inventors. A corporate patent, as you have heard several times, is a defensive thing. I believe that IBM does not make money in any real sense on patent royalties. They sell computers. General Motors does not make money on patents even though they have a great many for various defensive and trade reasons.
They sell cars. So that a patent to a large corporation is a defensive thing; it's a trade thing; it is not a way of getting money. As a matter of fact, I am told that many of their patent staffs cost more than the royalties they collect, but they are valuable for other reasons, obviously. It may well be that the patent system of the United States should be so changed that the patents issued to corporations should have different rights, different durations, different ways of issuing as compared to an individual inventor. One of the suggestions is that the fees could be different and that the search should be done by the attorney, when he's a corporate attorney, and it should be made by the Patent Office, when he's a private inventor. In that case, the fees to the private inventor could follow Dr. Ellett's idea, that the private inventor pay a fee according to the royalties he collects.

B. Walker: On the question of percent of gross from the patents, I wonder if you really mean gross or net, because you can have some very severe costs in connection with getting a patent. I think that should be maybe net, and then, also do the taxes on royalties accomplish almost the same result? Taxes will probably amount to at least 50 percent of the gain on royalties, whether to an individual or to a corporation, but the Government very seldom figures a net basis. If the Patent Office produces something that results in a lot of taxes, maybe the Patent Office should be credited with the taxes derived from the patents, either in royalties or in income.

W. B. McLean: I would agree entirely that the requirement that the Patent Office should be selfsufficient is pure nonsense, but in that area of pure nonsense you can make some things less nonsensible; I mean, you can provide a rationale that is understandable to the accountants for not increasing the patent fees to a completely unreasonable level. In other words, the Patent Office has to do a good job if the patents are going to be of any stimulus at 
all to the economy, and that's a Government function. If it isn't a Government function, we could just abandon the whole patent system, but I was just trying to make a reasonable method of funding the Patent Office. I don't think that you really need to have a reasonable method. As Jack has said very often, the income to the country from the patents makes the total cost of the Patent Office look miniscule. What is it? At least $\$ 2$ billion versus $\$ 30$ million?

K. Hansen: You've had considerable experience in the Government laboratory area. I wonder what your comment would be on the following observation. There has been a definite phenomenon since World War II of establishing Government laboratories. Most of them were, in the very beginning, concretely mission oriented and I believe that there is a rather remarkable record of inventiveness, innovation and accomplishment. It would appear that in the last 5 to 8 years, however, there has been a change in the approach, that more and more of these laboratories have been legislated out of their mission and we have seen the solution looking for a problem. It seems to me that a good deal of real inventive and innovative capability has been locked up. I've sat in Government and seen a parade of Government laboratories come by, offering all kinds of ideas that they would like to work on, as a basis for staying alive. I wonder if you have a comment on this.

W. B. McLean: I think that the change that has occurred is that all of the laboratories in the Government are now on a national industrial funding base. where they have no fixed budget for the year. The capital that they have to work with is based on the projects that they can sell. The review process in Washington has gotten to the point where it's almost impossible to sell anything because there are so many people that can say, "No." I think the laboratories are having exactly the same problem that industry is having in dealing with the Government in Washington, and that is that the number of things you have to present, in order to get one accepted, is very large and the chance that anything really new will be accepted is almost zero. There's just too much review. We used to be able to go to the Chief of a Bureau in the Navy and he had the fund allocating authority. If he liked your idea, it went ahead. He called in his people and said, "Do it," and they found the cash. Now, the cash is so well distributed, there are so many reviews that nobody can really change things once they get underway. As Jack said, when you spend all your time on proposals, funding, and accounting, you have no time to be inventive. I think the inventive rate in the Government is probably well down at the present time. I can't think of any new project that is really important that has gotten started in the last 10 years.

R. Fullman: You mentioned that you were going to skip some things that you had intended to say about the significance of invention and innovation to the economy and the elements of trade problem because they have been discussed before. Now, those subjects were armed-waved at, if you'll forgive the expression. We heard some motherhood statements but I don't think we heard any real sound evidence type of talking yet in this whole conference about really what is the evidence of how important innovation is, to what aspects of progress in the economy, have we fallen behind or are others just catching up with us - anything quantitative that you really had available to tell us about in that respect, I'd certainly appreciate it if you would peek through those notes and bring them back out.

W. B. McLean: I'm afraid I don't have a good answer. I think it's important but it's a feeling I have. Of course. it's obvious if we are going to have to put out a large part of our capital in order to get energy, rather than developing our own, we are going to be in trouble and we've got to do something else. We've got to be in the same position, I think, as Japan if we can't be self-sufficient.

R. Kuntz: I think the subject of the Government patent or the patent emanating from Governmentsponsored research and development is sometimes dealt with too lightly. The data that has been accuinulated is overwhelming and tells us what the lack of incentive in the system can do. The policies of the Government, either in retaining title or retaining license to practice, have had a highly detrimental effect on the application of this technology. The inventor has no incentive to disclose under a Government procurement situation because there's no pay-off for him. The company only maintains housekeeping in filing those disclosures so that he can stay clean with respect to the procurement officer. In the event that there is a filing and the Government retains right, that patent never sees the light of day because no one is going to fund it with the capital necessary to 
bring it to the marketplace without an exclusive license to practice. What do you suggest in the use of Government patents?

W. B. McLean: I suggest that Government patents should cease to exist. I think they're a complete fallacy. You might just as well publish it in the open literature, as to try to take out a Government patent, because there's just no feasible way for the Government to license anybody on an exclusive basis; and if you don't have an exclusive license, what's the reason for putting any money in to develop it? So, open publication would be equivalent to the system we now have, and I think would be much preferable.

M. Coler: Apropos of Dr. McLean's last remark, I want to bring up again the fact that know-how transmission is basically a kind of service industry, and the Government is not geared to serve its licensees in the same sense that a company or an inventor, who sells license rights, helps tailor them to specific. problems. The Government is not going to help you get a pilot plant on stream.

J. Rabinow: Regarding the question on hard statistics, the statistics are these: that while initially, an industry starts with a great invention, if you look at the number of patents issued in any industry, you find that the relation between the size of the business and the number of patents is very close. Nobody knows whether patents lead an industry or follow it; they probably do both. So if you look at the half-life of a patent art, as it develops in the Patent Office, the number of patents rise and then gradually fall, and then they're looked at once every
5 years. You'll find that if you study the number of patents issued in any industry, you know how the industry is doing. They're an infallible measure of the activity of an industry, because as an industry gets developed, of course people patent more. And if you look at the history of some of the new arts, you'll find that the foreigners are now outstripping us. While the total number of patents filed in the United States by foreigners is now about 33 percent or so, in certain arts it's 60 and 90 percent. When somebody says that the balance of trade is fiction, I suggest you come to me and I'll give you a list of four pages of arts which are very active today, where the foreigners are outstripping us in the United States; in some instances, 90 percent of the patents are filed by foreigners. This means that that art will certainly be foreign. And it means the manufacturing will follow it, and the trade will follow it, because the patents are infallible guides when there are large numbers, not individual patents.

M. Coler: I disagree with Jack on what I call the Goldilocks theory, where you have one kind of patent for the big bear and one kind of patent for the little bear, because little bears have a habit of becoming big bears, and sometimes big bears shrink. You can't say, these people patent for nuisance and protection, and these people patent for the original intent of the patent system; it's not that simple, and I think it would be the same as saying that a dollar in G.E.'s pocket is only worth 90 cents, but if he's poor it's worth $\$ 1.25$. I don't think it's administratable, but we can argue about that later. 


\title{
The Employed Inventor and the Corporation
}

\author{
C. E. Anagnostopoulos
}

\author{
New Enterprise Division, Monsanto Company, St. Louis, Mo. 63166
}

\begin{abstract}
The idea that the goals of the employed inventor conflict with those of the corporation is an outmodec fallacy. The creative challenges of the modern corporation are totally compatible with the creative drives of the employed inventor. Through invention, he discovers new and useful solutions to problems. Through innovation, the corporation commercializes such technical advances. Corporate growth and profitability today depend upon planned and systematic innovation.

Such innovation requires not only the technical certainty of a useful invention. but also an evaluation and reduction of its commercial risks by such criteria as corporate fit, market timing and potential business volume. The presumed conflict between the employed inventor and the corporation is at this interface between his empirical proof that his invention works and the corporation's pragmatic assessment of it as a business risk.

Actually, this point of stress is a constructive interfacial tension that can be most productive if kept in dynamic equilibrium. This is a task for a middleman who, more than a research director, is a technological entrepreneur; technically well-grounded and with a full grasp of corporate objectives. His role: motivating interpreter to both the employed inventor and the corporation, having the respect and confidence of each.
\end{abstract}

Key words: Corporation; employed inventor; innovation; invention; research director; technological entrepreneur.

I am honored and delighted to share with you my views on this somewhat controversial topic of the employed inventor and the corporation. In my opirion, there are some important aspects to this relationship that need to be brought to light and examined. And these are quite aside from what I see to be the obvious advantages of being an employed inventor rather than being an unemployed inventor.

As the general manager of the New Enterprise Division, I am charged with developing product lines new to the company and offering good growth and profit potential. Obviously, the role of the employed inventor is vital to this function. It is a role that was mine in my earlier career with Monsanto. It was then, and it is even more today, a source of excitement and challenge to me.

Whether you are an inventor or an academician or a corporate R. \& D. manager, you are sure to know what I mean when I speak of this type of excitement and challenge. It is a kind of exhilaration of the spirit; the galvanic charge that courses through any creative person at grips with an opportunity to express his creativity through invention or innovation.

I have put it in terms of technological creativity for our purposes today, but it does not differ from the thrill of creative science or creative art. It is a deliberate pursuit of what psychologists would call the "Aha!" experience. Such creative problem solving is instinctive to us as the highest expression of human intelligence.

Our bodies of science are living monuments to man's instinctively inquiring mind. Similarly, he is forever applying his knowledge creatively to invention and innovation because he has an instinctively reasoning or problem-solving mind. I am not at all sure whether man's first technological innovation was the use of fire or of the fig-leaf bikini. In either case, he has been inventing and innovating ever since.

I shall be referring to invention and innovation quite often today, and primarily in a corporate frame of reference. If you understand what I mean by those 
terms, you may then better understand what I am trying to say. By my definition, invention is the bringing of new products or processes into existence. Innovation, by my definition, is the bringing of such inventions into commercial use. We should agree further that, in the corporate world, "research" refers to the inventive function. The innovative funciion we call "technical development."

But let us take a closer look at the meaning of invention. By anyone's definition, it is essentially the creation of new technology. Any invention worthy of the name must meet three criteria: (1) It must be a solution to a problem; (2) it must be original in concept; and (3) it must be useful in the broadest sense of that term. In short, an invention must solve a problem in a novel and useful way.

The first two of these three criteria yield quite easily to empirical proof. The invention either solves the problem it was meant to solve or it doesn't. Similarly, it is either an original solution, or someone else beat you to it. Failure in either of these criteria sends the project back to the drawing board or the bench.

It is the third criterion - that of the usefulness of the invention - in which proof is by no means selfevident. It is a value judgment of "Who needs it how much?"; the pride of the inventor versus the prejudice of the rest of the world. The classic example of the inventor's view toward usefulness was voiced by Benjamin Franklin. You probably know the anecdote about his being asked by a friend to explain what good was some minor invention. Franklin is reported to have answered his friend by asking him, "What good is a newborn baby?"

To the public, however, the usefulness of an invention is the ultimate measure of its meaningfulness. This criterion of the utility of a problem-solving and novel product or process is the interface between invention and innovation or, in industry, between research and technical development; between the employed inventor and the corporation.

Unfortunately, the public is very pragmatic about what it considers to be a useful and therefore desirable innovation. The corporation depends upon that public for a marketplace. It must be equally pragmatic in deciding what to offer to its market. And it is this type of realism that has led, in my opinion, to a very outmoded and faulty inference about the relationship between the employed inventor and the corporation.
There is an obsolete misconception that corporate management has some type of built-in or reflexive resistance to anything new or different.

From this follows a faulty inference that technological creativity is basically incompatible with the corporate function.

The result of such thinking is the fallacious conclusion that there is an irreconcilable conflict between the goals of the employed inventor and those of the corporation.

I should like to examine this misconception with you in some detail. In doing so, I believe that we can gain some important insights to the very meaningful relationships that exist between the employed inventor and the corporation.

The concept of corporate management as resistant to change has been obsolete for more than a half-century. That long ago there was a strong trend among corporations to establish internal research laboratories to generate new technologies for their technically-oriented business. In this, they were following the leads of General Electric, American Telephone and Telegraph and Eastman Kodak, all three of whom established strong research functions around outstanding academic scientists early in this century: Whitney at GE, Jewett at A.T. \& T., and Mees at Eastman.

Since World War II, and spurred by the technological breakthroughs of that era, practically all of industry has been embarked on a search for new and dramatic ways to grow creatively. Corporations have engaged in the most vigorous competition for any creative business activity that is technically sound, uniquely effective and profitably productive. They have undertaken continuing programs of research and technical development deliberately designed to obsolete their current products and processes through next-generation technology. Their reasoning in this has been simple: If anyone is going to obsolete their products or processes, it had better be done by them.

Their goals have been equally simple: to protect or gain the proprietary position that ensures the greatest profit margin. As a result, corporate management today accepts and invites innovation as a crucial means of keeping up with, or moving up on, its equally innovative competition.

In other words, the key to corporate profitability and growth today is the orderly use of planned and systematic innovation. I have given special emphasis 
to the words "planned" and "systematic" because they relate directly to this question of the utility of an invention; to the interface between the inventor and his employer.

As for the idea that technological creativity is basically incompatible with the corporate function, this may be a derivative of the line of thought, popularized by C. P. Snow, about a "cultural gap" between science and the rest of the world. It is true that the scientific method of appeal to evidence is shared by all scientists and engineers, including inventors. But there is a world of difference between the purposes of scientific inquiry and scientific invention. The purpose of scientific inquiry is to prove a hypothesis. If it is successful, its result is the discovery of new knowledge. In contrast, the purpose of scientific invention-as $I$ mentioned before - is to solve a problem in an original and practical way. A scientific discovery looks like a mathematical equation, and it is the beginning of a new area of knowledge. But a technical invention looks like a device or a recipe, and it is an end point of a current area of knowledge. It boils down to the difference between Edison's light bulb and Einstein's $E=m c^{2}$. Incidentally, it has been almost 100 years since the light bulb was invented-and we have progressed to lasers, masers and holography, but scientists still have not succeeded in devising an experiment that can prove what the nature of light really is!

The corporation has its scientists, too. Their pursuit of knowledge has commercial objectives, but their goals are to prove or to disprove theories. A negative result is as productive as a positive one, just so long as the inquiry shows beauty, precision, generality and importance to its area of knowledge. The scientist's assignment is to search out facts, and his satisfaction comes from demonstrating them reproducibly.

The inventor, on the other hand, is more of a technologist than a scientist. Like the engineer, he uses his scientific knowledge and creative skills to build things; to bring things into novel combinations that work and solve a problem. His assignment is to find a new and better way of making a device or a system work, and his satisfaction comes from the tangible proof of having done this.

To me, these goals and satisfactions of the employed inventor sound remarkably like the goals and rewards of the corporation!
The corporation asks of the employed inventor, "Can you put us into this business? Can you find a way to do this better? Can you give us a proprietary advantage in this market area?" Those are very creative challenges. And I see them as being totally compatible with the creative drives of the employed inventor.

How, then, can there be any validity to the conclusion that there is an irreconcilable conflict between the goals of the employed inventor and those of the corporation?

Consider the advantages that the corporation of fers him. Literally millions of dollars worth of physical resources are put at his disposal in terms of field and laboratory facilities, computer capabilities, etc. $\mathrm{He}$ is put into close communication with colleagues of his own and other scientific and engineering disciplines with whom he can cross-pollinate to gain fresh insights to his professional problems. He is frequently a member of a team or group which together is working on the problem. He does not need to feel alone nor does he need to be alone in his struggle unless he wants to be so-and only when he wants it that way. He has the incentive of participating in shared corporate objectives. With timetables as well as objectives, he is prevented from wasting his time on the truly impractical; protected, if you will, from getting caught up in the misleading artistry of invention for invention's sake.

At the same time, of course, this means that he can't invent just anything he wants to invent; he can't choose his problems to solve in terms of his own personal interests. But $I$ find that the employed inventor has very little difficulty identifying with the corporate problems available to him.

It is also true that the employed inventor has very little chance of becoming a millionaire from an in. vention. But he also is in no danger of going broke if the invention doesn't work! Again, I find that the recognition of an important problem uniquely solved is much more satisfying to the inventor than is money without such recognition. His name on the patent is much more important to him than the fact of assignment.

Finally, the employed inventor has advocacy of his function and objective evaluation of it through his management. The corporation is his only customer but, on the other hand, he is working on assignment. This implies the acceptance by the corporation of 
the invention if it is assessed as a marketable innovation.

This is where we reach the crux of the matter. This is the interface of the inventor's technical certainty that his invention works and the corporation's question of its risk as a marketable product. This is the area of dynamic conflict between the employed inventor and corporate management.

I see this to be a dynamic tension or stress rather than a conflict, however. The inventor's job is to minimize the uncertainties of his invention as a novel and useful solution to a problem. It is understandable that the inventor, as he minimizes these uncertainties, assumes that he is increasing the utility - and marketability - of the invention. But the corporation cannot make that same assumption. What seems like a logical marketing opportunity to the inventor, because the invention is useful, novel and works, is not yet a marketing opportunity in the eyes of the corporation. There remains the very important corporate step of evaluating the business risk involved.

The management of risk is perhaps the most crucial function of a corporation. It must foresee and quantify the potential risks and rewards of one course of action and weigh these against the potential risks and rewards of an alternate course. For an innovation, the decision-making process is one of risk evaluation and reduction.

Quite aside from the certainties of an invention's novel and useful solution to a known problem - in other words, despite the inventor's achievement of his objective, the business risk of the invention must be evaluated against existing alternatives. The three basic criteria for this corporate evaluation of the invention are its corporate fit, its market timing and its potential volume or size.

Corporate fit involves the question of whether the new product or process is reasonably compatible with the corporation's business goals and objectives. This is not often a major question, for the employed inventor welcomes and follows guidance on the areas in which he should be working.

Timing is more of a problem. This calls for a determination of whether the product or process is so innovative that it is too far ahead of its time, in which case the market is not ready to accept it. It is also possible that the corporation's product or process that could be obsoleted by the invention still holds a healthy competitive advantage over the competition.
The corporation might hold up on the invention as a next-generation product or process to be innovated when competition catches up with their present advantage. Timing also can find the invention to be too late; a "me, too" product or process in comparison with the competition's newest entry - or perhaps a step or two behind.

Size is the most critical test of the business risk. Assuming a proper fit and good timing, what is the invention's potential as a contributor to the sales and profits of the corporation? If its market is limited and its sales potential small, can a place be found for it in a present product line? Is there any chance of finding new markets for it that would give it a sufficient sales volume soon enough to justify it as a new product line? What are the chances of finding such markets? The larger the corporation, the more im. portant this question becomes. And the tension mounts at the interface of technical certainty and business risk.

It is extremely important that this tension between the employed inventor and the corporation be maintained in a dynamically productive equilibrium. And I am not sure that this has been accomplished generally to date. You will recall that, following World War II, corporations went on a researchminded binge. They invested heavily in research facilities and talent, gave their scientists a mandate to create miracles and then left them to their own devices while they waited for their miraculous products. This was particularly true of the chemical industry. Its technologists followed their own interests in turning out strange molecules which were then exhibited around the circuit of other chemical companies by "dog and pony shows." The result was an incestuous marketing interchange within the chemical industry which had become a slave to its own technology.

By the early 1960's corporate disillusionment with research had set in. Management turned to newly em erging marketing concepts to combat its competition. With the seller's market now a buyer's market, the customer became management's prime concern. And the customers' needs became a rigid template for industrial research. The result was twofold: (1) it reduced the corporation's risk in technical innovation, but (2) it also reduced its chances of coming up with truly innovative products.

What happened to industrial research both in the fifties and in the sixties were overreactions which 
created disequilibrium between employed inventors and corporate management. Research for its own sake has no place in a profit-seeking organization. If technology dominates management policy, the corporation easily can find itself inventing products and processes for which it has no management, manufacturing or marketing skills. On the other hand, if technology is throttled by management policy, the corporation soon may find its markets usurped by innovative competition.

I believe that the pendulum is now steadying itself, and the relationship between the employed inventor and the corporation is finding a balanced and optimum course. The man-in-the-middle through all of this, of course, has been the research director. During the research-enchanted fifties he was the equivalent of a housemother. During the disenchanted sixties, he was assigned the grim task of executioner. What should be his true role in the dynamic tension I have described between the employed inventor and the corporation?

If we persist in the misconception that there is irreconcilable conflict between the employed inventor and the corporation, it would follow that the research director would have to fulfill one of two different roles. As in the relationship that has come to exist between the corporation and organized labor, the research director would have to be equivalent to either the "shop steward" for the inventors or the "shop foreman" for management. In the former case, he would be squarely on the side of the inven. tors. In the latter, he would be squarely on management's side. In neither case could he make effective use of the interfacial tension between technical in- vention and commercial innovation.

Actually, what is needed is a genuine middleman; one who can do two essential tasks: (1) He must be able to motivate the technologists to apply their skills creatively to practical objectives, and (2) he must be able to convince management that the achievement of those practical objectives is deserving of appropriate boldness in risk-taking.

What I am advocating is the type of research director who has both the strong technical background needed to work with technologists and a grasp of corporate needs and goals which gives him status with management.

This, in essence, means a research director who is also a technological entrepreneur. Innovation is a series of proposed-disposed relationships across both vertical and horizontal barriers within the corporation. The technological entrepreneur must be in the core of this matrix. He should be the bridge between the employed inventor and the corporation, having the respect and confidence of both.

His would be the task of continuing to strengthen the stature and role of the employed inventor. But he would also be charged with responsibility for halting technical projects that were wide of corporate objectives. Both technically and managerially, he would be a communicator, interpreting the business risks to the employed inventor and interpreting technical uncertainties to corporate decision-makers.

With such policies and practices, the employed inventor and the corporation surely would become less aware of their assumed differences and more aware of their broadly shared interests and goals.

\section{Discussion}

M. Harris: Implicit in the discussions here the last few days, and other places, is that corporate structures are no longer interested in R. \& D.; and I maintain that they're not only as interested, they're probably more so, and more critically so, than ever before. The only thing they're asking for today is an accountability. The reason is very simple: two decades ago the R. \& D. budgets were a small part of the total profit picture; today they're almost equivalent. In several companies in which I happen to be a director, the total R. \& D. budgets are close to $\$ 100$ million; the profits are about $\$ 100$ million. This is a very different picture than when the R. \&
D. budgets were a few percent of the total profit picture.

I wanted to ask one very important question, though, when I saw the title. I don't want to pry into the inner workings of your company, but along these lines a number of companies in recent years have tried the "new venture" route by way of either setting up small independent operations, completely autonomous companies, or buying into them. Have you looked into this matter, and do you have anything to report? There are varying experiences now, and I'd certainly appreciate hearing yours. 
C. Anagnostopoulos: I would like to keep that short, if I may, not because I'm not interested, because if I'm let loose I will make it too long. In Monsanto we started this about 5 years ago, when we started a separate division, self-sufficient in terms of all its operations, manufacturing, marketing, research, to undertake new ventures. We call it the "New Enterprise Division." Through the 5 years that this has been in existence, I think we've lived through every statement about new ventures that I have read, whether it refers to an independent in. ventor or to a large corporation. When we started, there was no "how-to" manual and we had to write our own, and believe me, we are half-way through the first volume, and we expect it to be a 10-volume presentation some day, if we write it. So I believe that the main thing that one has to recognize is that when you set up an independent operation in a large corporation for new ventures, you have to realize that you cannot duplicate the outside world of small business and independent inventors. There is no way that you can get an independent inventor and put him in the fish bowl of a large corporation-no way. He will not survive in it. An employed inventor is a different kind of an animal from an independent inventor, or from a technical entrepreneur, which I call the individual who is both an inventor and a businessman at the same time. So, there's no point trying to imitate the outside world; you just have to realize that you are going to take the best advantage of your employed inventors, the ones that come to the corporation because that is where they like to do their inventing. They're not the same kind of an animal as the outside inventor. So, comparing the two is useless. Oh, you might compare it because you would like to see the differences, or because it's an interesting discussion during a cocktail hour. But there is no comparison between the two, and to try to displace an outside inventor, transplant an outside inventor into the corporation, you're sure to fail, and I think most of the companies that have failed in this aspect, it is because that is what they tried to do.

M. Coler: When you talk about the independent inventor, the entrepreneur, the scientists and technologists: these are not biological distinctions. Man is a remarkably adaptable creature. When I worked for Union Carbide, I worked in the mold that Costas described. When I was an independent consultant, I worked in that mold. To succeed in each of these molds yeu have to perform differently, perhaps. Some years ago a man wrote a book and dedicated it to pedestrians. When you're walking you're a pedestrian; when you're in the car you're not a pedestrian. You can be an inventor; you can be a businessman; when you're investing in your friend's invention you're a much different person than when you're buying stock in Monsanto.

C. Anagnostopoulos: I'm in trouble, because I have an example of an individual who apparently can be both an independent inventor and a hired inventor. I'm at a disadvantage because I've always been a hired inventor, and not an independent one.

J. Rabinow: I'm not sure that's a disadvantage when I think of some of the experiences I had as a businessman. I don't disagree with you, Costas, but your own admission is that the constraints in a large corporation are quite different from a small corporation; and the thing you say about the market size is very important. When I worked for Control Data, I'd come up with an idea, and the boss would say, "How much market can we get out of this?" "I don't know, a million, maybe," and he would say, "Forget it." He's absolutely right; in his place and in your place, I'd do exactly the same thing. So when I talk about large corporation constraints, I do not mean it as a criticism. I wish I were a large corporation; I didn't make it twice. I would then do all the stupid things that large corporations have to do; there's no choice; and the thing that you must do is say that nothing less than $\$ 10$ million, in your company, is worth doing. This means automatically that you must make the right choices as to whether it will or will not make $\$ 10$ million. This, nobody can do. There is no way on this earth of predicting the sale of new items - nobody could have predicted the computer; nobody predicted Xerox; nobody predicted Polaroid. This is why you must encourage inventions without knowing what they're going to do; this is a terrible act of faith, that you must take Bill McLean and say, here's a couple of million bucks, go and do your guided missile, and if you fail we'll fire you, and if you succeed, we'll make you a hero. This is what society must do. I don't disagree, for example, with Myron Coler, that there is no physical difference between small and big business; but there is a difference that mathematicians have expressed very well. When a thing is very different in magnitude, it is different in quality. It must change. I think, 
Costas, you yourself say that when the size is large, your rules of inventing are quite different; and this is the penalty. This is why General Motors did not invent the Wankel, although they knew how Wankel operates long before Mr. Wankel; this is why Honda had to develop their engine; this is why computers did not come out of IBM; they came from Eckert and Mauchley, who were two college students. This is why 60 percent of Du Pont's products were not developed at Du Pont. And when you talk of large corporations, you must make a very sharp distinction between chemical corporations and those which are not chemical. You are different from General Motors in a very real way, as you know. Your patents are much more important to you than they are to General Motors. I think the large corporations will not innovate because they are in their own straitjacket, which is size.

C. Anagnostopoulos: I agree with what you said, and there is nothing wrong with large corporations not having the major breakthrough inventions to their credit. I think there is room for the independent inventor. I don't think that the large corporation should be blamed for that. Its role is primarily in innovation, not in invention. One without the other, there's no point in doing it.

B. Kemp: The issue is not only the one you've raised, the question of what happens when a company this size, for its own purposes, decides not to pursue a particular invention. From a social point of view, the real question then becomes, how can you facilitate some other company, large or small, to take up that idea, to go ahead and utilize that product for the society as a whole? I think what we really ought to be thinking of are ways to facilitate that process. You mentioned one of them; that is, go to the small company. What happens with those ideas, which if they were made public knowledge, would really be useful to somebody who could get to them? That seems to me to be a major social issue.
C. Anagnostopoulos: I believe that you have a point there, and that, of course, comes under the category of how can we take best advantage of all the creativity that exists in our country, regardless of where it is located and whether or not that unit in which that creativity is located is interested in it or not. I have no idea of how we can take the total inventive capability of our country and pool it. We're making some attempts at this; there are the research institutes, the venture capital groups. In our particular case, for example, if anybody wants any of the patents that we do not use, they can contact us. We have a policy of patenting, for example, in our company. We don't keep secret anything except improvements on the same theme. We don't have a major discovery that we hold back. Variations on the same theme, we do hold back, because we call those trade secrets, etc. I really have no answer to that, and I don't think there is an ideal answer to that question, but it's an area that I think all of us have the responsibility of addressing ourselves to.

H. Forman: I think part of the purpose of this conference is to come up with solutions and get to the top administration in this Government as to how to utilize the inventions that you don't want to use. I have some thoughts; I'd like to hear others, and hopefully, we can come up with recommendations.

C. Anagnostopoulos: I think that's a total subject large enough that we can't really attack it right here now. I think you are probably giving the large corporations a little more credit than they deserve. I don't think that we or the Du Ponts have that many ideas that we are putting away. And if there are ideas, many of them are still in the very beginning, and they're really not that useful. I think that in the competitive environment in which we live today, we really try hard to use all the good ideas that we have; and there aren't that many in our vaults; at least, I don't think so. 



\title{
The Institutions and Environment for Inventors in IBM
}

\section{David DeWitt}

\author{
IBM Corporation, Route 52, Hopewell Junction, N.Y. 12533
}

\begin{abstract}
IBM seeks to create and maintain in its laboratories an environment conducive to innovation. Inven. tors are aided by instruction in patent practice, prompt and competent evaluation of submissions, and the help of experienced patent attorneys. Innovation is encouraged by a system of recognition and rewards for patents issued and outstanding technical contributions.

The IBM Fellow appointment is an attractive long-range objective for inventive people: it is a lifetime appointment which gives the Fellow freedom to do innovative work of his own choosing, with appropriate support.

The IBM institutions for encouragement of innovations were introduced about 10 years ago, and have been modified from time to time. They are still being evaluated, but the results have been largely favorable.
\end{abstract}

Key words: Environment for innovation; IBM Fellow; institutions for inventors; inventors; rewards for inventors.

The IBM company believes very firmly that innovation is an essential requirement for continued success as a business. Internally it has set up institutions which facilitate, encourage and reward invention and its reduction to practice. The following quotation is from a Corporate Instruction to Laboratory Management:

\section{Subject: Innovation in Engineering, Programming and Technology}

IBM must create and maintain in its laboratories an environment conducive to innovation. New concepts must be welcomed by management at all levels, funds and facilities must be provided for the development of appropriate proposals, and employees must be kept aware of management's encouragement of creative ideas. For the Company's continued successful growth, every effort must be made to prevent the press of day-to-day operations from stifling innovation.

This instruction calls for the establishment of formal programs to assure that creative expression within IBM will be utilized with increasing effectiveness, and the atmosphere for individual professional development will be enhanced.
While internal invention is fostered, IBM desires the maximum of freedom of action to use inventions made elsewhere and this is obtained by the use of IBM's patent portfolio to exchange patent rights or by royalty bearing agreements. To be effective we require patents essential to the best practice of our technologies and those of related industries. Such patents are more likely to come from early work when a field is new than from the final optimizations of actual product development. An environment must be created which stimulates the disclosure and reduction to practice of ideas whose time has not come yet.

IBM must employ the patent system defensively to protect its internally developed ideas and maintain its freedom to use them. For this reason good ideas must either be patented or published at an early date so that the rights are not lost to a later reinventor. An encouraging environment is required to stimulate early disclosure and prosecution of ideas not required by the project to which the inventor is assigned.

The elements which IBM uses to create an encouraging environment for invention and its disclosure are: 
1. Constant reminders from management that invention is wanted in the form of publicity about IBM inventors. There are articles in house publications, releases to the local press and attractive graphic displays in the laboratories.

2. Instruction of engineers and scientists in patent practice, notebooks and disclosure forms which are easy to use and a system for the prompt and competent evaluation of submissions.

3. On-site patent attorneys experienced in the fields covered on the site.

4. Arrangements to permit reduction to practice of good ideas not applicable to the inventor's assigned work.

5. A system of recognition and fixed financial rewards for disclosed inventions which are filed or published.

6. A system of unusual recognition and substantial financial reward for outstanding technical contributions, both patented and unpatented.

7. The IBM Fellow appointment which is a career goal for creative people who want to work as individual contributors.

A very real fact of life is that projects can be planned and scheduled but invention cannot, particularly those inventions which open new prospects. Hence for many inventors there is a serious motivational conflict between service to the urgencies of the project and the pursuit of a new idea. It is easy for the inventor to make his own evaluation and decide to reject the idea. Only 10 percent of submitted disclosures are filed with the Patent Office and about $1 / 3$ are published. Hence the majority of disclosed ideas are closed and it is easy for a modest inventor to assign to a good idea the average probability of acceptance of all disclosures. In proportion to his own technical competence to reduce an idea to practice, the inventor knows in advance how much work is likely to be needed to demonstrate an idea which needs more than constructive reduction to practice. These impediments to disclosure and pursuit of invention are very real and apply specially to the best technical people who are the very ones selected for difficult and urgent projects. To continuously demonstrate the importance of invention to the business, a great deal of personal publicity is given to inventors with pictorial displays in laboratory public space, bulletin board displays and publications. Outstanding inventions and contributions get the most intensive publicity but every inventor is publicly recognized at the time of his first filed invention and further recognized as he achieves further stated levels of accomplishment.

The company makes it easy to disclose invention. There is a good manual (Patents in IBM) which explains the workings of the patent system and the tools for the inventor. There is a readily available registered notebook which has all of the features needed for a personal notebook for all technical activity but with the built-in features which encourage and remind the inventor to make it a good legal record of invention. There is an invention disclosure form which is used to disclose invention directly to the professional patent attorneys. No elegance is required. It can be handwritten with hand sketches, copied pages from the notebook can be included and any other documented material. The communication path is directly from the inventor to the attorneys. There is no requirement or implied requirement that management filter what the inventor perceives as patentable novelty. He selects his witnesses.

Timely and competent evaluation of disclosures is an important process. We have experimented with many schemes and are still using a variety of methods on the various sites but there are common elements. The two most important elements in the initial evaluation are the technical evaluator who is a senior practitioner of the art and the experienced attorney. The technical evaluator looks for novelty, feasibility, importance to IBM and to others and ease of avoidance. The attorney uses his existing knowledge of the field to make an initial determination of patentability. The most common scheme for selecting technical evaluators is for laboratory management to assign the task for defined areas to senior people as a part-time responsibility. As an example, in the Yorktown Research Laboratory there are nearly 30 assigned. I know 12 of them well and can characterize them as members of management who are very familiar with both the history and the newest work in their fields. Most of them are current personal contributors to important advances.

The initial evaluation takes place in a meeting of the technical evaluator and the attorney, usually with the inventor present. Typically it takes about 3 months from disclosure to evaluation, with 6 months as a limit. The evaluation determines whether the invention will be filed, published or closed in advance of a formal search and final decision on patentability. The inventor can ask for reconsideration by 
another technical evaluator if he is in serious disagreement with the decision. A decision to close is never final if what is required is further work on the inventor's part or if later information suggests that the evaluation was wrong.

After a decision to file or publish the process becomes the business of the inventor and the attorney. There is a formal search and final decision on patentability with the inventor participating in the analysis of the material uncovered. While the inventor must furnish the invention and the teaching of how it is practiced he can do this in the form natural to his own work and the attorney makes it into a patent application with properly constructed claims. In the case of publication, either may prepare the material but the attorney must insure that the publication will secure the desired future freedom of action.

The greater the novelty of an invention, the more likely it is that quantitative analysis and/or experimental work is needed to establish its feasibility and value. For many inventions this work is added to the inventor's assigned tasks and is done without any special arrangements. To provide for those cases where the inventor needs more free time and support facility, there are formal provisions in most product development laboratories for what is called Creative Development. At the present time about 100 such individual arrangements are active. It is required that the work not be part of the planned technical program and the study only go far enough to show initial feasibility after which further work must become part of a regularly funded plan.

There is a formal system of recognition for inventive achievement, based on the number of inventions. For the first filed invention an inventor receives some publicity and an engraved deskpen. Beyond that a point system is used, with three points for a filed invention and one point for a publication. On reaching the first 12 points the inventor received $\$ 1,600$, a set of distinctive jewelry, a diploma for his office wall and publicity. Every 12 points thereafter he gets another $\$ 1,600$, another diploma and more publicity. Co-inventors receive a full complement of points as though they were each individual inventors.

For outstanding contributions, whether or not patentable, there is a policy of making exceptional awards. They are made both at a site level and at the corporate level. There is a set of jewelry, diplomas and publicity. The corporate awards have been made at an elegant, several-day, all expenses function at a big New York Hotel with wives and husbands invited. Local awards are made at banquet functions. The local money awards extend into the thousands of dollars and the corporate awards into the tens of thousands with $\$ 60,000$ as the highest to one individual so far. In some cases second awards have been made for the same contribution as its importance became more apparent.

The IBM Fellow appointment provides an attractive long-range objective for inventive people who might otherwise perceive increased managerial and executive responsibility as the only worthwhile career path. It is a lifetime appointment which gives the Fellow the freedom to do innovative work of his own choosing with appropriate support. He has access to all of the laboratories and is encouraged to maintain outside professional and university contacts. Fellows are expected to be available for consultation and mas be asked to work on short-term special studies.

How well does this set of institutions create an environment for innovation and its prosecution? We have some measurements but no way of being definitive.

The system has not made a prolific inventor out of every technically qualified person. About 40 percent of the engineering population has some stake in the point system but only about 7 percent have 12 or more points and less than $1 / 2$ percent have 48 or more. The contributing fraction will probably increase, because the full set of institutions is less than 5 years old and much of our technical population was hired in the past 10 years.

It is not easy to compare the system with alternatives because it has had increments to its features over time. When its initial form was introduced about 10 years ago, there was a 40 percent increase in the disclosure rate. The patent attorney community believes that the system has increased the rate of disclosure, made the technical population more interested in patents and more qualified and knowledgeable. An important result has been to produce earlier and more thorough patent activity which has facilitated product clearance.

The perceptions of the engineering population have been surveyed from time to time and two significant improvements were indicated. One was to increase the amount and the frequency of the finan- 
cial reward for points and the other was the Corporate Instruction requiring that arrangements be available for reduction to practice. Interview results are largely favorable, showing a belief that the company is interested in patent disclosures and that reticent inventors are encouraged. The negative comments, fewer in number but very significant, show a belief that too many trivial or insufficiently worked out ideas are submitted, with the implication that some must leak through the evaluation system.

The system of rewards for points does have the weakness that it can motivate some people to exploit the system by the vigorous defense of ideas of little value. The management of at least one of our laboratories believes there is a very small but troublesome fraction of the population who do just that. At present the only control is the quality of the evaluation. One feature of the point system which makes exploitation possible is the possibility of being rewarded for publications only. There are very few people in this category, however.

The system I have described is relatively new, incompletely justified and not very rigorously compared with a set of well understood alternatives. It is hard for me to be objective because it so contrasts with the non-system I worked under at another company for the first half of my career. Consider me an enthusiastic advocate. My hope is that you people will ask hard questions and unmercifully point out weaknesses. I hope to come away sadder but wiser with ideas for reconsideration and more sophisticated measurements than those we have used.

\section{Discussion}

W. H. Calkins: I would like to know what percentage, roughly, of your major projects in which your research laboratory is engaged, originated through this kind of a program?

D. DeWitt: I'm searching for a way to answer the question. Everything that's disclosed as an invention goes through this program, and people are highly motivated to disclose things. So you're really asking me to search it out by exception. Do I know of something important going on in the company which did not originate by an IBM disclosed invention? And I would have to say, yes; for instance, we are working in the field of magnetic bubbles; we've recently published and we're doing some inventive work there, and I believe the original idea came from Bell Telephone Laboratories. But at the same time, I've looked at the records of the people working there, and I did it for one reason, because some of them are evaluators, and I wanted to evaluate the evaluators, in order to report to you about the system. There are people who are doing what I consider very important inventive work, which is the basis for our thinking that it's a very important field to stay in.

W. H. Calkins: I guess I'm searching for how many innovative changes and directions for brand new programs arise from the grass roots this way.

D. DeWitt: I don't have real statistics; we have not been branching out as a business; as you know, we tend to stay in our business, which is very large and has kept us very busy. When we were so busy with card machines, apparently we were a little late in getting into stored program machines, etc. So I can't claim that IBM has branched out and done great things; now they've done some things which are socially useful and are carried for that reason; we have a blood analysis machine which falls into much less business than a big company is supposed to undertake, but we've done it because it's important, and it came from an independent inventor within the company, motivated because his brother died of a rare blood disease. So there's one example in that direction.

F. Neumeyer: Do you advise the same type of incentive system to employees of subsidiaries abroad?

D. DeWitt: I can't honestly answer that question. I had so much to learn in order to make this talk that I didn't do research except on the United States. However, we have in the group here a gentleman who might know the answer to that.

J. Jancin, Jr.: The plan is essentially the same throughout the world. As you know from your previous studies with respect to inventor recognition and remuneration, this has not always been the case.

B. Walker: How does IBM evaluate outside inventions, and are many accepted, and does the outside 
inventor have the right of appeal that the inside inventor has?

D. DeWitt: I'm not an expert on that either; all I can say is that I've had some personal experience in evaluating outside inventions, because they were in my field of expertise. One of the parts of the process, I know from practice, is to refer them to people within the company who know something about it.

J. Jancin: I wouldn't call it an appeal; we always make an effort to review things properly and fairly, and everything is open to reconsideration. For rather obvious reasons there has to be a matter of control in the way that information that comes in from outside the company is handled and maintained within the company; and as a result, we have one group, very small, two individuals in New York, that come within what we call the IBM commercial development area, and they handle what we refer to as the outside submissions. Every outside submission that's submitted to the company goes to this particular group, which then seeks evaluations, and maintains communications with the outside entrepreneur; and then it's taken from there.

K. R. Hansen: With so much spotlight on the inventor, what system do you have for those who develop the invention to commercialization? Do they have a similar program?

D. DeWitt: Yes, I mentioned that we have rewards for outstanding contributions, whether they're patentable or not; and in general, when there has been a successful completion of an important project, or when somebody has made a significant contribution that wasn't patented, and in the area of softwear it's very difficult, as some of you may know, to get patents, we make these special awards. I ac- tually looked at the dollars involved. Last year we handed out almost 10 times as many dollars for outstanding contributions awards as we did for outstanding patent awards.

K. R. Hansen: Do you actually keep a case history of the contributions of the development people in order that when the work is done, the record is there as to who's going to get what part of the pie?

D. DeWitt: I would have to confess that we don't do as good a job at that as I think we should. There is one problem: you don't know what an outstanding thing is going to be done until it's happened, and most of the time while it's on its way to being an outstanding accomplishment, it's in great risk of being an outstanding disaster, and you don't sit around planning for hero medals.

F. Barron: Have you done any research on the intellectual and personal characteristics of the individuals of recognized productivity under your system? I ask this because I've noted in this conference a certain lack of attention to the problem of identifying potential inventiveness.

D. DeWitt: No. I wouldn't say we have. I can do it with young people; I've brought a lot of young people into the business, and I don't have any trouble telling which ones are going to be inventive and which ones are going to be analytical, and which ones are going to be very good managers. You can usually tell in about three trips to the blackboard whether somebody's inventive, but that's all. No, I don't know of any internal research that we have done on that. We have had people in telling us what the inventive process consists of, and we've had college professors who have sets of slides and talked to whole laboratories. But it could be done. 



\title{
The Role of the Inventor in an Industrial Laboratory
}

\author{
Jan. A. Rachman
}

RCA David Sarnoff Research Center, Princeton, N.J. 0854.0

\begin{abstract}
The industrial research laboratories of large corporations have been a great success: as one of the main mechanisms for harnessing the process of innovation they have benefited their sponsors, society and the scientist-inventor. To the imaginatively inclined technical man they have provided a living and a place in society. Furthermore, a seasoned laboratory provides broad options to the individual to pursue his ambitions according to his talents, as it exploits with subtlety the fact that it is at the crossroads between science, production and the market place and therefore finds good value in individual genius, cooperative work as well as managerial initiative. To a great many technical men the industrial laboratory offers the proper arena for undertaking technical innovations. The personal experiences of the author, at RCA Laboratories, as individual contributor as well as manager, illustrate the point.

The present antitechnical crisis has various symptoms. In the industrial laboratory, budgets are no longer lush, there are problems with non-growing staff, and there is a shift from science to engineering that is accompanied by short range expectations. More alarming are symptoms of disillusionment elsewhere, mostly with the young, among whom many fewer aspire to science and technology. As one possible remedy a plea is made for society to show far greater appreciation and respect toward technical innovators in addition to bestowing them with essential material awards.
\end{abstract}

Key words: Antitechnical crisis; industrial laboratory; industrial research; scientist-inventor; technical innovations.

When Jack Rabinow asked me to talk about the role of the inventor in an industrial laboratory, I was rather hesitant. Having spent my professional career in just such a laboratory as a member of the staff, an inventor if you will, and later in management, I have, in fact, had a great deal of inside experience. But being so much of an insider I don't have a clear-cut general view of the situation. Perhaps I feel as though I were in a forest and saw all the trees but had no clear view of the forest as a whole. Also I find it difficult to tie the situation in an industrial laboratory with the wider issues of the declining patent disclosure rate in the United States, the problems with research budgets, the antiscientific attitudes, the unfavorable balance of payments, and other bad symptoms that Jack mentioned to me when he called me and about which we have heard so much in this meeting. However, I accepted because I believed that a few thoughts I have may be of some interest. Right at the moment I have a further difficulty in that Dr. Anagnostopoulos has taken much of my thunder as he has already explained most brilliantly the workings of a laboratory of a large corporation. I would like to recapitulate briefly, though I am afraid less eloquently but perhaps differently, some of the things he has said, and add a few comments.
The industrial research laboratory has flourished in the 20th century because some forward-looking companies such as General Electric, Bell Labs, RCA and others, have recognized that it simply makes good business sense to organize the venture of innovation. Generally they started by having some original idea, and they found that in order to implement that idea they needed a group of specialists. They found, rather empirically, that when they had that group of men, these men in fact innovated other ideas beyond the original one, ideas which gave them a tremendous competitive edge, not only in improving their own products, but generating new products. The laboratories grew, and all the other companies were forced to have research laboratories also. The war provided a tremendous stimulus, that was sustained by the cold war. As a result of all these factors, the ever flourishing industrial laboratories ushered a profusion of fantastic innovations, whose enumeration I won't bore you with, because it would be completely trite, but which have truly revolutionized our lives. I would like to emphasize the fact that we have witnessed a complete revolution.

It would be an oversimplification to say that the industrial laboratories were the sole instrument of 
these innovations; obviously many other factors have influenced them; our whole makeup and our whole civilization did it. But, I believe that the industrial research laboratory was, in a way, a key mechanism which was at the crossroads between science, invention, the needs of the market as perceived in the most subtle way; that is, the needs of the market as it existed and also perhaps more importantly in imagining what the market might be, and therefore it was in the most sensitive nerve of the whole system. Therefore, it had a tremendous leverage in the whole enterprise of innovation. More pragmatically, the total dollar investment in these laboratories was a rather negligible investment compared to dollar value of the continued flow of goods and services that originated from them.

The advent of industrial laboratories provided steady employment for the individual inventor. Therefore a young man interested in devoting his life to imaginative inventive work, no longer had the necessity of choosing a hazardous life leading to "rags or riches," but could choose a career with a steady salary. Then, as the laboratories flourished and competed for talent, the salaries, at first miserably small, grew and became quite good. In the sixties the scientific research personnel became well paid; in fact, very well paid in relation to the engineering or practicing profession. Furthermore, perhaps more remarkably, the occupation of scientist and inventor became respectable. For example, if you had to register your occupation in a hotel, you could put "scientist" or "inventor" without fear of being taken for a peculiar absentminded irresponsible person, but someone with a perfectly legitimate and responsible occupation. In the public eye, this is a very important point. In other words, the public accepted or even respected the scientist for having made great contributions and his employers started to pay him reasonably well.

Thus the industrial research laboratories of the large corporations have been a great success: as one of the main mechanisms for harnessing the process of innovation they have benefited their sponsors, society and the scientist-inventors.

This relatively fine situation started to change in the early 1970's together with a general disillusionment about the pursuit of science and innovation, in industry, Government and the public at large. Worse yet, research scientists and inventors are starting now to have doubts as to their own mission. We are going through a crisis in the last few years that has the various symptoms we have discussed here at some length. For one, the budgets of the laboratories have been much harder to obtain. Some restraint is legitimate because the budgets in the sixties were increasing at the rate that was so much greater than that of the gross national product that if continued for 50 years the whole national gross income would be devoted to research! Unfortunately the necessary budgetary restraint has been too large and too abrupt. There's a great deal of unemployment among talented people. One of the most serious consequences is that there is a lack of enrollment in colleges in technical fields. Fewer patent disclosures are being applied for. Generally, there is an attitude of pessimism. It is possible that we have already passed through the worst of that period, but we are still in a crisis.

In a period of crisis there is a feeling of uncertainty among many that translates itself often in an overconservative behavior and sometimes in panic. To my mind, this period can become a very favorable time for constructive thinking. During the time of tremendous expansion of the laboratories we were too busy with the expansion itself. We were in such a hurry for great and big things that we did not have time to think rationally about our aims, either our technical or our organizational aims. The time of crisis is a time for rethinking some of our goals, the goals of our projects and those of the organization. Perhaps it is better to welcome the inescapable with fortitude rather than to shed tears.

I would like to switch gears from this pseudohistorical introduction and address myself to the industrial research laboratory, particularly from the point of view of the scientists, engineers and inventors in its employ.

The salary in most industrial laboratories is determined largely according to merit and it is usually administered with sagacity and with great care. Salary administration is a large subject on its own right, of course, and though I am not a professional I believe that on the whole, it's a very fair system and one that is working very well and that, generally, does produce a large discrepancy between people who have merit and those who do not. (By the way, such outright recognition of performance, prevalent in the United States, does not always exist in other countries, e.g., Japan, where the social climate does not 
permit it.) The salary is usually the main, if not the entire compensation of the inventor. Some laboratories have extra compensation for patents and awards. I would like to comment about these in our laboratory.

Patents are important to our laboratory, as they are for all industrial laboratories, for the many reasons that were abundantly spelled out in this meeting. As we cannot possibly exploit all innovations we make or even fully those that we do exploit, we have an important business of patent licensing that gives further special importance to patents. However, we do not have an elaborate system of incentives related directly to patentable inventions. We merely pay a flat modest fee for each filing of a patent disclosure in the Patent Office.

On the other hand we have an achievement award system in the laboratory. A number of awards are given annually to individuals and teams for the best work performed. These are relatively substantial monetary awards combined with public recognition that is significant within the laboratory, the community and the profession.

So much for compensation. Now I would like to say a few words about the climate for work which, in many ways, is as important as the compensation. In the first place, the research person is encouraged to have as much initiative as he possibly can and to initiate projects on his own as much as possible. Many of the projects have originated from the scientists themselves and not from management, although of course many projects have also originated from different levels of management. Next, we encourage the laboratory staff to have as much coupling as possible with the planning function in the corporation, which today is very significant. Secondly, we try to have a very great deal of coupling with the scientific community through professional meetings, publications, etc.

Perhaps the most important couplings are with the Product Divisions. This is so because the innovations that we try to introduce must be accepted by the Product Divisions and a large part of the success resides in their convictions about our proposals. The laboratory is a central corporate organization independent from the Divisions; and by and large each Product Division is also independent and decides on its own what it will do. Thus mutual agreement is of essence. To facilitate the transfer of results from the laboratory to the Divisions, we have a rather unique system in our corporation that you might be interested in hearing about. It is really very simple, the trick is called "money." Part of the laboratory's budget is earmarked so that we can assign the Product Division to work for us in areas at our discretion. This is the opposite of what many corporations do, where the laboratory does work for the Divisions. When we have developed a certain idea to sufficient degree, we can go to an appropriate Product Division and ask them to carry it further. We have some initial money to start the project going, though not enough for the 21, 39 or whatever steps that were mentioned necessary to make it all the way to the product. These monies are relatively trivial as far as corporate money goes but they are sufficient to support one or two men. Usually we arrange for an equal number of men on Divisional money. Of course, we see to it that the right personnel is assigned to the project. Thus these projects turn out to be miniature schools of management for our staff. It turns out that this system for transferring laboratory results, though requiring relatively small amounts of money, has a tremendous leverage in the company. Many important innovations can be traced to this route.

Coming back to the individual within the research laboratory - and I will be increasingly thinking of our own RCA Laboratories - in the final analysis how does the scientist-inventor fare under all these conditions? Perhaps one way of looking at the situation is to note that the research laboratory is somewhat of a self-contained world in miniature engaged in unusually vital activities that entail most of the complexities associated with real action. The young man who comes into this world comes from an academic environment where concern for publications and initial authorship are only natural since ideas in their most pristine form constitute the substance of life. He comes into an organization where achievement is the ultimate goal and where ideas are still paramount but no longer the end in itself. He finds that achievement requires group action, this in turn requires cooperation and sharing of ideas not only for intellectual enrichment but also for providing a group spirit. Thus the notion of the single scientistinventor having free reign for his individual genius and the notion of groups with some effaced individual stardoms come often into conflict for the individual. Actually, a seasoned laboratory knows how best to take advantage of the values of individual 
genius and those of cooperative group actions - and as Jack often pointed out in this meeting - in real life seemingly contradictory values need not be necessarily considered in an adversary sense.

This very flexibility or perhaps subtlety of the mature laboratory organization provides a number of options as far as the career of the individual is concerned. The man who is better at influencing others than having ideas, or enjoys it more, gradually shifts to directing others. In this case he often comes gradually to no longer care whether it is his idea or that of others and he becomes a manager. He may even come to the point when he no longer cares whether he manages research or not and becomes a top executive with wider responsibilities in the corporation. Other men, having many ideas and being very sensitive to good ideas in their group and also being good at influencing others, become leaders of research at various management levels. They are intellectually inspiring and leading. Still others prefer the individual pursuit in their work. For our senior cutstanding scientists with this preference, we have a position of Fellow, similar to Life Fellow at IBM mentioned by DeWitt. Presently we have about 15 Fellows at RCA Laboratories, who are all very eminent in their fields. Besides these career possibilities within the Laboratory, there are excellent opportunities for transferring to a Product Division, with one's own ideas, as the leader of a group to continue the steps of innovations that were started at the Laboratory, or in many other circumstances made explicit by the everyday associations with the Product Divisions.

Do all the material benefits and the career possibilities make the industrial laboratory the best of all possible worlds for the applied scientist or for the inventor? The answer is a relative "yes." As with all human institutions, even the best, it provides the right environment, not for all, but for a great many, if not most inventively inclined men. There are of course those who are so impatient when a project they have initiated and made successful in the laboratory is not immediately taken up by the corporation, or so disappointed when it is not taken up at all, that they leave tò start their own companies. Those eventualities are probably inevitable (particularly in good business cycle times) and in any case are desirable, acting as they do as antidotes to the lethargy, bureaucracy, shortsightedness and other shortcomings possible and perhaps inevitable even in the best run laboratories and sponsoring corporations who do not like to lose their most prominent and active men and acting also as avenues for individuals who aspire to carve for themselves a prominent place in industry - as captains of industry if not as millionaires.

I would like now to shift from general abstract remarks, as prompted by Jack Rabinow and Dr. Coler, and relate a few of my personal experiences. The RCA Laboratories have been engaged in a great deal of imaginative research and I had the good luck of being associated with some of it. My early work with electrostatically focussed electron multipliers did result in a product that surprisingly is still going well today. Perhaps it is not generally known that RCA Laboratories was the first, or at least among the very first, to engage in electronic computers. We did this in 1939, and I was associated with that work from the very beginning. We invented many basic parts of computers, both analog and digital. Among these were various types of arithmetic and logic units. Of special interest was a resistive matrix digital core converter, that today would be called a read-only memory. This is an invention that is near to my heart as at the time it was at first difficult to have it accepted and later it provided a very important element for ENIAC. This period also has an interesting episode relating to the subject of our discussions. Because of our expertise we were asked by the Government to build a large electronic computer, a job that the Laboratories management turned down because of its magnitude, and that was taken up by the University of Pennsylvania and eventually resulted in the ENIAC. As an enthusiastic young inventor and engineer I was greatly disappointed by that decision, though still so eager for novel fields then useful for defense that I plunged myself in work with an idea for using the betatron as a microwave generator.

As it turns out I became engaged in computer works soon afterwards. This is through an association with the Institute for Advanced Study and Dr. John von Neumann who knew us well through his consulting. We were to develop the memory, indispensable for a stored program machine, which eventually gave me a lifelong interest in memories for computers. I invented a special tube, a selectively addressable storage tube, that in modern terms could be called an example of "integrated vacuum tube technology," and which was the first electronic 
truly random access memory. This tube was produced by RCA in pilot quantities and worked in several installations quite well until it was replaced by magnetic core memories. Actually I conceived the core memory and we developed many of the pioneering technologies for the system, circuits, materials, processes, testing, etc. As it turns out often in the history of technology, my ideas on the subjects were similar to those of another inventor, Forrester at MIT, who holds the most important patent claims following a patent controversy with us. When we had developed our first memory planes, I was promoting the core memory within RCA and tried to interest our ferrite plant, then engaged in making television yokes, to make cores. "How many tons of ferrites are you going to sell?" was their question. Their naivete was matched by mine as I did not know what the market might be, except that I knew that cores would be sold in millions, and of course my seemingly wild predictions turned out to be conservative. Actually RCA did not go into the memory core business until much later when it was already shown by others to be substantial. A group of the very few associates I had at the time decided that RCA was missing an opportunity, as indeed it was, and left to start a small company (that eventually, after much effort, succeeded quite well).

Within my own experience there are many examples in which the laboratory and the company were very foresighted. Outstanding among these was the eventual decision to enter the computer field as a main growth opportunity. This entailed a considerable enlargement of research in computers. I was in charge of that effort during the period of greatest expansion and became a director and manager of research with practically no vestiges of invention or technical work of my own. In that period we pioneered at the laboratories many new innovations. Some of these were further developed in the corporation through the mechanisms I mentioned above. This period had been one of extraordinarily high technical production from which we have derived many technical benefits, whose enumeration I will resist to impose on you. I was very sorry that the business conditions forced our eventual withdrawal from the computer business 2 years ago.

Let me comment on recent times and consider one area of forward looking research of our laboratories. This is in holography. While holography is an outstanding invention, it has yet to see commercial ap- plications and RCA is perhaps the best poised to offer the first ones. I will cite three possibilities. First, we did develop a way of recording color television through holographic techniques that produces extremely good quality pictures and has a number of advantages for pre-recorded television reproduction, such as simplicity in use, a low cost of medium replication, etc. Because we worked on an entirely different system to accomplish the same purpose that turned out to be somewhat better for home use, we are considering the holographic system for other uses. Secondly, we have started a small commercial enterprise to make identity cards, that holographically encode credit card numbers or other data. The third application, perhaps at the moment still the most experimental, and one that I have been greatly interested in, attempts to provide to the computer field a memory storage device that could combine the attributes of mass storage of discs with that of nimble and fast access of transistor or core memories. This would eliminate today's memory hierarchy with many of its headaches. This is an ideal that would have tremendous implications.

Perhaps I have elaborated too much about my experiences and RCA. so let me come to the original theme of this meeting and one of the items of interest, namely, what can we do about the crisis of inventors? One of the results of the crisis in research laboratories in the specific area of electronics, is a shift from science to systems and devices. There was a time, roughly in the early sixties, that doing science was much more honorable than inventing, and amongst the professional people, being a Scientist (with a capital S) was quite "the thing" and "inventor" was almost a derogatory term. I think that in the professional societies you could really fee] that distinction very strongly. I believe that our present crisis is restoring the respect for the inventor and the systems man, the man who has the imagination to choose that physical phenomenon that will do the most good to accomplish a certain purpose, and not be in love with a certain physical phenomenon because of its beauty and the possibility of finding more intriguing wrinkles in it. The new trend is salutary because there tended to be a lack of balance between science and invention. The danger in that route that $\mathrm{I}$ see is that some parts of management tend to equate that trend with shortterm results too easily, and they tend to equate an engineering shift towards 2-year time scales; for- 
getting to realize that the conception and imagination of great goals, are relatively long range undertakings. Indeed, many of the technological goals that are really significant for corporate industrial laboratories must be founded on an inherent need with social benefits that are also translatable in profits for the sponsoring company and whose attainment resides in great part in solving a technical problem. Such goals are usually few, but extremely important and long range in nature, and their characteristic is to spell out the desired result but not specify the technology leading to it. Hence imaginative and persevering inventors and systems men with a strong admixture of scientists, provide the most hopeful team.

Finally, I would like to offer a comment on the present crisis that relates to the esteem given to the inventor-scientists. As mentioned before, in the period of the last two decades, when the research laboratories, led by industrial laboratories, started to provide really good pay, the inventor-scientist also gained respect in society. The young were interested in enrolling into scientific and technical subjects in colleges, and these were filled to the brim. Today the respect is being eroded and the enthusiasm of the young greatly cooled with resultant penuries in technical college enrollments. I would like to suggest that merely looking at the essentials of monetary and straight-forward career considerations may not be enough to remedy the condition. The uncertainties about the real place in our society and the esteem he will have, may well be at the root of some of the feeling of the prospective young inventors. After all, the talented technical imaginative man that is a prime factor in fashioning our modern society is still a rare individual, as Professor Kayton so eloquently told us. While most of these men have self-esteem, all are greatly sensitive to esteem and respect from society. A climate that makes heroes out of those relatively few who can advance technology rather than heroes of the many more who can utilize that technology to make a lot of money would help in this regard. Perhaps the scientist-inventors themselves are somewhat at fault here, as they emphasize the tangible final results of their work in terms of gadgets more often than the cultural, intellectual and esthetic values that should be an equally important fruit of our enlightened rational civilization. All too often in the popular mind the man who became the president of a corporation with a huge salary has really "made it," whereas the inventor is still "some kind of a nut." These attitudes have to be changed. Adequate financial award to inventors and scientists is certainly indispensable for this, but in itself not sufficient. The attitude of the public towards science and inventors is an essential element in our society that the public must recognize as being not only heavily based on technical gadgets but on rational and imaginative thinking of man.

\section{Discussion}

W. D. Johnston: What percentage of salaries, additionally, has to be paid to get this additional output which you are striving for?

J. Rajchman: We really don't know that there is any particular relation between awards and output. I don't think there is any data, because some laboratories don't give any awards, and others give quite a bit. However, I can answer the question from the way we think. The overall system of awards encompasses the merit in the first place. In other words, the salary of a good man is very much higher than the salary of a poor man, so the fact that he is doing great inventions is already reflected in his compensation. The extra compensation is really not the significant thing, I would say.
E. Hardy: Do you believe that the education the young people get has contributed to the crisis in that they're not invention-oriented, and if so, what can we do about it?

J. Rajchman: That's a tremendously large and important question. There, again, I don't pretend to have the answers. I think a lot better preparations could be had. Generally, I think that some of the brightest people we have are extremely wellprepared intellectually; that is, they know their stuff very, very well. However, they tend to have too much of an analytic approach to life; the intuitive approach, and the tolerance to ambiguity that are necessary in real life and in invention, are much too low. However, the people who are really good 
develop that rather fast. So, it's a very good question as to whether one should teach that in college. The point is that the college years are the only years in which you have actually the time to get a rigid discipline in analytic thinking. It is a question in my mind, whether during that time you should be actually nursed into all the other parts of life. Shouldn't you simply learn them as you go? After all, you shouldn't learn everything in school; what you should learn mostly is to learn how to learn.

H. I. Forman: Do you concern yourself with where your projects will take you, and how the ideas of your inventors will fit in with your prospects for getting a good patent structure?

J. Rajchman: Yes, We can answer yes, or we can speak for 2 hours. 



\title{
Systems to Stimulate Employee-Inventions in Europe
}

\author{
Fredrik Neumeyer
}

\author{
Consultant in International Industrial Property Law, Faltmarskalksvagen 39, 161 \\ 35 Bromma, Sweden
}

\begin{abstract}
An analysis is made of systems, in Europe and elsewhere, to stimulate employee-inventions by legal and voluntary incentive systems, which are part of the overall pattern of the economic and political regime prevailing in a country. The following countries are examined: the Soviet Union, Sweden, Denmark, Norway, Finland, Austria, Holland, Germany, Japan, Great Britain, and Canada. The legal incentive systems in these countries include tangible and intangible rewards. Tangible rewards are: extra compensation, tax relief, standard cash payment, or release of the rights of invention. Intangible rewards include the right to be mentioned in the patent, and honorary titles conferred on the inventor. The objects of these measures are human beings; we need their imagination; and generosity and justice to them will be repaid by them manifold.
\end{abstract}

Key words: Awards to inventors; employee-inventors; European incentive systems for inventors; Japanese incentive systems for inventors; legal employee-inventor incentive systems; Soviet Union incentive systems for inventors.

I have been asked to talk to you about "Systems to Stimulate Employee-Inventions in Europe." You have invited me and my colleague for a trip of about 6,400 U.S. miles to this Conference. Your expectations of our knowledge and experience must therefore be enormous and I must say frankly that I feel unable to live up to this. My only excuse for accepting the invitation is that I want to give you as much factual information as possible to contribute an answer to some of the 19 questions listed in the program as relevant to the Conference.

Before I start, please allow me to make two important remarks as to the subject matter of my talk. One is that I wish to extend my remarks also to some countries outside of Europe. In today's world situation the perspective of the problem treated here cannot be strictly limited to European countries. Commercial, political and legal cooperation between countries makes this limitation artificial and reduces the understanding of the problems which are rather similar in the whole industrialized world, as well as in the world being in a state of transition into industrialization.

The other remark is that systems to stimulate em ployee-inventions by legal and voluntary incentive systems are by no means an isolated problem to be seen in a vacuum, a closed world of law or of corporate policy. These systems are applied by employers with the definite expectation of a valuable intellectual performance of the employee, in return for benefits granted. The working cooperation between employer and employee embraces at the same time many other obligations and rights of a legal and voluntary character on both sides, which together represent what we often call "industrial labor relations." In addition, we should always keep in mind that invention incentive systems - their structure, function and not the least, their success - are part of the overall pattern of the economic and political regime prevailing in a country. The latest international developments show, in addition, an interesting trend that countries "starting from scratch"-I mean developing countries - have started to combine parts of legal systems used in a number of industrial countries in this field, into a single national statute with the idea of creating in this way a more or less flawless and perfect system. No proof has, however, been given that this theory does work in practice.

Let me start now with a short survey of what I call 
"legal incentive systems." By this I mean certain principles in national laws made mandatory in connection with production of inventions and technical innovations by employees, as well as recommended in certain important international (conventions) and model laws. It will be suitable in this connection to distinguish between intangible incentives and tangible incentives. The best-known type of tangible incentives is extra-compensation to the inventor as cash award. A number of European countries have regulated the right to extra-compensation for inventions assigned to the employer and used by him, in express law provisions. This is the case in the special laws on employee-inventions as valid in Sweden (sec. 6), Denmark (sec. 8), Finland (sec. 7), Norway (sec. 7), Germany (sec. 9 and 10), in the patent acts of Holland (sec. 10(2)), Austria (sec. 6-19), Switzerland (sec. 332 service contract law), Italy (sec. 23), Portugal (sec. 9) and Japan (sec. 35(3)).

In addition, the extensive ordinance on inventions and discoveries of the Soviet Union of April 1959 has laid down the principle that the owner of a certificate of authorship of an invention and the owner of a diploma for a scientific discovery are entitled to special compensation and certain other benefits depending on the specific situation (sec. 15). Details are regulated in a special ordinance of the same date. All seven East-European communist countries outside of the Soviet Union (Albania, Bulgaria, Czechoslovakia, the German Democratic Republic, Hungary, Poland and Yugoslavia) have also compensation rules, although in some countries modified as compared with the Soviet Union.

Employers unfamiliar with such award systems feel often uncertain how to assess any "reasonable compensation" or are generally negative about being able to apply any workable system of this kind. The legislators in countries with mandatory rules on reasonable compensation have, however, been quite conscious of this situation. We find, therefore, as part of a number of laws prescribing special compensation, express reference to some circumstances which should be considered when assessing compensation. In two countries, Germany and the Soviet Union, one has, in addition, gone much further and issued detailed "guidelines" (Germany), and tables of amounts of money to be paid to inventors in different practical situations (Soviet).

A practical example of directing attention to certain general circumstances in fixing this compensa- tion is the Swedish law (sec. 6) which refers for assessment to the (economic) value and the (technical) scope of the inventive right acquired by the employer as well as to the significance the inventor's employment may have had in the creation of the invention. Compensation is only paid "to the extent that the value of the title acquired by the employer exceeds what might reasonably be considered compensated for by the employee's wages and other benefits derived from his service." Similar wording is found in the laws of Denmark, Norway, and Finland. The German law bases amount of compensa. tion on the scope of title acquired by the employer. In case of "limited" acquisition of right in Germany, prerequisite of compensation is that the employer actually uses the invention (sec. 9 , subs. 1 ; sec. 10 , subs. 7). Austrian law is quite similar to the German law. Compensation in the Soviet Union is based on the savings made during one year and additional amounts for performances like that where the inventor has actively supported the introduction of the invention into operation by producing drawings, models or the like, and whether the invention is used by a number of different people-owned enterprises, and not only by his own firm. Dutch law is based on the doctrine that the inventor has to be compensated for the loss of the patent on his invention which is owned by the employer, also in this country with the reservation that extra-compensation will only be made if the inventor has not been adequately compensated earlier by salary or other benefits. Some years ago even the Swiss law on service contracts was revised (new art. 332) and adapted to the concepts used in the cited European countries.

Before continuing with examples for regulation of other "tangible" incentives to employee-inventors, some words must be said about the German guidelines for just compensation of inventors in private service, which were issued by the Federal Department of Labor in July 1959. These rules - being more or less a systematic manual of economic evaluation of all thinkable cases of producing inventions during employment - have been studied by experts in many other countries (including the United States) with a mixture of fright and admiration. These German guidelines were originally issued in October 1944, by the Federal Minister for Weapons and Ammunition, Hermann Goering, in the midst of burning World War II. The guidelines present a complete value analysis of all possible types of em. ployee-inventions laid down in 43 main sections and 
ending up in a system of mathematical formulas for the assessment of the value of inventions, of which the most simple formula runs:

$$
V=E \chi A,
$$

in which $E$ is the "value of the invention" to be properly assessed by one of four different methods: (1) analogy to royalty agreements for free inventions, (2) in terms of usefulness of the invention to the employer, say by profit or savings made, (3) by straight estimation of value, or (4) by analogy to the price that an outright sale of the invention would bring. $A$ is the "share factor" expressed in percentage constituting the part played by the inventor, from which is to be deducted the part played by the enterprise in which the inventor is employed. A more complete presentation of the German system you can find in my so called "Senate study" of 1963 ("The Law of Employed Inventors in Europe," study No. 30, U.S. Senate Subcommittee on Patents, 87th Congress, 2d Session).

The guiding rules sketched here do not constitute binding legal provisions of German law, but rather recommendations and working rules, to which courts and arbitration boards may look for guidance without being bound to follow them. There exists, however, a relatively strong presumption that compensation assessed along the lines of these rules is reasonable (see Schade-Schippel, Das Recht der Arbeitnehmererfindung, Kommentar, 4th edition/178, Berlin 1964).

Now, you ask me: is all this just a kind of academic play? Well, it is not. Since the issuance of the German special law in July 1957 the arbitration board installed at the Patent Office to interpret the law and to reach peaceful settlement between disagreeing employers and employees has issued more than 1,000 suggestions of consent, of which a large percentage referred to the assessment of a reasonable financial compensation for the employee-inventor. Supplemented by a series of ordinary court decisions (mostly in disputes about various types of contracts) and decisions by German labor courts there exists today a body of law which gives some guidance as to the principles of compensation payments and their size in current German law.

We find decisions and recommendations for extracompensation in the form of lump sums, royalties or other income sharing derived from turnover or profits made by the use, licensing or sale of employee-inventions by his employer, or combinations of them.

A well known practical problem in the field of extra-compensation by cash awards is that at the time when law prescribes settlement of these claims (which is usually some months after an invention has been offered to the employer), or (by contractual arrangement between the parties) when a domestic patent has been granted by the Patent Office, the economic value of the invention to the employer is not known yet. To fix compensation at this stage remains more or less an act of speculation or an educated guess. This is a well known fact, but to overcome it has not shown any unsurmountable difficulties. The employer may offer a low lump sum combined with a royalty on turnover or sale per piece, weight unit, number of installations, or whatever it may be. He may offer the inventor a relatively high lump sum in return for the obligation of the inventor to refrain from any future claims, once and for all. This latter method may, however, be illegal according to the law of certain countries.

The laws of some countries admit expressly readjustment of paid compensation if it can be proved that substantial changes of market situation, general technological development, or use of the invention have occurred. Developments may be both in favor of or to the disadvantage of an invention. The general validity of contracts may not be endangered by such a provision. Article 12, subsection 6 of the German special law gives opportunity for such a rearrangement, if both parties agree to it (see Schade-Schippel, Op. cit/279 ff). Repayment of already executed payments is not allowed.

The German legislator also favors compensation for employee-inventions by special tax relief. An ordinance of June 1951 provides that the tax for income attributable to patentable service inventions of an employee is to be reduced by 50 percent. The ordinance prescribes at the same time that compensation paid to the employed inventors by employers may not be "unreasonably high." This is to prevent an employer from evading taxes for himself by transferring income to inventors in his service. American corporations sometimes practice the method to increase cash awards to their inventors by assuming income tax or applicable local withholding taxes. These questions have again become high actuality 
in the United States through the recent decision of the U.S. Court of Appeals in the Rogallo Parawing case where the court decided that the 35,000 dollars awarded by NASA to the two inventors was not a "prize" excludable from gross income (Internal Revenue Code, sec. 74 b). An elaborate system to exploit the provisions of the American Internal Revenue Tax Act (of 1954, sec. 1235) in favor of employed inventors has been suggested by a leading U.S. patent expert, William Woodward, formerly with Western Electric (compare Practicing Law Institute, Current Problems in Federal Taxation, New York 1960; new presentation of these problems by Woodward is under preparation).

Another type of payment to inventors should be mentioned here which is practiced in a number of European industrial countries as well as in the United States. That is a standard cash payment offered to all employees, in one or more installments, who have disclosed inventions, for which patent applications have been filed (and patents later be granted) in the home country, and in foreign countries. Payments being usually between 100 and 500 U.S. dollars per application, followed sometimes by higher standard payments for each foreign patent application. These payments should not be mixed up with extra-compensation for the creation of new inventions discussed before. The function of the standard payments is exclusively to encourage the inventor to produce without delay all documents and signatures, drafts of answers to official patent office actions and the like, for the employer and his patent personnel. It is just a "lubrication oil" in the administrative corporate machinery.

Another European country with more than 20 years experience with mandatory rules for reasonable compensation is Sweden. The official government arbitration board, instituted to furnish opinions and rulings in cases of dispute brought before them either by employers or employees, has produced between 40 and 50 advisory opinions, many of which contain basic statements ("Dicta") for assessing compensation in connection with section 6 of the Swedish special law. An observation in connection with this activity is that the majority of board cases in Sweden were started by government employees. The explanation for this is most likely that government employees - as in most countries - are subject to prefixed unelastic rules of salary and promotion, and have found here a source to increase their ordi- nary income, and are willing to fight for it. Another observation is that the size of compensation assessed by the Swedish board, compared, for instance, with payments suggested and made in Germany, is greater. In recent years, Swedish Government Defense and Telecommunications agencies have in certain cases paid up to 150,000 Swedish Crowns (about 35,000 dollars). The inventions in question either carried large annual savings of government operations with them (in terms of millions of Crowns), or substantial accountable quality improvement of weapons, telephone services, or the like. The relatively high amounts of money paid in Sweden are also affected by the fact that inflation in Sweden is bigger than, for instance in Germany.

To the group of tangible incentives for employeeinventions $I$ also count the fact when an employer abstains, wholly or partly, from his legal right of ownership to such inventions. Sometimes an employer judges the economic or competitive value of an employee-invention not to be attractive enough in the short run or long run of his business activities, and releases these rights to the inventor. Especially foreign invention rights are often released in this way. Ordinary employee-inventors have; as a rule, not much advantage of such property rights. I have, however, seen examples in my practice that inventors have been enthusiastic about such "presents," even preferring them over any kind of cash awards. Prerequisite of such a positive reaction is that the inventor has already some established international reputation in the engineering world, and that he has some business talent and experience. Inventors of that kind do exist, to a limited extent.

Now a short glance at the legal treatment of extracompensation in two big industrial countries: the Soviet Union and Japan. As mentioned before, on the same day the Soviet government issued the basic Statute on Discoveries, Inventions and Innovations Proposals, April 24, 1959, it also put into force an extensive regulation on compensation for the three categories: scientific discoveries, inventions, and innovation proposals (Prop. Ind. 1960/3 ff). Excepting "service inventions" of a similar type as in most Western countries, section 7 of this Soviet regulation presents scales of compensation amounts from 200 to 200,000 rubles and from 100 rubles to 50,000 rubles for inventions or innovation proposals respectively, depending on the amount of annual savings made by their use. For scientific discoveries, com- 
pensation is maximized by law to 50,000 rubles (sec. $3(1)$ ). As a curiosity of tangible rights granted to Rus. sian authors of discoveries, and inventors and innovators who have provided valuable proposals, article 77 of the Statute, of April 1959 is cited, which says that such persons "shall be entitled to additional dwelling space on equal terms with scientific workers." This just shows that incentives can vary from country to country.

When asking leading officials at the Patent Office in Moscow for statistics about paid compensations they could not be produced by them since the law decentralizes such payments to heads of local government and local unions out in the country, hav ing no obligation to report to Moscow. I understand, however, that the new invention law under preparation for the Soviet Union now will introduce some centralized register for paid compensations.

Looking at Japan we find that Japanese law has been familiar with the concept of payment of reasonable monetary compensation to employed in. ventors ever since the enactment of their Patents Act of 1921. Today, 50 years later, we have a brand new Japanese Patent Act in force since January 1, 1971 , in which, however, the relevant article 35 on employee-inventions is entirely unchanged com. pared with the preceding Act of 1959. The article defines the "service invention," reserves a non-exclusive license to the employer free of cost (an arrangement similar to a U.S. shop right). In addition, the article fixes the right to reasonable compensation for the employee-inventor in case the employer has acquired from him a patent application, a granted patent or an exclusive license for the use of the invention (art. 35 (3)). Subsection 4 of article 35 reminds of some European law regulations in providing that the amount of compensation is to be determined by the amount of profit which the employer derives from the invention, and the extent to which the employer has contributed to accomplish the in vention.

Some knowledge about how much compensation is actually paid to employee-inventors in Japan can be derived from an interesting document which I have recently received, and which refers to the payment of compensation for service inventions made by Japanese Federal civil servants, in force as internal office rules since April 1, 1969. The head of the Patent Office, or the chief of the government agency administering a special fund shall pay compensation not exceeding 3,000 Yens, in case government either acquired the right to obtain a patent for a service-invention or the granted patent for such invention. If the government receives income from the utilization or disposal of a patented service-invention the head of the Patent Office shall pay compensation per calendar year according to a specific table. Maximum compensation per inventor per year shall not exceed 1 million Yens ( $\$ 1.00$ is 260 Yens). The above rule shall be applied "mutatis mutandis" when the invention is not a service-invention. For utility models and design patents the payment shall not exceed 1,500 Yens.

If I understand the situation correctly, most provisions of article 35 of the Japanese Patent Act, including the right to reasonable compensation mentioned before, can, however, be eliminated by contract. This is in contrast to German and Scandinavi. an law, where these rules are mandatory and cannot be "contracted away."

Returning for a moment to European countries, we may put forward a general question of interest in connection with cash awards to employee-inventors: How much do these payments really cost employers? There are no statistics or collection of figures about this, either national or international ones (government agencies may have some internal material on it). Being familiar with a number of individual cases in some industries and government agencies in various countries, and finding that cash awards for inventions naturally dominate in research-oriented corporations and organizations my conviction is that funds of companies used for these purposes can practically be neglected (bonus pay. ments made annually to directors and high officials in American stock corporations would in comparison make a more accountable amount of money). Really large award payments for employee-inventions such as, for instance, firms like the German Siemens were forced to make for the invention of the electronic microscope, or by the Swedish Defense authorities for improved small firearms and air shelter constructions, are exceptions hardly affecting the average situation. Research about these problems by a nonprofit organization, preferably some university institution, on a national and international basis would be most welcome.

Another question put by outsiders, or say legislators not familiar with the specific problems of this field, is: Are employed scientists, engineers or 
research workers really interested to receive financial incentives? There is no single answer to this. Their interest may vary depending on age, education, their personal economic situation, the economic situation of their country, the political system prevailing there. A young scientist or engineer may be much more interested to collect visible proof of his productivity as a successful patentee, or author of scientific papers, books or the like, instead of receiving some cash award. On the other hand, he may need immediate financial support (he wants to marry, buy a house, go to a university). He may also be under ideological pressure from his own employer, from colleagues or the society he is living in, which expects a certain attitude from him. A Soviet citizen, for instance, is bound to be conscious of the role he has to play as a citizen in a demanding society. Further, in bad times of general unemployment an employed inventor will be willing to accept modest, or no incentives, if he only can keep his job. Closer investigations of thèse questions by research grants would be most interesting. Some attempts have been made in the United States in the 1950's by the National Industrial Conference Board (NICB) in New York, and by the late colleague Joe Rossman.

Leaving now the discussion of legal incentives of a tangible character I turn to the intangible incentives given to inventors. The main representative of this group of measures goes in professional discussion under the name of "droit moral," or in German literature called "Erfinderpersonlichkeitsrecht" (law of the inventor's personality). Both terms mean that the inventor, or the inventors, have a right to be mentioned with their full name in all patent documents. This sounds both simple and natural, but can lead to confusion and many disputes. Most national patent acts contain some provision with regard to citation of the name of the inventor. Their wording is more or less vague. German law, for instance, prescribes that the applicant has to cite the inventor within 3 months after filing and to assure that, to the best of his knowledge, no further persons share the invention.

The French Patent Act of 1968 says in this respect just that the inventor has the right to be mentioned as such in the patent. He may also oppose being mentioned (sec. 4).

The British Patent Act says under section 1 that an application for a patent may be made by any person claiming to be the true and first inventor of the invention, or his assignee. The official Committee to Examine the Patent System and Patent Law in England (the "Banks Committee") complained in 1970 that this requirement is difficult to comply with $(\mathrm{Op}$. cit. 157), hut suggests that applicants "should" name those believed to be the inventors and that they be named in the published specifications (Op. cit. 158).

It should also be mentioned that one reason why most countries with a patent act have included some provision on the citation of inventor's name is most likely that the Paris Convention for the Protection of Industrial Property of 1883 at the Revision Conference of London in 1934 introduced a new article 4. ter with the wording: "The inventor shall have the right to be mentioned as such in the patent." At the end of the year 1972 the London text of the Convention had been ratified by 19 member countries only (Ind. Property 1973, No. 1/15), but later revisions including this article 4 ter have been ratified by 36 nations (in Lisbon 1958) and by 22 nations (in Stockholm 1967). The article has, therefore, now wide application. It might be mentioned that Japan up to now never cared to introduce any "droit moral" of this kind. The regulation of the "droit moral" contains, however, according to the opinion of some influential organizations in certain countries, serious flaws. Many laws do not make citation of inventor's name a clear-cut mandatory rule, the patent offices do not check correctness of the information given by an applicant, and there are no sanctions for misuse.

A debate about these regulations may come up in connection with the Munich Diplomatic Conference on the European Patent in September which is aimed to adopt and sign the two conventions on the European patent.

In addition to the more or less self-evident incentive to have its creative authorship documented by citation of his name, employers sometimes wish to encourage meritorious inventors and innovators by bestowing them with some kind of honorary title. I have found only one country which does this by force of law, and that is the Soviet Union. Already in 1938 the presidency of the Highest Soviet of the U.S.S.R. issued an ordinance to bestow on scientists who by special performance through scientific discoveries "have contributed to the upswing of the economy, the culture and science, the increase of power and glory of the U.S.S.R." the title of a "Hero of Socialist Work," followed by another ordinance in 1940 creat - 
ing the honorary title of "Meritorious Scientist" for extraordinary practical-scientific activities. At the same time as the before-mentioned basic law on inventions and discoveries was issued in April 1959, a decision of the Council of Ministers of the U.S.S.R. (No. 435, art. 5) introduced two additional honorary titles: "Meritorious Inventor of the Republic" (a badge in gold), and "Meritorious Rationalizer of the Republic" (a badge in silver).

Another country in which this kind of incentive is not unfamiliar is the United States. Presenting honorary titles to outstanding inventors is practiced in various industrial corporations. This kind of action in the U.S. is, however, entirely voluntary and in. dividual, and not based on any law. Just as examples I may mention Radio Corporation of America bestowing the title of "Fellow" on scientists of the RCA Laboratories if they have done outstanding work. The title carries no tangible reward, but may give the receiver more freedom to pursue personal research projects (compare Neumeyer, The Employed Inventor in the United States, Cambridge, Mass. 1971/131), one bearer of such a title is today sitting among us. Another American corporation encouraging their creative employees by all kinds of tangible and intangible incentives is the Minnesota Mining and Manufacturing Company. For their most distinguished inventors a club was founded and title is given opening membership to the top layer of their many innovators.

A system very similar to the one of RCA was introduced by the International Business Machine Corporation. IBM instituted an honorary incentive system by appointing employees who have outstand. ing records of sustained innovation and creativity to the title of "IBM Fellow." The elected persons are for a limited time free to pursue any research project they desire in their chosen field.

Mindful of the limited time I have to present the complex subject matter of systems to stimulate employee-inventions I wish to point only at two more countries, illustrating that the climate of general support of stimulating measures to creative employees by law does not exist everywhere. A definitely negative attitude in official circles (representing primarily employer organizations) we find in today's Great Britain and in Canada. Some official statements may be sufficient to prove this.

The "Banks Committee" which was appointed to examine the British Patent System presented in July
1970 to Parliament a report (Cmnd 4407, London 1970), in which chapter 16 treats the problems of employee-inventions. There it is stated that evidence given "by industrialists was unanimously against the introduction of any statutory obligations on employers to reward employee-inventors" (Op. cit. 137). Six well known and unproved reasons against such systems were cited: (1) the inhibiting effect on effectiveness of R. \& D. departments, (2) the difficulties to assign staff to work which is less likely to result in inventions, (3) secrecy created between staff members, (4) difficulty to identify real inventor in today's team work, (5) that employees making important contributions which are not patentable, cannot qualify for special awards, and (6) legislation relating solely to patentable inventions would discriminate in favour of only one of many employee-contributions. In its summary the Banks Committee recommended that "the Department of Employment and Productivity should give special consideration in the general context of industrial relations to the encouragement of voluntary award schemes to reward employee-inventors on the lines of the schemes already in operation in many organizations." The Committee does, however, not care to describe any such scheme in use in England.

In Canada the Economic Council of Canada had been requested in 1966 by the government to study and advise regarding patents, trademarks, copyrights and registered industrial designs, and carry out studies that would be a first and necessary step in the determination of a cohesive economic policy in relation to these matters as a whole. As a result a large "Report on Intellectual and Industrial Property" was presented by the Council in January 1971. With regard to patents certain policy recommendations were made (ch. 5) including the questions of special awards to employee-inventors. The Council makes the following remarks:

"It is our impression that large companies with major continuing research programs are usually able to discern why, in their self interest, if they wish to retain and encourage unusually creative individuals on their staffs, they should take care to provide appropriate incentives and rewards to such individuals. If, however, it should come to light that a significant number of Canadian companies are falling down in this regard, consideration might well be given to appropriate adaption to Canadian cir- 
cumstances of certain provisions of the West German patent law regarding rewards to individual inventors working within corporate organizations." (Op. cit/98f)

This statement is unusually confused, badly worded and partly directly incorrect. Does it represent the total lack of interest of the Canadian Government in these questions? There seem to exist serious reasons to analyze these problems in Canada much closer than the Economic Council has done.

Mr. Chairman, gentlemen, I have now cited all kinds of law paragraphs and committee statements about employed inventors, but at the end I want to remind you that the objects of all these measures are human beings. They react as such the same way as we all do. Generosity and justice to them will be repaid by them manifold. They are in all countries just a small minority of people, but in spite of this we need their imagination and their belief in change and renewal.

(Combined discussion follows next paper by $\mathrm{Mr}$. Romanus.) 


\title{
A European Perspective of the Inventor Ecology
}

\section{Harald Romanus}

\author{
Nordenskioldsgatan 86, 11521 Stockholm, Sweden
}

\begin{abstract}
Examines the hazards and impediments to inventors, and the methods that some states-in particular, Sweden - are taking to remove these impediments.

Inventors need technical help to develop their ideas, financial help, advice on patenting, and aid in selling their ideas to industry. Having grown from a small beginning in the 1930's, the Swedish Board for Technical Development now has the know-how and resources to perform these services for inventors who they consider are worthy of help. The Board also evaluates proposed legislation affecting inventors. and studies the climate of invention activities.

The practices of the Swedish Board for Technical Development are being followed in other European countries in an effort to support the first link in the innovation chain - invention.
\end{abstract}

Key words: European efforts to aid inventors; inventor; inventor ecology; Swedish Board for Technical Development.

"Nobody shall devise or invent something new, nor shall he use or practice anything such, but everybody shall in civic and Christian love follow his neighbor." This is an old Swedish statute for a medieval guild. In fact, it implies a prohibition against making inventions. It certainly must have been a cold climate for inventors. But evidently some inventors must have stuck their necks out anyhow, since it was found necessary to put in a clause against them in the statute.

I was reminded of this statute when I read the somewhat provocative question in the conference program: "Should we call a halt to inventions?" I don't think we should; I don't even think we could. Creative instinct is a very innate quality of the human mind. I will not go back to the introduction of the use of fire or the invention of the wheel. Nor will I take up the question of whether it was the inventive mind which prompted man to branch out from the ape and descend from the trees to live on the ground, or the changed conditions of life, when he was forced to live on the ground, which made him inventive in order to survive.

Anyhow, I am a firm supporter of the belief that the inventive ability of mankind will not become extinct, even in a very inhospitable ecology. But the inventors may become passive and scarce, and that would be bad enough. The question, therefore, in my opinion should read: "Do we have enough inventors, and do we make use of them in the most efficient way?"

\section{Different kinds of inventors}

First, some words about different kinds of inventors. Who are the typical inventors? Certainly not Edison, Marconi, Eastman, or any of the other worldfamous ones. They are the figureheads who had not only the luck to enter a new technical field at the right moment, but also the ability and the endurance to carry through the development work, and the marketing of their ideas. Certainly we would like to have more of this kind of inventors.

At the other end of the spectrum, we have the eccentric inventors, with such inventions as the lightning-conductor umbrella, the rotating Christmas tree, or even perpetual motion machines. Some call them crackpots, and they certainly are, but I hesitate to use that word, because I don't think we should hurt their feelings. Unfortunately, they also get a lot of publicity in some magazines and newspapers, and therefore contribute to the general conception of inventors. They are a nuisance, but we can't get rid of them. By suitable means we could eliminate some of the troubles they cause. More important is that we 
might help some of them to get rid of their irrational ideas and channel them into more productive work.

Between these extremes lies the main bulk of inventors-not so conspicuous and glorified as the bigshots, and most of their inventions are not revolutionary. The industrial value of each single invention is often not very impressive, but as a whole they give a steady contribution to technical progress. If the inventor succeeds in getting a fair share of the economic value of the invention, it could also mean a lot for his personal economy.

Unyielding tenacity is not an uncommon quality in real inventors, but economic talent and the power to carry through successful business negotiations are very rare, indeed. I dare say that technical creativity and economic talent are almost mutually exclusive qualities in the same man. The heritage may include one of them, but very seldom both. In fact, when I have to deal with an inventor who is extremely successful in selling his inventions, I might become a little suspicious, and take another look at his inventions. They often turn out to be superficial, and not give the entrepreneur what he expects in the long run. Such a man is a clever salesman, but not a real inventor.

Of the groups I have mentioned, it is the middle group that is most sensitive to the environment. I will postulate that we can increase or reduce the number of such inventors and, in addition, their efficiency, by changing the climate for inventors.

\section{Is the inventive effort adequate?}

This brings me to another question in the conference program: "Is the inventive effort of the United States adequate for our present and foreseeable future?" My answer is that up to now I have not found a single country in the world in which the general support for inventive activities, in my opinion, has reached the optimum level, seen from the point of view of the interest of that country. As a contrast, I might add that I would not dare to make the same statement about the money and assistance spent on R. \& D. in some countries.

Most inventors in Scandinavia, and I'm sure also in other countries in Western Europe, dream of the United States as the land of promise, abounding with milk and honey. I'm not presumptuous enough to believe, after some short visits to your country-or rather continent - that I have a clear conception of the situation of your inventors. But I have found that you yourselves are not overly satisfied with the situation. Even the first two speakers of the conference, Dr. Draper and the Assistant Secretary of Commerce Dr. Ancker-Johnson, made it clear that you have a desire to encourage the creation of more inventions, and that you are planning incentives to that end. My following reflections are based on the same attitude.

\section{Hazards and impediments on the inventor's route}

Now some words about the hazards and impediments which the inventor usually encounters on his route from the conception of the invention idea to the stage where he can leave it in other hands, or market it himself. I will naturally restrict myself to the independent inventor. The inventor in an industry or a research institute working on an invention for his employer has a quite different situation. Material resources and specialists for different phases of the development work will be supplied by the employer. The inventor is relieved of most of the daily troubles which the independent inventor has to overcome in his work. He may have other kinds of troubles, such as his relation to the employer, the general climate for inventors in his environment, and last but not least, the important question about economic compensation for his invention.

In any case I will not talk about the independent inventor. There is no standardized inventor route. Each one has to find his own trail. It is an adventurous trail, and most often he will meet some unexpected impediments on his way, which he has to overcome. In many cases overcoming such a crucial point may actually imply the real birth of the invention.

Most of the troubles appearing during the development work, however, have no relation to the proper idea of the invention and have nothing to do with the creative process. They are problems in the most varying fields of the technique, such as the physical and chemical properties of different materials, calculations and design at the drawing board level or sometimes a scientific analysis, testing methods and testing equipment, etc. Usually they are only routine work for a man skilled in the special profession concerned. But if the inventor cannot find the right man, trust his confidentiality, and pay the costs, the 
problem may assume very great dimensions in his mind and even endanger a positive result of his work.

A common critical point is the stage when the inventor has completed and tested his first model, and-as is usually the case-its performance does not satisfy his expectations. It is then important to analyze the deficiencies and to determine whether they are intrinsic in the principle of the invention or only due to trivial failures in the construction of the model.

For an independent inventor in the above-mentioned situation or encountering other unexpected impediments in his development work, it is often difficult to make a balanced evaluation of the nature and seriousness of the troubles, all by himself, and of the prospects of carrying through the invention to a practically useful solution. Unfamiliarity with some of the obstacles involved and the psychic stress of the situation may induce him to draw the conclusion that he has been on a wrong trail and the invention is useless, even in cases in which a man in the proper profession could have circumvented the impediment. And the invention goes into the drawer together with a lot of disappointment and shaken self-confidence. Once in the drawer the invention will seldom come out again. If you tell the inventor that you could see some good features in his invention and ask him why he doesn't start the experiments over again, he will have all kinds of excuses. But the real reason is that he doesn't like to open the drawer; there are too many unhappy feelings in it.

\section{The patent question}

Now to the patent question, which contains some important and interesting differences between the American and European systems.

The purpose of the patent systems is to provide legal protection for the inventor's intellectual achievement, the invention. But contrary to the protection for other producers of intellectual property, such as authors, painters, composers, etc., who are automatically protected by the law without any action on their part - or in some cases after a simple registration - the protection for inventors is a complicated and costly procedure. In America the rights of the inventor are principally acknowledged from the very birth of the invention. The European inventor, on the other hand, has no legal protection whatsoever until he has filed a patent application with the
Patent Office. In professional language this is the "first-to-invent" principle versus the "first-to-file" principle.

I don't think most of you could realize what this means to the inventor in his practical work. A European who conceives an invention idea always runs the risk that someone else subsequently will get the same idea and immediately file a patent application. In that case, the first man has no possibility at all of getting a patent for his idea although he is the first and true inventor.

Naturally this means a psychological press on the inventor to run as quickly as possible to the Patent Office, and he often does, even before the invention idea is sufficiently developed for patenting. Unlike Pallas Athena, who sprang fully developed out of the head of Zeus, most inventions have to pass a long chain of developments including amendments, im. provements and adaptation to practical functions before they reach a stage that is practically useful and competitive. For full protection this might necessitate a long series of patent applications, some of which later may prove to be worthless, and still all improvements made from time to time may not be covered. It is almost inconceivable to the European inventors that the inventor in the United States can go on developing his invention without worrying about a patent application, only making dated notes in a properly verified way and, when the invention has reached operability, file an application for those attributes he needs to have protected. This is not to speak about the "year of grace" - the right to wait up to one year after marketing the invention before the patent application is filed - which to the European inventor sounds absolutely too good to be true.

It is impossible here to deal with all other differences between the American and European patent systems. I shall comment on only one more.

Early publication of all patent applications 18 months after the priority date is compulsory in some European countries and also in the new international European patent system now being prepared for Western Europe. ${ }^{1}$ To an inventor with limited resources and an invention idea for which he needs some years of development work this may put him in a real dilemma. If he must use outside experts or workshops for certain parts of the development work he will have to do so without using the legal protec-

\footnotetext{
' Its final shape was decided at an international diplomatic conference in Munich in
} October 1973. 
tion which a patent application is meant to give him. Otherwise his idea will be spread all over the world 18 months later, with the consequence that big companies and research laboratories may put their immense resources on the problem and arrive at the final, practically useful solutions ahead of him. Also the American inventor should keep this early publication in mind when he considers filing patent applications in Europe.

It is commonly said that the patent law has the purpose of providing legal protection for the intellectual property of the inventors, and should be modeled to promote inventiveness in the country. Exaggerating a little, I would say that in practice the problem of the law rather is to perform the patent granting function with as little hampering and distorting effect as possible on the natural inventing activities.

I have met very few European inventors active in developing an invention, who do not feel that the time and money they have to spend on the patent question are "stolen" from the real development work and often also force them to deviate from the most efficient development route. They may often give the hazards built into the patent system unrealistic dimensions, with the consequence that they are working under a permanent nervous strain.

It was in this respect a striking experience to me to meet American inventors. They never started a discussion of an invention at the patent question but jumped into all kinds of technical and economical problems. To me they sometimes appeared almost too negligent of the patent matter, maybe because I was still biased by the European attitude.

Of course there are complaints against the U.S. patent law too-high cost of litigation, doubtful validity of patents, etc. - and you are at present working on a revised patent law. But I would urge you never to give up the "first-to-invent" principle. It is more apt to fit the needs and practical developing ways in the field of inventions and is thereby more promotive to inventiveness than the "first-tofile" principle can ever be.

\section{Financing the development work}

Another impediment to the inventor is the financing of the development work. Often very modest costs for certain steps in the development work may force him to deviate from the most efficient way, or even skip the whole thing before the experiments have reached the stage where an evaluation of the idea is possible. From the society's point of view this seems irrational, considering the desire for a steady flow of new inventions as an incentive to technical progress, and the very small costs compared to the sums spent on science and research. The cheapest way to accomplish the first study and experiments of an invention is to let the inventor do it himself. To have it done in a research laboratory would cost five times as much.

\section{Marketing the inventions}

Inventions made by employees are usually marketed by a company, the employer. This matter is dealt with in another paper by Dr. Neumeyer. If the employer is not interested in a certain invention, the inventor may be in the situation of an independent inventor. The third alternative, where the employer only claims a part of the inventor's right, leaving the rest to the inventor, is more interesting. An increased use of this alternative could be beneficial to society and to technical progress.

Most of the independent inventors do not start a company of their own for the manufacturing or marketing of the invention, but want to sell or license the invention rights. However, almost all of them - and often the most ingenious and creative ones-lack talent and experience in the very special field of negotiating and contract writing. They often contact the industries too early, before having thoroughly developed the invention and produced the necessary "presentation material," such as basic experiments, models and test results, which would make it easy for the industry to form an opinion on the marketing prospects. They talk too much about their dreams and too little about technical facts, and they have often no realistic conception of the inherent economic value of the inventions.

The inventors, therefore, in most cases ought to use skilled advisors for this kind of job, or delegate the whole thing to them. The trouble is only that the consultants and firms offering to help the inventors to sell their patents are of varying quality, and it is very difficult for the inventor to find out whether or not they are doing an adequate selling effort.

My teacher long ago in National Economics at the Institute of Technology in Stockholm, Professor Sven Brisman, used to say that inventors are a necessary element in the technical progress, but the inventors' economic return taken as a whole for all 
inventors is certainly negative. It is the big income of the few and the optimistic hopes of the rest that keeps the whole business running. I believe this to be true also today, at least for inventors in Europe. How it is in the United States I would not dare to say-there is a common belief in Europe that the inventors have better chances in the United States-but it would be an interesting subject for a study.

On the other hand, an investigation by the OECD (Organization for Economic Cooperation and Development) and other investigations have shown that the annual growth of the GNP cannot be explained only by contributions of capital and labor. The rest is credited to a third factor, the technical progress, and inventions are certainly an important element in that factor.

When contrasting these findings with the statement of Professor Brisman the situation neither seems reasonable from the inventors' point of view nor efficient with regard to the technical progress.

\section{Improvements of the environment for the inventor}

In countries with a liberal economic system and free competition a reasonable balance among the different parties concerned in industry and commerce is a prerequisite for good-effective functioning. A weak party will tend to become even weaker and get less favorable working conditions. That is what has happened to the inventors in most countries, although to a most varying extent. In some European countries the inventor is not even to be named in the patent, and it is claimed that the independent inventor nowadays has no raison d'etre. In the United States the inventor situation has deteriorated, much less, but this does not mean that there is the balanced state referred to above.

In many countries there has long been a general concern about the diminishing rate of new inventionbased industries, and a demand for action to turn this trend. To this end some kinds of institutions or corporations for the development and exploitation of practically useful results from scientific research and other inventions have been established. In Europe, they are usually state supported or based entirely on government grants, but should in the long run become self-sustaining. The biggest one in $\mathrm{Eu}$ rope is the National Research Development Corporation (NRDC) established by the British Parlia- ment in 1948. As far as I know none of the European bodies have up to now become self-sustaining in the sense that they pay normal interest on the invested capital. In the U.S. the Research Corporation, and I think also some others, have been successful in that respect.

The demand for self-sustainment has the consequence that they normally do not invest in inventions which have not been developed far enough so that their commercial use can be appraised. Therefore they decline to discuss the big stream of inventions offered to them by private inventors whose ideas are in immature state with insufficient presentation material. Therefore, they have in practice, proved to be of little value to the average inventor.

In some countries another kind of institution aimed primarily at the genesis and the very first development steps of invention ideas has appeared, especially in recent years. As a common denomina. tor for such institutions, the term "Invention Office" is used. The invention offices should in principle give the inventors advice, personal assistance (i.e., in finding suitable experts, laboratories, workshops, etc.) and, when necessary, economic grants for the cost of certain steps in the development work. Of course this must be done together with a successive screening of the inventions. The first screening, in which eight- or nine-tenths of the ideas drop out, should be liberal. It is better to pay for a simple laboratory test, a model covering the basic principle or an expert analysis, than to have long discussions with the inventor on a purely theoretical basis. The first selection thus should be on the safe side as to the possible usefulness. During the following development steps more and more facts will be available and more of the inventions will be dropped. For the inventions remaining, when the development work has reached the stage where satisfactory presentation material is available, the inventor should be helped to contact suitable industries or development corporations and-if he so wishes - be helped also with the contract negotiations.

The ownership of the invention at all times remains with the inventor, and he has no obligation to follow the advice of the office, if he does not agree with them. In any case, the office has reasonable means to direct him by the possibility of granting him economic support for certain development steps, when it finds it advisable.

With regard to financing, the invention of- 
fices - contrary to the development and exploitation institutions-should not strive to become selfsustaining. Their purpose is to spend the grants they get from the government or foundations, together with their income from the fees they may charge for some of their services, in the best way to promote the utilization of inventive ideas. If an invention, which has been economically supported by the office, is marketed and the inventor gets an income from it, he usually shall pay back the grants he has received. There has been much discussion whether the office also should have a further part of the income from the invention, e.g., in the form of a royalty, but this has been found not to be justified. The society is in fact a silent partner in every successful invention, and gets, through the ordinary income taxes, a large share of the profits from it. The office therefore can dispense with the complicated way of writing special royalty contracts and enforcing them many years later.

A basic principle of the offices is the obligation for the staff to observe secrecy. This is of special importance in European countries, because it induces the inventor to contact the office in the very early stages of the invention. Otherwise many inventors, who are extremely anxious not to disclose their invention to any outsiders before they have filed a patent application, (due to the first-to-file system), may wait too long and make unneccessary mistakes before they contact the office.

Invention offices exist at present in the Scandinavian countries and in some other countries in Europe. They are rapidly expanding in staff and financial resources. Establishment of new offices is considered in other countries. In the U.S. the Office of Invention and Innovation seems to be an institution intended for such purposes. But I cannot comprehend why the office does not get appropriations for expansion of its activities, which most certainly would prove to be profitable to the country in stimulated inventiveness and revived industry. I have also found some embryos of local Invention Offices in the United States and Canada, which, however, lack the small funds necessary for helping some inventors in their first steps of invention development.

Another measure to improve the situation for the inventors is the granting of inventor fellowships, which can be done by the invention office or another body. In contrast to the ordinary inventor grants, which is given for the development of a certain in- vention, the fellowship is not connected with any specific invention but intended to relieve the inventor of the daily work for his livelihood during a certain period, to enable him to spend his time on inventive activities. Granting of inventor fellowships was started in Sweden 2 years ago with 10 fellowships annually, which is a small number compared to the fellowships for scientists.

Invention expositions are one way to facilitate contact between the inventor and interested indus. tries or entrepreneurs, when he has produced sufficient presentation material on his invention. Unfortunately most of the invention expositions in Europe are pure business enterprises aiming at attracting a great public and caring little about what is really useful to the inventors. The value of these expositions in bringing about real contracts with producers has been disputed. Another kind of exposition concentrates on assistance to the inventors. However, they are often poorly arranged and advertised due to lack of economic resources. The State Invention Expositions in the United States, sponsored by state agencies or local chambers of commerce, seem to be a very good solution. I am sorry I have not had a chance to visit one.

The really big problems to tackle in the environment of the inventor, however, are the general conditions in a country under which the inventors have to live and work. These conditions include the laws, the educational system, the taxation regulations, the attitude of the society towards inventiveness, the social standing of the inventor as a profession, inventor awards, publicity, and many other elements.

Laws affecting the invention field concern, for instance, patents, antitrust questions and employee inventions. Laws on employee inventions exist in several European countries and a general investigation is being made by the International Labour Office (ILO) in Geneva. Eventually this question will have to be solved also in the United States.

In the educational field there are the age-old questions, whether or not the common school system frustrates creative thinking, and whether it is possible to teach ordinary people to become creative and to invent. As to taxation, unfavorable tax rules will counteract the pursuance of many invention ideas, whereas favorable ones may have a strong stimulating effect.

There has been a tremendous industrial evolution in the last hundred years, but the inventors are in 
many respects lagging behind. In some cases changes have even been made in a direction which clearly aggravates the situation for the inventors, as for instance the introduction of the compulsory early publication of patent applications in Europe.

One or another of these problems have at different times been studied by special committees. But the long-term environmental problems have such a wide scope and are so interconnected that they ought to be watched and studied by a permanent body, which could initiate investigations and submit observations or proposals to the government. Some of the Invention Offices are trying to perform such a function, but their staff is too small and too busy with the individual problems of inventors to enable them to set aside special people for long-term environmental studies. In the United States, the National Inventors Council seems to be the right body for this important work.

How about the inventors themselves? Sometimes they are "geniuses" wishing to be left alone. More often they feel isolated in a cold climate-more often so, I think, in Europe than in the United States. All other professionals in the field of innovation have their own associations, where they can meet and discuss their problems, and which can speak for them in public debate.

Where any inventor associations exist at all, they are usually small and have little money, relying only on membership fees. In Europe, however, some of them have grown to national associations, recognized by the government for submitting observations on legal propositions and other questions from the government. A few of them also are given annual grants from government funds to enable them to expand their work on current inventor problems and to take part in foreign conferences.

In the United States I have found many local associations, some of which are one-man organizations and fade away with him. None of the local associations seem to have contacts with any other. Why not bring them together in a congress, as is done with scientists on questions of national interest? If I should venture to voice an opinion, I would say that you have to be a little inventive yourselves, and invent ways and means to support the inventor associations, making them a useful element in the efforts to encourage the creation of more inventions.

\section{The efficiency of the inventor's work}

In my whole paper I have made a lot of statements about the inventor's way of working, the chief hazards in his work, his need for outside assistance at certain steps, and when and why the invention often goes into the drawer. Yet all the statements are based on no other facts than my personal experience from contacts with many individual inventors. I have no statistically relevant grounds for transferring this experience to the whole universe of inventors, to speak generally about the frequency and the seriousness of the different situations and characteristics of development work. And furthermore, I have never found a scientific investigation based on interviews with inventors as a group through representative sampling.

Knowing that even well-planned industries spend a great amount of money on time studies and MTMmeasurements for continued streamlining of every element in the production line to save even a fraction of a percent in time and cost, it seems really as tonishing that no such study has been made of the development process of inventions.

This process still usually remains in a free and wildgrown state, and we know there are many bottlenecks and impediments that have a very disturbing effect on the time schedule and efficiency of the work. A systematic study here ought to give indications for possible improvements of a quite different order of magnitude than in the factories.

Therefore, if the U.S. Government now is going to spend money on projects to stimulate inventiveness, it seems to me that one of the basic and most urgent projects should be a broad and thorough interview investigation of the inventors' way of working and the different factors that affect the efficiency of their work.

Having the privilege to speak here from a European perspective I cannot help dreaming of what might be the conclusions if the same investigation - with the same questionnaire-could be made simultaneously in some other inventor environments, say, for instance, Canada and one large and one small country in Europe. The result could indicate which factors are fundamental and independent of the environment, and how other factors fluctuate due to varying environmental conditions. 
Should we encourage our young men and women to invent?

Let me finally take up still another question from the Conference program: "Should we encourage our young men and women to invent?" As much as I feel that more inventors would be beneficial to the society, I must reluctantly answer "No." In my opinion society still has a long way to go before inventors generally are given a reasonable chance to succeed. Young people without special preferences, looking around to choose a profession that could give them a fair income and position in life, ought not to be advised to start as inventors unless they have shown a very special talent for such work. There will be many people, anyhow, who cannot think of becoming anything else but inventors-just like some feel a calling to become authors or actresses - in spite of all warnings of future hardships. The best way to encourage inventor activities at present seems to be to support those who start on the inventor route by their own free choice, and assist them to overcome certain impediments in their work.

This brings me back to where I started, to the inventor ecology. The present situation is certainly not very favorable, but I am sure it will never be necessary to create a game reserve for inventors to preserve the specimen on earth. On the other hand, if we improve their environment, their numbe: and activity will increase, and they will give a far greater contribution to technical progress.

\section{Discussion}

C. Rodenberger: I would like to ask the question of the two gentlemen as to what role, if any, did the university play in invention and innovation in the European scheme?

H. Romanus: Naturally they are making inventions, but mostly as independent inventors. The employee invention law in Sweden makes an exemption for teachers at universities. They are not regarded as employees; they own their own inventions. If they are not teaching, they can have a contract for research, and then it depends on the contract who owns the inventions. But certainly there are a lot of inventions made at the universities. But we don't have universities directed entirely on inventions; it's a by-product. Most of them can do what research they wish, and that means they can do invention work, too.

R. Kuntz: Do you feel that the system that has evolved in this country affecting the employees who invent, is satisfying his human needs, and giving him the incentive that's necessary?

F. Neumeyer: Well, Bob, to answer this I would need to write another book, of course. But, as you know yourself, the legal regulation of this field is practically not existing in the United States, with the exception of certain types of Government employees. From our European view, we think that there might be, a possibility to develop a more uniform improvement of incentives. But in a country of this size, I can't give you this recommendation. I think there could be developed a long list of useful and positive suggestions to increase incentives for American inventors, for this is also obviously the meaning of the message of President Nixon of March 1972. But it's up to you to find the best way. We cannot give you any advice, but we just can tell you facts from other parts of the world.

N. Zepell: I wanted to find out if it's true-I heard a few years ago - that in Common Market countries, there will be a patent law that will cover all those countries. Is this correct, or is this rumor incorrect?

F. Neumeyer: The history of harmonization of patent acts, industrial property legislation in Europe, in this connection is a long story which goes back several decades. The first draft for a European patent, for the member countries of the Common Market, is more than 20 years old, but was later on stopped by France. But about 4 years ago a new development occurred which made the whole development much more exciting and fast, with the result that this fall in September we'll have a diplomatic conference in Munich, at which two European conventions will be signed: one which we call the Inner European Patent Convention, and the other one, the Outer one. The Inner one is meant to give a uniform European patent for all nine member coưntries of the European market, which means that my own country is not included. The Outer Convention will be signed at the same time, in which all European countries can take part, and go into the market 
with certain remarkable advantages. So, in a few months there will happen very important things in Europe in this field, and I'm sure that the experts in the United States will follow very carefully what's happening there. We are looking forward to a new situation which has never existed before in the history of European patent legislation. 



\section{WORKSHOP PANELS ON RECOMMENDATIONS AND QUESTIONS FOR FURTHER STUDY}

\section{The Role of the Patent System}

\section{J. Stedman, Chairman}

The Panel expressed serious concern regarding the sharp deterioration that has occurred in recent years with respect to the esteem in which the patent system has been traditionally regarded, and wishes to make some suggestions for improving that unfortunate situation.

To this end, our basic recommendation is that we strongly urge the National Inventors Council to secure the appointment of a group to study these proposals, and other proposals that may be suggested, and to come up with some firm recommendations. Since many of the things we suggest are matters that may require legislation, this group should be expected to report within a year, so that they would have materials available for a forthcoming Congress.

The Panel has 14 specific suggestions. The first two relate to efforts to provide more flexibility in the patent system than it has at the present time.

1. Provision for a petty or utility patent, so that courts and the Patent Office would not be limited to a choice between awarding too much or giving nothing at all, which is the only choice that they often have at the present time.

2. Provision for patents of addition, similar to that found in various countries, in which, if an inventor makes an invention and obtains a patent on it, and later makes some improvement which does not merit a patent in itself, nevertheless it can be added to the original patent for the remainder of that patent period.

The next two proposals deal with the "integrity" of the patent system.

3. Some kind of an opposition proceeding, with careful protective devices, so that an application would be subject to review from the standpoint of why the patent should not issue.
4. Obligation on an applicant to disclose relevant information that is known to him at the time of his application (to a considerable extent he has this duty now).

The next five recommendations deal with Patent Office procedure.

5. Deferred examination, again with some very careful protective devices.

6. Make the Patent Office a separate agency.

7. Take advantage of developments in computerized searching and data collection. This does not mean that the computer makes the decision, but it can be of great help to human beings in arriving at the decision. Whether this is done in the Patent Office, as a matter of general Government operation, by tapping the resources of private industry or on an international basis is something to be determined by the study group.

8. Consider reexamination of the fee structure covering both application procedures and the furnishing of services and materials by the Patent Office, in order to lighten the burdens, especially at the outset, upon applicants.

9. Consider the appointment of an Assistant Secretary of Commerce for Invention, Innovation, and Intellectual Property, for the purpose of dealing with those agencies in the Commerce Department which are directly involved in the questions of invention and innovation. These would include the National Technical Information Service, the Office of Invention and Innovation, the Office of Technical Forecasting and Assessment, and any others that may be appropriate.

The remaining five recommendations deal with court procedures. 
10. Give consideration to what appropriate steps might be taken to achieve greater uniformity in the courts as far as patent decisions, patent doctrine, etc., are concerned.

11. Encourage the use by judges of masters for dealing with complex factual questions.

12. Encourage the use of court-appointed experts by courts, especially those that are technologically ignorant. The expert's function would be to hold the judge's hand, so to speak, and give him some idea of where he is going.

13. Provide for references back to the Patent Office in patent litigation, for the purpose of getting a second guess from the Patent Office as to how, in the light of the information that has been presented in court litigation, they would view a particular patent in terms of validity.

14. Give consideration to the possibility of developing an administrative procedure for dealing with patent litigation, especially in the areas of validity and infringement - highly technical questions, both of them-in lieu of the traditional court litigation that we have always used. This could include such procedures as the Court of Claims' practice of using special commissioners to deal with such problems.

In addition to these specific suggestions, we note a number of areas in which we feel that information is greatly needed, information that at the present time is lacking. We recommend, therefore, that certain studies be made, looking to a better understanding of how the patent system is operating, and to developing means for improving its effectiveness. These include the following:

1. A study of changing attitudes on the part of the courts over recent decades with respect to patents. Such a study could conceivably be made by the American Bar Association Foundation, or the recently reconstituted Patent, Trademark and Copyright Foundation.

2. Organization and operation of seminars with the Federal Judges, presumably through such an institution as the Judicial Conference, for the purpose of exchanging ideas, and for the purpose of educating the judges-because many of them do need education - with respect to the operation and effectiveness of the patent system.
3. A study of the Patent Office fee structure, including the effect upon applicants and applications of higher fees; examination of the validity or invalidity of the self-support theory of Patent Office fee setting; development of means for reducing fee burdens in appropriate cases; a look into the excessive divisional cases that now exist, etc. This project could presumably be handled by the National $\mathrm{Bu}$ reau of Standards.

4. A study to determine, and gather data concerning, the economic benefits of the patent system.

5. Development of regional search centers and patent advisory offices, presumably tied in with regional Commerce Department offices, and of means for providing additional assistance to inventors, especially assistance to those in need.

6. A study and report by the Patent Office to clarify what is involved in the so-called "quality review," how it operates, and what it accomplishes or is intended to accomplish.

There were four other areas of concern where it was our feeling that meaningful resolution of problems could come only if patent people and patent institutions were to work together with the other affected institutions concerned with these problems, for the purpose of reaching a satisfactory resolution of the conflict:

1. The question of international harmonization, which involves considerations that go beyond the patent system itself.

2. The employer-employee relationship.

3. Government patent policy, which involves ramifications that are quite outside of, although they directly affect the patent system.

4. The patent-antitrust relationship. A majority of the panel expressed concern-concern that is not limited to themselves but is deemed to be of widespread existence among others as well-regarding what they feel is the steadily increasing encroachment of the antitrust laws upon the patent donain. All of the panel was in full agreement that the patent-antitrust relationship is a crucially important one, that there presently exists a serious conflict between them, and that the public interest demands the resolution of this conflict at the earliest possible moment, consistent with reaching a wise and satisfactory adjustment. 


\section{The Role of Industry}

\section{E. Anagnostopoulos, Chairman}

The activities of the workshop panel covered herein are divided into two parts. The first are three recommendations that were the results of significant discussion within the group, and the second are the personal observations and concerns expressed by Robert J. Kuntz, P.E., to the panel and to the assembly. The latter part was included in the report and presented to the assembly at the direction of the panel chairman, since it represents a philosophy and school of thought previously not illuminated in the National Inventors Council.

\section{Panel Resolutions}

\section{Inventors Who Are Employees}

Recognizing that creativity is a unique human quality, and creative problem solving is instinctive to man as one of the highest expressions of human intelligence; and further recognizing that our social well-being is critically dependent upon creativity, therefore: The Panel recommends that guidelines be established for the enhancement of creativity and inventiveness in the corporate enterprise system and that such guidelines implement the theory of positive reinforcement and include award systems that are adaptable to variations that may exist in the environment in which inventors practice.

\section{The Position of the United States in the World Market}

There is increasing concern for the position of the United States in the world market, the deficit of payments, the number of patents of origin compared to some of the other highly industrialized countries, and the concentration of research and development which can have a significant impact on the United States' technological competitive capability in the world market. Therefore: The Panel recommends that investigations be conducted to illuminate concentrated areas of technological research and development by competitive countries in the world market, and that the information be made available to the affected sectors of our system. This information would also be used as a guide in establishing pri- orities in the allocation of national resources for research and development.

\section{Government Patents}

Recognizing that the Government may stimulate the invention of many new products, materials, and processes because of its significant involvement in the funding of research and development; and recognizing that the present policy of the Government concerning the ownership and/or use of patents resulting from these inventions lacks uniformity in the various departments and agencies, and Government owned patents seldom result in direct benefit to our social well-being, therefore: The Panel recommends that a uniform policy be adopted by the Federal Government against Government patent ownership and the Government retain a license to practice for Government use only, and that the inventor's position in such patents be similar to that of a Government Employee.

\section{Remarks by Robert J. Kuntz, P.E.*}

\section{Classification of Inventors}

There have been many discussions concerning the rights of employed inventors to retain some interest in inventions that are assigned to their employers. Responses to the questions raised by individual inventors or groups representing their interests have referred to the individual who is employed to invent, paid a high salary, and is given laboratory facilities in which to experiment and develop his inventions for the employer. Such an individual recognizes and accepts this position with the full realization that the employer has purchased his creative talents and that his job is to invent. However, the majority of patents issued are the results of activities of individuals who are employees but are not hired to invent; rather, they are employed to carry out specific job assignments. Invention is ancillary to the job, and the employee's productivity has little or no relation to the invention process. Therefore, when considering the recognition and rights of inventors, three entities must be realized. They are:

\footnotetext{
* President, California Society of Professional Engineers
} 
1. The independent inventor who is in essence a private practioner. This individual solves problems, creates inventions, and markets or develops his patents independent of the employment arena.

2. The employed inventor who is specifically hired to invent and enjoys all of the rights, privileges, and recognition that that position in corporate enterprise affords him. This individual clearly recognizes his role as being paid to invent.

3. The employee who invents, but is not hired to invent. This individual is employed to perform a myriad of functions for his employer which can range from design to sales. His productivity is gauged and evaluated independent of his inventive capability. Invention is ancillary to his job assignment.

\section{The Constitutional Purpose of the Patent System}

It is axiomatic that the dependence of our social well-being necessitated the free flow of new ideas and creativity, and this free exchange of information was the primary concern of the founding fathers of our Constitution when they uniquely provided a reward to creative persons by granting them an exclusive right to their inventions. The patent system was established as the Government-protected means to reward inventors for their free and public disclosure of their findings.

Many changes have taken place in our society since the founding of the Constitution. Presently, a significant majority of patents issued have been preassigned to the inventor's employer, and as such, there is no direct benefit brought to the inventor by the patent. In the present environment, it must be recognized that there are two entities that exist in the invention process. One is the inventor who conceives the idea and creates the invention. The other is the innovator who provides the resources to bring the invention to the marketplace so that our social well-being may benefit from the new products, processes, and materials. One is useless without the other. If the inventor does not disclose, there is nothing to develop and market. If the resources are not available, a creative idea or invention will never reach fruition.

Recognizing these facts, there must exist a bilateral and mutual dependence of these two enti- ties - the inventor and the innovator-in fulfilling the intent of the Constitutional provisions, and the proper functioning of the patent system cannot be achieved if either interest is subordinated to the other.

Unfortunately, every conflict between social interest and corporate interest has necessitated resolution through legislative means. Many Government agencies and numerous laws have been established to protect the public's interest in fields that could have been adequately addressed by independent or collective actions of private origin. Often the competitive aspects of our system which have benefited the public with the highest standard of living known to man, have prevented singular action to resolve deficiencies. Environmental, labor, pure food and drug, child protection, and numerous other laws have been passed.

The impact of invention and creativity on our social well-being is so profound and covers every facet of society, that National concern is mandatory. The conflict that has developed between inventors and innovators can only be adequately resolved through legislative action if for no other reason than the fact that it is necessary to establish uniformity in practice which does not affect the relative competitive position of all segments of our institutions. The Moss Bill (HR 2370) provides a legislative resolution and recognition of the rights and interests of both the inventor and innovator. This legislation should be objectively analyzed in light of the Constitutional intent; i.e., disclosure for the good of the public.

\section{Guidelines}

In the interim, lacking a legislative resolution to the rights of inventors and innovators, guidelines should be established by national organizations which consider the social, economic, and philosophical needs of both entities. These guidelines should provide for incentive and award systems that relate to the worth of the invention. Disclosures that are not subjected to the patent process should be released to the inventor for independent exploitation or publishing.

The theory of positive reinforcement should be applied to stimulate disclosure. The inventor should be kept involved in the evaluation process and provided the proper encouragement with appropriate feedback. The principal of "find 10 reasons why it will 
work" should be adopted by corporate evaluation boards.

Procedures should be established by corporate enterprise which simplify the disclosure process and remove all impedances to proper documentation for those employees who invent. Technical and legal assistance should be available. The inventor should be given the courtesy of rebuttal. There should be a full release of inventions of no interest to the corporation to the inventor, and inventions performed outside of the employment situation should not be considered of corporate interest but the sole interest of the inventor.

\section{Education}

Efforts should be made to include discussion and provide information to students concerning the invention and patent process. Since engineers are 20 times more likely to invent than all other occupations collectively, there should be an infusion of course study concerning the patent system, invention, creativity, innovation and the law into the Bachelor's Degree curriculum. Additionally, there should be developed public education to achieve greater support for the patent system by illuminating the benefits to our social well-being that this system has provided through new products, processes, and materials.

\section{The Role of Government}

\section{W. B. McLean, Chairman}

We believe that the present policy of assigning all patents resulting from work supported by the Government, to the Government, hinders rather than promotes the utilization of the technology involved. Therefore, we recommend that the title of inventions resulting from Government-supported work be left with the inventor in order to achieve his assistance in putting them to work. Specifically, we suggest that the present administration review the last Bill introduced by Senator McClellan to try to enact an across-the-board Government patent policy, the nature of which was to encompass the Kennedy policy memorandum of 1963, as further amended by the Nixon memorandum of 1972 , on the same subject, plus certain additional features. We believe that this Bill should now be reconsidered for possible enactment. This will be consistent with existing policy that inventions are National assets which should be exploited.

In addition to this recommendation, we also raised the following questions:

1. Can data be developed to show the importance of the Patent Office function, to avoid the assumption that it should be self-supporting on fees alone?

2. Would gains result from making the Patent Office an independent activity?
3. Should the independent inventor get tax breaks?

4. Should we have maintenance fees on an ascending scale?

5. Should we set minimum requirements on the share an inventor should retain of the fruits of his invention?

6. Should we provide the little inventor with help, financial, technical, administrative, to get his invention appraised, tested, produced, or utilized, as we understand is now being tested out in Sweden, with a special office to communicate with the small inventor?

7. Should we try to establish a list of the $\mathrm{X}$ most wanted inventions?

8. Can we set up a mechanism by which senior citizens could take some of the risk necessary to utilize innovation? When people approach retirement age, a lot of them are looking for something useful to do. Some of them have collected capital which could be usefully put to work; could a mechanism be set up by which these people could communicate with the younger inventors who probably now have most of the ideas, in such a way that a useful product could result to society? 


\section{The Rolle of the Educational System}

\section{W. Bollay, Chairman}

\section{University Patent Policy}

The Panel recommends that the Department of Commerce attempt to persuade all governmental agencies which have anything to do with educational institutions to agree on a common patent policy for dealing with educational institutions, and that this be an enlightened policy, not retaining the patent rights to the Government, which means that the patents would not be used, but to grant patent rights to the educational institutions; and secondly, that they also attempt to persuade the universities to adopt equally enlightened patent policies with respect to the individual inventor.

\section{Fellowship Programs}

We believe that Government-financed fellowship programs to encourage scientific research should be supplemented to encourage creative engineering and invention and innovation on the university level. We recommend that the Department of Commerce take a position of leadership in helping to define the criteria for selection, and in making sure that funding is set up for such fellowship programs.

\section{Innovation Centers}

We endorse the idea of establishing innovation centers at or near universities, and recommend the expansion of such programs. We believe the Government should condition the award of funds upon the requirement that there be willing and helpful cooperation between the key departments, such as the School of Engineering and the Business School. It is also desirable that the Government not try to force all innovation centers into one pattern. We further believe that it is important to have inventors and innovators in residence at these innovation cen- ters, to make sure that it is the best experience which is transmitted to the students.

\section{Research and Development for Critical National Needs}

We recommend that the Department of Commerce provide leadership in the initiation of research and development activities in areas of critical national needs, and award research contracts either to industry or to universities which have com. petence in the areas involved. We suggest that a fund of $\$ 25$ to $\$ 50$ million per year be set up for such programs, that half of it should be for projects of clearly recognized national need, and the other half should be open for unsolicited proposals.

\section{Source Material}

We recommend that the Department of Commerce assist the universities in providing source material which can be used for teaching patents, patent law, and creative engineering.

\section{Industry Internships}

We recommend that industry could make a contribution to the university community by encouraging internship experience by qualified graduate students to work with some of their outstanding inventors and innovators.

\section{Continuing Education for Engineers}

Recognizing that continuing education for engineers is a very serious problem, and that the half life of an engineer is now about 5-10 years, we recommend that earnest consideration be given to this problem, and that some universal provision be made for the continuing education of engineers. 


\section{The Role of the Independent Inventor}

\section{S. Ruben and B. Walker, Chairmen}

The substantially unanimous opinion of the panel was as follows:

1. In the past, the independent inventor has made important contributions and it is believed that he is still important. Information should be collected and disseminated on this subject.

2. We recommend that the NIC or other suitable group put out a list or lists of inventions needed for the public good and to aid our balance of trade.

3 . We advocate collecting and disseminating information on public counseling services available to inventors and innovators with no more than a nominal charge.

4. We urge that more information be developed on what knowledge and services are needed by inexperienced inventors and potential inventors.

5. The practices of the Small Business Administration procurement and some other Government procurement agencies should be amplified and en- couraged where new inventions by independent in ventors are involved.

6. Do not increase obstacles to the independent inventor such as:

a. Do not change the capital gains treatment available to an independent inventor on proceeds of an exclusive license.

b. Do not shorten the present 17-year life of an invention unless going to 20 years from the time of filing with suitable extension if unduly delayed by interference.

c. Do not increase the filing fees.

d. Do not institute a maintenance fee on patents issued to independent inventors.

We also have one added as a minority report: As an added incentive to the independent inventor, allow such an inventor a depletion allowance on income earned on his patent.

\section{The International Aspect}

\section{J. Rabinow, Chairman}

1. Every effort should be made and continued to develop a world patent system. The committee recognizes the great difficulties and the legal and social problems of doing this but feels that at least a single technical document could be produced which describes the inventions and defines the claims. The laws applicable to patents could still be different.

2. The committee was unanimous that the "firstto-invent" system is better than the "first-to-file" system now used throughout the world. It recommends that the first-to-invent system be maintained in the United States. It further recommends, however, that with this exception to the maximum extent possible, the U.S. patent system shall be harmonized with those of the rest of the world.

3 . We recommend that a detailed and continuous study be made of how the Common Market patent situation of Europe will affect U.S. applicants.

4. We recommend that there be a continuous study by a permanent Government agency of matters pertaining to patents, innovation, and related matters. Among these may be the work of the Office of Economic Cooperation and Development in Paris and other such bodies.
5. We recommend that a very thorough in-depth study be made of the incentives provided to inven. tors in various South American, European, and Asiatic countries. This recommendation is made with the view that the legal guarantees given to employed inventors as to their rights may be applicable to U.S. inventors as well, and the similarities and differences in their positions here as related to inventors in other countries should be better understood.

6. We recommend that the United States participate in international conventions or conferences related to employed inventors, such as the one we were told about by Dr. Neumeyer that may be held in the near future in Europe.

7. We recommend that hard data be developed on the amount of royalties collected by U.S. firms, by European firms; on royalties they collect from each other; and, if possible, the amount of taxes paid on such royalties both here and abroad.

The Committee felt that such data should also be developed for royalties paid on patents where the arrangements are internal to the United States. 


\section{PARTICIPANTS}

James Adams

Department of Engineering

Stanford University

Stanford, Calif. 94305

C. E. Anagnostopoulos

Monsanto Company

800 North Lindbergh

St. Louis, Mo. 63166

Betsy Ancker-Johnson

Assistant Secretary for Science and

Technology

Department of Commerce

Washington, D.C. 20230

Donald Baker

National Bureau of Standards

Washington, D.C. 20234

Donald W. Banner

Borg-Warner Corporation

200 S. Michigan Avenue

Chicago, Ill. 60604

Frank Barron

University of California

Santa Cruz, Calif. 95060

Lawrence B. Biebel

Biebel, French \& Bugg

2500 Winters Bank Building

Dayton, Ohio 45402

William Bollay

4592 Via Vistosa

Santa Barbara, Calif. 93105

Theodore L. Bowes

Westinghouse Electric Corporation

Research \& Development Center

Pittsburgh, Pa. 15235

Jay Boyce

231-B No. Euclid Street

Anaheim, Calif. 92801

Edward Brenner

The Association for the Advancement of Invention and Innovation

Suite 1007 - Crystal Plaza 1

2001 Jefferson Davis Highway

Arlington, Va. 22202

William H. Calkins

E. I. du Pont de Nemours Company

Wilmington, Del. 19898

George D. Colchagoff

Proformagen, Inc.

4425 Cass Street

San Diego, Calif. 92109

Myron A. Coler

New York University

Suite 7D, One Fifth Avenue

New York, N.Y. 10003
Robert Daly

Stanford Research Institute

333 Ravenswood Avenue

Menlo Park, Calif. 94025

Herbert L. Davis, Jr.

136 Washingt on Place

Ridgewood, N.J. 07450

Joseph H. DeFrees

Allegheny Valve Company

419 Third Avenue

Warren, Pa. 16365

Daniel V. De Simone

Federal Council for Science and Technology

National Science Foundation

Washington, D.C. 20550

James Deters

Borg-Warner Corporation

200 S. Michigan Avenue

Chicago, Ill. 60604

David DeWitt

IBM Corporation

Route 52

Hopewell Junction, N.Y. 12533

James D. D'Ianni

The Goodyear Tire \& Rubber Company

142 Goodyear Boulevard

Akron, Ohio 44316

Roger G. Ditzel

Iowa State University Research Foundation, Inc.

Ames, Iowa 50010

Charles S. Draper

Charles Stark Draper Laboratory

68 Albany Street

Cambridge, Mass. 02139

J. E. Drummond

Maxwell Laboratories, Inc.

9244 Balboa Avenue

San Diego, Calif. 92123

Orval T. Ellsworth

Ellsworth Associates

Stanford P. O. Box 6101

Palo Alto, Calif. 94305

Ralph L. Ely, Jr.

Research Triangle Institute

Research Triangle Park, N.C. 27709

Arthur Ezra

National Science Foundation

Washington, D.C. 20550

Thomas E. Feare

Chemical and Engineering News

1155 16th Street, NW.

W ashington, D.C. 20036
Isase Fleischmann

U.S. Patent Office

Washington, D.C. 20231

Thomas D. Fontaine

University of Florida

Gainesville, Fla. 32601

Howard I. Forman

Rohm and Haas Company

Independence Mall West

Philadelphia, Pa. 19105

James Fulleylove

Research Corporation

405 Lexington Avenue

New York, N.Y. 10017

R. L. Fullman

General Electric Company

P.O. Box 8

Schenectady, N.Y. 12301

S. C. Gilfillan

870 Hilgard Avenue

Los Angeles, Calif. 90024

W. Gary Goodson

Itek Corporation

10 Maguire Road

Lexington, Mass. 02173

Patricia S. Grant

Money Magazine

Time and Life Building

Rockefeller Center

New York, N.Y. 10020

William E. Hanford

Olin Corporation

120 Long Ridge Road

Stamford, Conn. 06904

Kenneth R. Hansen

Adlai Stevenson Institute 3030 Klingle Road

W ashington, D.C. 20008

Darrel G. Harden

University of Oklahoma

Norman, Okla. 73069

Leonard S. Hardland

National Bureau of Standards

Washington, D.C. 20234

Edgar E. Hardy

Monsanto Research Corporation

P. O. Box 8, Station B

Dayton, Ohio 45407

Milton Harris

3300 Whitehaven Street, N.W.

Washington, D.C. 20007

Thomas J. Hogan

National Science Foundation

Washington, D.C. 20550 
Julius Jancin, Jr.

IBM Corporation

1601 North Kent Street

Arlington, Va. 22209

Frank S. Johnston

Office of Naval Research

Arlington, Va. 22217

William D. Johnston III

5309 Riverdale Road

Riverdale, Md. 20840

Harry Kantor

2806 W oodstock Avenue

Silver Spring, Md. 2,0910

Narinder S. Kapany

2126 Greenways Drive

Woodside, Calif. 94061

Irving Kayton

George W ashington University

W ashington, D.C. 20006

Bernard A. Kemp

George Washington University Medical Center

Washington, D.C. 20037

Lillian Kraff

468 South Roxbury Drive

Beverly Hills, Calif. 90212

Robert J. Kuntz

National Society of Professional Engineers 7800 Willow Crest Way

Fair Oaks, Calif. 95628

Lawrence M. Kushner

Commissioner, Consumer Product Safety Commission

W ashington, D.C. 20207

Pierre Lamontagne

Department of Industry, Trade and Commerce

Ottawa, Ontario, KlA OH5, Canada

Theodore H. Lassagne

Counsel, Huebner \& Worrel

610 South Broadway

Los Angeles, Calif. 90014

Clarence Lindquist

Office of Education, HEW

W ashington, D.C. 20202

Anthony C. Mamo

R.C. Ingersoll Researcn Center

Wolf \& Algonquin Roads

DesPlaines, Ill. 60018

John T. Maynard du Pont Experimental Station

Wilmington, Del. 19898

William B. McLean

Naval Undersea Center

271 Catalina Boulevard

San Diego, Calif. 92132
Richard S. Morse

MIT Development Foundation

Massachusetts Institute of Technology

50 Memorial Drive

Cambridge, Mass. 02139

Frederik Neumeyer

Faltmarskalksvagen 39

16135 Bromma, Sweden

Franz O. Ohlson, Jr.

Aerospace Industries Association, Inc. 1725 De Sales Street NW.

Washington, D.C. 20036

Norman C. Parrish

University of California

Berkeley, Calif. 94701

Gerald P. Parsons

Limbach, Limbach \& Sutton

3000 Ferry Building

San Francisco, Calif. 94111

Barbara J. Patton

20282 La Paloma

Saratoga, Calif. 95070

Robert B. Pond

The Johns Hopkins University

Baltimore, Md. 21218

Jacob Rabinow

National Bureau of Standards

Washington, D.C. 20234

Jan Rajchman

David Sarnoff Research Center

RCA Laboratories

Princeton, N.J. 08540

Martin D. Robbins

Denver Research Institute

University of Denver

Denver, Colo. 80220

Richard W. Roberts

Director, National Bureau of Standards

Washington, D.C. 20234

Charles A. Rodenberger

Texas A. \& M. University

College Station, Tex. 77843

Harald Romanus

Nordenskioldsgatan 86

11521 Stockholm, Sweden

Jack Roth

Inventors Workshop International

$223 \mathrm{~S}$. Beverly Drive

Beverly Hills, Calif. 90212

Samuel Ruben

Ruben Laboratories

271 North Avenue

New Rochelle, N.Y. 10801
Eric P. Schellin

National Patent Council

122519 th Street N. W.

Washington, D.C. 20006

Leslie L. D. Shaffer

Oregon Inventors Council

University of Oregon

Eugene, Oreg. 97403

William B. Schockley

Bell Laboratories

600 Mountain Avenue

Murray Hill, N.J. 07974

Alan A. Smith

Director, The PTC Research Foundation

68 Leonard Street

Belmont, Mass. 02178

Gene W. Smith

5008 La Canada Boulevard

La Canada, Calif. 91011

John Stedman

University of Wisconsin

School of Law

Madison, Wis. 53706

John A. Stephens

Excel-Mineral Co.

4400 Via Abrigada

Santa Barbara, Calif. 93105

Malcolm L. Sutherland

Morton, Bernard, Brown, Roberts \&

Sutherland

1054.31st Street, NW.

W ashington, D.C. 20007

John P. Sutton

Limbach, Limbach \& Sutton

3000 Ferry Building

San Francisco, Calif. 94111

Robert D. Tollison

Council of Economic Advisers

Washington, D.C. 20506

Peter P. Toma

Latsec, Inc.

7852 Ivanhoe Avenue

La Jolla, Calif. 92037

Thomas Ubois

National Science Foundation

Washington, D.C. 20550

Brooks Walker, President

Shasta Forests Company

1280 Columbus Avenue

San Francisco, Calif. 94133

Richard Walton

10 W est Hill Place

Boston, Mass. 02114

E. J. Wedrall

Brea, Calif. 92621 
Arthur R. Whale

The Dow Chemical Company

Midland, Mich. 48640

\section{Thurman White}

Newsweek Magazine

Market at Polk Street

San Francisco, Calif. 94102
F. Karl Willenbrock

National Bureau of Standards

W ashington, D.C. 20234

Richard S. Woodbury

Southwest Research Institute

8500 Culebra Road

San Antonio, Tex. 78284
Stephen Yerazunis

Rensselaer Polytechnic Institute

Troy, N.Y. 12181

Nathan A. Zepell

Prodūct Development 1359 Santa Teresita Drive

Santa Barbara, Calif. 93105 


\section{APPENDIX A}

\section{The Inventor - His Motivations and Society}

\section{Samuel Ruben*}

Inventors today are recognized by society as a factor in the progress of our civilization.

This was not always so, for the inventors who initiated the beginning of the industrial revolution were treated with suspicion and hostility, often by the very people who in the long run benefited by their efforts.

This was particularly highlighted by violence in mass reaction in England and France with the introduction of textile machinery. Kay, the inventor of the flying shuttle, was mobbed when he introduced his invention in Lancashire. A mob destroyed the spinning frame invented by Hargrave. Crampton, the inventor of the spinning mule, hid it for fear of a similar fate. Jaquard barely escaped being drowned in the Rhone by angry weavers on account of his new loom. In Nottingham there were riots on the introduction of the stocking loom. Today the climate is different and sometimes the inventor is afforded recognition and honors, particularly if the product of his efforts results in widespread acceptance. The growth of industries is dependent upon invention and innovation, for one reads in company statements that some of their major revenue producers were not in existence 20 years ago.

We have come to take inventions for granted and the beginnings of many have been forgotten in the dimmed vision of time. Even such a common utensil as a fork or the progeny of the wheel, namely the vehicles, are hardly thought of as inventions. Today the younger generation takes such a popular utility as the television set or other modern appurtenances as something related to advertising programs and not as an application of imaginative thought in the use of modern technology.

The modern technological inventions of today are in a different class from those of earlier days of our patent system on account of the tremendous expansion in science and technology with its accompanying increase in the diffusion of knowledge. They tend to become a more sophisticated project in order to

\footnotetext{
* Member, National Inventors Council
}

properly integrate the imaginative concept to present technology.

Self motivation is a necessary factor to catalyze the generation of imaginative concepts.

In a lecture on motivation given by that eminent Nineteenth Century scientist, Michael Faraday, he stated, "...in the pursuit of science we first start with hope and expectations; these we realize and establish, never again to be lost, and upon them we found new expectations of further discoveries and so go on pursuing, realizing, establishing and founding new hopes again and again." This motivating philosophy could be applied to invention. The true inventor is motivated by the intellectual excitement of the thought process and will resist adverse premature opinions of others who lack imaginative thinking.

In general, progress has always required creative thinking and a determined effort in the pursuit of bold dreams, however imaginative. Goals become reality only when ideas are complemented by a working technology.

The most important factor that an imaginative in. dividual is endowed with is an inner sense of direction. The effectiveness of this inner sense of direction requires the understanding of the concept in relation to the existing science and technology. This involves the planning and practical embodiment of the imagined concept and persistence in order to bring it to effective realizati $n$ as a real world invention.

No achievement in the history of technology has had a greater impact on civilization than did the means of generating electric currents by rotating conductors in a magnetic field, or in the induction of current in one coil from another by variation of the exciting electromagnetic field. Sir Robert Peel, then Prime Minister, visited Faraday in his laboratory of the Royal Institution in London and seeing a model of the magnetoelectric generator, inquired, "Of what use is it?" Faraday is said to have replied, "I know not, but I wager some day your government will tax it." How true this prophecy was, for with the com- 
mercialization of magnetoelectric-produced electricity since 1880 the government income from electric utility taxes has become an increasing source of revenue. It took 35 years before a commercial embodiment of Faraday's discovery of magnetoelectric generation in the form of a dynamo took place.

If one is ahead of the times it may well happen that the acceptance of a proven development does not take place until the expiration of a patent covering the invention and with it goes the hope for protection, reward and recognition of one's intellectual property.

I have experienced this situation on various occasions in the past when the time and state of the art was such that my inventions reached wide-scale commercial application at the time of expiration of my patents.

While such experiences are discouraging, they point out the need for an independent inventor to avoid depending upon a single invention. I was able to realize the hopes given by our American Patent System by having inventions that fitted into the new and developing technology at the right time in reference to the state of the art.

The translation of the imaginative concept in respect to today's technology requires an accumulation of a broad mental tool storage of the facts of science and technology made possible by continuous study and experience. In the particular field I have been engaged in during the past 50 years I have found an important mental tool source to be the understanding derived from an early recognition of the importance of the science of materials and more specifically in later years, the analytic study of the periodic table of the elements and their electron configurations.

Conceptual creativity of a high degree has been the product of independent activity by individuals working alone or in a limited size group who have confidence along with the habit of creative thinking.

An increasing number of new products will be derived from those best trained in the complex of scientific thought which is the basis of technology. It will, to a certain extent, depend upon whether enough encouragement is given to engineering students to apply independent thinking for snythesis of new products with the basic knowledge acquired rather than just being a listener, reader and memorizer. Some of the combined academic and work application courses are in the right direction of real world problem thinking which is conducive to creativity.

The independent inventor will always be important, though to a lesser degree in view of the large expansion since World War II, in organized industrial and Government sponsored development projects. He is in a position to be able to think away from or independently of popular trends with respect to a given project. The statement implying necessity as being an innovator of invention may also be related to the factor of inner recognition which may precede real world recognition of a need. In the course of the complete development of an invention there are factors of importance to commercial success such as the cooperation of one's laboratory associates and the very important part played by the entrepreneur. A necessary ingredient for success is that the management of the prospective licensee manufacturing organization have the courage and foresight to carry a development through the production trials and tribulations encountered with all inventions before they become sought-for commercial products.

Along with progressive management, a licensee must have the cooperation of the engineering department which must complement the inventor's work in reference to production problems and design to meet public acceptance.

While most of this essay has been related to the independent or self-employed inventor, the problems of the organizational inventor need increased consideration. This is particularly so since by necessity a large percentage of potentially creative individuals need support derived from a steady job. They need encouragment and recognition of their efforts to bring out the best work. Invention in a group may involve both the conceptual inventor and the technological improvement type.

The accomplishments of the inventor of a practical conceptual invention should not be obscured by being in a large group organization. His work, if of proven value, should be made known by trade organizations and professional societies. He should not only be the recipient of professional recognition but should in some manner participate if an extraordinary increase of income to his employers is directly derived from his contribution.

Fewer men are willing today to undertake the risks of independent activity compared to former 
days when money requirements were not so great nor was employment in research and development plentiful.

Science with its systematic extension of information provides a translating knowledge from which technology has acquired the substance of its explosive growth. It has given the inventor an increasing supply of mental tools to compose his imaginative concepts and their translation to practical reality. The computer with its ability of coordinated retrieval capacity will in time become a great aid toward real world application of imaginative thought.

Today, because of the disregard of the secondary effects of explosively enlarged applied technology, we note adverse effects on our environment. It has become necessary to consider equal effort to prevent further adverse effects and correct those derived from the past. One can observe from the world literature that less emphasis is advocated on the advancement of technology by invention and entrepreneurship. This has been highlighted in an address by Dr. C. Stark Draper, President of the Stark Draper Laboratory at MIT. He stated that engineers and technologists will have to think of all developments from a viewpoint of overall situations in which the desired subsystem and remedial subsystem be considered in their true perspective as inseparable parts of a complete system technology. Any effective attack to improve existing bad situations and to prevent others from appearing must come from system technology in which engineers consider the beneficial results and undesirable part as a common problem.

One hurdle an independent inventor sometimes has to overcome even with demonstrable models and data is the inherent reluctance of the technical staff of his prospective licensees to accept outside ideas. In industry this is known as the NIH factor (not invented here).

Some managements override a biased preliminary opinion and form their own judgment on trial results.

The American patent system is a basic source of encouragment for the inventor, for it provides him with a means of protecting his intellectual property which is the practical result of his imaginative thinking, giving him hope for reward and recognition.

This system has enabled me to function as an independent inventor and maintain a laboratory for the past 50 years with support, except for the first 3 years, derived entirely from licensees and sales of patents.

I am most grateful for the opportunities afforded by our American patent system. 


\section{APPENDIX B}

\section{Excerpts from The Employed Invenıor in the United States, F. Neumeyer, (MIT Press,}

Cambridge, Mass., 1971)*

\section{EVALUATION OF UNIVERSITY EMPLOYER INVENTION POLICY}

\author{
Suggestions for a University Patent Organization \\ and Its Tasks
}

1. There should be some kind of formalized university-employee invention policy and program handled by a permanent university office or an office authorized by the university in all universities with research activities.

2. The program should be administered by a fulltime legal staff, assisted and supervised by a committee of faculty, research staff, and graduate students.

3. The office should preferably have six main functions:

a. To publish (and from time to time update) general regulations in the invention field for the information of all faculty members, employees, students, consultants, and temporary guests; to prepare standard forms for important invention procedures, such as invention assignments, filing of patent applications and invention disclosures; and to provide guidelines in general patent law. ${ }^{1}$

b. To assist all types of university employees working under Federal Government and state research contracts and grants in fulfilling contract requirements concerning inventions and data, including the drafting and prosecuting of waiver applications to respective departments, agencies, or other supporting bodies or organizations.

c. On application, to assist employees in domestic and foreign patent prosecution and in getting into contact with one or more nonprofit or profit invention-exploiting institutions or firms.

\footnotetext{
* Reprint is courtesy of MIT Press.
}

1 This could be carried out with the assistance of law professors and students to in spire them to study this specialifield of law and to lecture about it, especially in univer. sities with science and engineering departments. d. If supported by the regents of a university or a majority of faculty members, to procure the utilization of university-employee inventions by licensing or selling non-Government-owned patents through the university office or a delegated body and to administer the income from such activities for the benefit of the university and the inventors.

e. To create a loose, nationwide head organization of all university and college administrations in the invention field, which would have annual meetings for the purpose of exchanging experiences, would publish pamphlets in this field, and would cooperate with public service institutions such as the Civil Service Commission's Office of Career Development (Section of Federal Incentive Awards Program), the Federal Council for Science and Technology of the Department of Commerce, and the Patent Office.

f. On application, to assist employees in placing copyrightable material commercially, for instance with domestic and foreign publishers, schools, educational institutions, film and educational equipment producers, or manufacturers of various kinds.

4. State laws and regulations concerning the handling and allocation of industrial property rights produced by employees of state institutions should be made more uniform.

Suggestions Regarding Rights and Duties of University Inventors

1. University inventors should have to disclose to the university administration all inventions made during ordinary service or employment, including inventions made in the course of special research projects where the in ventor has used university facilities. ${ }^{2}$

2. If a university inventor is unable to analyze the

\footnotetext{
${ }^{2}$ The administrative, legal, and economic relations between a university inventor and his employer depend on the character of the invention and the circumstances under which it was made.
} 
character of his own invention he should have to consult the invention office of his university.

3. Unless prohibited by Government contract, a university inventor should always be entitled to a substantial share of income (profit) from inventions made by him and assigned and commercially exploited by the university, a licensed enterprise, or a licensed institution.

4. The percentage distribution of income from university inventions between the parties cannot be generally fixed in advance. It depends, among other things, on who is paying for the costs of patenting, negotiating, licensing, or sale, and eventual additional development costs for producing a marketable product or process.

5. Net income retained after expenses by a university from assigned employee inventions should be used for general university purposes, substantially to promote those research fields most useful in terms of broad educational objectives, including the school from which income from invention was received.

6. Income from employee inventions should not affect salary and other official income to which a university employee is entitled.

7. In all financial or other economic arrangements between a university administration and university inventors, due concern should be given to the public interest, since most universities are public institutions.

8. Disputes between university inventors and the university about correct analysis of the type of invention made, allocation of right, patenting and exploitation of inventions, and distribution of income from licensed or sold inventions should be referred to a special Federal board or court deciding such questions for all nonprivate employees, i.e., Government, state, or municipal employees. Employees of private universities enjoy the same right.

\section{EVALUATION OF INDUSTRY-EMPLOYER INVENTION POLICY}

The case studies of this chapter show that when industrial corporations have a conscious employeeinvention policy, regulations regarding advance assignment of ail future inventions an employee can make, as a condition of employment, are universally used and are in principle alike. Advance assignment provisions in contracts with employees seem to be legally permissible. ${ }^{3}$ The scope of such assignment provisions, however, can vary substantially, for instance in defining the engineering field or field of science for which inventions are required to be as signed, the group of assignees to whom the invention rights are granted, or the time period for which assignment will be in force. A negative feature is that extra compensation or other special benefits above the salary in return for inventions are rarely promised in these contract provisions, even if invention-award systems exist. ${ }^{4}$ Token awards in the form of standard cash amounts of some one hundred dollars each are not considered by the author to be extra compensation in this connection; neither are ordinary bonus plans to reward the merits of a small exclusive group of top employees and managers. ${ }^{5}$ Nonmonetary (honorary) inventor awards are practiced in a great number of different ways in special award plans not a part of the employment contract. Many of these have the character of a patriarchal, eighteenth-century attitude toward the employee, a pat on the shoulder by the patron, who knows best.

Company-wide, state-wide, and nationwide publicity for successful employed inventors does occur and is sometimes encouraged by industrial employers. ${ }^{6}$ Inventor awards expressed in salary raises, company promotion, or special work assignments are for obvious reasons difficult to assess statistically, but they naturally play an important role in research-minded industries working under hard domestic and international business competition.

The selection of groups of employees eligible for invention awards depends usually on whether the employee is required to sign an invention assign. ment agreement as a condition of employment. J. H. O'Meara, for instance, has found that among a group of 83 companies the types of employees required to sign assignment agreements were distributed as in table 3.6.

\footnotetext{
${ }^{3}$ Compare the common law situation as analyzed in Chapter 2.

4 There are a few exceptions, for instance in the aeroplane and aerospace industry. and Gulf Oil Corp.

${ }^{5}$ Some exceptions: Polaroid Corporation, General Electric Co., Du Pont de Nemours extend bonus payments or shares of stock expressly to employees who are outstanding as inventors.

${ }^{6}$ Examples: IBM, RCA, Westinghouse Electric.
} 
TABLE 3.6. Employees required to sign invention-assignment agreements in 83 selected companies.

\begin{tabular}{l|c|c}
\hline \hline Type of employee & $\begin{array}{c}\text { Number of } \\
\text { companies }\end{array}$ & $\begin{array}{c}\text { Percentage } \\
\text { of total } \\
\text { companies }\end{array}$ \\
\hline All............................... & 25 & 36 \\
R\&D and engineering............ & 58 & 70 \\
All management................... & 29 & 35 \\
Some management............... & 26 & 31 \\
All salesmen....................... & 20 & 24 \\
Some salesmen.................... & 22 & 26 \\
All production..................... & 2 & 2.4 \\
Some production.................. & 37 & 45 \\
\hline
\end{tabular}

Source: J. H. O'Meara, "Employee Patent and Secrecy Agreements," NICB, Studies in Personnel Policy, No. 199, New York, 1965 , p. 15.

To make more general statements about the employee selection policy practiced in industry, more extensive statistics would be needed, but the author's research shows a trend similar to the one related by O'Meara. The emphasis on requiring invention assignment by $R$. \& $D$. personnel (hired to invent and to develop) is natural, but in practical industrial life there are many equivocal categories. "Occasional inventors" not hired specifically to create new technology have often produced valuable inventions during employment.

I will evaluate the material presented in this chapter by concentrating on some points only. Among suggestions that can be made for an improved industrial employee-inventor policy some are negative, aimed at abolishing certain practices, and some positive, proposing new or improved measures. My suggestions are as follows:

\section{Abstain in invention-assignment contracts from}

1. Blanket provisions covering assignment of all inventions made by an employee "in the field of business" or in the business of the employer, "present and prospective."

2. Invention assignment in favor of those other than the direct employer with whom employment contract is executed. Domestic and foreign subsidiaries, associated companies, and the like, to be excluded as assignees except with special compensation.

3. Clauses compelling employee to assign inventions made after conclusion of employment.
Express clearly in invention assignment contracts that

1. The invention assignment is limited to inventions conceived and made during employment.

2. Assignment is limited to the field in which the employee is actually intended to work at the time of employment and in which he may have special experience and education. ${ }^{7}$

3. All disclosures of inventions offered by an employee will be examined by the employer within a definite period and the result will be communicated to the employee, giving the reasons for the decision in writing.

4. Inventions made during employment and having substantial commercial value to the employer will result in reasonable extra compensation in cash, above salary, and some honorary measures.

5. Any productive employed inventor is eligible for bonus plan payments irrespective of his current level of salary.

6. Domestic (U.S.) rights will be treated differently from foreign rights, the latter to be left to the inventor unless special interests of the employer require world-wide rights in his favor.

7. Inventions assigned by an employee, which after a certain period of time are not used by the employer, will be released to the inventor free of cost.

\section{Make these provisions}

1. That cash awards to inventors be constructed in such a way as to relieve the inventor partly or wholly from income tax or other tax claims.

2. That in important cases above a certain commercial level, where an invention award is given or refused to an employee, the employee has the right to appeal the company decision to a central mixed governmental-industrial arbitration board, or a special Federal court (to be created).

3. That in corporate engineering and research fields in close financial cooperation with Government agencies and departments invention-award provisions for employees be shaped in cooperation with the affected Government offices.

\footnotetext{
${ }^{7}$ If working tasks are substantially changed during employment, definition of fields of inventions should be changed by modification of contract.
} 
Experiences from a more open, more widespread and positive industrial employee invention policy will improve the usefulness of such policy and lead to more employee inventions to choose from, expansion of industrial production and higher innovation pace, which in turn will increase employment opportunities.

\section{EVALUATION OF GOVERNMENT- EMPLOYER INVENTION POLICY}

As we saw in the Overview of this chapter, serious thought on the creation of a nationwide Federal invention and patent policy goes back about 30 years. Criticism of patent policy and suggestions for change are as old as the policy itself. The discussion gained intensity as Government became more and more engaged as sponsor of research and development on a large scale after the end of World War II. Particular impact on the general discussion of Federal patent policy was made by the Atomic Energy Act of 1954 and the National Aeronautics and Space Act of 1958, both containing extensive special provisions on inventions and patents applicable to their new fields of technology. Senator Russell Long's periodic forays injecting "title provisions" for employee or grantee inventions into more than a dozen Federal laws concerned with scientific and engineering research and frequent Congressional hearings preceding such legislation "kept the pot boiling." 8 (The more important of these Federal laws are listed on page 212 of this chapter.)

Consistent with the subject matter of this book, my evaluation of employee patent policy is restricted to those parts of the policy which concern the relations of employers-in this chapter Government agencies, departments and commissions-in their capacity as employers, sponsors, and contract-ordering principals of their own employees, grantees, or contractor's employees. These relations have been evaluated in the light of the specific studies of four Government departments as presented in the preceding part of this chapter. All conclusions and suggestions for future policy here presented are made with a strong feeling of caution. Some of the great obstacles to recommendations for an efficient uniform Government-employer policy toward inventive employees and grantees are, of course, the

\footnotetext{
${ }^{8}$ Research by Caruso, Forman, Holman, O'Brien, Rossman is mentioned in footnote $I$ of this chapter.
}

heterogeneous premises with regard to the type of people representing employees, on the one hand, and with regard to the objectives of their performance (inventions, discoveries, improvements, suggestions) on the other hand.

An efficient, reasonable, and uniform policy must be guided by an acceptable compromise between the public interest, the employers' interests and the em. ployees' (and grantees') interests. The employees range from those with a minimum of professional training, education, and experience up to research and science leaders with lifetime's accumulation of those assets. It will be easier to establish common policy rules for assignment, release, or other allocation of inventions produced by all employees than to establish rules for reasonable awards, because the merit of reaching certain research results or other valuable performance and the usefulness of these results to the employer when expressed in dollars and cents will rarely be more than a rough guess. These difficulties, however, should not prevent us from establishing an improved employee-invention policy. Any chosen system is open to future improvement.

Some conclusions and suggestions of the author of this part of the book are the following:

1. Uniform regulations regarding disclosure and submission of all inventions made by Government employees within their assigned job responsibilities and official duties should be drafted and brought to the knowledge of all employees upon starting the job. (Executive Order 10096 is not uniformly applied by all departments and agencies, neither is its text presented to all employees.)

2. Determination to patent, publish, or keep secret patentable employee inventions should lie with the employing agency, but the employee should have the express right to appeal these determinations to a special court or board.

3. Similar regulations should apply to important technical, commercial, and educational information, data, trade secrets (for industrial employees), knowhow, and other nonpatentable results produced by Government employees and employees of Government contractors.

4. Decentralized handling by individual employing departments and their subordinate divisions and bureaus to determine allocation of employee inventions and to give awards seems appropriate. 
5. Copies of all rights and awards determinations should be collected and surveyed by a central Federal office, suitably the Civil Service Commission or the Department of Justice. Summaries of such determinations should be printed regularly. ${ }^{9}$

6. A special Federal court or board should be established as a place of appeal for all determinations (regarding both allocation and awards) made on departmental level. It must be open to both parties. Chairman of such a court should be a Federal judge assisted by assistant judges or a jury with competence in law, Government personnel administration, and engineering. Procedure of the court should be public, free of cost, and without compelling the parties to choose legal advisers (lawyers) to represent them. ${ }^{10}$ The Government Patents Board at the Patent Office must be dissolved, and its rulings must be published without delay. The functions of this new special Federal court have to be defined in order not to interfere with ordinary Federal courts, especially in regard to contract litigation. Existing Atomic Energy Commission and National Aeronautics and Space Administration invention boards should become divisions of such a court.

7. A division within a suitable Government agency (for instance, the Civil Service Commission or the Bureau of Standards) should be established to advise Government employees on all legal and commercial questions regarding Government inventions. This organization should be staffed by experts in patent prosecuting and in patent licensing and selling, both domestic and foreign. ${ }^{11}$ The Division's work would be similar to that of the nonprofit invention-exploiting institutions such as Research Corporation and Battelle Memorial Corporation. ${ }^{12}$

8. A Federal periodical should be started, reporting regularly the pending and decided law cases regarding allocation of inventions and awards for inventions of Government employees. Surveys and annual

\footnotetext{
${ }^{9}$ Provisions must be made for exemptions from publication in special cases of military secrecy or substantial commercial competitive interest.

${ }^{10}$ The latter point makes it possible to the employee as the weaker party economically and in law competence to freely choose personat legal advice.

${ }^{11}$ A great number of such experts have been working for many years in various Government agencies, especialiy in the branches of the Department of Defense, AEC, NASA, and the Patent Office.

${ }^{12}$ Foreign examples: National Research Development Corporation in London, INFOR and EFOR in Sweden. now Swedish Development Corporation.
}

statistics based on the extensive material accessible at the Award Office of the Civil Service Commission and the Federal Council for Science and Technology (Patent Advisory Panel) should be published. Invention incentive and patent plans introduced by industrial corporations and faculty and staff invention regulations at universities should be reported. Important developments in law, Government and industry policy in the field of employee-invention management from other countries and international institutions are to be reported. ${ }^{13}$ Abstracts of individual case histories of employee inventions of general interest should be presented in some way, perhaps in brochures like those of the Civil Service Commission or like $N A S A$ 's annual incentive award programs.

9. Government experiment stations should be established to carry out developing and prototype work for Government employee inventions not developed and used by the Government and owned by the employee. ${ }^{14}$

10. Employees of foreign corporations or institutions supported by U.S. Government funds or foreign grantees of U.S. Government should normally leave title to U.S. patents to the U.S. Government but should be allowed to keep rights in their own country. ${ }^{15}$

11. Inventive capacity of Government employees (as shown by granted patents, published articles, awards and prizes) should be officially accepted by Government employers as substantial merit for promotion.

12. In industrial research supported by the Federal Government or in cooperative Government-industry research both governmental and industrial employees should receive the same invention awards and honors (not excluding "special treatment" by their direct employer irrespective of the individual award). The same should apply to State Government employees, who now are sometimes bound by special provisions of state laws regarding state-supported research.

\footnotetext{
${ }^{13}$ These should include work prepared by the International Labor Office, the Bureaux Internationaux pour la Protection de la Propriete Intellectuelle (BIPPI), and the Association Internationale pour la Protection de la Propriete Industrielle (AIPPI).

${ }^{14}$ Such a suggestion was made by former Assistant Attorney General Wendell Berge in his book Cartels-Challenge to a Free $W_{\text {orld }}$ (Toronto: Progress Publishing Co.. 1945), but it was never adopted.

${ }^{15}$ In Germany and Sweden this is. in fact, a national legal obligation.
} 
FORM NBS.114A (1.71)

\begin{tabular}{|c|c|c|}
\hline $\begin{array}{l}\text { 1. PUBLICATION OR REPORT NO. } \\
\text { NBS-SP }-388\end{array}$ & $\begin{array}{l}\text { 2. Gov't Accession } \\
\text { No. }\end{array}$ & 3. Recipient's Accession No. \\
\hline \multirow{2}{*}{\multicolumn{2}{|c|}{$\begin{array}{l}\text { 4. TITLE AND SUBTITLE } \\
\text { Proceedings of the "Conference on the Public Need and the } \\
\text { Role of the Inventor" }\end{array}$}} & $\begin{array}{l}\text { 5. Publication Date } \\
\text { May } 1974\end{array}$ \\
\hline & & 6. Performing Organization Code \\
\hline $\begin{array}{l}\text { 7. AUTHOR(S) } \\
\text { Florence Essers and Jacob Rabinow, Edito }\end{array}$ & & 8. Performing Organization \\
\hline \multicolumn{2}{|l|}{ 9. PERF ORMING ORGANIZATION NAME AND ADDRESS } & 10. Project/Task/Work Unit No. \\
\hline \multicolumn{2}{|l|}{$\begin{array}{l}\text { NATIONAL BUREAU OF STAND ARDS } \\
\text { DEPARTMENT OF COMMERCE } \\
\text { WASHINGTON, D.C. } 20234\end{array}$} & 11. Contract/Grant No. \\
\hline \multirow{3}{*}{\multicolumn{2}{|c|}{ 12. Sponsoring Organization Name and Address }} & $\begin{array}{l}\text { 13. Type of Report \& Period } \\
\text { Covered }\end{array}$ \\
\hline & & Final \\
\hline & & 14. Sponsoring Agency Code \\
\hline
\end{tabular}

15. SUPPLEMENTARY NOTES

Based on recommendation of National Inventors Council

Library of Congress Catalog Card Number: 73-600324

16. ABSTRACT (A 200-word or less factual summary of most significant information. If document includes a significant bibliography or literature survey, mention it here.)

This book presents the proceedings of the "Conference on the Public Need and the Role of the Inventor," held at Monterey, California, on June 11-14, 1973. The conference was sponsored by the office of Invention and Innovation, Institute for Applied Technology, under a grant from the Experimental Technology Incentives Program, NBS, and was based on a recommendation of the National Inventors Council. The purpose of the conference was to study the climate for invention and how to make it one in which America's inventors can flourish for the common good. A total of 18 invited papers were presented. In addition, the proceedings include statements from the chairmen of the three sessions: Charles S. Draper, Jacob Rabinow, and Myron Coler. The proceedings are divided into three sessions with an edited version of the floor discussions following each paper. At the conclusion of the presentation of papers, the participants of the conference separated into six workshop panels. Their recommendations are presented at the end of this volume.

17. KEY WORDS (Alphabetical order, separated by semicolons)

Antitrust doctrine; employed inventors; entreprenetirship; innovation; invention; needs of society; new enterprises; Patent Office; patent system; technological policy making; technology

\begin{tabular}{l|l} 
18. AVAILABILITY STATEMENT & 19. SECURITY CLASS
\end{tabular}

X UNLIMITED.

FOR OFFICIAL DISTRIBUTION. DO NOT RELEASE TO NTIS.

\begin{tabular}{|l|c|}
\hline $\begin{array}{l}\text { 19. SECURITY CLASS } \\
\text { (THIS REPORT) }\end{array}$ & 21. NO. OF PAGES \\
UNCL ASSIFIED & 215 \\
\hline $\begin{array}{c}\text { 20. SECURITY CLASS } \\
\text { (THIS PAGE) }\end{array}$ & 22. Price \\
UNCL ASSIFIED & $\$ 5.55$ \\
\hline
\end{tabular}








19 (1) 